CRUSTAL ACCRETION AND EVOLUTION AT SLOW AND ULTRA-SLOW SPREADING MID-OCEAN RIDGES by

Allegra Hosford

B.S., Geology-Physics/Math, Brown University, 1995.

Submitted in partial fulfillment of the requirements for the degree of MBL/WHOI LBRAEY Woods Hole, MA Marine Biological Laboratory Woods Hole Oceanographic Doctor of Philosophy at the MASSACHUSETTS INSTITUTE OF TECHNOLOGY and the WOODS HOLE OCEANOGRAPHIC INSTITUTION

September, 2001

(C) 2001 Allegra Hosford. All rights reserved.

The author hereby grants to MIT and WHOI permission to reproduce paper and electronic copies of this thesis in whole or in part and to distribute them publicly. 


\section{TABLE OF CONTENTS}

$\begin{array}{ll}\text { ABSTRACT } & 7\end{array}$

$\begin{array}{lr}\text { VITA } & 9\end{array}$

ACKNOWLEDGEMENTS

Chapter 1. CRUSTAL ACCRETION AND EVOLUTION AT SLOW AND

ULTRA-SLOW SPREADING MID-OCEAN RIDGES 13

Background and Motivation 13

$\begin{array}{ll}\text { Thesis Overview } & 16\end{array}$

$\begin{array}{ll}\text { Future Work } & 19\end{array}$

$\begin{array}{ll}\text { References } & 22\end{array}$

Chapter 2. CRUSTAL EVOLUTION OVER THE LAST 2 MY AT THE MIDATLANTIC RIDGE OH-1 SEGMENT, $35^{\circ} \mathrm{N}$

Introduction $\quad 27$

Geologic Setting $\quad 28$

Experiment and Data $\quad 30$

Data Analysis $\quad 33$

Inversion Method 35

Results $\quad 38$

$\begin{array}{lr}\text { Upper Crust } & 40\end{array}$

Middle and Lower Crust $\quad 42$

Moho and Uppermost Mantle $\quad 42$

Density Structure $\quad 44$

$\begin{array}{ll}\text { Interpretation and Discussion } & 47\end{array}$

Evolution of Velocity Structure with Age 49

$\begin{array}{ll}\text { Upper crust } & 49\end{array}$

Middle and lower crust and upper mantle $\quad 50$

$\begin{array}{ll}\text { Upper mantle } & 51\end{array}$

Low-Velocity Anomalies in the Mid-Crust Near Segment Ends 52

High-Velocity Anomalies in Mid-Crust Beneath Seamounts 54

Anomalous Crustal Thickness of the OH-1 Segment 57

$\begin{array}{ll}\text { Conclusions } & 60\end{array}$ 
$\begin{array}{ll}\text { References } & 63\end{array}$

Table $\quad 68$

$\begin{array}{ll}\text { Figures } & 70\end{array}$

Chapter 3. CRUSTAL MAGNETIZATION AND ACCRETION AT THE SOUTHWEST INDIAN RIDGE NEAR THE ATLANTIS II FRACTURE ZONE, 0-25 MA $\quad 89$

Introduction $\quad 91$

Regional Setting $\quad 94$

Magnetic Analysis $\quad 98$

Data Collection and Processing 98

Spreading Rate Results 102

Tectonic Results 103

Present Day Segmentation 103

Paleosegmentation 106

Southern Flank Morphology 108

Northern Flank Morphology 110

Fracture Zone Structure $\quad 111$

Magnetic Results 113

Axial Magnetization $\quad 113$

Off-axis Magnetization $\quad 116$

$\begin{array}{ll}\text { Discussion } & 119\end{array}$

Prolonged Asymmetric Spreading 119

Longevity of a Non-transform Discontinuity $\quad 122$

Source of Axial Crustal Magnetization $\quad 123$

Off-axis Isochronal Trends in Crustal Magnetization 128

Atlantis Bank 131

$\begin{array}{ll}\text { Summary } & 135\end{array}$

References $\quad 139$

Tables 148

$\begin{array}{ll}\text { Figures } & 150\end{array}$

Chapter 4. EVIDENCE FROM MORPHOLOGY AND GRAVITY DATA FOR ASYMMETRIC CRUSTAL STRUCTURE ACROSS THE SOUTHWEST INDIAN RIDGE AT 56 $45^{\circ}-58^{\circ} 40^{\prime} \mathrm{E} \quad 185$

$\begin{array}{ll}\text { Introduction } & 187\end{array}$ 
$\begin{array}{lr}\text { Geologic Setting } & 189\end{array}$

Data Sources 193

Gravity Analysis $\quad 195$

$\begin{array}{ll}\text { Results } & 200\end{array}$

Regional Variations $\quad 200$

$\begin{array}{ll}\text { Segment AN-1 south } & 204\end{array}$

Segment AN-1 north 205

Segment AN-2 south 205

Segment AN-2 north 206

Axial Variations 206

Spatial and Temporal Variations 208

Interpretation $\quad 211$

Evidence for a Single "Super Segment" between Atlantis II and Novara $\begin{array}{ll}\text { fracture zones } & 211\end{array}$

Crustal Thickness Asymmetry at Segment AN-2 213

Case 1: Anomalously thick crust on north flank of AN-2 215

Case 2: Anomalously thin crust on south flank of AN-2 216

Case 3: Asymmetric mantle temperature/density structure 217

$\begin{array}{ll}\text { Conclusions } & 218\end{array}$

References $\quad 221$

$\begin{array}{ll}\text { Tables } & 226\end{array}$

$\begin{array}{ll}\text { Figures } & 230\end{array}$ 


\title{
CRUSTAL ACCRETION AND EVOLUTION AT SLOW AND ULTRA-SLOW SPREADING MID-OCEAN RIDGES
}

\author{
Allegra Hosford
}

\begin{abstract}
Half of the ocean crust is formed at spreading centers with total opening rates less than $40 \mathrm{~km} / \mathrm{Myr}$. The objective of this Thesis is to investigate temporal variations in active ridge processes and crustal aging at slow-spreading centers by comparing axial crustal structure with that on conjugate flanks of the slow-spreading Mid-Atlantic Ridge (MAR) (full rate, $20 \mathrm{~km} / \mathrm{Myr}$ ) and the ultra-slow spreading Southwest Indian Ridge (SWIR) (full rate, $14 \mathrm{~km} / \mathrm{Myr}$ ). Seismic refraction data collected along the rift valley and flanking rift mountains of the OH-1 segment $\left(35^{\circ} \mathrm{N}\right)$ at the MAR show that the entire crustal section is constructed within a zone that is less than $5 \mathrm{~km}$ wide. Shallow-level hydrothermal circulation within the axial valley is suggested by the rift mountain seismic profiles, which show that the upper crust is $20 \%$ thinner and $16 \%$ faster along strike than zero-age crust. These effects probably result from fissure sealing within the extrusive crust. Deeper crustal velocities remain relatively constant at the segment midpoint within the first $2 \mathrm{Myr}$, but are reduced near the segment offsets presumably by faulting and fracturing associated with uplift out of the rift valley. A temporal variation in axial melt supply is suggested by a $15 \%$ difference in along-strike crustal thickness between the rift valley and rift mountains, with relatively less melt supplied today than $2 \mathrm{Ma}$. Crustal accretion at the SWIR appears to occur in a similar manner as at the MAR, although gravity and seismic data indicate that the average crustal thickness is $2-4 \mathrm{~km}$ less at the ultra-slow spreading SWIR. A $25 \mathrm{Myr}$ record on both flanks of the ridge shows that seafloor spreading has been highly asymmetric through time, with $35 \%$ faster crustal accretion on the Antarctic (south) plate. A small-offset non-transform discontinuity between two ridge segments is just as stable as two neighboring transform discontinuities, although a single mantle Bouguer gravity anomaly centered over the nontransform offset indicates that this boundary does not significantly perturb underlying mantle flow. Off-axis magnetic anomalies are recorded with high fidelity despite the very low spreading rates and the absence of a basaltic upper crust in one area. The lower crust may be the dominant off-axis carrier of the magnetic signal, contrary to traditional models of crustal magnetic structure. Morphological and gravity data show evidence of asymmetric crustal accretion across the SWIR ridge axis, with slightly warmer mantle temperatures beneath the slower-spreading African (north) plate.
\end{abstract}




\section{CURRICULUM VITA}

Education

Ph.D. in Marine Geology and Geophysics, Massachusetts Institute of Technology/Woods Hole Oceanographic Institution Joint Program in Oceanography, 2001.

B.S. in Geology-Physics/Math, Brown University, Magna cum Laude, 1995.

\section{Employment}

Research Assistant, Woods Hole Oceanographic Institution, 1995-present.

Research Assistant, Hydrologic Associates USA, Inc., 1991 (summer), 1992-93.

Research Assistant, Brown University, 1991, 1993-95.

\section{Honors}

Top Undergraduate Award in Geology Department, Brown University, 1995.

Explorer's Club grant, 1994.

Barry M. Goldwater Scholarship for Excellence in the Physical Sciences and Mathematics, 1993-95.

National Merit Scholarship, 1990-95.

\section{Professional and Volunteer Activities}

Member: American Geophysical Union, 1994-present.

Member: Sigma Xi, 2001.

Participant, RIDGE Plume-Ridge Interaction Workshop, 2000.

Co-Chair: AGU Spring Meeting, "Evolution of Oceanic Spreading Centers and Their Discontinuities," 1999.

Member: WHOI Committee to restructure Geodynamics Seminar; WHOI committee to restructure department speaker series, 1999-present.

Participant, RIDGE Summer School on Active Processes, Iceland, 1997.

Participant, Interior of the Earth Gordon Conference, 1998.

Volunteer: Falmouth and Dartmouth, MA public schools, 1995-present.

\section{Field Experience}

Research cruise, Southwest Indian Ridge. Shipboard scientist and CoInvestigator for 25-day geophysics program, 2000.

Research cruise, Southwest Indian Ridge. Shipboard scientist and CoInvestigator for 29-day geophysics program, 1998. 
Research cruise, Mid-Atlantic Ridge. Shipboard scientist and data processor for 36-day seismic refraction and reflection experiment, 1996.

Field camp, Mogollon Rim, Arizona. Six week field camp, 1994.

\section{Publications}

Hosford, A., J. Lin, and R.S. Detrick, Crustal evolution over the last 2 m.y. at the MidAtlantic Ridge OH-1 segment, $35^{\circ} \mathrm{N}$, J. Geophys. Res., in press, 2001.

Hosford, A., M. Tivey, T. Matsumoto, H. Dick, and H. Schouten, Crustal magnetization and accretion at the Southwest Indian Ridge near the Atlantis II Fracture Zone, 0-25 Ma, J. Geophys. Res., submitted to J. Geophys. Res., April, 2001.

Abstracts:

Hosford, A., M.A. Tivey, and D.K. Smith, Building the crust at the Southwest Indian Ridge, 57 $-58^{\circ} 30^{\prime}$ E, Eos Trans. AGU, 81 (48), Fall Meet. Suppl., F1129, 2000.

Hosford, A., M. Tivey, and T. Matsumoto, The spreading history, segmentation, and crustal structure of the Atlantis segment, Southwest Indian Ridge, Eos Trans. AGU, 80 (46), Fall Meet. Suppl., F946, 1999.

Hosford, A., H.J.B. Dick, T. Matsumoto, and H. Schouten, Regional tectonic setting of Atlantis Bank, Southwest Indian Ridge, from bathymetry and gravity data, Eos Trans. $A G U, 80$ (17), Spring Meet. Suppl., S342-343, 1999.

Matsumoto, T., A. Hosford, P.B. Kelemen, T. Fujiwara, T. Yamazaki, and M. Joshima, Structure of the crust-mantle boundary and construction of the spreading axis in the slow-spreading mid-oceanic ridges, Eos Trans. AGU, 80 (17), Spring Meet. Suppl., S342, 1999.

Hosford, A., R. Detrick, J. Collins, J. Lin, and D. Toomey, Seismic structure and gravity models of inside-corner crust at $35 \mathrm{~N}$ on the Mid-Atlantic Ridge, Eos Trans. AGU, 79 (17), Spring Meet. Suppl., S335, 1998.

Hosford, A., R. Detrick, J. Collins, J. Lin, and D. Toomey, MAR bullseye seismic experiment: Structure of inside-comer and outside-corner crust in the rift mountains at $35^{\circ} \mathrm{N}$, Eos Trans. AGU, 78 (46), Fall Meet. Suppl., F692, 1997.

Royden, L.H., and A. Hosford, Deformation in convergent orogens as a function of crustal strength and mantle rigidity, Eos Trans. AGU, 77 (17), Spring Meet. Suppl., S269, 1996.

Scheirer, D., D. Forsyth, and A. Hosford, Multitaper estimates of the lithospheric strength of the Basin and Range province, Eos Trans. AGU, 76 (17), Spring Meet. Suppl., S282, 1995. 


\section{ACKNOWLEDGEMENTS}

John Donne said "No man is an island" and perhaps that is never more true than for the man (or in this case, woman) who is in graduate school. Even though the last few weeks have felt a bit like solitary confinement, the rest of my six years in the Joint Program have been filled with advisors, colleagues, and friends - and those categories aren't mutually exclusive. First, a big thanks to my co-advisors Jian Lin and Maurice Tivey who never once said "No" when I knocked on their doors and asked if they had a "minute" (well, except for the day that Maurice gave me a surprise wedding shower, but I've forgiven him). Jian and Maurice have different styles of advising and of doing science, and I benefited from witnessing both first-hand. I could not have asked for two better advisors to guide me through the past three years. I am also grateful to Bob Detrick for his guidance on my seismic work, to Henry Dick for making the two Southwest Indian Ridge cruises possible, to Suzanne Carbotte for her mid-ocean ridge expertise, and to Debbie Smith for serving as the chair of my thesis defense.

When I started graduate school, I was told by many people that I would learn more from my fellow students than from my advisors. That seemed unlikely at the time but now I know that to be true. I was very lucky to share offices and computer labs with Emilie Hooft, Stefan Hussenoeder, Helen Webb, Jennifer Georgen, and Mark Behn. Post-doc Andrew Barclay took Stefan's place after he left for Exxon as not only a great science resource but also a great friend. I'm glad our friendship survived the $8 \mathrm{pm}$ to $8 \mathrm{am}$ watch on the Ewing five years ago! Dave DuBois also proved a constant source of friendship in the OBS lab. I was lucky enough to have three WHOI scientists whom I secretly think of as my personal cheerleaders. Neal Driscoll, John Collins, and Hans Schouten were constant suppliers of pep-talks when I really needed them! Thanks also to Brian Tucholke and the members of "Research Group" for several years of suggestions.

A huge thank you to the folks in the Education Office: John, Judy, Marcey, Julia, Stella, Jake, and Marsha. You truly made my way through the program easier, not only by always saying "Yes" to my many funding requests over the years but also by your moral support. The G\&G staff likewise provided practical and emotional support when I managed to break free of the lab. Thanks Pam, Elaine, Diane, Maryanne, and Shirley.

From Iceland to Hawaii to Nova Scotia to Mauritius to Woods Hole, the one constant in my life these past six years is my husband, Dan. Thanks for reading several drafts of all my papers, for looking at "broken" shell-scripts, and for taking me physically and mentally away from it all when necessary. If planning a wedding and six years of grad school are the most stressful experiences we'll ever have, then the best is yet to come. 
Funding was provided by the National Science Foundation through Contract No. OCE-9300450 and by the Joint Oceanographic Institutions through Subcontract No. JSC1-00. 


\section{CHAPTER 1}

\section{Crustal Accretion and Evolution at Slow and Ultra-slow Spreading Mid-Ocean Ridges}

\subsection{Background and Motivation}

Fully one-half of the ocean crust is formed at spreading centers with total opening rates less than $40 \mathrm{~km} / \mathrm{Myr}$. The most well-studied slow-spreading mid-ocean ridge is the central and northern Mid-Atlantic Ridge (MAR). Numerous studies over the last 30 years have investigated along-axis variations in seafloor morphology, crustal structure, lithosphere properties, and mantle melting, upwelling, and focusing at the MAR. These properties at individual segments of the MAR are thus reasonably well-understood, and segments generally share similar structure: segment centers are characterized by relatively shallow seafloor, narrow axial valley, thick crust, thin/weak lithosphere, closely-spaced small-throw faults, shallow seismicity, and elevated mantle temperatures [Kuo and Forsyth, 1988; Lin et al., 1990; Kong et al., 1992; Shaw and Lin, 1993; Tolstoy et al., 1993; Detrick et al., 1995]. In contrast, relative to segment centers, segment ends typically have deeper seafloor, broader axial valleys, thinner crust, thicker/stronger lithosphere, wider-spaced larger-throw faults, deeper seismicity, and lower mantle temperatures. Less is known about segments of the ultra-slow spreading Southwest 
Indian Ridge (SWIR), where the plates separate at $\sim 16 \mathrm{~km} / \mathrm{Myr}$ [Patriat et al., 1997]. Much of our inferences about crustal accretion at the SWIR has been based on analogy with the central and northern MAR, which spreads $60 \%$ faster than the SWIR. Recent along-axis surveys show that while SWIR segments resemble MAR segments in many cases, significant differences do occur.

Because investigation has focused toward understanding active mid-ocean ridge processes, few studies have ventured away from the axial valley. At the MAR, to date only a few surveys extend to 10 Myr old crust [Gente et al., 1995; Pariso et al., 1995; Sempéré et al., 1995; Rabain et al., 2001] and one survey extends to 29 Myr old crust [Tucholke et al., 1997] on both flanks. However these surveys span less than $15^{\circ}$ of latitude along the MAR. At the SWIR, the largest off-axis geophysical surveys (prior to the one discussed in this Thesis) extended to $3 \mathrm{Myr}$ old crust between $15-25^{\circ} \mathrm{E}$ [Grindlay et al., 1998] and to $\sim 10 \mathrm{Myr}$ old crust at $61^{\circ} \mathrm{E}$ [Rommevaux-Jestin et al., 1997]. Much of our knowledge about the aging of the crust and lithosphere derives from studies of largeoffset fracture zones such as the Kane [Pockalny et al., 1988; Tucholke and Schouten, 1988] and Oceanographer [Sinha and Louden, 1983; OTTER, 1984] fracture zones on the MAR and the Atlantis II fracture zone on the SWIR [Dick et al., 1991]. However, temporal studies of crust formed near large fracture zones is likely to be poorly 
representative of the evolution of the majority of "normal" ocean crust, because crust adjacent to fracture zones is anomalously thin, fractured, and serpentinized.

The utility of off-axis studies can be considered in at least two ways. On one hand, ridge flank surveys reveal morphologic changes associated with the aging of the crust. These include changes caused by faulting, sedimentation, and erosion. Using geophysical methods that sense deeper crustal levels (magnetics, seismics), we can infer processes of crustal aging such as the loss of magnetism and the decrease in porosity in layer 2 due to the effects of hydrothermal alteration. On the other hand, off-axis studies provide information on variations in magmatic accretion and tectonic extension at the ridge axis through time. Geophysical data collected from ridge flanks is thus valuable for addressing basic questions such as: (1) what controls the formation and persistence of ridge segments and their intervening discontinuities; (2) how do the relative roles of magmatism and tectonism along strike influence crustal structure, and how do these change with time; and (3) how does melt segregate in the mantle and subsequently build the crust. Such questions are optimally addressed if off-axis surveys cover both ridge flanks out to similar age crust. The goal of this Thesis is to use studies of conjugate ridge flanks to address these and other fundamental questions concerning crustal accretion and evolution at slow and ultra-slow spreading mid-ocean ridges. 


\subsection{Thesis Overview}

The short-term record of crustal accretion and evolution at slow-spreading ridges is investigated in Chapter 2 using seismic refraction data from the $\mathrm{OH}-1$ segment on the MAR at $35^{\circ} \mathrm{N}$. Much of the interest in segment $\mathrm{OH}-1$ derives from a seamount chain which extends from the rift valley along flow lines in both directions to $8 \mathrm{Myr}$ old crust [Deplus et al., 1998] and a large-amplitude ( 50 mGal), circular mantle Bouguer gravity anomaly (MBA) low [Detrick et al., 1995]. These features, both located at the segment midpoint, have been interpreted to indicate a particularly large magma budget at $\mathrm{OH}-1$ compared to other MAR segments. The focus of the chapter is to determine the crustal and mantle velocity structure of 2 Myr old crust along the strike of the eastern rift mountains of $\mathrm{OH}-1$, and to synthesize the results with those from two companion experiments along the rift valley [Hooft et al., 2000] and conjugate rift mountains [Canales et al., 2000] of the segment. The three combined data sets provide evidence for both crustal aging and temporal variations in accretion. Within $2 \mathrm{Myr}$ of emplacement, the upper crust (defined as the depth to the $6.5 \mathrm{~km} / \mathrm{s}$ contour) thins by $20 \%$ relative to zero-age crust and the mean velocity increases by $16 \%$. These effects probably result from fissure sealing and mineral alteration within layer 2A [Carlson and Herrick, 1990]. Deeper crustal velocities remain relatively constant at the segment midpoint within the first $2 \mathrm{Myr}$, but are reduced at the segment endpoints probably by faulting and fracturing 
associated with uplift out of the rift valley. The results also show the crust was $2-4 \mathrm{~km}$ thicker north of the segment midpoint 2 Ma than the crust currently forming on-axis, suggesting that the average axial melt production at $2 \mathrm{Ma}$ was greater than it is today.

A long-term record of crustal accretion and evolution at slow-spreading ridges is investigated in Chapters 3 and 4 using underway geophysical data from the SWIR. The survey covered two ridge segments ("AN-1" and "AN-2") between the Atlantis II and Novara fracture zones and between the ridge axis and $25 \mathrm{Ma}$ crust on both flanks. This is the most extensive off-axis survey anywhere in the Indian Ocean basin, and is comparable to the $0-29$ Ma survey between $25^{\circ} 30^{\prime}-27^{\circ} \mathrm{N}$ on the MAR [Tucholke et al., 1997]. The analysis in Chapter 3 shows that the three discontinuities and both segments in the survey area are extremely long-lived features of the plate boundary, and may have originated with the formation of the SWIR $\sim 54 \mathrm{Ma}$. The longevity of the $15 \mathrm{~km}$ long non-transform discontinuity (NTD) is noteworthy because NTDs at the MAR and other regions of the SWIR are relatively unstable features. Seafloor spreading has occurred asymmetrically during the entire $25 \mathrm{Myr}$ record, and neither the magnitude nor the sense of the asymmetry has varied significantly. Such prolonged asymmetry is not commonly observed along the mid-ocean ridge system; rather, asymmetric accretion tends to average out over time scales of more than a few million years [Stein et al., 1977; Carbotte et al., 1991]. 
Chapter 3 also addresses the source of marine magnetic anomalies in slow-spread ocean crust. The source of magnetic anomalies remains inconclusive despite decades of work, and the conventional view maintains that most or all of the magnetic signal resides in the upper $500 \mathrm{~m}$ of extrusive crust within seismic layer 2A [Talwani et al., 1971; Atwater and Mudie, 1973]. However, magnetic anomalies are recorded with high coherence and fidelity over Atlantis Bank, an oceanic core complex consisting solely of gabbro and peridotite adjacent to the Atlantis II fracture zone. Atlantis Bank is also the site of Ocean Drilling Program (ODP) Hole 735B. Similarities between magnetic anomalies over Atlantis Bank and those from the remainder of the survey area suggest that alteration of the upper crust off axis all but destroys the magnetic signal, leaving the lower crust as the dominant off-axis carrier of marine magnetic anomalies in the study area.

The factors that control ridge segmentation and temporal variability in crustal production at the SWIR study area are the primary subjects of Chapter 4. A single, largeamplitude ( $\sim 40 \mathrm{mGal})$ mantle Bouguer gravity low is centered midway between the Atlantis II and Novara fracture zones that bound the ridge segments. This gravity anomaly, together with morphology, magnetic, and numerical models of mantle thermal structure, suggest that a single region of mantle upwelling exists beneath the two segments. Furthermore, the dominant wavelength of upwelling may be governed by the 
separation of the fracture zones $(\sim 140 \mathrm{~km})$, rather than by the presence of the small offset non-transform discontinuity. Along-strike crustal structure, as inferred from gravity data, was similar between $\sim 25-12$ Ma to that commonly observed at the MAR, with thicker crust emplaced at segment midpoints relative to segment ends. Crustal production was subsequently disrupted by the uplift of Atlantis Bank and by a propagating rift, suggesting that local tectonic events strongly modify the crust. A significant degree of asymmetry is observed in seafloor morphology and inferred crustal thickness across the axis of segment AN-2. The qualitative observation of smoother seafloor on the slowerspreading north flank is confirmed by abyssal hill data, which show that abyssal hill heights are $175 \mathrm{~m}$ smaller on the north flank than on the faster-spreading south flank. Additionally, crustal thickness values inferred from gravity data are $25 \%$ larger on the north flank than on the south flank through time. These observations may be explained by a combination of slightly greater crustal production on the north flank, slightly greater crustal extension on the south flank, and/or cross-axis variation in mantle temperature and/or density.

\subsection{Future Work}

The work presented in this Thesis demonstrates the benefits of collecting detailed data sets on conjugate ridge flanks. The comprehensive seismic experiment at $\mathrm{OH}-1$ 
complements the already extensive axial and near-axis studies utilizing active- and passive-source seismic methods, dredging, bathymetry, gravity, and magnetic surveying, submersible reconnaissance, geochemical analyses, and geodynamic modeling. We thus were able to interpret the seismic results in the context of these previous studies to address fundamental questions such as the nature of buoyant upwelling and the interplay between magmatic and tectonic extension at slow-spreading ridges. The larger body of work conducted at segment $\mathrm{OH}-1$ also allowed us to look beyond such first-order questions to address secondary problems such as crustal aging and intrusive bodies beneath seamounts.

To capitalize on the intellectual and financial investment dedicated to the $\mathrm{OH}-1$ segment, farther-reaching questions should be asked. One subject area of long-standing interest is the interaction between mid-ocean spreading centers and hotspots. Studies of plume-ridge interaction commonly focus on segments closest to a ridge-centered or nearridge mantle plume. Farther-field interactions between mid-ocean ridges and mantle plumes could be studied at the $\mathrm{OH}-1$ segment, which is located $\sim 450 \mathrm{~km}$ southwest of the Azores hotspot platform. For example, down-ridge flow of plume-derived melt would encounter the first major structural barrier at the $110-\mathrm{km}$ long Oceanographer fracture zone. A geochemical gradient associated with the Azores hotspot might help to distinguish between two-dimensional and three-dimensional mantle upwelling, at least at 
the OH-1 segment. If the mantle upwells as a diapir beneath the segment center, the composition of the crust should be similar at both ends of the segment. If the mantle upwells vertically beneath the entire length of the segment, however, plume affinities should be detected in rocks from the northern end of $\mathrm{OH}-1$ more strongly than rocks collected $90 \mathrm{~km}$ away at the southern end of the segment.

The data presented in Chapters 3 and 4 constitute the most extensive geophysical survey of any ultra-slow spreading center. Together with ODP Hole 735B and several seismic refraction lines, this survey makes the area between the Atlantis II and Novara fracture zones the most comprehensively studied portion of the SWIR. To test many of the ideas discussed in Chapters 3 and 4 , additional data is required. The average degree of melting along strike and variations in magnetic properties of the upper crust could be determined with a dense rock sampling program along the axial valleys of segments AN1 and AN-2. A three-dimensional array of ocean bottom seismometers at the nontransform discontinuity would allow us to assess the maximum depth of seismicity and thus constrain the thickness of the brittle lithosphere at the NTD. Seismic refraction experiments along the axial valleys of $\mathrm{AN}-1$ and $\mathrm{AN}-2$ would measure the absolute crustal thicknesses along the segment, as opposed to relative crustal thickness variations determined with gravity data. We could also test the idea in Chapter 3 that the upper crust maintains a relatively constant thickness along strike, while the lower crust thins by 
2-2.5 $\mathrm{km}$ from the segment midpoints toward the segment ends. Seismic refraction experiments conducted across the axial valley of segment AN-2 would test the inference from gravity data of thicker crust beneath the north flank than beneath the south flank.

Further studies can also be conducted with the geophysical data already collected.

The on- and off-axis record of volcanism and faulting could be studied by characterizing seamount and fault populations evident in the multibeam bathymetry. Flexural analyses might help to determine how inside-corner highs are compensated at depth and how contrasts in lithospheric flexural rigidity across axis are related to seafloor morphology and inferred crustal structure. Finally, analysis of three-dimensional magnetic data collected on the two recent SWIR cruises would constrain the strike of magnetic polarity boundaries in the study area. This information may help resolve contradictory inferences on the slope of polarity boundaries at Atlantis Bank [Allerton and Tivey, 2001; Hosford et al., submitted].

\section{References}

Allerton, S., and M.A. Tivey, Magnetic polarity structure of the lower oceanic crust, Geophys. Res. Lett., 28, 423-426, 2001.

Atwater, T., and J.D. Mudie, Detailed near-bottom geophysical study of the Gorda Rise, J. Geophys. Res., 78, 8665-8686, 1973.

Canales, J.P., R.S. Detrick, J. Lin, J.A. Collins, and D.R. Toomey, Crustal and upper mantle seismic structure beneath the rift mountains and across a non-transform offset at the Mid-Atlantic Ridge (35'N), J. Geophys. Res., 105, 2699-2719, 2000. 
Carbotte, S., S.M. Welch, and K.C. Macdonald, Spreading rates, rift propagation, and fracture zone offset histories during the past 5 my on the Mid-Atlantic Ridge; $25^{\circ}$ $27^{\circ} 30^{\prime}$ S and $31^{\circ}-34^{\circ} 30^{\prime}$ S, Mar. Geophys. Res., 13, 51-80, 1991.

Carlson, R.L., and C.N. Herrick, Densities and porosities in the oceanic crust and their variations with depth and age, J. Geophys. Res., 95, 9153-9170, 1990.

Deplus, C., et al., Linking variation in magma supply and segment growth: temporal evolution of segment $\mathrm{OH}-1$ (MAR at $35^{\circ} \mathrm{N}$ ) during the last $12 \mathrm{Myr}$, Eos Trans. $A G U$, 69 (44), Fall Meet. Suppl., F856, 1998.

Detrick, R.S., H.D. Needham, and V. Renard, Gravity anomalies and crustal thickness variations along the Mid-Atlantic Ridge between $33^{\circ} \mathrm{N}$ and $40^{\circ} \mathrm{N}, J$. Geophys. Res., 100, 3767-3787, 1995.

Dick, H.J.B., et al., Tectonic evolution of the Atlantis II fracture zone, in Proc. Ocean Drill. Program Scientific Results, edited by R.P. Von Herzen, and P.T. Robinson, pp. 359-398, Ocean Drilling Program, College Station, 1991.

Gente, P., R.A. Pockalny, C. Durand, C. Deplus, M. Maia, G. Ceuleneer, C. Mével, M. Cannat, and C. Laverne, Characteristics and evolution of the segmentation of the Mid-Atlantic Ridge between $20^{\circ} \mathrm{N}$ and $24^{\circ} \mathrm{N}$ during the last 10 million years, Earth Planet. Sci. Lett., 129, 55-71, 1995.

Grindlay, N.R., J.A. Madsen, C. Rommevaux-Jestin, and J. Sclater, A different pattern of ridge segmentation and mantle Bouguer gravity anomalies along the ultra-slow spreading Southwest Indian Ridge $\left(15^{\circ} 30^{\prime} \mathrm{E}\right.$ to $\left.25^{\circ} \mathrm{E}\right)$, Earth Planet. Sci. Lett., 161, 243-253, 1998.

Hooft, E.E.E., R.S. Detrick, D.R. Toomey, J.A. Collins, and J. Lin, Crustal thickness and structure along three contrasting spreading segments of the Mid-Atlantic Ridge, 33.5'-35 N, J. Geophys. Res., 105, 8205-8226, 2000.

Hosford, A., M. Tivey, T. Matsumoto, H. Dick, H. Schouten, and H. Kinoshita, Crustal magnetization and accretion at the Southwest Indian Ridge near the Atlantis II fracture zone, 0-25 Ma, J. Geophys. Res., submitted.

Kong, L.S.L., S.C. Solomon, and G.M. Purdy, Microearthquake characteristics of a midocean ridge along-axis high, J. Geophys. Res., 97, 1659-1685, 1992.

Kuo, B.-Y., and D.W. Forsyth, Gravity anomalies of the ridge-transform system in the South Atlantic between 31 and $34.5^{\circ} \mathrm{S}$ : Upwelling centers and variations in crustal thickness, Mar. Geophys. Res., 10, 205-232, 1988.

Lin, J., G.M. Purdy, H. Schouten, J.-C. Sempéré, and C. Zervas, Evidence from gravity data for focused magmatic accretion along the Mid-Atlantic Ridge, Nature, 344, 627$632,1990$. 
OTTER, The geology of the Oceanographer transform: the ridge-transform intersection, Mar. Geophys. Res., 6, 109-141, 1984.

Pariso, J.E., J.-C. Sempéré, and C. Rommevaux, Temporal and spatial variations in crustal accretion along the Mid-Atlantic Ridge $\left(29^{\circ}-31^{\circ} 30^{\prime} \mathrm{N}\right)$ over the last $10 \mathrm{~m} . \mathrm{y}$. : Implications from a three-dimensional gravity study, J. Geophys. Res., 100, 1778117794, 1995.

Patriat, P., D. Sauter, M. Munschy, and L. Parson, A survey of the Southwest Indian Ridge axis between Atlantis II Fracture Zone and the Indian Ocean Triple Junction: Regional setting and large-scale segmentation, Mar. Geophys. Res., 19, 457-480, 1997.

Pockalny, R.A., R.S. Detrick, and P.J. Fox, Morphology and tectonics of the Kane Transform from Sea Beam bathymetry data, J. Geophys. Res., 93, 3179-3193, 1988.

Rabain, A., M. Cannat, J. Escartin, G. Pouliquen, C. Deplus, and C. Rommevaux-Jestin, Focused volcanism and growth of a slow spreading segment (Mid-Atlantic Ridge, $35^{\circ}$ N), Earth Planet. Sci. Lett., 185, 211-224, 2001.

Rommevaux-Jestin, C., C. DePlus, and P. Patriat, Mantle Bouguer anomaly along an ultra-slow spreading ridge: Implications for accretionary processes and comparison with results from central Mid-Atlantic Ridge, Mar. Geophys. Res., 19, 481-503, 1997. Sempéré, J.-C., et al., The Mid-Atlantic Ridge between $29^{\circ} \mathrm{N}$ and $31^{\circ} 30^{\prime} \mathrm{N}$ in the last 10 Ma, Earth Planet. Sci. Lett., 130, 45-55, 1995.

Shaw, P.R., and J. Lin, Causes and consequences of variations in faulting style at the Mid-Atlantic Ridge, J. Geophys. Res., 98, 21839-21851, 1993.

Sinha, M.C., and K.E. Louden, The Oceanographer fracture zone, 1, Crustal structure from seismic refraction studies, Geophys. J. R. Astron. Soc., 75, 713-736, 1983.

Stein, S., H.J. Melosh, and J.B. Minster, Ridge migration and asymmetric seafloor spreading, Earth Planet. Sci. Lett., 36, 51-62, 1977.

Talwani, M., C.C. Windisch, and J. Langseth, M. G., Reykjanes ridge crest: A detailed geophysical study, J. Geophys. Res., 76, 473-517, 1971.

Tolstoy, M., A.J. Harding, and J.A. Orcutt, Crustal thickness on the Mid-Atlantic Ridge: Bull's eye gravity anomalies and focused accretion, Science, 262, 726-729, 1993.

Tucholke, B.E., J. Lin, M.C. Kleinrock, M.A. Tivey, T.B. Reed, J. Goff, and G.E. Jaroslow, Segmentation and crustal structure of the western Mid-Atlantic Ridge flank, $25^{\circ} 25^{\prime}-27^{\circ} 10^{\prime} \mathrm{N}$ and 0-29 m.y., J. Geophys. Res., 102, 10203-10223, 1997.

Tucholke, B.E., and H. Schouten, Kane Fracture Zone, Mar. Geophys. Res., 10, 1-39, 1988 . 


\title{
CHAPTER 2
}

\section{Crustal Evolution Over the Last 2 m.y. at the Mid-Atlantic Ridge OH-1 Segment, $35^{\circ} \mathrm{N}$}

\begin{abstract}
We present the crustal and mantle velocity structure along the strike of the eastern rift mountains at $35^{\circ} \mathrm{N}$ on the Mid-Atlantic Ridge. These results were obtained by an inversion of $\sim 1800 \mathrm{Pg} / \mathrm{Pn}$ and $\sim 450 \mathrm{PmP}$ travel times and by gravity modeling. As
\end{abstract} commonly observed at slow spreading mid-ocean ridges, thicker crust $(9 \mathrm{~km})$ occurs at the segment midpoint, while thinner crust $(7 \mathrm{~km})$ is found toward the segment ends. This along strike variation occurs primarily in the lower crust, which is $7 \mathrm{~km}$ thick at the segment center and 4-6 km thick at the segment ends. In contrast, the thickness of the upper crust is relatively constant along strike. At the segment ends, relatively low velocities extend for $10-15 \mathrm{~km}$ along strike and from the seafloor to $4 \mathrm{~km}$ depth. These low velocities may indicate an attenuated melt supply and/or fracturing and alteration within the shallow to mid-crust. Directly beneath a cluster of three seamounts at the segment center is a region of relatively high velocity $(+0.5 \mathrm{~km} / \mathrm{s})$ in the mid-crust. This feature may correspond to a frozen magma chamber that fed the overlying volcanoes. A synthesis of these results with those from two companion experiments along the rift valley and the conjugate flank provide a detailed record of crustal accretion and evolution 
at this segment. Specifically, the crustal velocity structures of each flank are nearly identical, and they exhibit a thinner and $16 \%$ faster upper crust than is observed on axis. The lower crust is remarkably similar in all three settings, except for a low-velocity body on axis, which is interpreted as a partially molten zone. The maximum crustal thickness is also similar in all three profiles, but north of the segment center, zero-age crust is nearly $4 \mathrm{~km}$ thinner than beneath the eastern flank and $2 \mathrm{~km}$ thinner than beneath the western flank. These differences may indicate that segment-centered mantle upwelling varies on a timescale of $\sim 2$ m.y.

Published in Journal of Geophysical Research, in press. 


\section{Introduction}

The Oceanographer fracture zone and the ridge segment to the immediate south ("OH-1") constitute one of the most thoroughly studied sites on the Mid-Atlantic Ridge (MAR). Previous work includes active- and passive-source seismic experiments [Fox et al., 1976; Sinha and Louden, 1983; Ambos and Hussong, 1986; Barclay et al., 1998], dredging [Schreiber and Fox, 1976], bathymetry, gravity, and magnetic surveying [Detrick et al., 1995; Deplus et al., 1998], submersible reconnaissance [Gràcia et al., 1999], geochemical analyses [Shirey et al., 1987; Yu et al., 1997], and geodynamic modeling studies [Magde et al., 1997]. Much of the interest in segment OH-1 derives from two features at its midpoint which have been interpreted to indicate a particularly large magma budget compared to other segments: a seamount chain which extends from the rift valley along flow lines in both directions to 8 m.y. old crust [Deplus et al., 1998] and a large-amplitude ( $\sim 50 \mathrm{mGal})$, circular mantle Bouguer gravity anomaly (MBA) low [Detrick et al., 1995]. The MBA "bull's-eye" over the center of OH-1 is elongated in an east-west direction, suggesting that crust is thicker than average along a flow line from the segment center; this feature persists in the residual mantle Bouguer gravity anomaly after an assumed thermal effect is removed [Detrick et al., 1995].

To investigate gravity-inferred crustal thickness variations both along and across isochron, three wide-angle refraction lines were acquired along the strike of segment $\mathrm{OH}-$ 
1. This 1996 cruise aboard the R/V Maurice Ewing, termed the Mid-Atlantic Ridge Bull's-eye Experiment (MARBE), was the first major controlled-source seismic experiment on the northern MAR south of the Reykjanes Ridge in over 15 years. In this

study we present the crustal and upper mantle seismic velocity structure and crustal thickness along a $70 \mathrm{~km}$ long refraction line on $2 \mathrm{~m} . \mathrm{y}$. old crust in the eastern rift mountains of OH-1 (Figure 1). We then synthesize the results with two companion OH-1 seismic refraction experiments, one along the rift valley [Hooft et al., 2000] and one on 2 m.y. old crust in the western rift mountains [Canales et al., 2000]. These three experiments at $\mathrm{OH}-1$ provide a record of spatial variations in crustal accretion and evolution over the last $2 \mathrm{~m} . \mathrm{y}$.

\section{Geologic Setting}

The $90 \mathrm{~km}$ long $\mathrm{OH}-1$ segment is one of the longest spreading segments on the MAR and is located $\sim 450 \mathrm{~km}$ southwest of the Azores triple junction (Figure 1a). The segment's northern end is bordered by the $128 \mathrm{~km}$ long Oceanographer fracture zone. The segment's southern end is adjacent to a $35 \mathrm{~km}$ long, right stepping non-transform offset (NTO). Spreading occurs symmetrically at a full rate of $22 \mathrm{~mm} / \mathrm{yr}$ with an azimuth of $100^{\circ}$ [DeMets et al., 1990]. Of the $40 \mathrm{MAR}$ spreading segments between $15^{\circ} \mathrm{N}$ and the Oceanographer fracture zone, OH-1's rift valley is one of the three shallowest, and it 
has the most negative MBA [Thibaud et al., 1998]. The rift valley is hourglass-shaped in map view. At the segment center the seafloor shoals to $2200 \mathrm{~m}$, and the innermost valley is $<3 \mathrm{~km}$ wide (Figure 1a). Toward both ends the rift valley deepens and broadens; it is $28 \mathrm{~km}$ wide and $3300 \mathrm{~m}$ deep at its northern end and $11 \mathrm{~km}$ wide and $3000 \mathrm{~m}$ deep at its southern end. At the northern end of $\mathrm{OH}-1$ the eastern and western flanks exhibit the typical topographic asymmetry of inside corners (IC) and outside corners (OC) [e.g., Severinghaus and Macdonald, 1988; Escartin and Lin, 1995]; the IC adjacent to the fracture zone is $1000 \mathrm{~m}$ shallower than the OC. At the southern end the IC adjacent to the NTO is $200 \mathrm{~m}$ shallower than the OC (Figure 1a).

The seamounts in the ridge-perpendicular chain at $\mathrm{OH}-1$ appear to differ fundamentally in size and shape from typical MAR valley floor volcanoes. They are large ( $\sim 115 \mathrm{~m}$ average height, $1.5-2 \mathrm{~km}$ diameter), form a linear chain in the direction of plate spreading, and appear to survive intact following their formation on axis and subsequent uplift into the flanking crestal mountains and beyond (Figures $1 \mathrm{~b}$ and $1 \mathrm{c}$ ) [Rabain et al., 1999]. In contrast, typical MAR rift valley volcanoes are small ( $\sim 60 \mathrm{~m}$ average height, $<1 \mathrm{~km}$ diameter), isolated or piled on top of one another, and often destroyed or severely disrupted upon uplift from the inner valley [Smith and Cann, 1993; Bryan et al., 1994; Smith et al., 1999; Jaroslow et al., 2000]. 
Like many segments of the MAR [e.g., Brozena, 1986; Carbotte et al., 1991;

Gente et al., 1992], the length of $\mathrm{OH}-1$ has changed through time. Recent off-axis surveying shows that $\mathrm{OH}-1$ initiated $\sim 15$ m.y. ago and propagated southward for 5 m.y.

[Deplus et al., 1998]. After a 5 m.y. hiatus, OH-1 again propagated southward to reach its present length of $90 \mathrm{~km}$. This second phase of propagation coincided with the formation of the seamount chain, which at the time of its initiation was located at the southern end of the segment [Deplus et al., 1998]. A prominent V-shaped tectonic scar on the seafloor marks the path of propagation and terminates at the NTO at the southern end of OH-1 (Figure 1a). Within the V-shaped wake, the seafloor is tectonically disturbed, particularly on the western ridge flank.

\section{Experiment and Data}

This study presents an analysis of seismic and gravity data collected on 2 m.y. old crust within the eastern rift mountains of $\mathrm{OH}-1$, located $\sim 20 \mathrm{~km}$ away from the rift valley. The $70 \mathrm{~km}$ long seismic refraction profile paralleled the $\mathrm{N} 10^{\circ} \mathrm{E}$ strike of the spreading center (Figure 1a). Its northern end is located over the IC high south of the Oceanographer fracture zone; the southern end of the seismic line is located on OC crust near the NTO. As part of the same survey, two other refraction profiles were collected at OH-1 (Figure 1a): one within the western rift mountains [Canales et al., 2000] and one 
within the rift valley [Hooft et al., 2000]. These lines provide a basis of comparison for the results presented here.

The eastern rift mountains of OH-1 comprise several normal-faulted blocks which rise in a stair step fashion from the rift valley [Gràcia et al., 1999]. Water depths at the southern end of the refraction line decrease gradually from $\sim 2500 \mathrm{~m}$ at the OC to $\sim 1750$ $\mathrm{m}$ near the segment center, where the line bisects three seamounts which are $1.5-2 \mathrm{~km}$ in diameter and rise $240-430 \mathrm{~m}$ above the surrounding seafloor (Figure 1c). North of the seamounts the seafloor along the seismic line remains nearly flat for $\sim 25 \mathrm{~km}$ but then rises sharply approaching the IC. The refraction profile ends at $\sim 1200 \mathrm{~m}$ water depth, just $10 \mathrm{~km}$ south of the $4000 \mathrm{~m}$ deep valley of the Oceanographer fracture zone (Figure 1a).

Eight ocean bottom hydrophones (OBH) from the Woods Hole Oceanographic Institution were deployed at an average spacing of $9 \mathrm{~km}$ and recorded shots from the 20gun, $139 \mathrm{~L}\left(8495 \mathrm{in}^{3}\right)$ air gun array of the R/V Maurice Ewing. The array was towed 88 $\mathrm{m}$ behind the ship's GPS antenna at a nominal depth of $12 \mathrm{~m}$. Steaming from south to north at $\sim 4.7$ knots $(0.5 \mathrm{knot}=0.5 \mathrm{~m} / \mathrm{s})$, the $120 \mathrm{~s}$ firing rate yielded an average shot spacing of $280 \mathrm{~m}$ and a total of 265 shots over the length of the line. All seismograms were digitized at a rate of $200 \mathrm{~Hz}$. 
Seismic record sections for a subset of the eight receivers are shown in Figure 2.

On these record sections, impulsive first arrivals from crustal phases $(P g)$ are visible at offsets $<45-50 \mathrm{~km}$; beyond this range the lower-amplitude mantle refraction $(P n)$ crosses over the $P g$ phase to become the first arrival. The $P g$ arrival is not visible within $2 \mathrm{~km}$ of each receiver because the direct water arrival obscures crustal phases; therefore the number of modeled rays which turn in the uppermost $0.5-1 \mathrm{~km}$ of crust is low. The Moho reflection $(P m P)$, which appears on five of the eight record sections, is identified as a high-amplitude arrival crossing the multiples of the crustal phases $(P g)$ at an oblique angle; Figure 2e illustrates a clear example. The amplitude characteristics and ranges of the three observed phases agree well with the same phases observed in other MAR refraction experiments [Detrick and Purdy, 1980; Sinha and Louden, 1983; Purdy and Detrick, 1986; Tolstoy et al., 1993].

A previous seismic experiment conducted at $\mathrm{OH}-1$ imaged the crustal structure within the eastern rift mountains along a similar transect to the one in this study (Figure 1a) [Sinh a and Louden, 1983]. Although that experiment used only three sonobouys and 23 shots, the results indicate a relatively normal velocity structure of seismic layers 2 and 3 and a crustal thickness that decreases gradually from a maximum of $9 \mathrm{~km}$ at the center of $\mathrm{OH}-1$ to $4-5 \mathrm{~km}$ at either end before thinning dramatically beneath the Oceanographer fracture zone. Interestingly, this experiment found that the thinnest crust does not occur 
beneath the deepest part of the fracture zone valley but, rather, at its northern and southern boundaries [Louden et al., 1986].

The bathymetry map presented in this paper contains data from two sources: Hydrosweep multibeam bathymetry from the R/V Maurice Ewing collected during the MARBE cruise and SIMRAD multibeam bathymetry collected on the R/V L'Atalante during a cruise in June-July 1991 [Needham et al., 1992]. Free-air gravity data from the two cruises were also merged to produce a combined data set. The MBA was then calculated by removing the predictable gravity effects of the water-crust interface (assuming a density contrast of $1700 \mathrm{~kg} / \mathrm{m}^{3}$ ) and the crust-mantle interface (assuming a density contrast of $500 \mathrm{~kg} / \mathrm{m}^{3}$ and a $6 \mathrm{~km}$ thick crust), following the methods of Kuo and Forsyth [1988] and Lin et al. [1990].

\section{Data Analysis}

High-quality seismic data were recorded on six of the eight OBHs; OBH 24 was noisy because it was deployed within the depth range of the SOFAR channel, where acoustic waves are amplified, and OBH 22 was contaminated by instrument noise. To compile the $P g$ and $P n$ travel time data set, we constructed record sections for each instrument by filtering the recorded data between 5 and $40 \mathrm{~Hz}$ and picking the first

arrivals with an interactive picking program. Application of a spiking deconvolution 
algorithm greatly facilitated the selection of all arrivals on the two noisy stations and of the low-amplitude $P n$ arrivals on the other stations. Of a maximum 2120 shot-receiver pairs we identified $1810 P g$ and $P n$ arrivals. Compilation of the $P m P$ travel time data set required a lower-frequency band-pass filter $(5-12 \mathrm{~Hz})$ due to the lower-frequency content of reflected arrivals. A total of $446 P m P$ travel times were picked on the five receivers on which they were observed.

The $P g$ and $P n$ travel times were assigned picking uncertainties which were used as weights in the tomographic inversion. These picking errors ranged from $10 \mathrm{~ms}$ for arrivals with small source-receiver offsets and high signal-to-noise ratios to $40 \mathrm{~ms}$ for large offsets and low signal-to-noise ratios. These values are comparable to the picking errors used for the rift valley [Hooft et al., 2000] and western rift mountain studies [Canales et al., 2000], which utilized similar shot-receiver geometry and recorded data of similar quality. The root-mean-square picking uncertainty of all refracted phases was 19 ms. All $P m P$ phases were assigned a constant arrival time uncertainty of $50 \mathrm{~ms}$.

The expected fit of a model that fully explains the data is equal to the sum of the variances of the individual sources of data error. Additional sources of error in this experiment include uncertainty in source position and in receiver position and depth. We determined these quantities by inverting the travel times of the water column arrival using the method described by Creager and Dorman [1982] (Table 1). While the 
relocation error ellipses indicate larger uncertainties in receiver position perpendicular to the refraction line than parallel to it, the relocated water depths differ from the Hydrosweep-derived water depths at the relocated positions by $<20 \mathrm{~m}$. The estimated travel time error due to receiver depth uncertainty is $6 \mathrm{~ms}$, and the error due to receiver position uncertainty is $12 \mathrm{~ms}$. The remaining source of experimental error is bathymetry along the refraction line. A common value for vertical depth accuracy in multibeam bathymetry systems is $10 \mathrm{~m}$ [McClain and Caress, 1993], which converts to an error of 3 $\mathrm{ms}$ in travel time assuming a water velocity of $1.5 \mathrm{~km} / \mathrm{s}$ and a seafloor velocity of $3 \mathrm{~km} / \mathrm{s}$. For this experiment, the root-mean-square uncertainty of all the errors is $23 \mathrm{~ms}$.

\section{Inversion Method}

The two-dimensional (2-D) tomographic inversion algorithm described by Korenaga et al. [2000] (hereinafter referred to as the Korenaga code) was used to invert the observed travel times for the crustal and mantle velocity structure and Moho depth beneath the eastern rift mountains of $\mathrm{OH}-1$. This code is an iterative method with forward and inverse operations which simultaneously solve for crustal velocities and reflector depth. The ray-tracing step of the modeling procedure occurs via a hybrid scheme that combines the graph method [Moser, 1991] with the ray-bending method [Moser et al., 1992] to produce highly accurate ray paths and travel times [Korenaga et 
al., 2000]. The inverse step maps the differences between these calculated times and the observed times into perturbations of the initial velocity model. The inversion is stabilized by the addition of user-defined smoothness "correlation lengths," one each in the horizontal and vertical directions for the velocity nodes and one for the depth nodes. All of the smoothing occurs by applying a Gaussian filter of width equal to one correlation length. The removal of travel time residual outliers and the application of post-inversion smoothing also stabilizes the inversion.

The velocity model was parameterized as a $70 \mathrm{~km}$ long by $15 \mathrm{~km}$ deep grid of nodes. We used a uniform horizontal grid spacing of $1 \mathrm{~km}$ and a variable vertical grid spacing which ranged from $100 \mathrm{~m}$ at the top of the model to $500 \mathrm{~m}$ at its base, for a total of 4446 nodes. The Moho was parameterized at a horizontal node spacing equal to the shot spacing along the line. Based on a series of tests of model regularization we chose a horizontal correlation length for velocity nodes that increased linearly from $5 \mathrm{~km}$ at the seafloor to $10 \mathrm{~km}$ at the base of the model, a vertical correlation length for velocity nodes that increased linearly from $0.5 \mathrm{~km}$ at the seafloor to $5 \mathrm{~km}$ at the base of the model, and a correlation length for reflector nodes of $5 \mathrm{~km}$. For all cases, 10 inversion iterations were performed; most of the variance reduction occurred within the first few iterations.

We tested two starting models for the velocity inversion, one from an experiment south of the Kane fracture zone [Purdy and Detrick, 1986] and one from the MARBE 
experiment in the rift valley of OH-1 [Hooft et al., 2000]. Each of these velocity structures varied only with depth and were hung from the seafloor bathymetry to form a 2-D grid. While 2-D inversions using these different starting models yielded similar velocity structures and travel time residuals, we chose the velocity profile from the rift valley of $\mathrm{OH}-1$ as the starting model to facilitate comparisons with rift valley crustal structure. For the starting Moho we used the Moho depth obtained by downward continuation of residual mantle Bouguer gravity anomalies along the eastern rift mountain refraction line.

A problem inherent to joint seismic refraction-reflection inversion algorithms is the difficulty in determining the relative contributions of lower crustal velocity changes and variations in Moho depth in producing the $P m P$ travel time residuals [Korenaga et al., 2000]. To explore this ambiguity, a depth kernel weighting parameter is used in the inversion which changes the relative contribution of each of these effects; a factor of 1 corresponds to equal weighting, while a factor $>1$ favors larger Moho depth perturbations and smaller lower crustal velocity perturbations. For this data set a weighting factor of 1 created large gradients in lower crustal velocities where ray coverage is poor, while a weighting factor $>1$ produced a velocity model and crustal thickness that are the most consistent with the results from the companion experiments at OH-1 [Canales et al., 
2000; Hooft et al., 2000] and with the prior eastern rift mountain experiment [Sinha and Louden, 1983].

\section{Results}

The $P$ wave velocity structure and Moho depth beneath the eastern rift mountains of OH-1 are presented in Figure 3. The tomographic inversion reduced the root-meansquare (RMS) misfit between the observed and predicted $P g$ and $P n$ travel times from an initial value of $172 \mathrm{~ms}$ to $30 \mathrm{~ms}$ after 10 iterations (Figure $4 \mathrm{~b}$ ). This final travel time residual is comparable to the estimated experimental error of $23 \mathrm{~ms}$. The RMS misfit for the $P m P$ travel times decreased from $124 \mathrm{~ms}$ for the starting model to $47 \mathrm{~ms}$ after 10 iterations (Figure 4c). To illustrate the agreement between the observed and modeled travel times, we overlay the model-predicted travel times on the record sections in Figures 2a-d.

One measure of the spatial resolution of the $2-\mathrm{D}$ velocity structure is the derivative weight sum (DWS) [Toomey et al., 1994], a numerical representation of the "hit count" or ray density near each model grid node. The DWS grid for our final velocity model indicates that much of the model space is well sampled by turning rays (Figure 4a). The highest DWS values (i.e., the best resolved areas) occur in the mid-crust between 2.5 and $5 \mathrm{~km}$ below the seafloor, in the shallow crust immediately beneath each 
receiver, and in the uppermost mantle. The lowest DWS values (i.e., the least resolved areas) occur at the edges of the model, in the shallow crust between receivers, and in the lowermost crust.

While the DWS array is useful for determining relative regions of high and low ray coverage, it does not account for the angular distribution of rays. We conducted resolution testing to assess the reliability of the inversion results in Figure $3 \mathrm{~b}$. Specifically, we wished to test if the regions of high and low velocities in our result were real or artifacts caused by variable ray coverage. In the resolution test, we calculated synthetic travel times for a perturbed velocity model with the same shot-receiver geometry and model parameterization as used for the real modeling. Then we added normally distributed, random noise to the synthetic travel times and inverted them using the initial unperturbed velocity model to determine how well the perturbations were recovered. The synthetic model consisted of a checkerboard pattern of alternating high and low velocities in similar locations as the observed positive and negative anomalies (Figure 5a). Each anomaly measured $15 \mathrm{~km}$ wide by $4 \mathrm{~km}$ tall and was perturbed by $3 \%$ from the background velocity model.

The result of the resolution test is shown in Figure 5b. Good recovery was obtained for all three velocity perturbations, with very little vertical and horizontal smearing of the central positive anomaly and some smearing of the distal negative 
anomalies; this latter effect probably results from the absence of crossing rays at the edges of the model. To confirm that the low-velocity anomalies at the segment ends are not artifacts of the ray coverage, we performed the same resolution test but with perturbations of opposite sign (high velocities at the segment ends and low velocities at

the segment center). Again, we recovered the input velocity structure quite well. Based on these results and adequate goodness of fit statistics (RMS $=30 \mathrm{~ms}, \chi^{2}=3.7$ ) we conclude that the inversion results presented in Figure $3 \mathrm{~b}$ are robustly supported by our data.

\subsection{Upper Crust}

Absolute velocity values in the upper crust (defined as the depth to the $6.5 \mathrm{~km} / \mathrm{s}$ contour) agree well with typical seismic layer 2 structure: velocities increase rapidly from $3.5 \mathrm{~km} / \mathrm{s}$ at the seafloor to $5 \mathrm{~km} / \mathrm{s}$ at $1 \mathrm{~km}$ depth, then increase more gradually to $6.5 \mathrm{~km} / \mathrm{s}$ at $3-3.5 \mathrm{~km}$ depth (Figure $3 \mathrm{a}$ ). The thickness of the upper crust varies by $\sim 1 \mathrm{~km}$ along the line, with a maximum value of $2.9 \mathrm{~km}$ at the southern end and a minimum value of 1.8 $\mathrm{km}$ at the center. Immediately beneath $\mathrm{OBH} 22$ and the adjacent seamounts, the upper crust thins locally by $\sim 500 \mathrm{~m}$ relative to the surrounding crust. A velocity perturbation plot (Figure 3b) reveals significant lateral heterogeneity in the upper crust relative to the average velocity-depth profile of the central axial valley, which was used as the starting 
model for the inversion. In particular, we image discrete regions of both anomalously high and low $P$ wave velocities, with the perturbation amplitude spanning $1.2 \mathrm{~km} / \mathrm{s}$ peak to peak. Two regions of relatively high velocities $(+0.5 \mathrm{~km} / \mathrm{s})$ are imaged within the shallow crust: one beneath OBH $23(x=-20 \mathrm{~km})$ and one beneath OBH $27(x=0 \mathrm{~km})$. In contrast, in between these two regions $(x=-10 \mathrm{~km})$, shallow velocities are only slightly higher than velocities in the shallow crust on axis. Each of the high-velocity anomalies extends to $1.5-2 \mathrm{~km}$ depth, although these thickness values may overestimate the real values due to downward smearing by the vertical ray paths beneath receivers.

Two relatively low velocity regions are detected at either end of the seismic profile, as shown in the velocity perturbation field (Figure $3 b$ ). These anomalies are lower in overall magnitude than the central high-velocity bodies $(-0.1$ to $-0.5 \mathrm{~km} / \mathrm{s}$ versus $+0.5 \mathrm{~km} / \mathrm{s}$ ), but they extend for greater along-axis distance as well as to greater depth. To the south the negative anomaly is $15 \mathrm{~km}$ wide and $4 \mathrm{~km}$ thick, and to the north it is at least $10 \mathrm{~km}$ wide and $4 \mathrm{~km}$ thick. Thus, while the shallower high-velocity bodies at the segment center probably lie wholly within the extrusive section of crust (layer $2 \mathrm{~A}$ ), these lower-velocity regions at the segment ends probably encompass both extrusive and intrusive crust.

Although the uppermost $1-1.5 \mathrm{~km}$ of crust is poorly sampled by seismic energy relative to other regions of the model (Figure 4a), the velocities we obtain for the upper 
crust agree well with the velocity-depth profile obtained from analysis of multichannel seismic (MCS) data in the same area [Hussenoeder, 1998]. At $1 \mathrm{~km}$ depth, for example, the velocity at $x=-18 \mathrm{~km}$ and $x=5 \mathrm{~km}$ is $5 \mathrm{~km} / \mathrm{s}$ in both the MCS velocity analysis and in our tomographic results.

\subsection{Middle and Lower Crust}

Middle and lower crustal velocities in our tomographic image correspond to seismic layer 3 values, with velocities increasing from $6.5 \mathrm{~km} / \mathrm{s}$ at the base of layer 2 to $7.6 \mathrm{~km} / \mathrm{s}$ at the Moho (Figure 3a). The thickness of layer 3 changes significantly along the profile from $4 \mathrm{~km}$ at the southern end to $6 \mathrm{~km}$ at the center to $5.5 \mathrm{~km}$ toward the northern end. A notable feature in the seismic velocity image (Figure 3a) is the upwarping of the $6.8-7.2 \mathrm{~km} / \mathrm{s}$ contours in the mid-crust. This high-velocity region measures $6.5 \mathrm{~km}$ wide by $2 \mathrm{~km}$ tall and is spatially associated with the seamount clusters located on either side of the seismic line (see Figure 1c). The perturbation plot (Figure 3b) shows that the high-velocity body exceeds rift valley velocities over the same depth range by as much as $0.6 \mathrm{~km} / \mathrm{s}$, an increase of $7 \%$.

\subsection{Moho and Uppermost Mantle}


The seismic Moho in the eastern rift mountains of $\mathrm{OH}-1$ is constrained seismically by nearly continuous $P m P$ reflections over the central $45 \mathrm{~km}$ of the profile (Figures 3a and 4d). Over this distance the crustal thickness is $7 \mathrm{~km}$ near the southern end of $\mathrm{OH}-1,9 \mathrm{~km}$ at the center, and $8 \mathrm{~km}$ approaching the northern end. This relatively modest variation in crustal thickness is consistent with the gentle gradient of the overlying seafloor (Figures 1a and 3a), with the relatively small variation in residual gravity along the line ( 12 mGal) [Detrick et al., 1995], and with the crustal thicknesses obtained by Sinha and Louden [1983]. The maximum crustal thickness of $9 \mathrm{~km}$ is larger than typically observed seismically at both the Mid-Atlantic Ridge [e.g., Purdy and Detrick, 1986; Tolstoy et al., 1993] and the fast spreading East Pacific Rise (EPR) [e.g., Caress et al., 1992; Van Avendonk et al., 1998].

It is important to note that the $P m P$ reflections in this data set were not recorded all the way to the inside corner adjacent to the Oceanographer fracture zone (Figure 1). Thus we cannot confirm with this seismic line alone the inference from gravity data of crustal thinning beneath inside corners [Escartín and Lin, 1995]. However, data from the Sinha and Louden [1983] experiment indicates that the crust beneath the eastern rift mountains does not thin by more than a few $\mathrm{km}$ until within $\sim 10$ kilometers on either side of the fracture zone valley. 
Because of the thick crust beneath the midpoint of the eastern rift mountains of

$\mathrm{OH}-1$, fewer than $20 \%$ of the first arrivals on the seismic record sections are $P n$ phases, and consequently, we imaged only the upper $0.5-1 \mathrm{~km}$ of the mantle beneath the seismic line. However, this portion of the upper mantle is relatively well resolved by our data set (Figure 4a). The average mantle velocity over the central $30 \mathrm{~km}$ of the seismic line ranges between 7.8 and $8.0 \mathrm{~km} / \mathrm{s}$. This value is consistent with the apparent $P n$ velocity observed on the record sections (Figure 2), with the results from the seismic line on conjugate crust [Canales et al., 2000], and with the $7.88 \mathrm{~km} / \mathrm{s}$ mantle velocity obtained by Sinha and Louden [1983].

\subsection{Density Structure}

In the absence of seismic data a common method of estimating crustal thickness and crust and mantle density variations is to calculate the residual mantle Bouguer gravity anomaly (RMBA) [e.g., Kuo and Forsyth, 1988; Lin et al., 1990; Detrick et al., 1995]. The seismic model obtained for the eastern rift mountains of OH-1 provides constraints on the sources which contribute to the RMBA. To take maximum advantage of the seismic constraints, we calculate a different residual anomaly, the residual crustal Bouguer anomaly (RCBA), to assess the effect of each of the crustal and mantle sources on the observed gravity signal. To convert the seismic velocity structure to density, we 
divided the velocity model into sub-blocks with interface boundaries at increments of 0.1 $\mathrm{km} / \mathrm{s}$ from the seafloor to $7 \mathrm{~km} / \mathrm{s}$; this final interface corresponds to the base of the most well-resolved portion of the seismic model. These 2-D interfaces were then extended in three dimensions and hung from the bathymetry within a 3-D volume. The density of each interface was calculated using a density-velocity relation for seismic layer 2 derived by Carlson and Raskin [1984], $\rho=3.5-3.79 / V_{p}$, where density $\rho$ is in $\mathrm{Mg} / \mathrm{m}^{3}$ and $P$ wave velocity $V_{p}$ is in $\mathrm{km} / \mathrm{s}$. Finally, the gravity contribution from each interface was calculated by mirroring the density surfaces on all sides and using the Parker [1973] Fourier method.

Because we have good resolution in crustal velocities to at least the depth of the 7 $\mathrm{km} / \mathrm{s}$ velocity contour, we follow the approach of Canales et al. [2000] and Hooft et al. [2000] to reduce the free-air gravity anomaly to RCBA. The RCBA is obtained by the formula $\mathrm{RCBA}=\mathrm{FAA}-g_{\text {crust }}-g_{\text {thermal }}$, where FAA is the observed free-air anomaly, $g_{\text {crust }}$ is the sum of the gravity contribution from each density interface from the seafloor to the $7 \mathrm{~km} / \mathrm{s}$ contour, and $g_{\text {thermal }}$ is the gravity effect of the mantle thermal structure based on a passive mantle upwelling model calculated using the approach of Phipps Morgan and Forsyth [1988]. The RCBA thus reflects unmodeled crustal and mantle density variations and Moho topography. 
Figure 6a illustrates each of the sub-blocks in the density model used to calculate the RCBA. The density gradient is largest in the uppermost crust where seismic velocity increases rapidly; below $\sim 2 \mathrm{~km}$ depth, crustal density increases more slowly to the final model density contour of $2950 \mathrm{~kg} / \mathrm{m}^{3}$ (corresponding to $7 \mathrm{~km} / \mathrm{s}$ ). Each successive density interface below the seafloor contributes only a few $\mathrm{mGal}$ to the total RCBA. Figure $6 \mathrm{~b}$ shows that the RCBA retains the general character of the MBA gravity low centered on OH-1 [Detrick et al., 1995]. Over the central $60 \mathrm{~km}$ of the line, however, the total amplitude of the RCBA is only $15 \mathrm{mGal}$, which is half the $30 \mathrm{mGal}$ RCBA variation observed in the axial valley over the same distance [Hooft et al., 2000].

The observed RCBA is compared with the gravity effect of the Moho topography in Figure 6b. Again using the Parker [1973] Fourier method, we assume a constant density contrast across the Moho of $350 \mathrm{~kg} / \mathrm{m}^{3}$ (Figure 6a). Since the seismic Moho is obtained only over the central part of the seismic line, we extended the Moho on either side by assuming a constant gradient in crustal thickness variation; this is a reasonable assumption considering the crustal thickness for the eastern rift mountains determined by Sinha and Louden [1983]. Similar to the results of Hooft et al. [2000], the calculated effect of the Moho topography accounts for most of the RCBA amplitude (Figure 6b, dotted line), although the predicted Moho effect is more gradual than the observed RCBA. The remaining anomaly therefore probably results from unmodeled density 
variations in the shallowmost crust (layer 2A), lower crust, and upper mantle or from uncertainties in the determination of the seismic Moho.

\section{Interpretation and Discussion}

The ridge-parallel seismic studies at segment $\mathrm{OH}-1$ provide a record of spatial variations in crustal accretion and evolution at the slow-spreading MAR over the last 2 m.y. Detailed discussions on the western rift mountain and the axial valley experiments are given by Canales et al. [2000] and Hooft et al. [2000], respectively. Here we provide a joint interpretation of the results of all three OH-1 refraction lines from the MARBE cruise.

Plate 1 and Figure 7 present the crustal velocity structure and thickness beneath the western rift mountains (Line W, Plate 1a), axial valley (Line C, Plate 1b), and eastern rift mountains (Line E, Plate 1c) over the region of common coverage (see Figure 1a). To compare the velocity structures along Lines $\mathrm{W}$ and $\mathrm{C}$, which were obtained using the Toomey et al. [1994] tomography program (hereinafter referred to as the Toomey code), with the structure along Line E (obtained using the Korenaga code), we inverted the rift mountain data sets (Lines $\mathrm{E}$ and $\mathrm{W}$ ) with both programs. The tests showed that the velocity models obtained for Line $\mathrm{E}$ using both methods were extremely similar. The 
same was true for Line W. Thus direct comparison of the three experiments is valid despite using different tomography algorithms.

Comparison of crustal thickness values from the three experiments is more complex. For Lines $\mathrm{W}$ and $\mathrm{C}$, the $P m P$ data were forward modeled using the algorithm of Zelt and Smith [1992] after first determining the seismic velocity structure using the Toomey code. This two-step procedure was necessary because in the Toomey code the ray tracer models only refracted phases. In contrast, the Korenaga code inverts refracted and reflected phases jointly. We used this newer method to analyze Line $\mathrm{E}$ to minimize errors which may have resulted from using inconsistent parameterizations for velocity structure and Moho depth modeling for Lines W and C. To test the effects of different methodologies on the crustal thickness solutions, we inverted the Line $\mathrm{W}$ data set using the Korenaga code and compared the results to that of Canales et al. [2000], which were obtained using the Toomey code and Zelt and Smith [1992]. The inverted Moho for Line W using the Korenaga code differed only slightly from the Moho determined using Zelt and Smith [1992] (Plate 1a), indicating that the methodology used to determine crustal thickness does not strongly affect the final result.

An unaccounted-for source of error in the results presented here, however, is the effect of three-dimensional ray sampling, or out-of-plane propagation, in the three ray sets. In the case of significant across-axis structure, such as through-going crustal 
faulting or large-scale lateral variations in Moho depth, two-dimensional analysis of the three ridge-parallel lines may introduce error into the results. Recent numerical experiments that incorporate realistic 2-D and 3-D source-receiver geometries, though, suggest that out-of-plane effects are relatively small, with errors in crustal velocity up to $0.15 \mathrm{~km} / \mathrm{s}$ and errors in depth up to $2 \mathrm{~km}$ [Zelt and Zelt, 1998]. These values approximate the uncertainties derived from the travel time inversion; thus we assume that out-of-plane effects do not significantly affect comparisons of the three isochron-parallel seismic lines.

\subsection{Evolution of Velocity Structure With Age}

7.1.1. Upper crust. The thickness of the upper crust or seismic layer 2 , defined as the depth to the $6.5 \mathrm{~km} / \mathrm{s}$ contour, varies along the strike of each $\mathrm{OH}-1$ refraction line, with generally the thickest upper crust at the segment ends and the thinnest upper crust at the segment center (Plate 1). On axis, the mean thickness of layer 2 is $2.9 \mathrm{~km}$. In contrast, the mean upper crustal thickness beneath both flanks on 2 m.y. old crust is $2.3 \mathrm{~km}$, significantly thinner than beneath the rift valley. The mean velocity of the upper crust differs in each setting as well, with a value of $4.5 \mathrm{~km} / \mathrm{s}$ on axis and $5.2-5.3 \mathrm{~km} / \mathrm{s}$ off axis, an increase of $16 \%$.

This observation of increasing seismic velocity in the upper crust with age is consistent with other studies which showed a rapid increase in the velocity of seismic 
layer $2 \mathrm{~A}$ in crustal ages from 0 to 5 m.y. [Carlson, 1998]. Although we cannot distinguish layer $2 \mathrm{~A}$ from layer $2 \mathrm{~B}$ in the $\mathrm{OH}-1$ refraction data, the observed increase in seismic velocity with age may actually reflect variations in layer $2 \mathrm{~A}$ velocity since other seismic studies indicate little age dependence of layer 2B velocity at the MAR and EPR [Carlson, 1998] and at the ultraslow spreading Mohns Ridge [Klingelhofer et al., 2000]. Some variability does exist in the thickness and mean velocity of layer $2 \mathrm{~A}$ at $\mathrm{OH}-1$. In the western rift mountains, for example, MCS images show that layer $2 \mathrm{~A}$ thickens by 150 $\mathrm{m}$ from the center of the segment to its northern end [Hussenoeder, 1998]. Similarly, at two locations on the eastern flank, the velocity of the upper $50 \mathrm{~m}$ of crust varies by $20 \%$ over an along-strike distance of only $5 \mathrm{~km}$. Such along- and across-strike variability suggests that the relationship between upper crustal structure and age at OH-1 is complex and probably dependent on numerous factors, including porosity, shallow along-axis melt migration, alteration, and tectonic modification.

7.1.2. Middle and lower crust and upper mantle . The middle to lower crust on all three $\mathrm{OH}-1$ seismic lines is characterized by the typical low velocity gradients of seismic layer $3\left(<1.0 \mathrm{~s}^{-1}\right)$ (Figure 7): between the base of the upper crust and the Moho, velocities increase from $6.5 \mathrm{~km} / \mathrm{s}$ to $7.6 \mathrm{~km} / \mathrm{s}$ over a depth of $2-6 \mathrm{~km}$. However, the thickness of layer 3 varies considerably along the strike of each line, with the thickest layer 3 at the 
segment center and the thinnest layer 3 at the distal ends (Plate 1). This result is similar to that observed at the rift valley on the MAR at $33^{\circ}$ S [Tolstoy et al., 1993].

In contrast to the observed along-strike variation in layer 3 thickness, the average velocity in layer 3 changes very little along each line. Further, the average lower crustal velocities are nearly indistinguishable on Lines $\mathrm{E}$ and $\mathrm{W}$ and from that of the on axis line, except at the segment center where layer 3 velocities are $0.5 \mathrm{~km} / \mathrm{s}$ lower on axis than on the flanks (Figure 7b). Magde et al. [2000] also imaged relatively low velocities (-0.4 $\mathrm{km} / \mathrm{s}$ ) in the middle to lower crust beneath the rift valley of $\mathrm{OH}-1$. They attributed these lower layer 3 velocities to elevated temperatures and the presence of partial melt. A similar difference in mean layer 3 velocity of zero-age and older crust was observed near the Kane fracture zone, where Purdy and Detrick [1986] found layer 3 velocities on axis to be $0.4 \mathrm{~km} / \mathrm{s}$ slower than in 7 m.y. old crust.

7.1.3. Upper mantle. The limited number of $P n$ arrivals on the rift valley and eastern rift mountain lines precludes a detailed comparison of upper mantle structure beneath the three $\mathrm{OH}-1$ lines. We note, however, that an upper mantle velocity of $7.8 \mathrm{~km} / \mathrm{s}$ is observed on both off-axis lines beneath at least the central $30 \mathrm{~km}$ of OH-1 (Plates 1a and 1c). Beneath the rift valley the mantle velocity is $0.4 \mathrm{~km} / \mathrm{s}$ slower, except in the immediate vicinity of the Oceanographer fracture zone (Plate $1 \mathrm{~b}$ ). The higher mantle 
velocity off axis may be partly caused by cooling of the upper mantle with time and/or the solidification of partial melt.

\subsection{Low-Velocity Anomalies in the Mid-Crust Near Segment Ends}

Although the images of absolute velocity shown in Plate 1 illustrate well the large-scale structure along the $\mathrm{OH}-1$ refraction lines, smaller-scale crustal heterogeneity is better emphasized by the deviation of the observed absolute velocities from a reference 1-D model. Plate 2 shows the difference between the observed absolute velocities and the 1-D velocity-depth profile from the segment midpoint of Line $\mathrm{C}$, which was used as the starting model for the Line $\mathrm{E}$ inversion. The most striking features in these velocity perturbation plots are the relatively low velocities at both ends of Lines $\mathrm{C}$ and $\mathrm{E}$ and at the southern end of Line W.

Anomalous crustal structure at segment ends is a common observation at MAR fracture zones [Detrick and Purdy, 1980; Sinha and Louden, 1983; Cormier et al., 1984; Ambos and Hussong, 1986; Louden et al., 1986; Detrick et al., 1993]; within the fracture zone valley itself, seismic layer 3 typically thins by several kilometers or disappears entirely, and the total crustal thickness can be as low as $2 \mathrm{~km}$. Several mechanisms may be responsible for these observations, including fracturing and alteration, restricted melt supply due to the large distance from segment-centered mantle upwelling, reduced in situ 
melting due to the thermal edge effect of adjacent cold lithosphere, and serpentinization of mantle peridotite. The magnitude of the observed variations in crustal velocities and thicknesses, however, vary significantly at MAR fracture zones, and the crust near the Oceanographer fracture zone in particular exhibits normal properties except within the fracture zone valley itself [Sinha and Louden, 1983; Ambos and Hussong, 1986]. A similar abrupt transition from normal thickness crust along strike to thinned crust in the fracture zone is also observed at the Kane fracture zone [Detrick and Purdy, 1980].

The mechanisms responsible for the large zones of low velocities at the distal ends of OH-1 are probably similar to those which are cited to alter fracture zone crust. In particular, the reduced shallow crust and mid-crust $P$ wave velocities at segment ends may result from serpentinization of mantle peridotite, fracturing and alteration, or a combination of these effects. Although we cannot rule out the presence of serpentinized mantle at the segment ends of $\mathrm{OH}-1$, a detailed analysis of the inferred density structure along Line W by Canales et al. [2000] suggests that serpentinization is likely restricted to the valley of the NTO and does not extend into the neighboring ridge segments. We believe instead that the large low-velocity regions at the distal ends of $\mathrm{OH}-1$ result from fracturing and cracking of newly accreted crust that is already somewhat thin due to attenuated melt supply. Abundant surface faults observed in the bathymetry map (Figure 1a) suggest that faulting significantly modifies newly formed crust as it is uplifted from 
the rift valley into the flanking crestal mountains. The inference of pervasive faulting at the ends of $\mathrm{OH}-1$ is consistent with the observation that microearthquake activity is found at the inside corners of both the NTO and Oceanographer fracture zone [Barclay et al., 2001]. However, inside corner tectonism does not explain the presence of the lowvelocity region at the southern end of Line $\mathrm{E}$, which is located at an outside corner. This particular low-velocity anomaly may result from tectonism associated with the southward propagation of $\mathrm{OH}-1$ since the southern end of Line E intersects the disturbed crust of the propagation wake.

\subsection{High-Velocity Anomalies in Mid-Crust Beneath Seamounts}

The western and eastern rift mountains have similar mid-crustal velocity

structures. A significant common feature is the presence of $\sim 7 \%$ higher than average velocities at 3-5 $\mathrm{km}$ depth at the segment midpoint (Plates 1a, 1c, 2a and 2c). On Line E this high-velocity anomaly lies between three seamounts adjacent to the refraction line (Figure 1c), and on Line $\mathrm{W}$ it occurs immediately beneath three line-centered seamounts (Figure 1b). Detection of high velocities beneath subaerial volcanoes is common. For example, a tomography experiment at the Hengill complex in southwestern Iceland imaged four regions of elevated velocities, three of which occurred directly beneath volcanoes [Foulger and Toomey, 1989]. In particular, the Husmuli volcano, which 
resembles the size of many of the $\mathrm{OH}-1$ seamounts, is underlain by a high-velocity body with a depth $(4 \mathrm{~km})$ and magnitude $(+7 \%)$ similar to the body imaged beneath the eastern rift mountains. The major difference between the two anomalies is in their aspect ratios: the Husmuli feature is tall and narrow, while the anomaly we image is short and wide.

Following the conclusion of Foulger and Toomey [1989], we hypothesize that the high-velocity bodies imaged beneath the seamounts at $\mathrm{OH}-1$ may be volcanic "roots" consisting of relatively unfractured intrusions or solidified magma chambers of the volcanoes. The volume of the root beneath Line $\mathrm{E}$ is calculated by multiplying its alongaxis length $(6.5 \mathrm{~km})$, depth $(2 \mathrm{~km})$, and cross-axis width $(3 \mathrm{~km})$; this latter number was determined by a 3-D MARBE experiment centered on the OH-1 rift valley [Magde et al., 2000]. Assuming the root has a rectangular cross section, its volume is $39 \mathrm{~km}^{3}$, which is a factor of 2 larger than the $15-20 \mathrm{~km}^{3}$ volume estimated for the anomaly beneath the Husmuli volcano [Foulger and Toomey, 1989]. However, because several seamounts lie adjacent to Line $E$, this large volume may be the sum of individual roots beneath each volcano.

The shape and velocity contrast of these high-velocity bodies are not sufficient to produce observable seismic reflections as might be recorded in multichannel seismic data. Similarly, the density contrast between the intrusions and the surrounding crust is too small to produce a noticeable gravity anomaly at the sea surface. However, based on 
the common occurrence of the volcanic roots on Lines E and W, similar high-velocity intrusions may underlie many if not all of the off axis $\mathrm{OH}-1$ seamounts.

An unusual feature of the velocity images from the two rift mountain lines is the apparent thinning of seismic layer 2 immediately beneath the seamounts (Plate 1 and Figure $7 \mathrm{~b}$ ). It is interesting to note that $\sim 3 \mathrm{~km}$ east of Line E, MCS analysis at two locations shows that layer $2 \mathrm{~A}$ is $275 \mathrm{~m}$ thinner at a site closest to a particularly large seamount [Hussenoeder, 1998]. A reduction in the volume of extrusive material beneath a volcano is counterintuitive. The most likely scenario is that the extrusive section beneath the seamounts is denser than the surrounding shallow crust, thereby increasing the seismic velocity and making layer 2 appear thinner. Increased densities could result from a more massive and less fractured extrusive section beneath the seamount relative to the surrounding extrusives or from a mixture of normal-density extrusive material with higher-density feeder dikes associated with the volcano. Cochran et al. [1999] invoke both of these factors to explain observed density differences within layer 2A at the EPR. Apparent thinning of layer 2 was not observed beneath the rift valley line (Plate 1b), potentially because of the counter-effects of low-density partial melt and higher temperatures within the axial upper crust [Barclay et al., 1998] and because the line did not directly cross a seamount. Future near-bottom gravity measurements would be one 
way to test if shallow crustal densities near the $\mathrm{OH}-1$ seamounts are indeed higher than the density of the surrounding extrusive crust.

\subsection{Anomalous Crustal Thickness of the OH-1 Segment}

Figure $7 \mathrm{~d}$ shows crustal thicknesses for all three $\mathrm{OH}-1$ refraction lines over the region of common coverage. Each line is underlain by very thick crust near the segment center $(x=-5 \mathrm{~km})$, with maximum thicknesses of $8.1 \mathrm{~km}$ on axis and $9 \mathrm{~km}$ off axis. These maximum values are 1-2 km larger than observed at $\mathrm{OH}-2$ and $\mathrm{OH}-3$, immediately to the south [Canales et al., 2000; Hooft et al., 2000]. They also lie at the top end of the observed range of seismic crustal thickness measurements at ridges that are unaffected by hotspots [White et al., 1992; Bown and White, 1994].

The seamount chain centered on $\mathrm{OH}-1$ is often cited as evidence for a high magma budget [e.g., Gràcia et al., 1999]. However, the seismic results in Plate 2 show that the inferred crustal magma bodies that underlie the seamounts are localized features with small volumes. Thus these small magma sources probably do not contribute significant volumes of melt to build the thick crustal roots at the segment center. Two main classes of models are commonly invoked to explain crustal thickness variations at slow spreading ridges. In the first model the mantle rises as a focused diapir beneath the center of an individual ridge segment. Because the diapir is hotter and more buoyant at 
its center than at its edges, decompression melting is enhanced in the core of the diapir, thereby creating thicker crust at the segment center than at either end [Kuo and Forsyth, 1988; Lin et al., 1990]. This model explains well the observation of circular MBA lows observed at the MAR. In the second model the mantle also rises vertically beneath a ridge segment, but melt production is constant along strike. The thick crust at the segment center results not from a larger extent of partial melting but rather from efficient migration of melt away from the segment ends toward the segment center [Magde and Sparks, 1997; Magde et al., 1997].

Hooft et al. [2000] suggest that the thick crust at the center of OH-1 results from efficient transport of melt along paths defined by steep mantle isotherms associated with the large-offset Oceanographer fracture zone. This conclusion seems to support the model where lateral variations in melt delivery explain crustal thickness variations. However, new geochemical analyses of lavas at $\mathrm{OH}-1$ show that the mantle beneath the segment center is enriched in incompatible elements, total alkalis, and $\mathrm{H}_{2} \mathrm{O}$ content [Niu et al., 2001], and thus likely melts extensively. Niu et al. [2001] thus support the mantle diapir model with the caveat that heterogeneous mantle composition is a critical variable governing crustal accretion at slow spreading ridges.

The three ridge-parallel seismic experiments at $\mathrm{OH}-1$ show that while the largescale crustal velocity structure of the crust has remained relatively constant over the last 2 
m.y., significant differences in crustal thickness exist. In particular, north of the segment center the crust is $4 \mathrm{~km}$ thicker beneath the eastern rift mountains relative to the rift valley and $2 \mathrm{~km}$ thicker relative to the conjugate western rift mountains (Figure 7d). We suggest that this pattern results from two possible scenarios. In the first scenario the crust beneath the rift mountains may have formed during a period of mantle melting in which the average melt production was greater than it is today. Based on the observation of alternating high- and low-amplitude residual gravity anomalies at $25^{\circ}-27^{\circ} \mathrm{N}$ on the MAR, Tucholke et al. [1997] estimate that the formation of buoyant melt diapirs and/or mantle heterogeneities occurs over a 2-3 m.y. cycle. If we assume that the effect of the Oceanographer fracture zone on the thermal state of the segment has remained relatively constant during the last 2 m.y., the along-strike variation in crustal thickness we observe between the rift valley and rift mountains lines must derive from variable melt production instead of from variable melt delivery. Although we cannot rule out the contribution of 3-D melt delivery in building the crust at OH-1, our results together with those of Niu et al. [2001] are more compatible with the focused mantle upwelling model to explain crustal thickness variations at $\mathrm{OH}-1$.

On the other hand, the differences in crustal thickness observed at $\mathrm{OH}-1$ may derive simply from asymmetric modification after the crust formed, with preferential thinning on the western flank upon uplift from the rift valley. This asymmetry may result 
from differences in the three-dimensional fault geometry on each flank and by variations in crustal accretion; Figure 1a shows that Line W lies on a topographic high, while Line $\mathrm{E}$ is located along a wide plateau. In addition, the southern end of Line W. may be especially thinned due to the combined effects of an NTO inside corner and the southward propagation of the $\mathrm{OH}-1$ segment.

\section{Conclusions}

From a joint interpretation of seismic and gravity data collected in the western rift mountains, rift valley, and eastern rift mountains at MAR segment $\mathrm{OH}-1$ we conclude the following:

1. The mean upper crustal (layer 2) velocity increases $16 \%$ from $4.5 \mathrm{~km} / \mathrm{s}$ on axis to $5.2 \mathrm{~km} / \mathrm{s}$ on $2 \mathrm{~m} . \mathrm{y}$. old crust on each flank. This increase in shallow crustal velocity off axis may reflect fissure sealing and mineral alteration primarily within layer $2 \mathrm{~A}$ as the crust ages. The mean thickness of the upper layer decreases $20 \%$ over the same time span, from 2.9 to $2.3 \mathrm{~km}$. In both on axis and off axis settings the upper crust is thinner at the segment center than at the segment ends. The mean lower crustal (layer 3) velocities are very similar for 0 and $2 \mathrm{~m}$.y. old crust, except for a small low velocity anomaly on axis interpreted as elevated temperatures and/or partial melt. In all three settings layer 3 
is thicker at the segment center than it is at the segment ends. The mantle velocity is 7.4 $\mathrm{km} / \mathrm{s}$ beneath the rift valley and $7.8 \mathrm{~km} / \mathrm{s}$ beneath either flank. The higher off-axis mantle velocities probably result from cooling of the mantle with time and/or the solidification of partial melt.

2. The maximum crustal thickness is $8-9 \mathrm{~km}$ beneath the center of all three seismic lines; this is at the high end of the seismic crustal thickness measurements for the MAR. The crust thins by $5 \mathrm{~km}$ toward the ends of the rift valley, by $4 \mathrm{~km}$ toward the ends of the western rift mountains, and by $2 \mathrm{~km}$ toward the ends of the eastern rift mountains. The Moho is as much as $2 \mathrm{~km}$ deeper beneath the eastern flank than beneath the conjugate western flank, despite their similar age. This large difference may derive from asymmetric post emplacement modification related to differences in fault geometry on each flank. Additionally, the southern end of the western line may be particularly thinned by the tectonic processes associated with the southward propagation of the segment.

3. Large regions (10-15 $\mathrm{km}$ wide, $4 \mathrm{~km}$ deep) of relatively low velocities ( -0.1 to $0.5 \mathrm{~km} / \mathrm{s}$ ) are imaged at both ends of the rift valley, both ends of the eastern rift mountains, and the southern end of the western rift mountains. These lowered values may be caused by fracturing facilitated by the greater tectonic deformation at segments ends and by the southward propagation of $\mathrm{OH}-1$. 
4. A mid-crust high-velocity body is spatially associated with clusters of large seamounts in the western and eastern rift mountains. We suggest that each body consists of a relatively unfractured volcanic root or the solidified magma chamber which fed the overlying seamounts. The upper crust thins by $500 \mathrm{~m}$ above these high-velocity anomalies, possibly indicating relatively higher densities in the extrusive section relative to the surrounding upper crust. These higher densities may result from a less fractured extrusive section beneath the seamounts or from a mixture of normal density basalt and higher density feeder dikes. Based on the relatively small size of these roots, volcanism associated with the seamounts probably does not contribute substantially to the thickened crust at the center of the segment.

Acknowledgments. We thank Beecher Wooding, David DuBois, Jim Dolan, John Bailey, and John Hallinan of the OBS group at WHOI for their technical support during this cruise. We also thank the crew of R/V Maurice Ewing Leg 96-08. We thank Andrew Barclay, Dan Scheirer, Pablo Canales, Emilie Hooft, and Jun Korenaga for helpful discussions during this study. We also thank Pablo Canales and Emilie Hooft for making available digital results of their studies. The comments of Keith Louden, Maya Tolstoy, and an anonymous reviewer also helped to improve the manuscript. This work 
was supported by National Science Foundation grant OCE-9300450 to the Woods Hole

Oceanographic Institution. Woods Hole Oceanographic Institution contribution 10362.

\section{References}

Ambos, E.L., and D.M. Hussong, Oceanographer transform fault structure compared to that of surrounding oceanic crust: Results from seismic refraction data analysis, $J$. Geodyn., 5, 79-102, 1986.

Barclay, A.H., D.R. Toomey, and S.C. Solomon, Seismic structure and crustal magmatism at the Mid-Atlantic Ridge, $35^{\circ} \mathrm{N}$, J. Geophys. Res., 103, 17827-17844, 1998.

Barclay, A.H., D.R. Toomey, and S.C. Solomon, Microearthquake characteristics and crustal Vp/Vs structure at the Mid-Atlantic Ridge, $35^{\circ} \mathrm{N}$, J. Geophys. Res., 106, 20172034, 2001.

Bown, J.W., and R.S. White, Variation with spreading rate of oceanic crustal thickness and geochemistry, Earth Planet. Sci. Lett., 121, 435-449, 1994.

Brozena, J.M., Temporal and spatial variability of seafloor spreading processes in the northern South Atlantic, J. Geophys. Res., 91, 497-510, 1986.

Bryan, W.B., S.E. Humphris, G. Thompson, and J.F. Casey, Comparative volcanology of small axial eruptive centers in the MARK area, J. Geophys. Res., 99, 2973-2984, 1994.

Canales, J.P., R.S. Detrick, J. Lin, J.A. Collins, and D.R. Toomey, Crustal and upper mantle seismic structure beneath the rift mountains and across a non-transform offset at the Mid-Atlantic Ridge (35N), J. Geophys. Res., 105, 2699-2719, 2000.

Carbotte, S., S.M. Welch, and K.C. Macdonald, Spreading rates, rift propagation, and fracture zone offset histories during the past 5 my on the Mid-Atlantic Ridge; $25^{\circ}$ $27^{\circ} 30^{\prime} \mathrm{S}$ and $31^{\circ}-34^{\circ} 30^{\prime}$ S, Mar. Geophys. Res., 13, 51-80, 1991.

Caress, D.W., M.S. Burnett, and J.A. Orcutt, Tomographic image of the axial lowvelocity zone at $12^{\circ} 50^{\prime} \mathrm{N}$ on the East Pacific Rise, J. Geophys. Res., 97, 9243-9263, 1992.

Carlson, R.L., Seismic velocities in the uppermost oceanic crust: Age dependence and the fate of layer 2A, J. Geophys. Res., 103, 7069-7077, 1998.

Carlson, R.L., and G.S. Raskin, Density of the ocean crust, Nature, 311, 555-558, 1984. 
Cochran, J.R., D.J. Fornari, B.J. Coakley, R. Herr, and M.A. Tivey, Continuous nearbottom gravity measurements made with a BGM-3 gravimeter in DSV Alvin on the East Pacific Rise crest near $9^{\circ} 31^{\prime} \mathrm{N}$ and $9^{\circ} 50^{\prime} \mathrm{N}$, J. Geophys. Res., 104, 10841-10861, 1999.

Cormier, M.-H., R.S. Detrick, and G.M. Purdy, Anomalously thin crust in oceanic fracture zones: New seismic constraints from the Kane fracture zone, J. Geophys. Res., 89, 10249-10266, 1984.

Creager, K.C., and L.M. Dorman, Location of instruments on the seafloor by joint adjustment of instrument and ship positions, J. Geophys. Res., 87, 8379-8388, 1982.

DeMets, C., R.G. Gordon, D.F. Argus, and S. Stein, Current plate motions, Geophys. J. Int., 101, 425-478, 1990.

Deplus, C., et al., Linking variation in magma supply and segment growth: temporal evolution of segment OH-1 (MAR at $35^{\circ} \mathrm{N}$ ) during the last $12 \mathrm{Myr}$, Eos Trans. AGU, 69 (44), Fall Meet. Suppl., F856, 1998.

Detrick, R.S., H.D. Needham, and V. Renard, Gravity anomalies and crustal thickness variations along the Mid-Atlantic Ridge between $33^{\circ} \mathrm{N}$ and $40^{\circ} \mathrm{N}, J$. Geophys. Res., 100, 3767-3787, 1995.

Detrick, R.S., Jr., and G.M. Purdy, The crustal structure of the Kane fracture zone from seismic refraction studies, J. Geophys. Res., 85, 3759-3777, 1980.

Detrick, R.S., R.S. White, and G.M. Purdy, Crustal structure of North Atlantic fracture zones, Rev. Geophys., 31, 439-458, 1993.

Escartín, J., and J. Lin, Ridge offsets, normal faulting, and gravity anomalies of slow spreading ridges, J. Geophys. Res., 100, 6163-6177, 1995.

Foulger, G.R., and D.R. Toomey, Structure and evolution of the Hengill-Grensdalur volcanic complex, Iceland: Geology, geophysics, and seismic tomography, $J$. Geophys. Res., 94, 17511-17522, 1989.

Fox, P.J., E. Schreiber, H. Rowlett, and K. McCamy, The geology of the Oceanographer fracture zone: A model for fracture zones, J. Geophys. Res., 81, 4117-4128, 1976.

Gente, P., G. Ceuleneer, C. Durand, R. Pockalny, and M. Maia, Propagation rate of segments along the Mid-Atlantic Ridge between $20^{\circ}$ and $24^{\circ}$ (SEADMA I cruise), Eos Trans. AGU, 73 (43), Fall Meet. Suppl., F569, 1992.

Gràcia, E., D. Bideau, R. Hekinian, and Y. Lagabrielle, Detailed geologic mapping of two second-order segments of the Mid-Atlantic Ridge between Oceanographer and

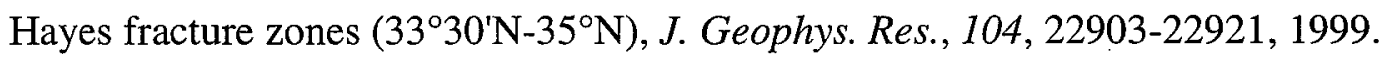

Hooft, E.E.E., R.S. Detrick, D.R. Toomey, J.A. Collins, and J. Lin, Crustal thickness and structure along three contrasting spreading segments of the Mid-Atlantic Ridge, 33.5-35N, J. Geophys. Res., 105, 8205-8226, 2000. 
Hussenoeder, S.A., Seismic and magnetic constraints on the structure of upper oceanic crust at fast and slow spreading ridges, Woods Hole Oceanographic Institution/Massachusetts Institute of Technology Joint Program in Oceanography, Woods Hole, 1998.

Jaroslow, G.E., D.K. Smith, and B.E. Tucholke, Record of seamount production and offaxis evolution in the western North Atlantic Ocean, $25^{\circ} 25^{\prime}-27^{\circ} 10^{\prime} \mathrm{N}$, J. Geophys. Res., $105,2721-2736,2000$.

Klingelhofer, F., L. Geli, L. Matias, N. Steinsland, and J. Mohr, Crustal structure of a super-slow spreading centre: A seismic refraction study of Mohns Ridge, $72^{\circ} \mathrm{N}$, Geophys. J. Int., 141, 509-526, 2000.

Korenaga, J., W.S. Holbrook, G.M. Kent, P.B. Keleman, R.S. Detrick, H.-C. Larsen, J.R. Hopper, and T. Dahl-Jensen, Crustal structure of the southeast Greenland margin from joint refraction and reflection seismic tomography, J. Geophys. Res., 105, 21591-21614, 2000.

Kuo, B.-Y., and D.W. Forsyth, Gravity anomalies of the ridge-transform system in the South Atlantic between 31 and $34.5^{\circ} \mathrm{S}$ : Upwelling centers and variations in crustal thickness, Mar. Geophys. Res., 10, 205-232, 1988.

Lin, J., G.M. Purdy, H. Schouten, and J.-C. Sempéré, Evidence from gravity data for focused magmatic accretion along the Mid-Atlantic Ridge, Nature, 344, 627-632, 1990.

Louden, K.E., R.S. White, C.G. Potts, and D.W. Forsyth, Structure and seismotectonics of the Vema Fracture Zone, Atlantic Ocean, J. Geol. Soc. London, 143, 795-805, 1986.

Magde, L.S., A.H. Barclay, D.R. Toomey, R.S. Detrick, and J.A. Collins, Crustal magma plumbing within a segment of the Mid-Atlantic Ridge, $35^{\circ} \mathrm{N}$, Earth Planet. Sci. Lett., 175, 55-67, 2000.

Magde, L.S., and D.W. Sparks, Three-dimensional mantle upwelling, melt generation and melt migration beneath segmented slow-spreading ridges, J. Geophys. Res., 102, 20571-20583, 1997.

Magde, L.S., D.W. Sparks, and R.S. Detrick, The relationship between buoyant mantle flow, melt migration, and gravity bull's eyes at the Mid-Atlantic Ridge between $33^{\circ} \mathrm{N}$ and $35^{\circ} \mathrm{N}$, Earth Planet. Sci. Lett., 148, 59-67, 1997.

McClain, J.S., and D.W. Caress, Seismic tomography in marine refraction experiments, in Seismic Tomography: Theory and Practice, edited by H.M. Iyer, and K. Hirahara, pp. 764-780, Chapman and Hall, New York, 1993.

Moser, T.J., Shortest path calculations of seismic rays, Geophysics, 56, 59-67, 1991. 
Moser, T.J., G. Nolet, and R. Sneieder, Ray bending revisited, Bull. Seis. Soc. Am., 82, 259-288, 1992.

Needham, H.D., M. Voisset, V. Renard, H. Bougault, O. Dauteuil, R. Detrick, and C. Langmuir, Structural and volcanic features of the Mid-Atlantic Rift Zone between $40^{\circ} \mathrm{N}$ and $33^{\circ} \mathrm{N}$, Eos Trans. $A G U, 73$ (43), Fall Meet. Suppl., F552, 1992.

Niu, Y., D. Bideau, R. Hékinian, and R. Batiza, Mantle compositional control on the extent of mantle melting, crust production, gravity anomaly, ridge morphology, and ridge segmentation: A case study at the Mid-Atlantic Ridge $33-35^{\circ} \mathrm{N}$, Earth Planet. Sci. Lett., 186, 383-399, 2001.

Parker, R.L., The rapid calculation of potential anomalies, Geophys. J. R. Astron. Soc., 31, 447-455, 1973.

Phipps Morgan, J., and D.W. Forsyth, Three-dimensional flow and temperature perturbations due to a transform offset: Effects on oceanic crustal and upper mantle structure, J. Geophys. Res., 93, 2955-2966, 1988.

Purdy, G.M., and R.S. Detrick, Crustal structure of the Mid-Atlantic Ridge at $23^{\circ} \mathrm{N}$ from seismic refraction studies, J. Geophys. Res., 91, 3739-3762, 1986.

Rabain, A., M. Cannat, C. Deplus, J. Escartin, and G. Pouliquen, Focused volcanism in the $\mathrm{OH} 1$ segment of the Mid-Atlantic Ridge $\left(35^{\circ} \mathrm{N}\right)$ : A study of seamount distribution and sizes in the off-axis bathymetric record, Eos Trans. AGU, 80 (46), Fall Meet. Suppl., F913-914, 1999.

Schreiber, E., and P.J. Fox, Compressional wave velocities and mineralogy of fresh basalts from the Famous area and the Oceanographer fracture zone and the texture of layer 2A of the oceanic crust, J. Geophys. Res., 81, 4071-4076, 1976.

Severinghaus, J.P., and K.C. Macdonald, High inside corners at ridge-transform intersections, Mar. Geophys. Res., 9, 353-367, 1988.

Shirey, S.B., J.F. Bender, and C.H. Langmuir, Three-component isotopic heterogeneity near the Oceanographer transform, Mid-Atlantic Ridge, Nature, 325, 217-223, 1987.

Sinha, M.C., and K.E. Louden, The Oceanographer fracture zone, 1, Crustal structure from seismic refraction studies, Geophys. J. R. Astron. Soc., 75, 713-736, 1983.

Smith, D.K., and J.R. Cann, Building the crust at the Mid-Atlantic Ridge, Nature, 365, 707-715, 1993.

Smith, D.K., M.A. Tivey, H. Schouten, and J.R. Cann, Locating the spreading axis along $80 \mathrm{~km}$ of the Mid-Atlantic Ridge south of the Atlantis Transform, J. Geophys. Res., 104, 7599-7612, 1999.

Thibaud, R., P. Gente, and M. Maia, A systematic analysis of the Mid-Atlantic Ridge morphology and gravity between $15^{\circ} \mathrm{N}$ and $40^{\circ} \mathrm{N}$ : Constraints of the thermal structure, J. Geophys. Res., 103, 24223-24243, 1998. 
Tolstoy, M., A.J. Harding, and J.A. Orcutt, Crustal thickness on the Mid-Atlantic Ridge: Bull's eye gravity anomalies and focused accretion, Science, 262, 726-729, 1993.

Toomey, D.R., S.C. Solomon, and G.M. Purdy, Tomographic imaging of the shallow crustal structure of the East Pacific Rise at 9³0'N, J. Geophys. Res., 99, 2413524157, 1994.

Tucholke, B.E., J. Lin, M.C. Kleinrock, M.A. Tivey, T.B. Reed, J. Goff, and G.E. Jaroslow, Segmentation and crustal structure of the western Mid-Atlantic Ridge flank, $25^{\circ} 25^{\prime}-27^{\circ} 10^{\prime} \mathrm{N}$ and 0-29 m.y., J. Geophys. Res., 102, 10203-10223, 1997.

Van Avendonk, H.J.A., A.J. Harding, J.A. Orcutt, and J.S. McClain, A two-dimensional tomographic study of the Clipperton transform fault, J. Geophys. Res., 103, 1788517899, 1998.

White, R.S., D. McKenzie, and R.K. O'Nions, Oceanic crustal thickness from seismic measurements and rare earth element inversions, J. Geophys. Res., 97, 19683-19715, 1992.

Yu, D., D. Fontignie, and J.-G. Schilling, Mantle plume-ridge interactions in the central North Atlantic: A Nd isotope study of Mid-Atlantic Ridge basalts from $30^{\circ} \mathrm{N}$ to $50^{\circ} \mathrm{N}$, Earth Planet. Sci. Lett., 146, 259-272, 1997.

Zelt, C.A., and R.B. Smith, Seismic traveltime inversion for 2-D crustal velocity structure, Geophys. J. Int., 108, 16-34, 1992.

Zelt, C.A., and B.C. Zelt, Study of out-of-plane effects in the inversion of refraction/wide-angle reflection traveltimes, Tectonophysics, 286, 209-221, 1998. 
Table 1. Instrument Positions and Depth

\begin{tabular}{lllll}
\hline OBH & Latitude, ${ }^{\circ} \mathrm{N}$ & Longitude, ${ }^{\circ} \mathrm{W}$ & Depth $Z, \mathrm{~km}$ & Position $X, \mathrm{~km}$ \\
\hline 24 & 35.1534 & 36.1289 & 1.245 & 29.12 \\
25 & 35.0603 & 36.1497 & 1.829 & 18.60 \\
16 & 34.9763 & 36.1645 & 2.019 & 9.17 \\
27 & 34.8944 & 36.1777 & 1.981 & 0.00 \\
22 & 34.8194 & 36.1923 & 1.852 & -9.43 \\
23 & 34.7206 & 36.2110 & 2.204 & -19.55 \\
26 & 34.6414 & 36.2285 & 2.420 & -28.50 \\
17 & 34.5852 & 36.2360 & 2.581 & -34.77 \\
\hline
\end{tabular}

Instrument geographic coordinates were derived using the relocation algorithm of Creager and Dorman [1982]. Depths were obtained from the Hydrosweep bathymetry grid at those relocated positions. The difference between the relocated depths and the Hydrosweep depths is $<1 \%$. The choice of ocean bottom hydrophone (OBH) 27 for the coordinate system origin is arbitrary. 
Figure 1. (inset) Location of the study area at $35^{\circ} \mathrm{N}$ on the Mid-Atlantic Ridge. (a) Bathymetry map of the study area $\mathrm{OH}-1$ gridded at $500 \mathrm{~m}$ resolution and contoured every $100 \mathrm{~m}$. Thick white lines with black dashes indicate air gun shot locations for all three refraction experiments at $\mathrm{OH}-1$ : Line $\mathrm{E}$ on 2 m.y. old crust in the eastern rift mountains (this study), Line $C$ in the central axial valley [see Hooft et al., 2000], and Line W on 2 m.y. old crust in the western rift mountains [see Canales et al., 2000]. Dashed lines labeled "SL1" and "SL2" correspond to lines C1 and B of Sinha and Louden [1983]. Numbered squares denote ocean bottom hydrophone $(\mathrm{OBH})$ locations on Line $\mathrm{E}$. Darkened section of Line E marks the locations of PmP reflections. Solid black circles denote the portions of Lines $\mathrm{W}$ and $\mathrm{C}$ that are jointly interpreted with Line $\mathrm{E}$. Solid inverted triangles denote position of $x=0$ on Lines $\mathrm{W}$ and $\mathrm{C}$ in Plates 1 and 2. Arrows indicate propagation wake of $\mathrm{OH}-1$. IC indicates inside corner; $\mathrm{OC}$ indicates outside corner. (b) Detail of seamounts along Line W, gridded at $125 \mathrm{~m}$ and contoured every 50 m. (c) Detail of seamounts along Line E, gridded at $125 \mathrm{~m}$ and contoured every $50 \mathrm{~m}$. 

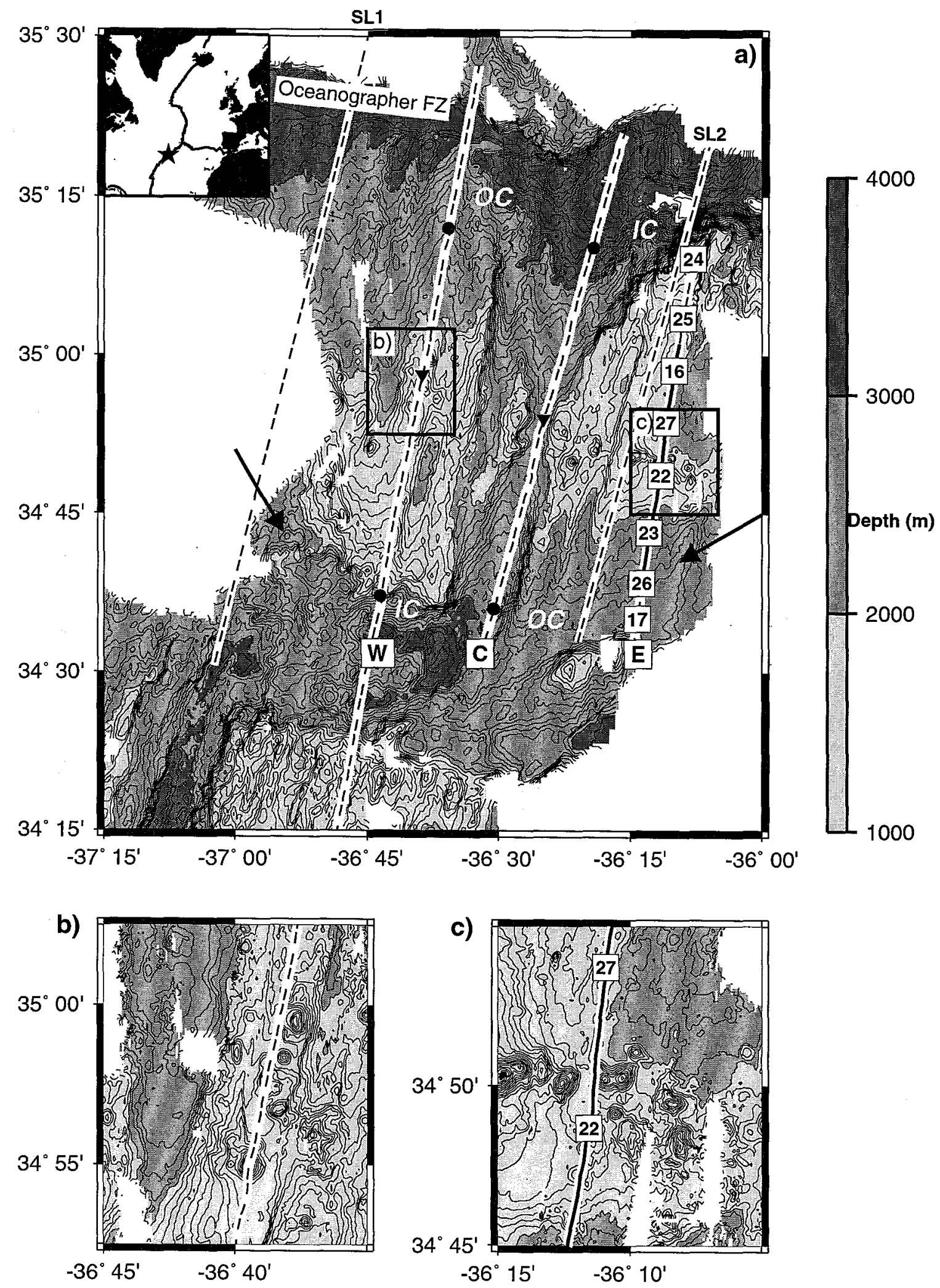

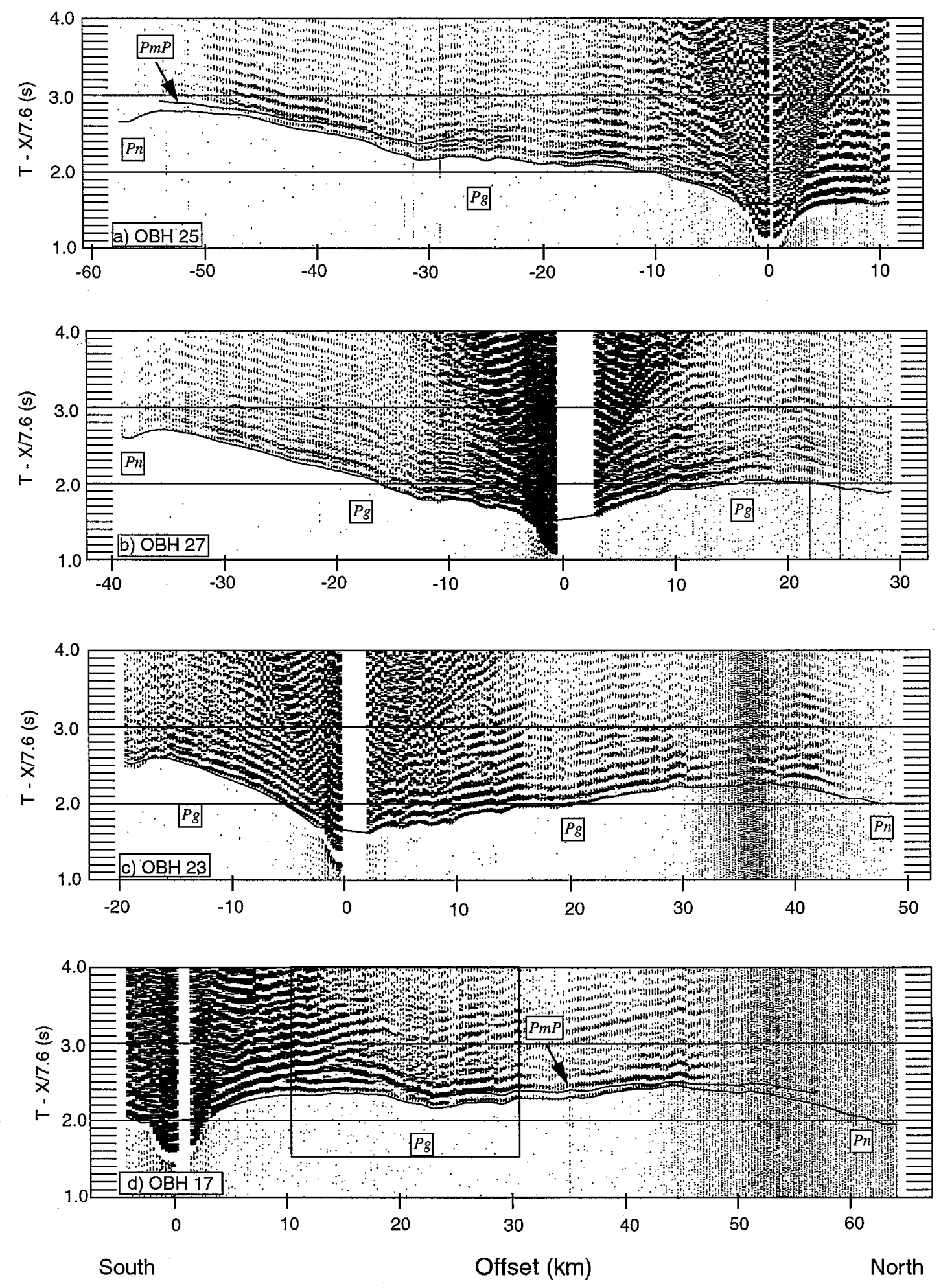


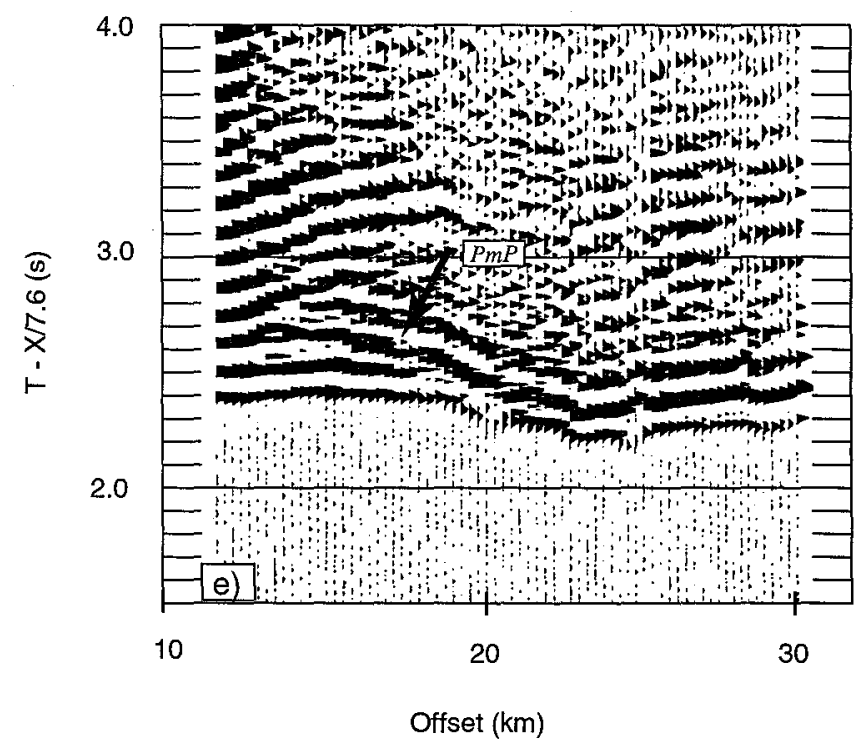

Figure 2. (a-d) Seismic record sections for four of the eight instruments. All record sections are band-pass filtered between 5 and $40 \mathrm{~Hz}$ except for Figure 2a, which has been run through a spiking deconvolution algorithm to increase the signal-to-noise ratio. Thin solid lines correspond to the model-predicted travel times and show excellent agreement with picked travel times. Traces are clipped to $1.5 \mathrm{x}$ the trace spacing and are not corrected for topography. The reduction velocity is $7.6 \mathrm{~km} / \mathrm{s}$. The $P g$ (rays refracted in the crust), $P n$ (rays refracted in the mantle), and $P m P$ (rays reflected off the Moho) phases are labeled. (e) Enlargement of record section for OBH 17 (box in Figure 2d) illustrating high-amplitude $P m P$ arrivals cross-cutting multiples of $P g$ arrivals. 
Figure 3. (a) Final $P$ wave velocity structure and Moho depth along the eastern rift mountains of $\mathrm{OH}-1$. PmP bounce points (white stars) and interpolation between them (thick solid line) define the seismic Moho over the central $45 \mathrm{~km}$ of the profile. Velocities are masked where ray coverage is sparse. Solid squares denote instrument locations and the open triangle marks the location of a seamount cluster adjacent to the line. (b) Difference between the final $P$ wave velocity model in Figure $3 \mathrm{a}$ and an average velocity-depth profile from the central axial valley of $\mathrm{OH}-1$. The dotted line marks the depth of the $6.5 \mathrm{~km} / \mathrm{s}$ interface and defines the boundary between the upper and lower crust. The thick solid contour emphasizes a velocity perturbation of 0 . Vertical exaggeration (VE) is 2.7 . 


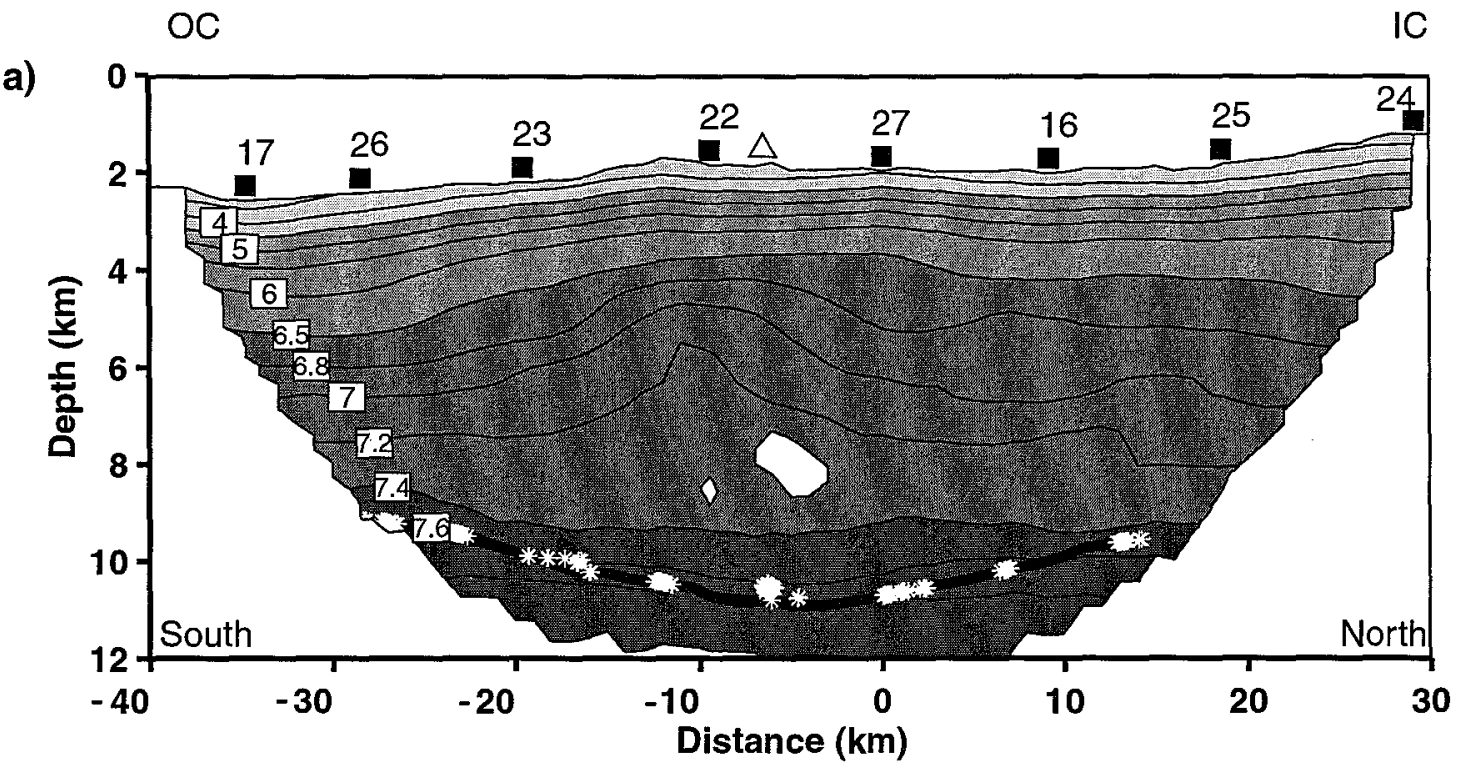

seafloor

4.5

6.5

7.4

mantle

Velocity $(\mathrm{km} / \mathrm{s})$

b)

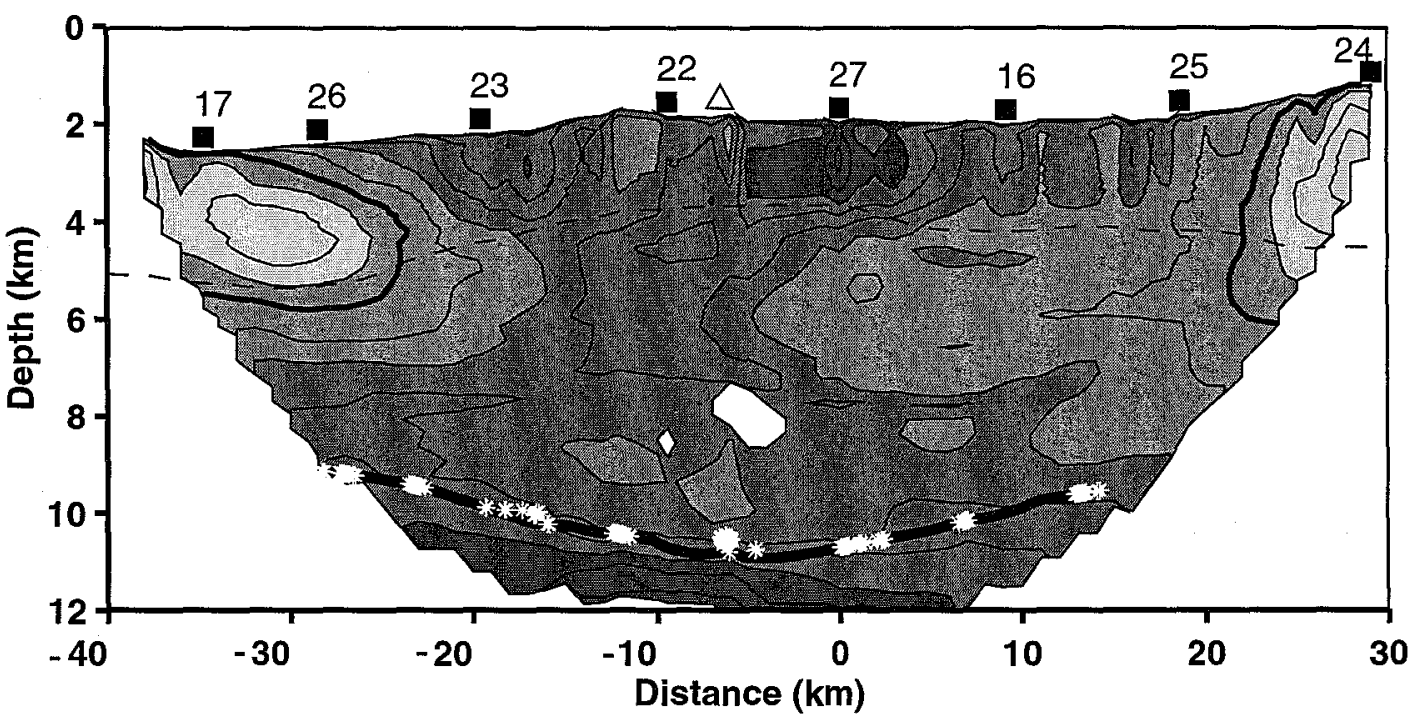

$-0.4$

0.4

0.8

Velocity Perturbation $(\mathrm{km} / \mathrm{s})$ 
Figure 4. (a) The derivative weight sum (DWS), a measure of refracted ray density, for the final seismic model (Figure 3a). Lighter shading indicates denser ray coverage and better model resolution. No rays pass through black regions. Grid cells indicate model parameterization; for clarity, every other horizontal grid line is shown. Color scale divides the data into quartiles. Thick line indicates Moho. Solid squares denote instrument locations. (b) Travel time residual between observed and model-predicted $\mathrm{Pg}$ arrivals. Final root-mean-square (RMS) misfit is $30 \mathrm{~ms}$. (c) Travel time residual between observed and model-predicted $P m P$ rays. Final RMS is $47 \mathrm{~ms}$. d) $P m P$ rays traced through the final seismic model, illustrating the nearly continuous insonification of the Moho over the central $45 \mathrm{~km}$ of the line. $\mathrm{VE}=2.7$. 
a)

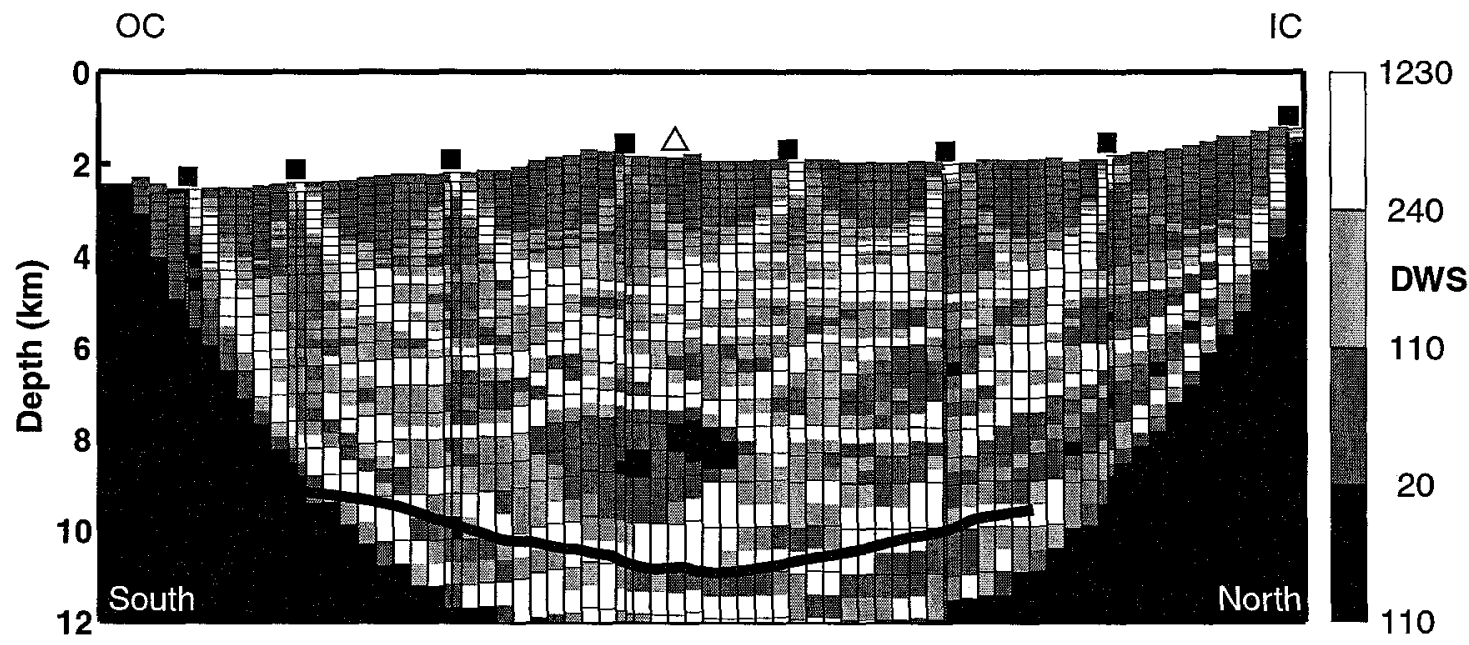

b)

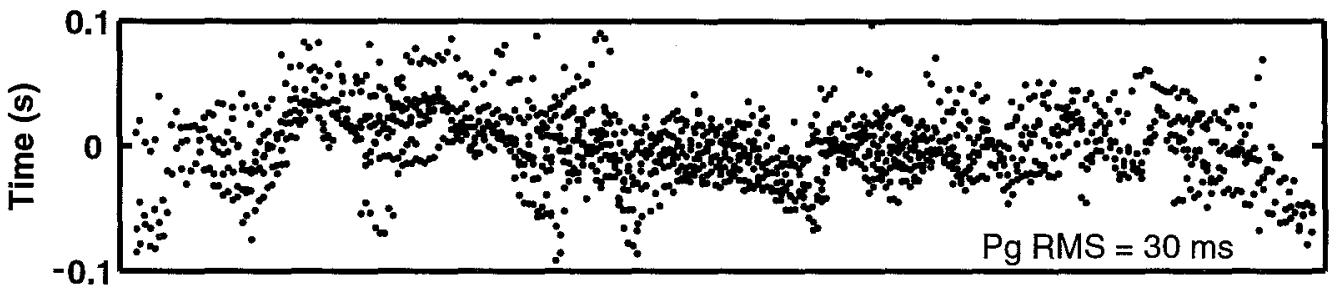

c)

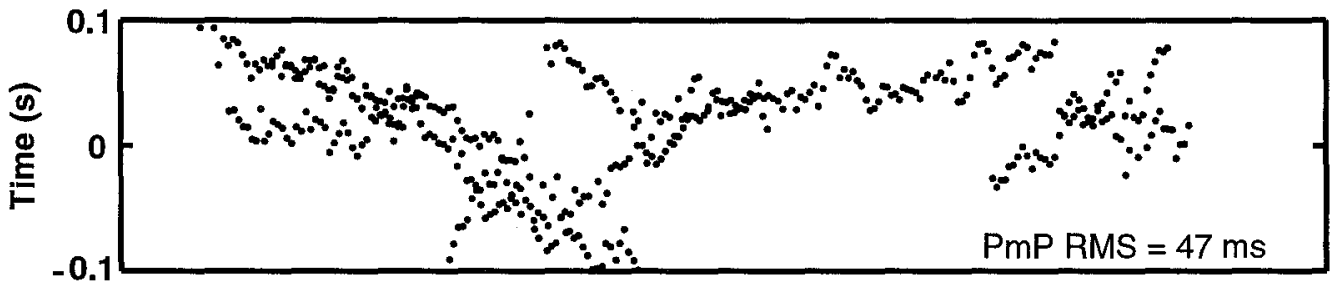

d)

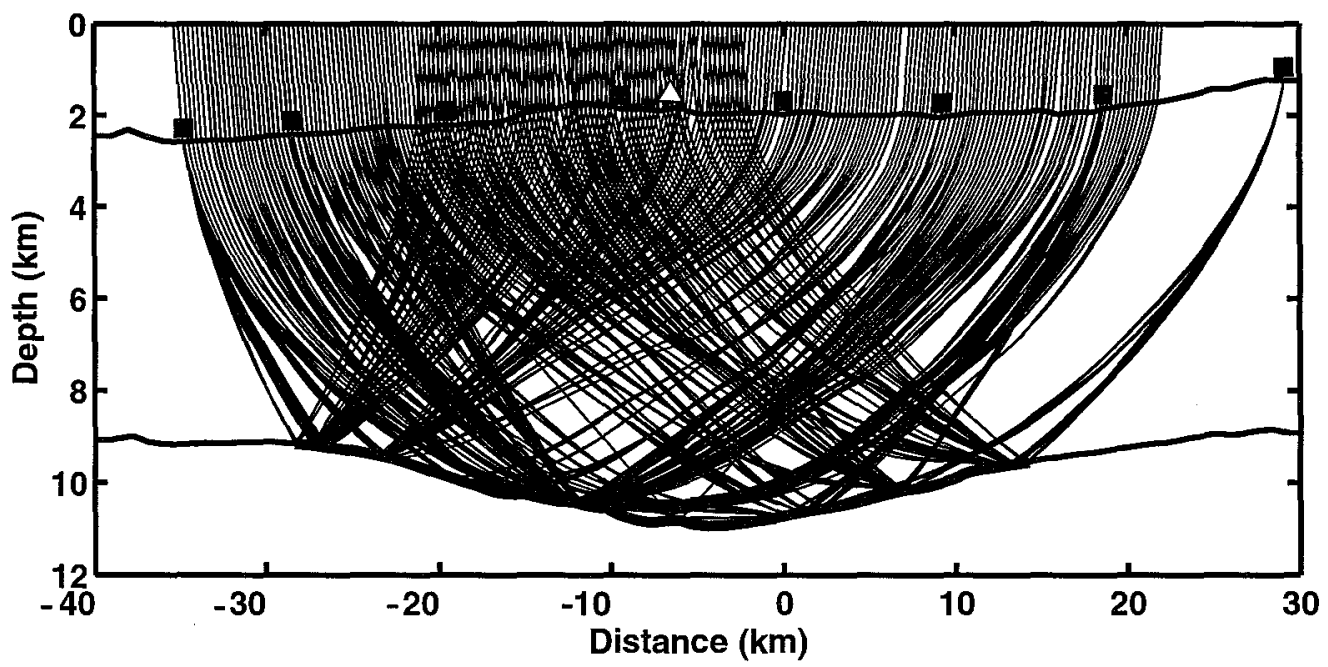


Figure 5. (a) Synthetic velocity model used to test the resolution of high- and lowvelocity bodies in the mid-crust. The velocity perturbation is $3 \%$ over the background velocity. (b) Recovered velocity model, using identical inversion parameters and ray paths as in the real experiment. $\mathrm{VE}=2.7$. 

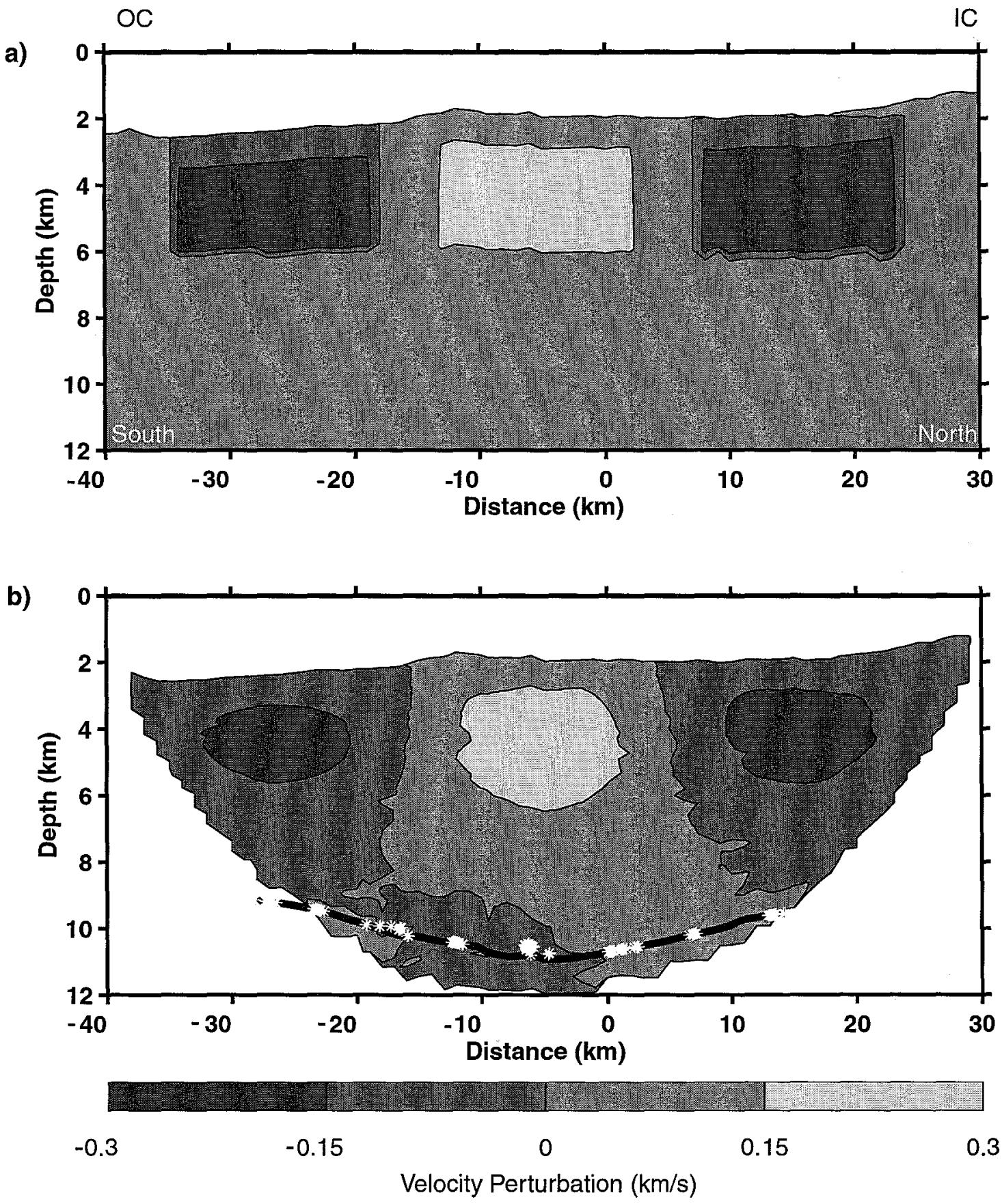
Figure 6. (a) Density model used to obtain the observed residual crustal Bouguer anomaly (RCBA) for the crustal structure in Figure 3a. Velocity contours were extracted from the velocity model at $0.1 \mathrm{~km} / \mathrm{s}$ intervals from the seafloor to the $7 \mathrm{~km} / \mathrm{s}$ contour and extended in three dimensions for the gravity calculation. We used a density contrast of $1525 \mathrm{~kg} / \mathrm{m}^{3}$ across the seafloor and a density contrast of $350 \mathrm{~kg} / \mathrm{m}^{3}$ across the Moho. (b) Observed (solid lines) and predicted (dashed line) RCBA for the seismic result in Figure 3a. RCBA1 (solid line) was calculated using the velocity-density relation in the text and RCBA2 (shaded line) was calculated using (3) of Carlson and Raskin [1984]. VE = 3.1. 

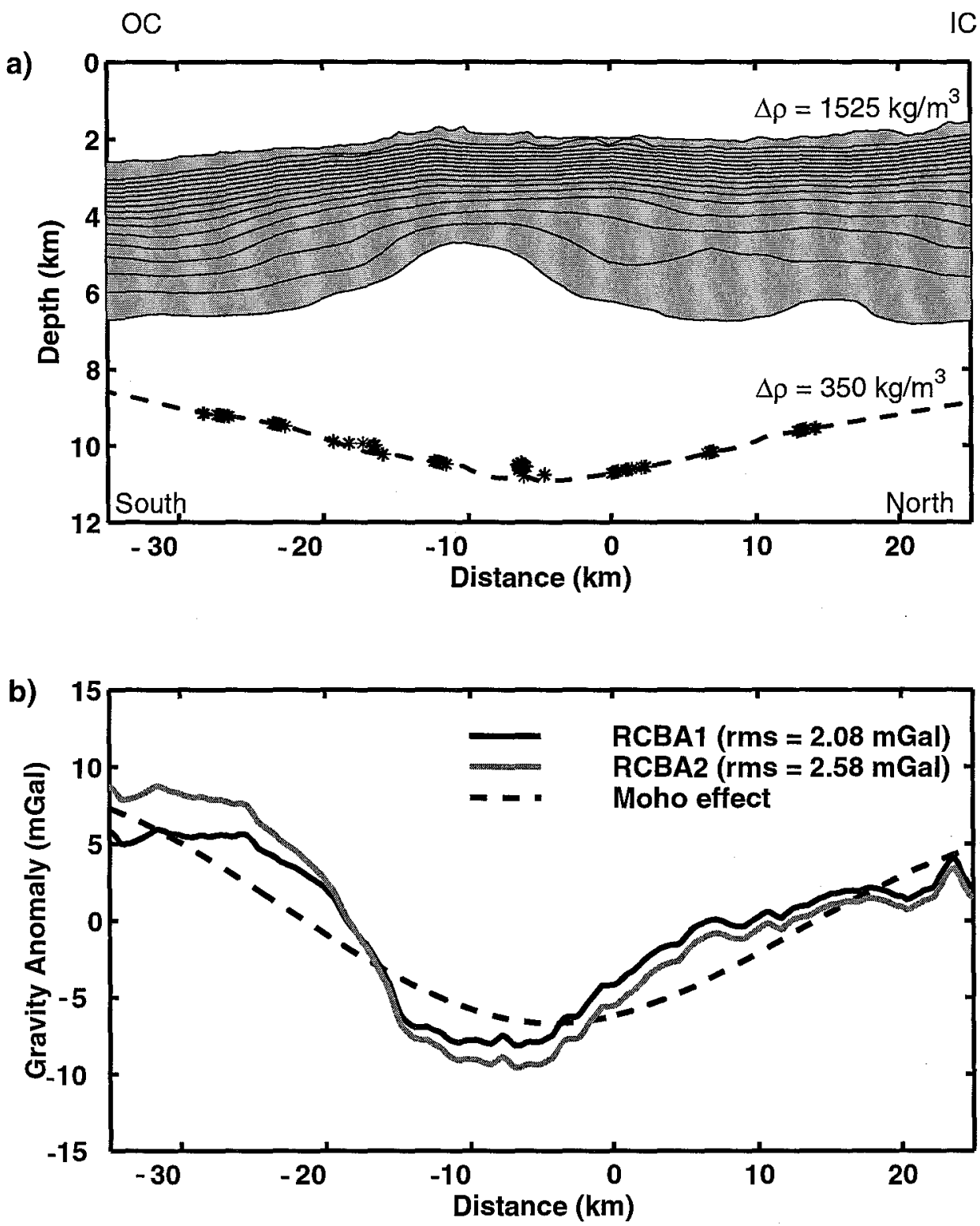
Plate 1. Final $P$ wave velocity models for the (a) western rift mountains (Line W), (b) axial valley (Line C), and (c) eastern rift mountains (Line E) of OH-1 (see Figure 1 for line locations). Both Lines $\mathrm{W}$ and $\mathrm{C}$ image 2 m.y. old crust. PmP reflection points are denoted by white stars, which define the seismic Moho along the lines. Note that the contour interval is $0.5 \mathrm{~km} / \mathrm{s}$ between 3.0 and $6.5 \mathrm{~km} / \mathrm{s}$ and $0.2 \mathrm{~km} / \mathrm{s}$ between 6.8 and 7.8 $\mathrm{km} / \mathrm{s}$ Coordinates for Line $\mathrm{C}$ are the same as by Hooft et al. [2000]. Coordinates for Line W correspond to coordinates 18-88 of Canales et al. [2000]. See Figure 1a for position of $x=0$ on Lines $\mathrm{W}$ and C; on Line $\mathrm{E}, x=0$ corresponds to OBH 27. The RMS travel time residual for each tomographic solution was $31 \mathrm{~ms}$ (Line W), $26 \mathrm{~ms}$ (Line C), and $30 \mathrm{~ms}$ (Line E). Solid squares and open triangles are as in Figure 3. VE $=2.4$. 

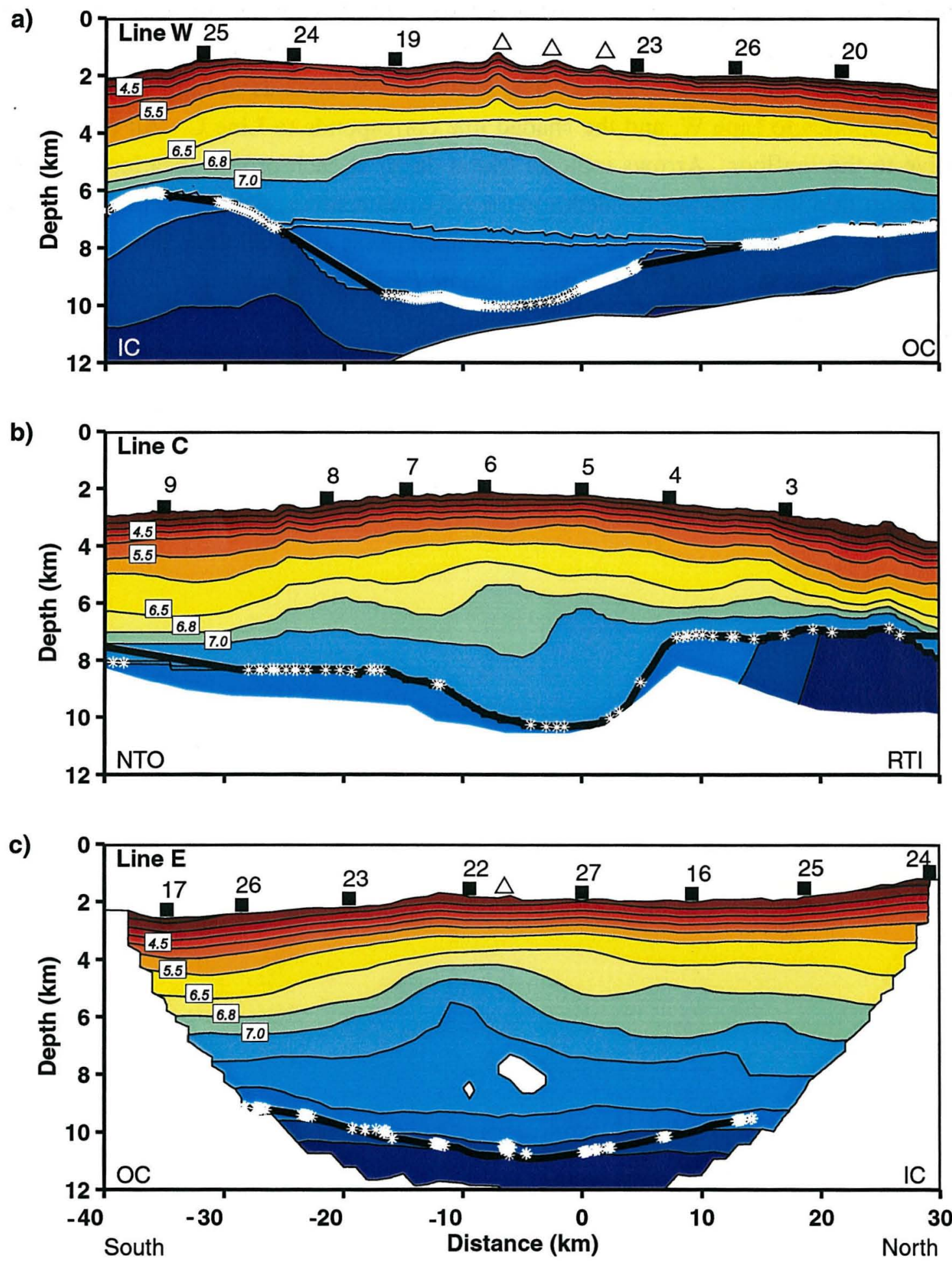

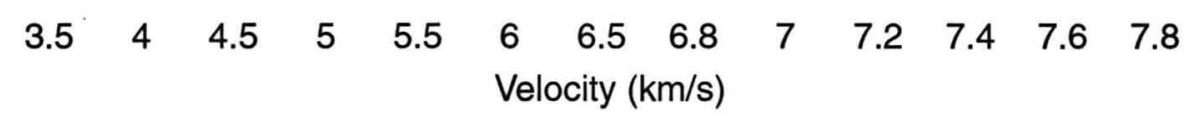


Figure 7. Velocity-depth profiles extracted from the two-dimensional tomographic images in Plate 1 at (a) the south end $(x=-28 \mathrm{~km})$, (b) the center $(x=-5 \mathrm{~km})$, and (c) toward the north end $(x=13)$ of $\mathrm{OH}-1$. The solid line corresponds to Line $\mathrm{E}$, the dashed line corresponds to Line $\mathrm{W}$, and the shaded line corresponds to Line C. All depths are relative to the seafloor. Arrows indicate Moho depth at each profile location for each line. Short thin lines indicate the depth to the $6.5 \mathrm{~km} / \mathrm{s}$ contour, defined as the boundary between the upper and lower crust. (d) Crustal thicknesses along all three lines, using the same line styles as in Figures $7 \mathrm{a}-\mathrm{c}$. Crosses denote $\mathrm{PmP}$ reflection points. 

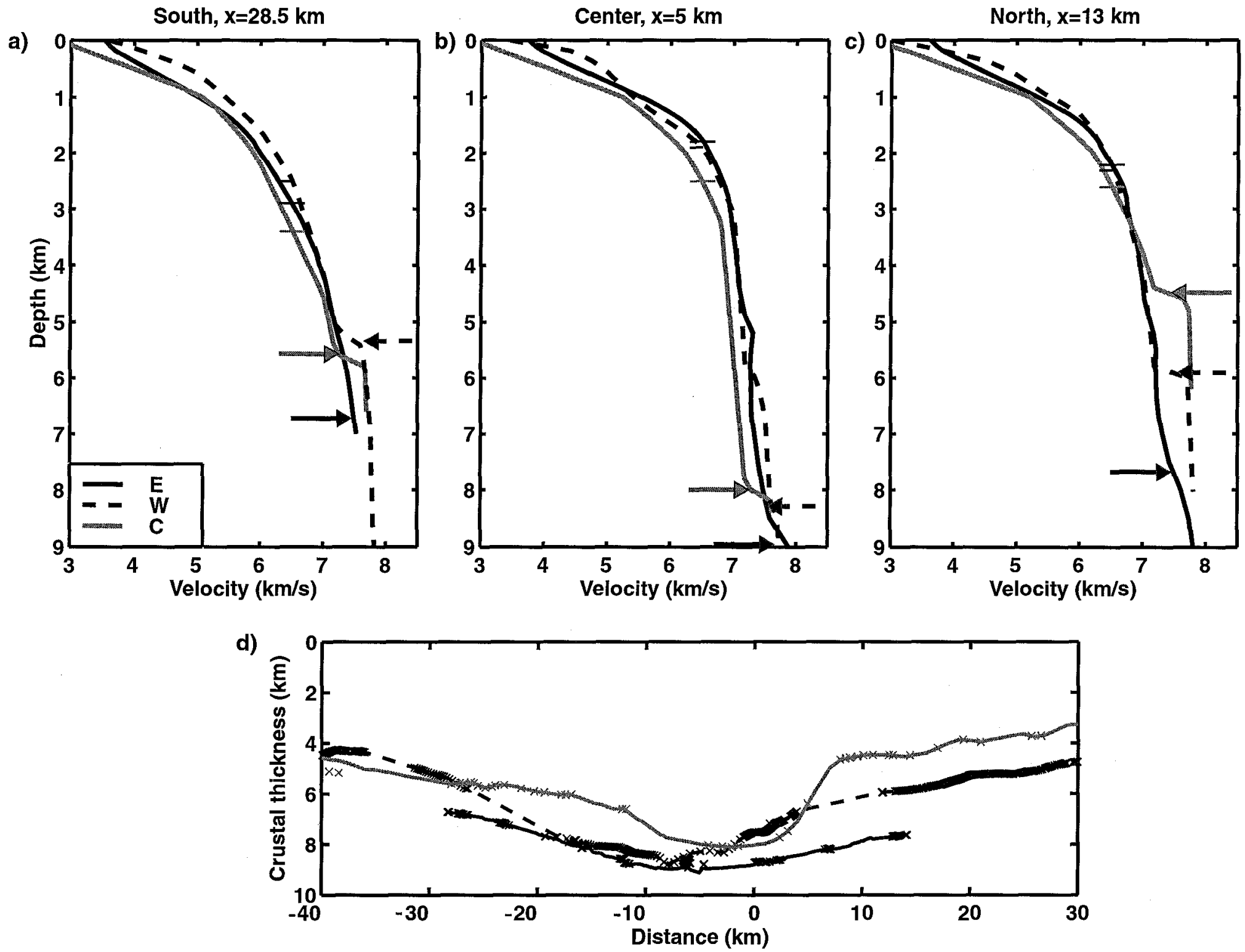
Plate 2. Difference between the $P$ wave velocity models in Plate 1 and an average velocity-depth profile from the central axial valley of $\mathrm{OH}-1$ for (a) Line W, (b) Line C, and (c) Line E. White solid line on each panel denotes the boundary between the upper and lower crust $(6.5 \mathrm{~km} / \mathrm{s}$ contour in Plate 1). Solid squares and open triangles are as in Figure 3. $\mathrm{VE}=2.4$. 

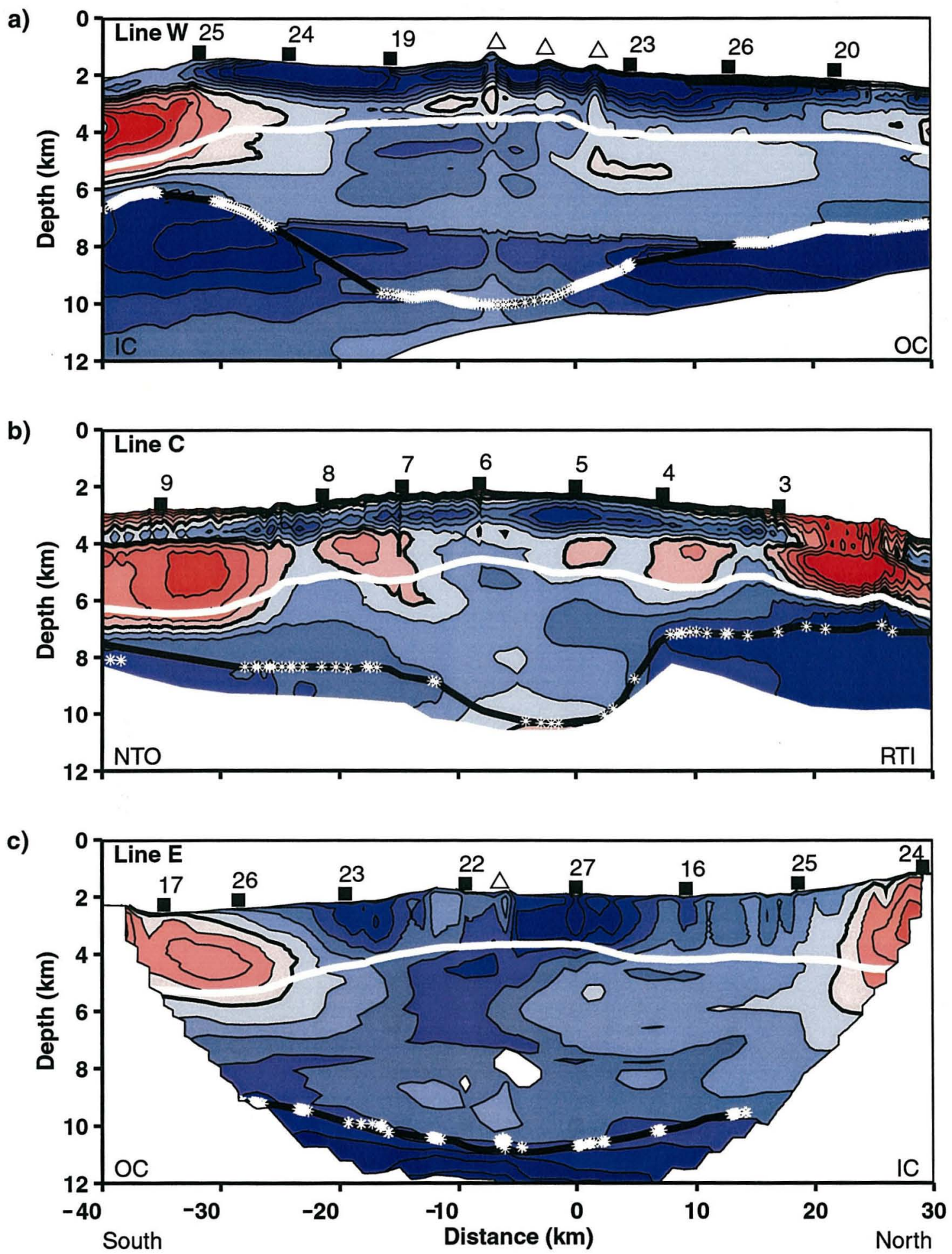

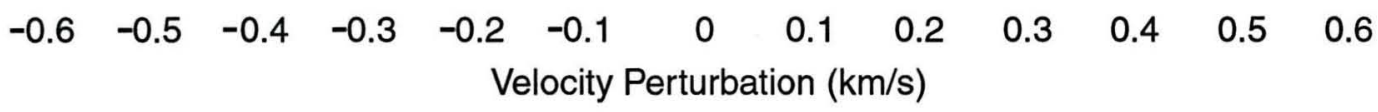




\title{
CHAPTER 3
}

\section{Crustal Magnetization and Accretion at the Southwest Indian Ridge near the Atlantis II Fracture Zone, 0-25 Ma}

\begin{abstract}
Two cruises to the Southwest Indian Ridge (SWIR) provide new insight on crustal accretion and evolution at ultra-slow spreading rates. We present an analysis of geophysical data that extend from 0 to $25 \mathrm{Myr}$ old crust on both flanks of two long-lived
\end{abstract} ridge segments. Lineated marine magnetic anomalies are consistent and identifiable over the entire study area, even over a plutonic body known to lack a basaltic upper crust. The total spreading rate of $14 \mathrm{~km} / \mathrm{Myr}$ has remained nearly constant since the last $20 \mathrm{Ma}$, but crustal accretion has been highly asymmetric, with half rates of 8.5 and $5.5 \mathrm{~km} / \mathrm{Myr}$ on the Antarctic and African flanks, respectively. In contrast to observations at faster spreading ridges, axial crustal magnetization and axial water depth correlate directly at both ridge segments. This trend is well explained with a two layer magnetic source consisting of a constant thickness upper crust underlain by a lower crust that is $2-2.5 \mathrm{~km}$ thicker at the segment midpoint than at the segment ends. Off-axis, magnetization amplitudes at segment ends are higher than at segment centers, suggestive of the presence of an induced component of magnetization. The mean magnetization along isochron decreases by $72 \%$ between the ridge and $20 \mathrm{Myr}$ old crust. This decay occurs more 
rapidly during the first half of that interval than in the second half. Segmentation in the survey area has remained nearly constant since at least $25 \mathrm{Ma}$, and a $15 \mathrm{~km}$ wide nontransform offset is just as stable as the two transform offsets. Bathymetric and magnetic data show a near-instantaneous change in plate motion at 19.5 Ma. Based on results from this study and from drill core data from ODP Hole 735B, the axial lower crust appears to have cooled quickly enough to lock in a coherent magnetic signal. Magnetic polarity boundaries within the intrusive lower crust may thus be steeper than originally envisioned, and the lower crust may be a significant source of crustal magnetization and reversal anomalies at ultra-slow spreading ridges.

Submitted to Journal of Geophysical Research, April 2001 


\section{Introduction}

The Southwest Indian Ridge (SWIR) is among the world's slowest spreading ridges, with an average full spreading rate of $\sim 15 \mathrm{~km} / \mathrm{Myr}$ [Patriat et al., 1997]. Much of our inferences about crustal accretion at the ultra-slow spreading SWIR has been based on analogies with the more extensively studied northern Mid-Atlantic Ridge (MAR), which at an average full rate of $24 \mathrm{~km} / \mathrm{Myr}$ spreads $60 \%$ faster than the SWIR. Some aspects of crustal accretion at the MAR and the SWIR are likely to be similar. For example, common observations such as rugged topography, deep axial valleys, asymmetric bathymetry across segment ends, and outcrops of serpentinized peridotite [Dick et al., 1992; Cannat, 1993] indicate that seafloor spreading along both ridge systems probably occurs in the absence of a ubiquitous and permanent magma chamber [Detrick et al., 1990; Sinton and Detrick, 1992]. However, observations and numerical models find significant changes in crustal accretion at total extension rates less than 15$20 \mathrm{~km} / \mathrm{Myr}$. Seismic estimates of crustal thickness, for example, decrease dramatically from a uniform worldwide mean of $\sim 7 \mathrm{~km}$ to a value of just $\sim 4 \mathrm{~km}$ at ultra-slow spreading ridges [White et al., 1992; Bown and White, 1994]. Crustal thickness estimates from rare earth element inversions likewise provide evidence for attenuated melting at low spreading rates, with a mean melt thickness of $\sim 8 \mathrm{~km}$ at spreading rates greater than $15 \mathrm{~km} / \mathrm{Myr}$ and a value of $3 \mathrm{~km}$ at very low accretion rates [Bown and White, 1994]. 
Numerical models provide explanations for the dramatic difference in melt volume at slow spreading ridges. At shallow levels, ridges with low half-spreading rates cannot maintain a permanent crustal melt lens [Chen and Phipps Morgan, 1996], while at deeper levels, restricted melting at very slow spreading rates arises from excessive conductive heat loss of the uppermost mantle. This latter effect depresses the top of the melting column to deeper depths beneath very slow spreading ridges and results in less melt production than at faster spreading ridges [Bown and White, 1994].

The combined effects of low crustal production and intermittent volcanic emplacement complicates the recording of marine magnetic anomalies in slow-spread ocean crust. Hypotheses on the nature of the source of magnetic anomalies remain uncertain despite decades of work. Many studies conclude that most or all of the magnetic signal resides in the upper $500 \mathrm{~m}$ of extrusive crust within seismic layer $2 \mathrm{~A}$ [Talwani et al., 1971; Atwater and Mudie, 1973; Fox and Opdyke, 1973; Bleil and Petersen, 1983; Arkani-Hamed, 1989; Gee and Kent, 1998]. However, compilations of intensity measurements of DSDP and ODP drill-cores show that a purely basaltic magnetic source cannot explain the total amplitude of marine magnetic anomalies, especially off axis [Dunlop and Prevot, 1982; Johnson and Pariso, 1993]. Deeper crustal sources probably also contribute to magnetic anomalies, but estimates of the magnitude of the contribution of the lower crust to the magnetic anomaly record range between 20- 
75\% [Blakely, 1976; Kidd, 1977; Dunlop and Prevot, 1982; Banerjee, 1984; Harrison, 1987; Pariso and Johnson, 1993b; Pariso and Johnson, 1993a; Tivey et al., 1998]. The magnetic contribution of diabase dikes and sills in the intermediate crust (layer 2B) is uncertain as well, as some authors deem them significant contributors to magnetic anomalies [Dunlop and Prevot, 1982] while others assert that the natural remanent magnetization (NRM) of layer 2B is weak and unstable [Kent et al., 1978]. Finally, the large NRM intensity of serpentinite potentially makes the upper mantle as important as layer $2 \mathrm{~A}$ in recording the geomagnetic field, if a sufficient volume of serpentinite exists and if it preserves a primary thermoremanent magnetization or very early chemical remanent magnetization [Dunlop and Prevot, 1982; Harrison, 1987].

A key issue in determining if the lower crust contributes significantly to marine magnetic anomalies is the shape of magnetic polarity boundaries within intrusive layers. In the traditional model of the magnetic structure of the oceanic lower crust, magnetic polarity boundaries dip shallowly away from the ridge axis along the Curie isotherm for magnetite as a result of slow, purely conductive cooling [Blakely, 1976; Cande and Kent, 1976; Kidd, 1977]. Transitions between normal and reversed polarity anomalies thus occur over longer length and time scales in lower crustal sections than within the quickly cooled upper crust. The magnetic contribution of the lower crust to the short wavelength magnetic signal thus may be small or even out of phase with the polarity of the overlying 
upper crust [Cande and Kent, 1976; Arkani-Hamed, 1989]. One way to constrain the shape of magnetic polarity boundaries in the lower crust is to determine the thermal evolution of such layers following emplacement. The thermal budget within any section of crust depends on both the amount of heat supplied by conduction, repeated magmatic intrusions, and latent heat release and the amount of heat removed by hydrothermal circulation and conduction. If heat removal is efficient and melt supply is ephemeral, magnetic polarity boundaries within the intrusive lower crust may be steeper than originally envisioned, and the lower crust may be a significant source of crustal magnetization and reversal anomalies.

We present an analysis of geophysical data collected between the Atlantis II and Novara fracture zones on the SWIR $\left(56^{\circ} 45^{\prime}-58^{\circ} 40^{\prime} \mathrm{E}\right)$. The data coverage extends to 25 Myr old crust on both flanks of two ridge segments. This is the most extensive off-axis survey of any portion of the SWIR, and comparable coverage of the MAR is available only for a single corridor north of the Kane fracture zone [Tucholke et al., 1997a].

\section{Regional Setting}

The segmentation patterns of the $\sim 8000 \mathrm{~km}$ long SWIR can be loosely subdivided into three provinces based on geophysical characteristics such as axial relief and frequency of transform offsets. The section that lies west of the Andrew Bain fracture 
zone at $30^{\circ} \mathrm{E}$ and the section that lies east of the Melville fracture zone at $61^{\circ} \mathrm{E}$ are both characterized by anomalously deep axial valleys, oblique spreading, poorly developed central magnetic anomalies and mantle Bouguer anomaly (MBA) bull's-eyes, and unstable transform and non-transform offsets [Grindlay et al., 1992; Patriat et al., 1997; Rommevaux-Jestin et al., 1997; Cannat et al., 1999]. These properties suggest that in these two regions of the SWIR the mantle is cold, the lithosphere is strong and thick, and magma supply is substantially limited. In contrast, the central portion of the SWIR between $30^{\circ} \mathrm{E}$ and $61^{\circ} \mathrm{E}$ is characterized by long-lived transform and non-transform discontinuities, perpendicular spreading, and well developed central magnetic anomalies and mantle Bouguer anomalies [Rommevaux-Jestin et al., 1997; Cannat et al., 1999]. The study area between the Atlantis II $\left(56^{\circ} 45^{\prime} \mathrm{E}\right)$ and Novara $\left(58^{\circ} 40^{\prime} \mathrm{E}\right)$ fracture zones thus falls within a section of the SWIR that appears to be similar to much of the central and northern MAR.

The geophysical data in this study encompass two ridge segments that lie between two transform discontinuities and that are separated by a non-transform discontinuity (NTD). To simplify the discussion of each segment, a naming convention is used that is based on a similar nomenclature used for the MAR [e.g., Detrick et al., 1995; Thibaud et al., 1998]. The western segment is termed AN-1 because it is the first segment between the Atlantis II and Novara fracture zones; the eastern segment is AN-2 because it is the 
second segment between the fracture zones (Plate 1, inset). For comparison, AN-1 and AN-2 are segments 19 and 18, respectively, in Cannat et al. [1999] and S2 and S3, respectively, in Rommevaux-Jestin et al. [1997]. Similarly, the segment east of AN-2 is referred to as NM-1 because it is the first segment between the Novara and Melville fracture zones (NM-1 is segment 17 in Cannat et al. [1999] and S4 in Rommevaux-Jestin et al. [1997]).

The Atlantis II transform formed at anomaly 24 time (56 Ma) [Patriat and Segoufin, 1988], when the Rodriguez Triple Junction marking the eastern terminus of the SWIR propagated eastward [Fisher and Sclater, 1983]. All three discontinuities in the study area offset the SWIR axis in a left lateral sense. The north-south striking Atlantis II and Novara transforms are $200 \mathrm{~km}$ and $45 \mathrm{~km}$ long, respectively, and the NTD offsets the segments by $15 \mathrm{~km}$. Satellite gravity maps [Sandwell and Smith, 1997] show that the offaxis traces of each fracture zone and of the NTD are marked by significant and continuing lows that extend north and south to the boundaries of the propagation wake of the Rodriguez Triple Junction. This is strong evidence that the three discontinuities in the study area have existed since the initiation of the SWIR plate boundary.

The Atlantis II transform and an uplifted crustal block called Atlantis Bank on its eastern edge have been the focus of numerous studies, including a site survey cruise (RC2709) in 1987 in preparation for drilling [Dick et al., 1991], two Ocean Drilling 
Program (ODP) legs (118 and 176) [Dick et al., 1991; Dick et al., 2000], a French survey of the SWIR axis between $55^{\circ}$ and $70^{\circ} \mathrm{E}$ [Mendel et al., 1997; Patriat et al., 1997], a rock coring and ROV expedition [Allerton and Tivey, 2001], a seismic refraction and reflection experiment [Muller et al., 1997; Muller et al., 2000], and two Japan Marine Science Technology Center (JAMSTEC) cruises, from which the data discussed in this study derive. Atlantis Bank, a plutonic complex consisting of gabbro and serpentinized peridotite, formed between 9 and $13 \mathrm{Ma}$ [Dick et al., 1991] at the intersection of the Atlantis II transform and segment AN-1. Atlantis Bank exhibits characteristics that are typical of seafloor adjacent to active transform faults ("inside corner"), including anomalous elevation above the surrounding seafloor, a positive residual gravity anomaly, and the absence of a basaltic upper crust [e.g., Karson and Dick, 1983; Severinghaus and Macdonald, 1988; Tucholke and Lin, 1994].

ODP drilling at Hole 735B on Atlantis Bank penetrated $1.5 \mathrm{~km}$ into dominantly gabbroic lithologies, providing the most detailed information to date on the composition, deformation, hydrothermal alteration, and late-state magmatism of the lower oceanic crust. Core-based studies lack the larger regional context, however, concerning the segment-scale processes and tectonic evolution of Atlantis Bank. The geophysical data presented in this study provide a regional geophysical and geological context in which to evaluate results from Hole 735B, and to extend those results to the remainder of the ridge 
segment. The new data also provide an excellent opportunity to characterize crustal accretion, to evaluate the fidelity of magnetic anomalies at ultra-slow spreading ridges, and to make comparisons with the more extensively studied Mid-Atlantic Ridge.

\section{Magnetic Analysis}

\subsection{Data Collection and Processing}

The majority of the data used in this study derive from two JAMSTEC cruises to the Atlantis II fracture zone region of the SWIR, one on board R/V Yokosuka in OctoberNovember, 1998 and one on board R/V Kairei in September, 2000. Both cruises were principally designed for submersible operations on Atlantis Bank with supplementary geophysical programs that included multibeam bathymetry, underway magnetics and gravity, and continuous GPS navigation. On the first cruise, nearly $35,000 \mathrm{~km}^{2}$ of seafloor were mapped along north-south oriented track lines spaced between 1.5 and 7 $\mathrm{km}$ apart (solid lines, Figure 1). Seafloor bathymetry was collected with the HS-10 multibeam surveying system manufactured by Furuno Electronics. This system generates depth values for 45 across-track beams spaced at $2^{\circ}$ increments, resulting in a nominal seafloor swath width equal to twice the water depth. The mapping program was completed on the second cruise using north-south track lines spaced between 6 and $12 \mathrm{~km}$ apart (dashed lines, Figure 1); this larger track spacing was possible because the 
SeaBeam 2100 multibeam system on R/V Kairei provides up to 151 soundings acrosstrack, resulting in a swath width equal to three times the water depth. Multibeam bathymetry data from cruise $\mathrm{RC} 2709$ were incorporated at the far western edge of the study area (shaded lines, Figure 1) to generate the final bathymetry map (Plate 1). The map was produced by gridding the bathymetry data from each cruise using the MBSystem [Caress and Chayes, 1996] and Generic Mapping Tools software [Wessel and Smith, 1991], giving precedence to the higher resolution SeaBeam 2100 data in regions where tracks from the three cruises coincided. Nearly $100 \%$ coverage was obtained over $59,000 \mathrm{~km}^{2}$ of seafloor.

The total intensity magnetic field was recorded on the three cruises with surface towed proton precession magnetometers. The sensors were towed $\sim 400 \mathrm{~m}$ behind the ships' GPS antenna and logged at a $\sim 20 \mathrm{~s}$ interval. Following pre-processing, data from the three cruises were combined, and the magnetic field anomaly (Figure 2) was calculated by removing from each measurement the regional magnetic field predicted by the best available International Geomagnetic Reference Field [International Association of Geomagnetism and Aeronomy (IAGA), 2000]. Magnetic data from the R/V Yokosuka cruise contained significant high-frequency noise, and every track line anomaly contained spikes of up to $250 \mathrm{nT}$. Application of a median filter with a window size of 9 samples removed all of the spurious data without degrading the anomaly resolution. Data quality 
was higher on the R/V Kairei cruise. As with the bathymetry data, magnetic data from cruise $\mathrm{RC} 2709$ supplemented data from the two recent cruises to produce the final magnetic data set. After applying a constant shift of $43 \mathrm{nT}$ to the RC2709 data, the rootmean-square error for 409 magnetic anomaly crossover points was $33 \mathrm{nT}$. Much of this error likely derives from daily secular variation, from large gradients in the magnetic field associated with the extreme topography near Atlantis Bank, and from navigational error.

To correct the magnetic anomaly data shown in Figure 2 for the effects of topography, which varies by $6 \mathrm{~km}$ over the study area, and phase shift due to latitude, a gridded version of the magnetic anomalies was inverted for source magnetization using the method described in Parker and Heustis [1974], as extended by Macdonald et al. [1980] for grid analyses. The assumptions required by this iterative, Fourier-based inversion procedure include: a constant thickness magnetic source layer that follows the seafloor topography and is uniformly magnetized with depth; a direction of magnetization consistent with the geocentric dipole; and filled and periodic grids of bathymetry and magnetic field anomaly. Specific parameters used for the inversion included a source layer thickness of $0.5 \mathrm{~km}$, a geocentric magnetic inclination of $-51.1^{\circ}$, and $1 \mathrm{~km}$ resolution grids of bathymetry and magnetic field anomaly. To stabilize the inversion, a bandpass filter tapered short wavelengths between $3.5-7 \mathrm{~km}$ and long 
wavelengths between $50-100 \mathrm{~km}$. A common step in finalizing crustal magnetization estimates is adding to the inversion solution the annihilator, a magnetization distribution for the assumed magnetic source layer that produces no external magnetic field at the observation level [e.g., Pockalny et al., 1995; Pariso et al., 1996; Weiland et al., 1996]. The addition of any multiple of the annihilator produces a near-constant shift of magnetization amplitudes and is usually done to balance the zero crossings of the main anomalies on either side of the ridge axis. Our final solution, shown in Figure 3, did not require the addition of any annihilator.

To determine the history of plate spreading in the study area, the magnetization solution (Figure 3) was sampled along the ship track lines and the peak amplitude of each seafloor spreading anomaly was identified. Each peak was assigned an age based on the middle of the corresponding polarity epoch of the geomagnetic time scale of Cande and Kent [1995] (Figure 4). Because of the very slow spreading rates in this area, identification of normal and reversed polarity chrons was straightforward for the major chrons ( $2 \mathrm{An}, 5 \mathrm{n}, 5 \mathrm{AC}-\mathrm{ADn}$, and $6 \mathrm{n}$ ), but more difficult for the chrons of shorter time span. Forward models of crustal magnetization profiles (Figure 5) and poles of rotation for the SWIR [Patriat and Segoufin, 1988] confirmed the isochron identifications and the consistency of those identifications on each flank. The magnetic coverage extends to 
anomaly $7 \mathrm{n}(25 \mathrm{Ma})$ on the southern ridge flank and to anomaly $8 \mathrm{n}(26 \mathrm{Ma})$ on the northern ridge flank (Figure 4).

\subsection{Spreading Rate Results}

Both the magnetic anomaly (Figure 2) and magnetization (Figure 4) profiles show well developed magnetic lineations that are orthogonal to the north-south spreading direction. The full-spreading rate and half-spreading rates are determined by fitting a least-squares line to crustal age vs. distance measurements (Figure 6), where the distance corresponds to the distance in the spreading direction between successive anomalies and the age corresponds to the peak age for each anomaly. Figure 6 shows a long history of asymmetric crustal accretion at both segments, with a mean northern spreading rate of 5.5 $\pm 1.6 \mathrm{~km} / \mathrm{Myr}$ at $\mathrm{AN}-1$ (Figure 6a) and $5.5 \pm 2.6$ at $\mathrm{AN}-2$ (Figure 6b), and a mean southern spreading rate of $8.5 \pm 2.3 \mathrm{~km} / \mathrm{Myr}$ at AN-1 (Figure $6 \mathrm{c}$ ) and $8.5 \pm 1.9 \mathrm{~km} / \mathrm{Myr}$ at AN-2 (Figure 6d) (see also Table 1). Relative to the mean half rate of $7.0 \mathrm{~km} / \mathrm{Myr}$, the spreading rate asymmetry between the two flanks is $36 \%$. The half-spreading rates determined in this study differ from those reported in Dick et al. [1991] using magnetic data collected on cruise RC2709 principally due to the updated geomagnetic time scale, which lowered global spreading rates by nearly 10\% [DeMets et al., 1994; Cande and Kent, 1995]. The very small error bars on the distance between successive anomalies in 
Figure 6a-d indicates that the shape of the present-day ridge is representative of its shape during the past $25 \mathrm{Myr}$.

Changes in slope between individual anomalies in Figures 6a-d indicate variations in crustal accretion that occur on the scale of an individual ridge segment. In contrast, changes in slope in a plot of total distance (distance between conjugate anomalies on either flank) vs. age are indicative of larger scale changes in plate motion. Figures 6e-f show that the total spreading rate for each segment has remained relatively uniform over the past 20 Myr (Figures 6e-f and Table 2). The least-squares fit yields a total opening rate of $14.3 \pm 2.2 \mathrm{~km} / \mathrm{Myr}$ at AN-1 and $14.1 \pm 2.2 \mathrm{~km} / \mathrm{Myr}$ at AN-2.

\section{Tectonic Results}

\subsection{Present Day Segmentation}

The detailed morphology of the rift valleys of segments AN-1 and AN-2 is shown in Plate 2a, and an interpretation of the major features in and around their inner valleys is shown in Plate $2 \mathrm{~b}$. The western ridge segment, $\mathrm{AN}-1$, is $48 \mathrm{~km}$ long. The trend of the axial valley of AN-1 is approximately east-west from its intersection with the Atlantis II transform to $57^{\circ} 28^{\prime} \mathrm{E}$, where it curves northward along a trend of $\mathrm{N} 30^{\circ} \mathrm{E}$ until it terminates at the NTD at $57^{\circ} 33^{\prime} \mathrm{E}$. The neovolcanic zone of each segment was defined 
by assuming that bathymetric closed-contour highs within the inner valleys are constructional volcanic features. At AN-1, twelve volcanoes with heights $\geq 50 \mathrm{~m}$ define the primary locus of eruptive activity in the axial valley (Plate $2 b$ ). Of these, eight form an en echelon array that follows the curvilinear trend of the segment's inner valley. The volcanoes range from 50 to $180 \mathrm{~m}$ in height and from 1 to $3 \mathrm{~km}$ in length. All of the identified volcanoes at AN-1 are located within the eastern two-thirds of the segment; no obvious volcanic edifices were observed in the western third of the inner valley of AN-1 approaching the nodal deep of the Atlantis II fracture zone.

The eastern ridge segment, $\mathrm{AN}-2$, is $75 \mathrm{~km}$ long. At the resolution of the multibeam bathymetry, terrain within the inner valley of AN-2 appears more volcanic in character than that within the inner valley of AN-1. The neovolcanic zone is defined by 31 volcanoes with heights that range between 50 and $230 \mathrm{~m}$ (Plate $2 \mathrm{~b}$ ). In contrast to segment AN-1, the volcanoes at segment AN-2 are higher, less faulted and extend along the entire inner valley. Approaching the Novara transform the volcanoes are more circular, isolated, and smaller than at the segment midpoint, suggestive of reduced volcanism. Along both segments, the neovolcanic zones defined by the en echelon volcanoes align with the peak of the Brunhes normal polarity epoch (thick shaded line in Plate 2b). 
The $15 \mathrm{~km}$ wide NTD between segments AN-1 and AN-2 exhibits no internal structures such as basins or septa that are common at non-transform offsets at the MAR [e.g., Tucholke et al., 1997a]. Instead, the NTD is a diffuse zone that is $\sim 500 \mathrm{~m}$ deeper than the seafloor of the adjacent ridge segments. The rift valley walls of each segment terminate within the NTD except for the northern bounding fault of AN-2, which overshoots the offset and penetrates the crust created at segment AN-1 (Plate 2). The bounding wall faults of segments $\mathrm{AN}-1$ and $\mathrm{AN}-2$ overlap by $\sim 7 \mathrm{~km}$. The volcanoes within the inner valley of each segment extend all the way to the NTD and three volcanoes lie within the zone of the NTD itself.

The rift valleys of segments $\mathrm{AN}-1$ and $\mathrm{AN}-2$ form hourglass shapes in plan-view, with topography that is $1-1.5 \mathrm{~km}$ shallower near their centers than at their ends (Plate 2). Evidence of large-scale mass wasting is observed on the southern boundary wall of AN-1 at $57^{\circ} 15^{\prime} \mathrm{E}$, where concave contours mark a $10 \mathrm{~km}$ wide landslide headwall. At the base of the inferred AN-1 slump-scar, the flat-lying to slightly-bulging topography of the valley floor may signal the presence of a debris field from the rockslide that flowed over the entire width of the inner valley. A debris field of significant volume may explain the absence of any obvious volcanoes within the western third of segment AN-1 (Plate 2b). Scalloped-shaped bathymetry contours suggestive of an additional rockslide are also observed on the southern boundary wall of AN-2 at $57^{\circ} 45^{\prime} \mathrm{E}$. The hourglass shape 
morphology of segments AN-1 and AN-2 thus may result from massive slope failure at their endpoints rather than reflecting an intrinsic property of the axial valley. Rockslides are commonly observed at slow spreading ridges [OTTER, 1984; Dick et al., 1991; Tucholke, 1992; Tucholke et al., 1997b].

\subsection{Paleosegmentation}

The off-axis trace of the NTD between segments AN-1 and AN-2 defines the tectonic evolution of the SWIR plate boundary between the Atlantis II and Novara fracture zones during the last $25 \mathrm{Myr}$. Using a combined analysis of seafloor morphology and magnetic isochron trends, the off-axis expression of the NTD was traced to the limits of bathymetric coverage on each flank (Figure 7). The off-axis trace of the discontinuity consists of a 10-15 km wide zone characterized by deep seafloor (Plate 1) and obliquely- trending magnetic isochrons (Figure 4). Where basement topography is not obscured by sediment cover, seafloor lineaments within the discontinuity zone also trend obliquely to the trend of the ridge axis (Figure 7). Abyssal hills commonly terminate within the discontinuity zone (Figure 7), although some of the lineaments overshoot the NTD in a manner similar to the present day northern boundary fault of segment AN-2 (Plate 2b). 
A secondary discontinuity is observed in the bathymetric data within segment AN-2 as V-shaped fabric that is symmetric about the ridge axis (Plate 1 and Figure 7). This feature, which is interpreted as a propagating rift scar, initiated at the western end of segment AN-2 at the trace of the NTD at anomaly 3n-old time (5.5 Ma) and propagated eastward until it terminated near the segment midpoint at anomaly $2 \mathrm{An}$ time ( $3 \mathrm{Ma}$ ) (Figure 4). Its internal structure consists of a series of ridge-parallel, elongate basins that link along strike and offset the magnetic anomalies between those chrons. The anomalously high accretion rate for segment $\mathrm{AN}-2$ between anomalies $2 \mathrm{An}$ and $3 \mathrm{An}$ (Table 2) is a direct consequence of crustal deformation associated with the propagator. The along-axis propagation rate of this intra-segment rift is determined using the formula $\mathrm{p}=\mathrm{v} / \tan \vartheta$, where $\mathrm{v}$ is the half-spreading rate determined from magnetic isochrons and $\vartheta$ is the acute angle between the ridge axis and the V-shaped seafloor fabric [Kleinrock et al., 1997]. Using the mean half-rate for the southern flank of $8.5 \mathrm{~km} / \mathrm{Myr}$ and a measured angle of $47^{\circ}$, the rate of eastward propagation is $7.9 \mathrm{~km} / \mathrm{Myr}$, or $93 \%$ of the spreading rate. The morphology, propagation rate, and confinement to a single segment are characteristics that were observed for small, rapid propagators at $26^{\circ} \mathrm{N}$ on the MAR [Kleinrock et al., 1997].

Paleosegment length is one indicator of the scale of a single magmatic-tectonic system. Figure 8 presents the segment lengths for AN-1 and AN-2 on both flanks of the 
ridge axis since $25 \mathrm{Ma}$. The length of each segment is calculated as the distance along axis between the axis of the NTD zone and the center of the bordering fracture zone valley. Figure 8 shows that the lengths of segments $\mathrm{AN}-1$ and $\mathrm{AN}-2$ correlate inversely through time, such that the minimum length of AN-1 occurs when the length of AN-2 is maximum, and vice versa. On a larger scale, the total distance between fracture zone valleys has increased by $\sim 15 \mathrm{~km}$ since $25 \mathrm{Ma}$, and much of this increase is due to the lengthening of segment AN-2 (Figure 8). A rapid increase in the length of AN-2 occurred between 5.5-9 Ma. This lengthening episode began immediately following the termination of uplift of Atlantis Bank at the western end of segment AN-1 and ended when the propagating rift initiated at the western end of segment AN-2.

\subsection{Southern Flank Morphology}

Seafloor fabric on the southern flank of segment AN-1 is dominated by obliquelytrending lineaments and elevated massifs (Plate 1 and Figure 7). The massifs are confined to the $10-20 \mathrm{~km}$ wide inside-corner corridor adjacent to the Atlantis II fracture zone. With the exception of Atlantis Bank, these inside-corner highs vary in diameter from 9 to $25 \mathrm{~km}$ and in spacing from 2 to $10 \mathrm{~km}$. At their summits, the massifs rise 700 to $1500 \mathrm{~m}$ above the surrounding seafloor. Atlantis Bank differs from the other basement highs in the inside-corner corridor in both its shape and size; it is elongated in the 
direction of spreading, implying a long formation time, and it rises $3000 \mathrm{~m}$ above the surrounding seafloor to its shallowest point of $700 \mathrm{~m}$.

Emanating from the eastward edges of the inside corner highs are several narrow, curvilinear ridges that extend across $\mathrm{AN}-1$ and terminate at the paleotrace of the NTD (Plate 1, Figure 7). On the youngest seafloor where sediment cover is sparse, these ridges rise nearly as high as the adjacent inside-corner highs and are separated by small intervening basins. On older seafloor, the ridges are increasingly buried by sediment, making the basins appear larger. Aside from the large faults associated with the insidecorner highs and these large ridges, the remainder of the seafloor lineaments at AN-1 are short, ridge-parallel and obliquely trending features that probably consist of small faults and relict volcanic ridges. Relatively few lineaments are observed south of $32^{\circ} 45^{\prime} \mathrm{S}$, where sedimented seafloor within the NTD zone obscures seafloor morphology.

The morphology of the seafloor on the southern flank of segment $\mathrm{AN}-2$ differs in several ways from that of segment AN-1 (Plate 1 and Figure 7). Between the spreading axis and about $32^{\circ} 30^{\prime} \mathrm{S}$, a large highland rises $\sim 2000 \mathrm{~m}$ above the surrounding seafloor. The highland extends for $\sim 60 \mathrm{~km}$ along axis, from the trace of the NTD to the deeper seafloor of the outside-corner corridor near the Novara fracture zone. Abyssal hill fabric is more regular on the southern flank of segment $\mathrm{AN}-2$ than at $\mathrm{AN}-1$, but as at $\mathrm{AN}-1$, many of the seafloor lineaments are short and oblique to the trend of the rift valley. The 
easternmost edge of segment $\mathrm{AN}-2$ slopes gently downward into the Novara fracture zone and the segment-parallel abyssal hills curve towards the ridge axis (Plate 1), presumably due to a change in the direction of the least compressive horizontal stress from ridge-perpendicular to transform-perpendicular. Both the downward-sloped outside corner and hooked ridges are common features of outside corner crust at the MAR [Karson and Dick, 1983; Severinghaus and Macdonald, 1988; Tucholke and Lin, 1994; Tucholke et al., 1997a].

\subsection{Northern Flank Morphology}

Abyssal hill fabric on the northern flanks of segments AN-1 and AN-2 is much more regular than on their southern flanks; the seafloor lineaments lie parallel to the ridge axis and commonly reach $20 \mathrm{~km}$ in length (Plate 1 and Figure 7). Superimposed on the abyssal hill fabric are two regions of elevated terrain. One of these consists of three small, circular domes that abut the trace of the NTD on segment AN-1 (3 shaded polygons in Figure 7). Although these domes are much smaller than the inside-corner highs observed near the Atlantis II fracture zone, their similar shape suggest they may be elevated inside-corner highs related to the NTD. The second region of elevated topography lies along the inside-corner corridor of the Novara fracture zone. In contrast to the discrete, quasi-circular domes within the Atlantis II inside-corner corridor, the 
elevated topography within the Novara inside-corner corridor is elongated parallel to the ridge axis, extending in some places for several tens of kilometers (Plate 1 and Figure 7).

\subsection{Fracture Zone Structure}

A major result of the field program in this region is the complete mapping out to $25 \mathrm{Myr}$ of two fracture zones formed at ultra-slow spreading rates. While much of the structure of the active Atlantis II transform was surveyed during RC2709, its inactive trace on the northern flank was mapped only to anomaly $5 \mathrm{n}(\sim 10 \mathrm{Ma})$ and little off-axis data existed for the Novara fracture zone (for a detailed description of the morphology of the Atlantis II fracture zone, see Dick et al. [1991]). The new off-axis bathymetry coverage shows that the $10^{\circ}$ counterclockwise change in plate motion first described by Dick et al. [1991] is also well-recorded in the trace of the Novara fracture zone (Plate 1). Unlike the subtle bend in the inactive trace of the Atlantis II fracture zone, however, the inactive trace of the Novara fracture zone bends sharply at the time of the reorientation near $32^{\circ} 45^{\prime} \mathrm{S}$ (Plate 1). The abrupt change in the trend of the Novara fracture zone thus allows the timing of the reorientation event to be more precisely determined than the 17 $20 \mathrm{Ma}$ age determined previously [Dick et al., 1991]. Magnetic isochron identifications on the Antarctic plate east of the Novara fracture zone pinpoint the time of the plate

motion change at anomaly 6n (19.5 Ma) (Figure 4). Large-scale reconstructions of the 
evolution of the Indian Ocean basin indicate that the last major change in spreading direction occurred between 20 and $10 \mathrm{Ma}$ [Patriat and Segoufin, 1988]. Thus, the observed reorientation of the fracture zones in this region is consistent with the overall history of the SWIR. The data further suggests that the reorientation was rapid and occurred at the beginning of the 20-10 Ma interval. The increase in the total distance between the fracture zones (dashed line, Figure 8) is a direct consequence of the reoriented spreading direction.

The nodal basins of the Novara and Atlantis II transforms mimic each other; the southern nodal deep of the Novara transform (at the eastern end of segment AN-2) is Vshaped in map view and is $30 \mathrm{~km}$ wide at its broadest point (Plate 1 and Figure 7), similar to the southern nodal deep of the Atlantis II transform. In contrast, the northern nodal basin of the Novara transform (at the western end of segment NM-1) is L-shaped, and resembles the northern nodal deep of the Atlantis II transform (at the western end of segment $\mathrm{AN}-1$ at $\left.31^{\circ} 55^{\prime} \mathrm{S}\right)$. The two fracture zone valleys also exhibit similar morphologies. On the faster-spreading Antarctic plate, the Atlantis II and Novara fracture zones consist of broad, deep valleys with flat-lying floors. On the slowerspreading African plate, though, both fracture zone valleys narrow substantially to a width of only a few kilometers. 
A striking feature discovered in the new bathymetry data is a region of highly lineated terrain created at segment NM-1, east of the inactive trace of the Novara fracture zone within an inside-corner corridor (Plate 1 and Figure 7). The east-west trending lineations consist of narrow $(<1 \mathrm{~km})$ ridges with crests that are studded with circular, closed-contour highs interpreted as volcanoes. The ridges are regularly spaced and at least $20 \mathrm{~km}$ long, and average several hundred meters in relief. Following the change in plate motion at $19.5 \mathrm{Ma}$, the limited bathymetry coverage shows that accretion of highly lineated topography ceased and more typical, elevated inside-corner topography developed, which persists to the present day. The unusual absence of elevated massifs between the southern boundary of bathymetry coverage $(30 \mathrm{Ma})$ and the time of the plate motion change may indicate a smaller degree of tectonic extension at NM-1 than is usually associated with inside-corner tectonic settings [e.g., Mutter and Karson, 1992; Tucholke and Lin, 1994].

\section{Magnetic Results}

\subsection{Axial Magnetization}

The most prominent feature in the crustal magnetization map is the largeamplitude, positive Brunhes anomaly that is centered over the present day ridge axes of segments AN-1 and AN-2 (Figure 9a). Axial magnetization values are greater than 
anywhere else in the study area, with a peak to trough amplitude of $25 \mathrm{~A} / \mathrm{m}$ (assuming a $0.5 \mathrm{~km}$ thick source layer). Along both $\mathrm{AN}-1$ and $\mathrm{AN}-2$, the Brunhes anomaly consists of two closed-contour highs, or magnetic sub-segments, that are separated by a local magnetization low (Figure 9a). At AN-1, the eastern magnetic sub-segment dominates the magnetic signal, while at $\mathrm{AN}-2$ the magnetic sub-segments are more equal in length and magnitude. Figure 9a also shows a close spatial association between the axial volcanoes and the magnetic sub-segments along both rift valleys. This coincidence is especially apparent along segment $\mathrm{AN}-1$, where the eastern magnetic sub-segment extends over the same region as a $25 \mathrm{~km}$ long curvilinear volcanic ridge (Plate 2). Such alignment of morphologic and magnetic axes is commonly observed at the Mid-Atlantic Ridge [Grindlay et al., 1992; Tivey and Tucholke, 1998].

An along-axis profile of the peak of the Brunhes anomaly highlights segmentscale trends in axial magnetization (Figure 9b). The dominant trend is a direct correlation between magnetization amplitude and water depth; the largest magnetization amplitudes occur at the centers of segments $\mathrm{AN}-1$ and $\mathrm{AN}-2$ where the seafloor shoals, and the smallest values occur at the segment ends, where the seafloor deepens. A similar direct correlation between axial depth and crustal magnetization is also observed between 15 and $25^{\circ} \mathrm{E}$ on the SWIR (Grindlay, pers. comm., 2000) and at the Mohns Ridge [Geli et 
$a l ., 1994]$. The axial magnetization profile in Figure $9 \mathrm{~b}$ also illustrates the local magnetization minima between the magnetic sub-segments.

For both segments, the variation in the peak amplitude of the Brunhes anomaly is $\sim 15 \mathrm{~A} / \mathrm{m}$, but the mean axial magnetization at $\mathrm{AN}-1$ exceeds that of $\mathrm{AN}-2$ by $5 \mathrm{~A} / \mathrm{m}$ (Figure 9b). An interesting feature in Figure 9b is the large difference in crustal magnetization at the two ridge-transform intersections; near the Novara RTI, crustal magnetization approaches zero, while at the Atlantis II RTI the Brunhes anomaly has a peak amplitude of $10 \mathrm{~A} / \mathrm{m}$. This discrepancy in magnetization at the two nodal deeps suggests that the magnetic source layer is considerably thicker at the Atlantis II RTI than at the Novara RTI. While no direct measurements of crustal thickness exist in either location, gravity anomaly analysis indicates that the crust at the Atlantis II RTI may be twice as thick as that at the Novara RTI [Hosford, 2001]. Additionally, shallow-level volcanism appears to be quite active within the Atlantis II nodal deep: fresh basalt, interpreted to have originated from several flows, was recovered by submersible in the central nodal deep [Kinoshita et al., 2001], and by submersible and dredge from a small volcanic complex at the southern end of the nodal deep [Dick et al., 1991; Kinoshita et al., 2001]. Young extrusive crust will enhance the overall crustal magnetization signal at the Atlantis II RTI. 


\subsection{Off-axis Magnetization}

The extensive data set collected in this region of the SWIR allows a detailed study of temporal variations in crustal magnetization over the past $25 \mathrm{Myr}$. The most obvious difference between the magnetization of zero age and older crust is the rapid decay in amplitude within the first few Myr (Figure 3). A rapid reduction in magnetization intensity is observed both in magnetization inversion solutions [Pockalny et al., 1995; Pariso et al., 1996] and in NRM values of dredged samples [Johnson and Atwater, 1977] at the MAR, and is commonly attributed to the alteration of titanomagnetite to lessmagnetic titanomaghemite [Irving, 1970; Johnson and Atwater, 1977]. In the SWIR area, the decay from high values on axis to much lower values off axis is complete by anomaly 2An time ( 2.9 Ma) on both flanks (Figure 3$)$. Although this result seems to concur with the well known, rapid destruction of the magnetic signal in young off-axis crust [e.g., Gee and Kent, 1994], Tivey and Tucholke [1998] suggest that at low spreading rates, anomalies between the Brunhes and anomaly $5 \mathrm{n}$ cannot be used to infer short-term magnetization decay because the frequent polarity reversals produce narrow spreading stripes that interfere when observed at the sea surface. In their view, the most reliable markers of off-axis magnetization intensity are anomalies of relatively long duration such as $5 \mathrm{n}$ and $6 \mathrm{n}$. If the magnetization decay rate is determined using only those two chrons, Figure 10 shows a long-term magnetization decay that is more modest than implied by 
the large loss of amplitude between the axis and anomaly $2 \mathrm{An}$. Figure 10 also indicates that long term decay may occur at different rates through time, with a more rapid loss of intensity in young crust $(0-10 \mathrm{Ma})$ than in older crust $(10-20 \mathrm{Ma})$. At AN-1, magnetization intensity decays by $64 \%$ from the peak of the Brunhes in the first $10 \mathrm{Myr}$ and by an additional $24 \%$ from $10-20 \mathrm{Ma}$ (Figure 10a). At AN-2, $71 \%$ of the axial magnetization is lost between the axis and anomaly $5 \mathrm{n}$ while an additional $54 \%$ is lost between anomalies $5 \mathrm{n}$ and $6 \mathrm{n}$ (Figure 10b). Because the intensity of the geomagnetic field has remained relatively constant through time [e.g., Johnson and Pariso, 1993], the overall $72 \%$ decrease in magnetization amplitude at both segments over the past $20 \mathrm{Myr}$ probably results from low-temperature alteration of the upper crust.

Variations in magnetization amplitude along isochron are superimposed on the regional decrease in magnetization amplitude with age. To determine if the axial magnetization pattern persists through time, magnetization intensity is plotted along isochron for normal polarity chrons in Figure 11a and for reversed polarity chrons in Figure 11b. Using only the isochrons in Figure 4 that extend over most of their respective segments, each curve in Figure 11 was determined by computing the isochronal values relative to their mean and normalizing the result to lie between -1 and 1; this normalization ensured the removal of the larger-amplitude age decay, which would mask the smaller, isochronal variations. Figure 11a shows that the axial pattern of 
low magnetization at segment ends is present for some normal polarity chrons (anomalies $5 n, 6 n$, and $7 n$ on the south flank of AN-2 and $5 n$ on the north flank of AN-1) but is not observed elsewhere. Instead, segment ends predominately tend toward higher magnetization during epochs of normal polarity, particularly on the north flank of $\mathrm{AN}-2$ adjacent to the NTD and on the south flank of AN-1 bordering the Atlantis II fracture zone (Figure 11a). In contrast, reversed polarity isochrons behave more like the axial anomaly, with more intense magnetization at the segment midpoints than at the segment offsets (Figure 11b). The apparent discrepancy between normal and reversed polarity magnetization amplitudes off axis is resolved if the isochronal variations are interpreted in terms of their "positiveness." That is, both normal and reversed polarity anomalies exhibit systematically more positive magnetization at segment ends than at segment centers. Possible causes for this effect are discussed in section 6.4.

Figures $11 \mathrm{a}$ and $11 \mathrm{~b}$ also permit an investigation of crustal magnetization amplitude in relation to inside- and outside-corner tectonic settings. Several mechanisms have been proposed to create and sustain the excess elevation of inside-corner crust, including viscoelastic rebound associated with corner flow at ridge-transform intersections [Bercovici et al., 1992], isostatic rebound [Collette, 1986], and plate flexure [Chen, 1989]. While the ultimate forces driving the formation of elevated inside corners remain unclear, the kinematics of uplift are though to occur via slip on a long-lived 
normal fault, or detachment, that roots beneath the rift valley at the RTI [Dick et al., 1981; Karson, 1990; Tucholke and Lin, 1994; Blackman et al., 1998]. In an idealized kinematic model, prolonged slip on a detachment fault exhumes lower crustal and upper mantle sections along its footwall and rafts these sections away to the inside corner, while the upper crust is stranded in the hanging wall and becomes the outside corner. If the dominant magnetic carrier in ocean crust is the extrusive upper crust, as commonly assumed, the detachment model predicts a strong asymmetry in observed magnetization between inside- and outside-corner corridors, with larger amplitudes at the outside corner than at the conjugate inside corner. Figure 11 shows that such an asymmetry is not observed; both inside-corner corridors and outside-corner corridors exhibit similar magnetization intensities despite the difference in crustal composition predicted by the detachment fault model. A similar observation was made at the MAR [Tivey and Tucholke, 1998].

\section{Discussion}

\subsection{Prolonged Asymmetric Spreading}

Between the Atlantis II and Novara fracture zones during the past $25 \mathrm{Myr}$, the SWIR plate boundary has consisted of a stable system of two ridge segments offset by a 
$15 \mathrm{~km}$ wide NTD, despite a prolonged, $36 \%$ asymmetry in half spreading rates. While the magnitude of the spreading asymmetry is similar to that commonly observed at other oceanic spreading centers [Rea, 1981; Carbotte et al., 1991; Cormier and Macdonald, 1994; Sempéré et al., 1995; Weiland et al., 1995], the longevity of the SWIR spreading asymmetry is distinctive. Along several segments of the southern MAR, for example, the magnitude of spreading asymmetry varies between $2 \%$ and $100 \%$ from one anomaly interval to the next and between adjacent ridge segments [Carbotte et al., 1991]. However, when averaged over periods of tens of millions of years and over along-axis lengths of several hundred kilometers, these extremes typically diminish and crustal accretion occurs symmetrically about the ridge axis [Stein et al., 1977; Carbotte et al., 1991; Weiland et al., 1995]. Tens of millions of years of asymmetric spreading is observed near the Kane fracture zone on the MAR [Tucholke and Schouten, 1988], but the sense of the spreading asymmetry has alternated through time. In contrast, the half spreading rate of the Antarctic plate exceeds that of the African plate throughout the 25 Myr record in this study area.

The causes of long-term asymmetric spreading probably differ considerably from the processes that give rise to short-term asymmetric spreading. Short-term asymmetry appears to result from discrete ridge jumps [Schulz et al., 1988], migration of ridge-axis discontinuities [Cormier and Macdonald, 1994], or variations in magma supply [Sempéré 
et al., 1995]. These processes are local in spatial scale and involve the transfer of lithosphere from one plate to the other. In contrast, long-term asymmetric spreading is probably driven by deeper seated processes such as the migration of a ridge with respect to a fixed or slowly moving mantle [Stein et al., 1977] or the propagation of the ridge towards mantle plumes [Small, 1995; Müller et al., 1998]. In the ridge migration model of Stein et al. [1977], a fluid mechanical formulation of asymmetric spreading predicts faster crustal accretion on the trailing flank of a migrating ridge. Absolute plate motion models [Müller et al., 1993] indeed show that the faster-spreading Antarctic plate is the trailing flank of the northward migrating SWIR. An alternate view is that asymmetric accretion results from ridge propagation towards mantle plumes [Müller et al., 1998], with deficits in crustal accretion found on ridge flanks that are underlain by hotspots. This model predicts that a larger population of hotspots should concentrate on the slowerspreading African plate, which is not observed. Instead, hotspots in the southwest Indian Ocean are disproportionately located on the Antarctic plate [Mïller et al., 1993], not the African plate as required by the Müller et al. [1998] model.

A model for long-term asymmetric spreading that is unrelated to underlying mantle motions proposes that the crust can accrete asymmetrically simply due to the geometry of the plate boundary. Crane et al. [1991] suggest that spreading asymmetry within the Norwegian-Greenland Sea was caused by the capture of a propagating ridge by 
a preexisting bend in the MAR, which placed one flank of the ridge under transtension and one flank under transpression. This asymmetric deviatoric stress distribution resulted in both asymmetric and oblique extension across the ridge axis [Crane et al., 1991].

The preexisting configuration of convective rolls in the mantle may be yet a fourth mechanism to explain asymmetric seafloor spreading. In numerical models of a slow-spreading mid-ocean ridge, convective rolls in the asthenosphere formed with no preferred orientation prior to the initiation of spreading [Rouzo et al., 1995]. When surface-imposed shear was included in the calculation, divergent forces oriented the convective rolls parallel to the spreading direction, but a "memory" of the initial thermal conditions coupled with a slow-response to the new boundary conditions maintained some degree of asymmetry in asthenospheric flow and lithospheric stress for $150 \mathrm{Myr}$ of model evolution [Rouzo et al., 1995]. Although these particular models aimed to produce segmented spreading centers, the results may be applicable to asymmetric seafloor spreading as well. If this is true, long-term asymmetric spreading in the study area may date to the formation time of the SWIR.

\subsection{Longevity of a non-transform discontinuity}

The longevity of the $15 \mathrm{~km}$ long NTD is a surprising result of this study. At the

MAR, most non-transform discontinuities change length and migrate along axis with 
time, leaving V-shaped migration wakes pointing in the direction of migration [Rona, 1976; Schouten et al., 1987]. In contrast, magnetic and morphologic data in this study area show that the NTD has meandered along axis in no consistent direction and by less than $20 \mathrm{~km}$ during the past $25 \mathrm{Myr}$. The remarkable stability of the width and along-axis position of the NTD are characteristics that are transitional between those associated with rigid, transform discontinuities and those associated with non-rigid, non-transform discontinuities, using the classification scheme of Macdonald et al. [1988; 1991]. The 2 Myr age offset across the NTD also places the NTD at the age proposed by Tucholke et $a l$. [1997a] as the boundary between transform and non-transform behavior on the MAR. Finally, the persistence of all three discontinuities in the study area in satellite gravity images [Sandwell and Smith, 1997] suggests that both the transform and non-transform discontinuities in the study area originated as long ago as $\sim 56 \mathrm{Ma}$. The NTD in this study area, then, appears to be just as stable a feature through time as the adjacent transform offsets. One mechanism for sustaining the small-offset NTD in the plate boundary geometry is via a thermal "memory" effect within the lithosphere, as proposed for "zerooffset" transforms on the MAR [e.g., Schouten and White, 1980; Schouten and Klitgord, 1982].

\subsection{Source of Axial Crustal Magnetization}


A common observation in axial magnetization at the MAR is the inverse correlation between topography and magnetization amplitude; magnetization is typically larger at topographic lows (segment ends) than at topographic highs (segment centers) [Grindlay et al., 1992; Hussenoeder et al., 1996; Pariso et al., 1996; Weiland et al., 1996; Ravilly et al., 1998]. Elevated axial magnetization is also observed at the tips of overlapping spreading centers and propagating ridges at intermediate- and fast-spreading ridges [Sempéré, 1991; Wilson and Hey, 1995]. In these settings, enhanced magnetization typically derives from iron and titanium enriched basalts and from an extrusive section that is thicker than at segment midpoints [Bazin et al., in press]. Elevated magnetization at segment ends on the MAR appears to be related to a more diverse suite of factors than at faster-spreading ridges. These factors include iron enrichment [Weiland et al., 1996], deepening of the Curie isotherm [Grindlay et al., 1992], thickening of the magnetic source layer [Grindlay et al., 1992], and an induced component of magnetization [Pockalny et al., 1995; Tivey and Tucholke, 1998]. To explain the observation in this study area of decreased axial magnetization at segment ends, these explanations must be reversed (i.e., reduced iron content, shallow Curie isotherm, thinned magnetic source layer, and no induced magnetization at segment ends on axis). 
A geochemical explanation for the axial magnetization pattern cannot be evaluated because the limited samples that exist in the study area are restricted to segment offsets [e.g., Dick et al., 1991; Robinson et al., 1996; Kinoshita et al., 2001]. These few rock samples do contain weight percentages of iron that cluster at the low end of $\mathrm{FeO}$ values in axial MORB [e.g., Gee and Kent, 1998], but the absence of samples from the central regions of the two segments makes it difficult to determine the significance of low $\mathrm{FeO}$ at the segment offsets as it pertains to the axial magnetization trend. Thermal demagnetization (i.e., shoaling of the Curie isotherm) is an unlikely mechanism for reduced crustal magnetization at segment ends on axis, because temperatures are required to be hotter at the segment endpoints than at the segment centers. Such a temperature gradient is unlikely to exist at the Atlantis II and Novara ridge-transform intersections because of the transform edge effect, which cools axial temperatures adjacent to transforms [Fox and Gallo, 1984; Shaw and Lin, 1996].

The simplest explanation for the observed axial magnetization pattern is that the magnetic source layer is thicker near the midpoints of AN-1 and AN-2 than at their ends. If the bulk of the magnetic signal resides in the extrusive upper crust (layer $2 \mathrm{~A}$ ) as commonly assumed [Talwani et al., 1971; Atwater and Mudie, 1973; Bleil and Petersen, 1983; Tivey, 1996], the observations require the upper crust to thin towards segment offsets. The thickness of layer $2 \mathrm{~A}$ is not known well at slow-spreading ridges because 
the uppermost $\sim 1 \mathrm{~km}$ of crust is difficult to image seismically [Purdy and Detrick, 1986; McClain and Caress, 1993]. There is limited evidence from the study area that the whole of the upper crust, or seismic layer 2, maintains a uniform thickness along axis. For example, seismic data from ridge-parallel and ridge-perpendicular refraction lines at segment AN-1 are well explained by a two layer crustal model consisting of a uniform thickness layer 2 underlain by a variable thickness layer 3 [Muller et al., 1997; Muller et al., 2000]. A similar crustal structure is observed east of the Melville fracture zone at $66^{\circ} \mathrm{E}$ on the SWIR [Muller et al., 1999], and at several ridge segments of the MAR [Tolstoy et al., 1993; Hosford et al., in press, 2001] and the ultra-slow spreading Mohns ridge [Klingelhofer et al., 2000].

To test the relative contributions of basaltic upper crust and gabbroic lower crust to the observed magnetization, we modeled the magnetic field anomaly that is expected from a two dimensional, variable thickness source layer of constant magnetization. The magnetization used for the basaltic source was $10 \mathrm{~A} / \mathrm{m}$ [e.g., Banerjee, 1984; ArkaniHamed, 1988] and the magnetization used for the gabbroic source was $5 \mathrm{~A} / \mathrm{m}$. The calculated magnetic field anomaly from each of these sources was then inverted for crustal magnetization, using the constant thickness source layer assumption of the inversion applied to the real data (Figure 3). Both the upper (Figure 12a) and lower (Figure 12b) crustal sources produced a good match between the modeled and observed 
magnetization pattern (Figure12c). However, the basaltic source model required an along-strike thickness variation $(1.5 \mathrm{~km})$ that is larger than supported by the seismic models in this area [Muller et al., 1997; Muller et al., 2000], whereas the $2 \mathrm{~km}$ thickness variation used for the gabbroic source model agrees well with those results. We therefore conclude from these models that the extrusive crust contributes a large but constant component to the axial magnetization, while the lower crust produces the along-axis variation in that signal.

Because the large-scale crustal structure along the rift valleys of the MAR and SWIR is similar, the contrasting axial magnetization patterns at the two ridges may derive from a smaller-scale difference in crustal architecture. One source of difference may be the structure of the extrusive crust, which is the strongest contributor to the amplitude of the axial crustal magnetization [e.g., Tivey, 1996]. Recent multichannel seismic images of layer $2 \mathrm{~A}$ at $35^{\circ} \mathrm{N}$ on the MAR show that the extrusive crust thickens by $150 \mathrm{~m}$ from the segment center toward the Oceanographer fracture zone [Hussenoeder, 1998]. This thickening is hypothesized to occur via along-axis redistribution of melt from a central injection point rather than from distributed in situ sources along the whole segment, and may explain the observations of relatively large-amplitude magnetic anomalies near the Oceanographer fracture zone [Hosford, unpublished data]. It is possible that local thickening of the extrusive crust near segment offsets may not occur at the SWIR because 
relatively low melt volume coupled with low injection frequency would inhibit significant down-axis flow within the shallow crust. The different axial magnetization patterns at the MAR and the SWIR may also derive from a difference in crustal and upper mantle temperatures. At the MAR, where the melt volume is presumably larger and supplied more often than at the SWIR, temperatures within the crust may be maintained above the Curie point for magnetite, thus preventing a coherent magnetic signal from locking in to the axial crust. A similar thermal demagnetization effect is proposed to explain a local magnetization low at the TAG hydrothermal mound on the MAR [Tivey et al., 1993]. In contrast, melt-starved SWIR segments may be colder near their midpoints relative to MAR segments, thus allowing the relatively high magnetization that results from a thicker crustal section to be maintained.

\subsection{Off-axis Isochronal Trends in Crustal Magnetization}

The observation of more positively magnetized crust at segment offsets off axis regardless of magnetic polarity (Figure 11) is strongly suggestive of the presence of an induced component of magnetization within the lower crust and/or upper mantle [Pockalny et al., 1995; Tivey and Tucholke, 1998]. These sections are the mostly likely carriers of induced magnetization because hydrous alteration of olivine and pyroxene produces magnetite that is highly susceptible to inducement by the present day field 
[Dunlop and Prevot, 1982; Gee et al., 1997]. The magnitude of the induced magnetization is estimated using a simple expression derived by Tivey and Tucholke [1998]. In their formulation, induced magnetization equals the sum of normal and reversed polarity isochron variations divided by two. Because of the dense magnetic isochron identifications in this study area, the calculation for induced magnetization is performed on grids of the normal and reversed polarity anomalies shown in Figure 11. The result (Figure 13) indeed shows a concentration of (inferred) induced magnetization near the two transform offsets and within the zone of the NTD.

The degree of serpentinization of the oceanic lower crust and upper mantle is poorly known, largely because the $P$ wave velocities of gabbro and serpentinite overlap [Horen et al., 1996] and because the $S$ wave data required to differentiate between them [e.g., Carlson, 1997] are not commonly acquired in marine refraction experiments. While both the lower crust and upper mantle are potential carriers for induced magnetization, evidence from the 735B drill core suggests that serpentinized peridotite rather than gabbro may be the dominant source of induced magnetization, at least over Atlantis Bank. Paleomagnetic studies on drill-core rocks provide constraints on the relative magnitude of induced magnetization through the Koenigsberger ratio, $Q$, which is defined as remanent divided by induced magnetization. If $Q$ is less than one, induced magnetization dominates remanence magnetization. In the upper $500 \mathrm{~m}$ of Hole 735B, 
96\% of 345 samples exhibited $Q$ values greater than one [Kikawa and Pariso, 1991]. Similarly, all of the 339 samples from the lower $1000 \mathrm{~m}$ of Hole 735B had $Q$ values greater than one [Dick et al., 1999]. These results indicate that crustal magnetization within the gabbros of Atlantis Bank is principally a primary remanent component. Thus, the more likely carrier of an induced magnetization component is serpentinized peridotite, which crops out extensively on the western wall of Atlantis Bank [Kinoshita et $a l ., 2001]$ and was the primary rock type in dredge hauls from the adjacent fracture zone valley [Dick et al., 1991].

Regardless of the ultimate source or sources of the induced magnetization, the effect is the same; induced magnetization at segment offsets, which matches the direction of the Earth's field, adds to the positive thermoremanent magnetization of normal polarity anomalies to produce a stronger magnetization (Figure 11a) and reduces the magnitude of reversed polarity anomalies to produce a weaker magnetization (Figure 11b). Reversed polarity crust at segment ends thus has weak magnetization from two effects, a thinner magnetic source layer due to a thinner lower crust and an induced magnetization component.

Figures 11 and 13 show that magnetization amplitude and inferred induced magnetization, respectively, are approximately symmetrically distributed about the ridge axis at segment ends, particularly at the NTD where data coverage is complete. Inside- 
corner and outside-corner crust must therefore be magnetically similar even if their lithologies differ. Further, unroofing the lower crust and upper mantle at inside corners does not appear to destroy the directional coherence of the magnetic signal. These observations constitute strong evidence that the lower crust provides the primary contribution to marine magnetic anomalies.

\subsection{Atlantis Bank}

The conclusion that the lower crust may contribute significantly to marine magnetic anomalies is based on inference from forward modeling, seismic data, and isochronal magnetization patterns. The coincidence of a dense magnetic survey with a 1.5. $\mathrm{km}$ long drill hole at Atlantis Bank allows this idea to be tested by examining the thermal conditions under which the lower crust formed.

One recent study at Atlantis Bank combined paleomagnetic measurements with deeptow magnetic profiles to estimate the dip of the boundary between the reversely magnetized rocks within Hole $735 \mathrm{~B}$ and an adjacent section of normal polarity crust. After correcting for a $20^{\circ}$ southward tilt of Atlantis Bank, Allerton and Tivey [2001]

obtained a dip angle for the reversal boundary of only $5^{\circ}$. This result seems to require a slow, conductive cooling history at Atlantis Bank, which is in agreement with traditional magnetic models of the lower crust [e.g., Blakely, 1976; Cande and Kent, 1976; Kidd, 
1977]. Other observations of the drill core from Hole 735B, however, suggest that Atlantis Bank experienced rapid cooling following emplacement. First, the drilled section is magnetized with a remarkably stable inclination down-hole [Kikawa and Pariso, 1991; Dick et al., 2000], suggesting that the section cooled below the Curie point rapidly (i.e., very near the ridge axis) [Pariso and Johnson, 1993a]. Second, alteration assemblages in the core formed under granulite- to amphibolite-facies conditions [Stakes et al., 1991; Dick et al., 2000]. Fluid temperatures would only have been high enough to produce these facies when the crust was still within the active rifting zone. Hightemperature alteration had the combined effect of cooling the newly-formed lower crust and sealing it from further alteration that could destroy the primary thermoremanent magnetization. Finally, thermochronologic data obtained from minerals within felsic veins in the $735 \mathrm{~B}$ core indicate that Atlantis Bank lost as much as $70 \%$ of its initial heat within $~ 0.5 \mathrm{Myr}$ of emplacement (John et al., Quantitative age and thermal history of insitu lower oceanic crust-Atlantis Bank, Southwest Indian Ridge, submitted to Earth and Planetary Science Letters, 2000). At a spreading half-rate of $8.5 \mathrm{~km} / \mathrm{Myr}$ and an inner valley half-width of $5 \mathrm{~km}$, these data imply that the lower crust cooled below the Curie point by the time it reached the rift valley walls.

Sea surface magnetic anomaly data also provide evidence for relatively rapid cooling at Atlantis Bank. Figure 4 shows that magnetic lineations continue uninterrupted 
across Atlantis Bank, and that reversely magnetized gabbros in Hole 735B fall within an appropriately reversed polarity chron. Further, inflections in the magnetic lineations over Atlantis Bank are sharp and even relatively short polarity chrons are recorded. Finally, no time lag is observed between the magnetic age of the crust at Atlantis Bank and the magnetic age of the crust from the remainder of the study area; interval half-spreading rates remain the same regardless of whether the calculation is made for tracks that cross the inside corner, segment center, or outside corner. The traditional model of sloped polarity boundaries in the lower crust precludes all of this observed behavior.

The discrepancy between these lines of evidence, which argue for relatively rapid cooling and thus steeply dipping reversal boundaries, and those of Allerton and Tivey [2001], which indicate shallowly dipping reversal boundaries, may be explained if the sloping boundary proposed by Allerton and Tivey [2001] is not an isotherm but rather a contact between intrusions. Alternatively, faulting within Atlantis Bank may have altered the dip of the polarity boundary to the observed low angle.

The applicability of the results from Atlantis Bank to the remainder of the study area and to slow-spread ocean crust in general depends on the extent to which the cooling history of Atlantis Bank is representative of a typical gabbro section. Certainly its tectonic position adjacent to the $200 \mathrm{~km}$ long Atlantis II fracture zone suggests that a strong thermal gradient enhances conductive cooling at the ridge-transform intersection 
[Fox and Gallo, 1984; Phipps Morgan and Forsyth, 1988]. Its setting as a footwall block also implies enhanced heat loss associated with unroofing the crust. At segment centers where these two cooling mechanisms are not relevant, rapid acquisition of the magnetic signal in the lower crust depends on other efficient heat loss mechanisms such as hydrothermal convection.

Figure 14 summarizes a new model for the magnetic structure of the ocean crust formed at low spreading rates. In this model, the magnetic signal resides in two layers, a constant thickness upper crust and a variable thickness lower crust (Figure 14c). On axis, the extrusive crust quickly locks in the magnetic field due to rapid cooling upon emplacement. The magnetization intensity is high, but provides only a constant shift to the total anomaly if variations in iron and titanium content and thickness are small (shaded line in Figure 14a). Heterogeneity in magnetization intensity along axis derives instead from thickness variations on the order of $2 \mathrm{~km}$ in the lower crust (solid line in Figure 14a). Within the lower crust, the magnetic field is quickly locked in at segment ends due to the combined effects of the juxtaposition of cold lithosphere across segment offsets and rapid uplift along large-throw faults at inside corners. Near the segment center, other cooling mechanisms such as hydrothermal circulation are required to cool the lower crust below the Curie point. To generate near-vertical polarity boundaries, this cooling must occur relatively quickly. Alternatively, lower crustal temperatures at the 
segment center may be inherently low because of the long time span between magma injections. As the crust ages, alteration of the extrusive upper crust attenuates the magnetic signal by a significant amount but it remains invariant along strike (shaded line in Figure 14b). The magnetization intensity of the lower crust is unchanged from its axial value (solid line in Figure 14b), except at segment offsets where serpentinized upper mantle may contain an induced magnetization component.

\section{Summary}

A geophysical survey of the two spreading segments between the Atlantis II and Novara fracture zones on the Southwest Indian Ridge provides the most detailed information to date on the accretion and evolution of very-slow spread ocean crust. The survey encompassed 0-25 Myr old crust on both the African and Antarctic plates. The tectonic and magnetics data results are summarized as follows:

1. A $36 \%$ asymmetry in half-spreading rates is maintained for at least $25 \mathrm{Myr}$, with a half-rate of $8.5 \mathrm{~km} / \mathrm{Myr}$ on the Antarctic plate and $5.5 \mathrm{~km} / \mathrm{Myr}$ on the African plate. Such long term asymmetry may be explained by the northward migration of the SWIR or by the preexisting configuration of the SWIR rather than by the influence of a mantle plume. Both the transform and non-transform discontinuities are long-lived features of the SWIR plate boundary, and may have originated beginning $56 \mathrm{Ma}$ via a 
series of discontinuous, eastward propagation events of the Rodriguez Triple Junction. The non-transform discontinuity may be maintained in the plate boundary geometry by a thermal "memory" effect within the lithosphere that dates to the original formation of the SWIR.

2. The ocean crust is well organized even at very low spreading rates. Lineated marine magnetic anomalies are consistent and identifiable, even over a plutonic body known to consist solely of gabbro and serpentinized peridotite. Magnetic isochron identifications pinpoint the timing of a $\sim 10^{\circ}$ counterclockwise change in plate motion at $\sim 19.5$ Ma.

3. Axial crustal magnetization is inversely correlated with seafloor depth, with the largest amplitudes observed at the shallow segment centers and the smallest amplitudes observed at the nodal deeps. This axial magnetization pattern is opposite to observations at many other spreading centers, including the Mid-Atlantic Ridge, Galapagos Ridge, and East Pacific Rise but is the same as observed farther west on the Southwest Indian Ridge and on the ultra-slow spreading Mohns ridge. Models show that the observed axial magnetization may be well explained by a two layer magnetic source that consists of a constant thickness upper crust underlain by a variable thickness lower crust. To fit the data, the lower crust must thin by $2-2.5 \mathrm{~km}$ towards segment ends, consistent with seismic data in this study area. 
4. Crustal magnetization decays by a total of $72 \%$ between the ridge axis and 20 Myr old crust. This decay occurs more rapidly during the first $10 \mathrm{Myr}$ following emplacement than during the subsequent 10 Myr. Normal polarity chrons off axis exhibit elevated magnetization at segment offsets, instead of reduced magnetization as observed on axis. In contrast, reversed polarity isochrons exhibit weak magnetization at segment ends. This pattern suggests the presence of an induced component of magnetization at segment offsets, probably within serpentinized peridotite. There is no correlation between magnetization intensity and tectonic setting; both inside- and outsidecorner corridors exhibit similar magnetization magnitudes. The symmetry of magnetization across segment ends implies that the magnetic source is similar at both inside and outside corners and that the magnetic signal at inside corners is not destroyed during exhumation of the lower crust.

5. The continuity of magnetic isochrons across the contact between gabbroic crust at Atlantis Bank and normal oceanic crust to the east suggests that the lower crust is also an important magnetic source in a segment center environment, even in the presence of an intact upper crust. Atlantis Bank probably cooled more quickly, however, than the lower crust at the segment center due to its unroofing history and the juxtaposition of cold lithosphere across the ridge-transform intersection. A primary thermoremanent magnetization could be preserved in gabbro at segment centers if newly-accreted crust 
cools through the Curie point and/or spreads off-axis before a subsequent melt injection re-warms the lower crust.

6. Accretion of the upper crust occurs in a similar manner as at the Mid-Atlantic Ridge. Elongated, en echelon volcanic ridges define the neovolcanic zones within the inner valleys at the segment centers, while circular, isolated volcanoes concentrate at segment ends. The peak of the Brunhes anomaly coincides with the trend of the axial volcanic ridges, indicating a close spatial and temporal association of the magnetic and morphologic axes. Scallop-shaped depth contours on the valley walls and flat-lying to slightly bulging contours on the valley floors indicate that landslides significantly modify seafloor morphology.

Acknowledgements. We thank the Japan Marine Science and Technology Center and the crews of R/V Yokosuka and R/V Kairei for helping to make the geophysics programs so successful. Discussions with Bobbie John, Greg Hirth, Brian Tucholke, Debbie Smith, and Dan Scheirer were helpful. Thanks to Dave Caress for adding the HS-10 format to MB-System. A.H. was supported by Joint Oceanographic Institutions Subcontract \#JSC1-00 to the Woods Hole Oceanographic Institution. Woods Hole Oceanographic Institution contribution $\mathrm{xxxxx}$. 


\section{References}

Allerton, S., and M.A. Tivey, Magnetic polarity structure of the lower oceanic crust, Geophys. Res. Lett., 28, 423-426, 2001.

Arkani-Hamed, Remanent magnetization of the oceanic upper mantle, Geophys. Res. Lett., 15, 48-51, 1988.

Arkani-Hamed, J., Thermoviscous remanent magnetization of oceanic lithosphere inferred from its thermal evolution, J. Geophys. Res., 94, 17421-17436, 1989.

Atwater, T., and J.D. Mudie, Detailed near-bottom geophysical study of the Gorda Rise, J. Geophys. Res., 78, 8665-8686, 1973.

Banerjee, S.K., The magnetic layer of the ocean crust - how thick is it?, Tectonophysics, 105, 15-27, 1984.

Bazin, S., et al., 3-D shallow crustal emplacement at the $9^{\circ} 03^{\prime} \mathrm{N}$ overlapping spreading center on the East Pacific Rise - I: Correlations between magnetization and tomographic images, J. Geophys. Res., in press.

Bercovici, D., H.J.B. Dick, and T.P. Wagner, Nonlinear viscoelasticity and the formation of transverse ridges, J. Geophys. Res., 97, 14195-14206, 1992.

Blackman, D.K., J.R. Cann, B. Janssen, and D.K. Smith, Origin of extensional core complexes: Evidence from the Mid-Atlantic Ridge at Atlantis Fracture Zone, $J$. Geophys. Res., 103, 21315-21333, 1998.

Blakely, R.J., An age-dependent, two-layer model for marine magnetic anomalies, in Geophysics of the Pacific Ocean Basin and its Margins, pp. 227-234, American Geophysical Union, Washington, D. C., 1976.

Bleil, U., and N. Petersen, Variations in magnetization intensity and low-temperature titanomagnetite oxidation of ocean floor basalts, Nature, 301, 384-388, 1983.

Bown, J.W., and R.S. White, Variation with spreading rate of oceanic crustal thickness and geochemistry, Earth Planet. Sci. Lett., 121, 435-449, 1994.

Cande, S.C., and D.V. Kent, Constraints imposed by the shape of marine magnetic anomalies on the magnetic source, J. Geophys. Res., 81, 4157-4162, 1976.

Cande, S.C., and D.V. Kent, Revised calibration of the geomagnetic polarity timescale for the Late Cretaceous and Cenozoic, J. Geophys. Res., 100, 6093-6095, 1995.

Cannat, M., Emplacement of mantle rocks in the seafloor at mid-ocean ridges, $J$. Geophys. Res., 98, 4163-4172, 1993.

Cannat, M., C. Rommevaux-Jestin, D. Sauter, C. Deplus, and V. Mendel, Formation of the axial relief at the very slow spreading Southwest Indian Ridge $\left(49^{\circ}\right.$ to $\left.69^{\circ} \mathrm{E}\right), J$. Geophys. Res., 104, 22825-22843, 1999. 
Carbotte, S., S.M. Welch, and K.C. Macdonald, Spreading rates, rift propagation, and fracture zone offset histories during the past 5 my on the Mid-Atlantic Ridge; $25^{\circ}$ $27^{\circ} 30^{\prime} \mathrm{S}$ and $31^{\circ}-34^{\circ} 30^{\prime} \mathrm{S}$, Mar. Geophys. Res., 13, 51-80, 1991.

Caress, D.W., and D.N. Chayes, Improved processing of Hydrosweep DS multibeam data on the R/V Maurice Ewing, Mar. Geophys. Res., 18, 631-650, 1996.

Carlson, R.L., A new assessment of the abundance of serpentinite in the oceanic crust, Geophys. Res. Lett., 24, 457-460, 1997.

Chen, Y., A mechanical model for the inside corner uplift at a ridge-transform intersection, J. Geophys. Res., 94, 9275-9282, 1989.

Chen, Y.J., and J. Phipps Morgan, The effects of spreading rate, the magma budget, and the geometry of magma emplacement on the axial heat flux at mid-ocean ridges, $J$. Geophys. Res., 101, 11475-11482, 1996.

Collette, B.J., Fracture zones in the North Atlantic: morphology and a model, J. Geol. Soc. London, 143, 763-774, 1986.

Cormier, M.-H., and K.C. Macdonald, East Pacific Rise $18^{\circ}-19^{\circ}$ S: Asymmetric spreading and ridge reorientation by ultrafast migration of axial discontinuities, J. Geophys. Res., 99, 543-564, 1994.

Crane, K., E. Sundvor, R. Buck, and F. Martinez, Rifting in the northern NorwegianGreenland Sea: Thermal tests of asymmetric spreading, J. Geophys. Res., 96, 14529$14550,1991$.

DeMets, C., R.G. Gordon, D.F. Argus, and S. Stein, Effect of recent revisions to the geomagnetic reversal time scale on estimates of current plate motions, Geophys. Res. Lett., 21, 2191-2194, 1994.

Detrick, R.S., J.C. Mutter, P. Buhl, and I.I. Kim, No evidence from multichannel reflection data for a crustal magma chamber in the MARK area on the Mid-Atlantic Ridge, Nature, 347, 61-64, 1990.

Detrick, R.S., H.D. Needham, and V. Renard, Gravity anomalies and crustal thickness variations along the Mid-Atlantic Ridge between $33^{\circ} \mathrm{N}$ and $40^{\circ} \mathrm{N}, J$. Geophys. Res., 100, 3767-3787, 1995.

Dick, H.J.B., et al., A long in-situ section of the lower ocean crust: results of ODP Leg 176 drilling at the Southwest Indian Ridge, Earth Planet. Sci. Lett., 179, 31-51, 2000.

Dick, H.J.B., J.H. Natland, and D.J. Miller, Proc. ODP, Init. Repts., 176 [CD-ROM], Ocean Drilling Program, Texas A\&M University, College Station, 1999.

Dick, H.J.B., P.T. Robinson, and P.S. Meyer, The plutonic foundation of a slowspreading ridge, in Synthesis of Results from Scientific Drilling in the Indian Ocean, pp. 1-39, American Geophysical Union, 1992. 
Dick, H.J.B., et al., Tectonic evolution of the Atlantis II fracture zone, in Proc. Ocean Drill. Program Scientific Results, edited by R.P. Von Herzen, and P.T. Robinson, pp. 359-398, Ocean Drilling Program, College Station, 1991.

Dick, H.J.B., G. Thompson, and W.B. Bryan, Low angle faulting and steady-state emplacement of plutonic rocks at ridge-transform intersections, Eos Trans. AGU, 62 (17), Spring Meet. Suppl., S406, 1981.

Dunlop, D.J., and M. Prevot, Magnetic properties and opaque mineralogy of drilled submarine intrusive rocks, Geophys. J. R. Astron. Soc., 69, 763-802, 1982.

Fisher, R.L., and J.G. Sclater, Tectonic evolution of the Southwest Indian Ocean since the Mid-Cretaceous: plate motions and stability of the pole of Antarctica/Africa for at least 80 Myr, Geophys. J. R. Astron. Soc., 73, 553-576, 1983.

Fox, P.J., and D.G. Gallo, A tectonic model for ridge-transform-ridge plate boundaries: Implications for the structure of oceanic lithosphere, Tectonophysics, 104, 205-242, 1984.

Fox, P.J., and N.D. Opdyke, Geology of the oceanic crust: Magnetic properties if oceanic rocks, J. Geophys. Res., 78, 5139-5154, 1973.

Gee, J., and D.V. Kent, Variations in layer $2 \mathrm{~A}$ thickness and the origin of the central anomaly magnetic high, Geophys. Res. Lett., 21, 297-300, 1994.

Gee, J., and D.V. Kent, Magnetic telechemistry and magmatic segmentation on the Southern East Pacific Rise, Earth Planet. Sci. Lett., 164, 379-385, 1998.

Gee, J.S., R.M. Lawrence, and S.D. Hurst, Remanence characteristics of gabbros from the MARK area: Implications for crustal magnetization, in Proc. Ocean Drill. Program Scientific Results, edited by J.A. Karson, Cannat, M., Miller, D. J., Elthon, D., pp. 429-436, Ocean Drilling Program, College Station, 1997.

Geli, L., V. Renard, and C. Rommevaux, Ocean crust formation processes at very slow spreading centers: A model for the Mohns Ridge, near $72^{\circ} \mathrm{N}$, based on magnetic, gravity, and seismic data, J. Geophys. Res., 99, 2995-3013, 1994.

Grindlay, N.R., P.J. Fox, and P.R. Vogt, Morphology and tectonics of the Mid-Atlantic Ridge $\left(25^{\circ}-27^{\circ} \mathrm{S}\right)$ from Sea Beam and magnetic data, J. Geophys. Res., 97, 6983$7010,1992$.

Harrison, C.G.A., Marine magnetic anomalies - The origin of the stripes, Ann. Rev. Earth Planet. Sci., 15, 505-543, 1987.

Horen, H., M. Zamore, and G. Dubuisson, Seismic wave velocities and anisotropy in serpentinized peridotites from Xigaze ophiolite: Abundance of serpentine in slow spreading ridge, Geophys. Res. Lett., 23, 9-12, 1996. 
Hosford, A., Crustal accretion and evolution at slow and ultra-slow spreading mid-ocean ridges, Woods Hole Oceanographic Institution/Massachusetts Institute of Technology Joint Program in Oceanography, Woods Hole, 2001.

Hosford, A., J. Lin, and R.S. Detrick, Crustal evolution over the last 2 m.y. at the MidAtlantic Ridge OH-1 segment, 35 N, J. Geophys. Res., in press, 2001.

Hussenoeder, S.A., Seismic and magnetic constraints on the structure of upper oceanic crust at fast and slow spreading ridges, Woods Hole Oceanographic Institution/Massachusetts Institute of Technology Joint Program in Oceanography, Woods Hole, 1998.

Hussenoeder, S.A., M.A. Tivey, H. Schouten, and R.C. Searle, Near-bottom magnetic survey of the Mid-Atlantic Ridge axis, $24^{\circ}-24^{\circ} 40^{\prime} \mathrm{N}$ : Implications for crustal accretion at slow spreading ridges, J. Geophys. Res., 101, 22051-22069, 1996.

International Association of Geomagnetism and Aeronomy (IAGA), D.V., Working Group 8, International Geomagnetic Reference Field 2000, Geophys. J. Int., 141, 259262, 2000.

Irving, E., The Mid-Atlantic Ridge at $45^{\circ} \mathrm{N}$. XIV. Oxidation and magnetic properties of basalt; Review and discussion, Can. J. Earth Sci., 7, 1528-1538, 1970.

Johnson, H.P., and T. Atwater, Magnetic study of basalts from the Mid-Atlantic Ridge, lat $37^{\circ}$ N, Geol. Soc. Am. Bull., 88, 637-647, 1977.

Johnson, H.P., and J.E. Pariso, Variations in oceanic crustal magnetization: Systematic changes in the last 160 million years, J. Geophys. Res., 98, 435-445, 1993.

Karson, J.A., Seafloor spreading on the Mid-Atlantic Ridge: Implications for the structure of ophiolites and oceanic lithosphere produced in slow-spreading environments, in Proceedings of the Symposium TROODOS 1987, edited by J. Malpas, E.M. Moores, A. Panayiotou, and C. Xenophontos, pp. 547-555, Geological Survey Dept., Min. of Agriculture and Natural Resources, Nicosia, Cyprus, 1990.

Karson, J.A., and H.J.B. Dick, Tectonics of ridge-transform intersections at the Kane Fracture Zone, Mar. Geophys. Res., 6, 51-98, 1983.

Kent, D.V., B.M. Honnorez, N.D. Opdyke, and P.J. Fox, Magnetic properties of dredged oceanic gabbros and the source of marine magnetic anomalies, Geophys. J. Royal Astron. Soc., 55, 513-537, 1978.

Kidd, R.G.W., The nature and shape of the sources of marine magnetic anomalies, Earth Planet. Sci. Lett., 33, 310-320, 1977.

Kikawa, E., and J.E. Pariso, Magnetic properties of gabbros from hole 735B, Southwest Indian Ridge, in Proc. ODP, Sci. Res., edited by R.P. Von Herzen, and P.T. Robinson, pp. 285-307, Ocean Drilling Program, College Station, 1991. 
Kinoshita, H., H.J.B. Dick, and Y.S.S. Party, MODE'98 Leg 4 Cruise Report, pp. 221, Japan Marine Science Technology Center, 2001.

Kleinrock, M.C., B.E. Tucholke, J. Lin, and M.A. Tivey, Fast rift propagation at a slowspreading ridge, Geology, 25 (7), 639-642, 1997.

Klingelhofer, F., L. Geli, L. Matias, N. Steinsland, and J. Mohr, Crustal structure of a super-slow spreading centre: A seismic refraction study of Mohns Ridge, $72^{\circ} \mathrm{N}$, Geophys. J. Int., 141, 509-526, 2000.

Macdonald, K.C., P.J. Fox, L.J. Perram, M.F. Eisen, R.M. Haymon, S.P. Miller, S.M. Carbotte, M.-H. Cormier, and A.N. Shor, A new view of the mid-ocean ridge from the behaviour of ridge-axis discontinuities, Nature, 335, 217-225, 1988.

Macdonald, K.C., S.P. Miller, S.P. Huestis, and F.N. Spiess, Three-dimensional modeling of a magnetic reversal boundary from inversion of deep-tow measurements, $J$. Geophys. Res., 85, 3670-3680, 1980.

Macdonald, K.C., D.S. Scheirer, and S.M. Carbotte, Mid-ocean ridges: discontinuities, segments, and giant cracks, Science, 253, 986-994, 1991.

McClain, J.S., and D.W. Caress, Seismic tomography in marine refraction experiments, in Seismic Tomography: Theory and Practice, edited by H.M. Iyer, and K. Hirahara, pp. 764-780, Chapman and Hall, New York, 1993.

Mendel, V., D. Sauter, L. Parson, and J.-R. Vanney, Segmentation and morphotectonic variations along a super slow-spreading center: The Southwest Indian Ridge $\left(57^{\circ} \mathrm{E}-\right.$ $70^{\circ}$ E), Mar. Geophys. Res., 19, 505-533, 1997.

Muller, M.R., T.A. Minshull, and R.S. White, Segmentation and melt supply at the Southwest Indian Ridge, Geology, 27, 867-870, 1999.

Muller, M.R., T.A. Minshull, and R.S. White, Crustal structure of the Southwest Indian Ridge at the Atlantis II Fracture Zone, J. Geophys. Res., 105, 25809-25828, 2000.

Muller, M.R., C.J. Robinson, T.A. Minshull, R.S. White, and M.J. Bickle, Thin crust beneath ocean drilling program borehole 735B at the Southwest Indian Ridge?, Earth Planet. Sci. Lett., 148, 93-107, 1997.

Müller, R.D., W.R. Roest, and J.-Y. Royer, Asymmetric sea-floor spreading caused by ridge-plume interactions, Nature, 396, 455-459, 1998.

Müller, R.D., J.-Y. Royer, and L.A. Lawver, Revised plate motions relative to the hotspots from combined Atlantic and Indian Ocean hotspot tracks, Geology, 21, 275278, 1993.

Mutter, J.C., and J.A. Karson, Structural processes at slow-spreading ridges, Science, 257, 627-634, 1992.

OTTER, The geology of the Oceanographer transform: the ridge-transform intersection, Mar. Geophys. Res., 6, 109-141, 1984. 
Pariso, J.E., and H.P. Johnson, Do Layer 3 rocks make a significant contribution to marine magnetic anomalies? In situ magnetization of gabbros at Ocean Drilling Program Hole 735B, J. Geophys. Res., 98, 16033-16052, 1993a.

Pariso, J.E., and H.P. Johnson, Do lower crustal rocks record reversals of the Earth's magnetic field? Magnetic petrology of oceanic gabbros from Ocean Drilling Program Hole 735B, J. Geophys. Res., 98, 16013-16032, 1993 b.

Pariso, J.E., C. Rommevaux, and J.-C. Sempéré, Three-dimensional inversion of marine magnetic anomalies: Implications for crustal accretion along the Mid-Atlantic Ridge (28ㅇ-3130' N), Mar. Geophys. Res., 18, 85-101, 1996.

Parker, R.L., and S.O. Huestis, The inversion of magnetic anomalies in the presence of topography, J. Geophys. Res., 79, 1587-1593, 1974.

Patriat, P., D. Sauter, M. Munschy, and L. Parson, A survey of the Southwest Indian Ridge axis between Atlantis II Fracture Zone and the Indian Ocean Triple Junction: Regional setting and large-scale segmentation, Mar. Geophys. Res, 19, 457-480, 1997.

Patriat, P., and J. Segoufin, Reconstruction of the Central Indian Ocean, Tectonophysics, 155, 211-234, 1988.

Phipps Morgan, J., and D.W. Forsyth, Three-dimensional flow and temperature perturbations due to a transform offset: Effects on oceanic crustal and upper mantle structure, J. Geophys. Res., 93, 2955-2966, 1988.

Pockalny, R.A., A. Smith, and P. Gente, Spatial and temporal variability of crustal magnetization of a slowly spreading ridge: Mid-Atlantic Ridge, Mar. Geophys. Res., 17, 301-320, 1995.

Purdy, G.M., and R.S. Detrick, Crustal structure of the Mid-Atlantic Ridge at $23^{\circ} \mathrm{N}$ from seismic refraction studies, J. Geophys. Res., 91, 3739-3762, 1986.

Ravilly, M., J. Dyment, P. Gente, and R. Thibaud, Axial magnetic anomaly amplitude along the Mid-Atlantic Ridge between $20^{\circ} \mathrm{N}$ and $40^{\circ} \mathrm{N}, J$. Geophys. Res., 103, 24201$24221,1998$.

Rea, D.K., Tectonics of the Nazca-Pacific divergent plate boundary, in Nazca Plate: Crustal formation and Andean convergence, Mem. 154, edited by L.D. Kulm, J. Dymond, E.J. Dasch, and D.M. Hussong, pp. 27-62, Geological Society of America, Boulder, 1981.

Robinson, C.J., R.S. White, M.J. Bickle, and T.A. Minshull, Restricted melting under the very slow-spreading Southwest Indian ridge, in Tectonic, magmatic, hydrothermal, and biological segmentation of mid-ocean ridges, edited by C.J. MacLeod, P.A. Tyler, and C.L. Walker, pp. 131-141, Geological Society of London, London, 1996. 
Rommevaux-Jestin, C., C. DePlus, and P. Patriat, Mantle Bouguer anomaly along an ultra-slow spreading ridge: Implications for accretionary processes and comparison with results from central Mid-Atlantic Ridge, Mar. Geophys. Res., 19, 481-503, 1997.

Rona, P.A., Asymmetric fracture zones and seafloor spreading, Earth Planet. Sci. Lett., 30, 109-116, 1976.

Rouzo, S., M. Rabinowicz, and A. Briais, Segmentation of mid-ocean ridges with an axial valley induced by small-scale mantle convection, Nature, 374, 795-798, 1995.

Sandwell, D.T., and W.H.F. Smith, Marine gravity anomaly from Geosat and ERS 1 satellite altimetry, J. Geophys. Res., 102, 10039-10054, 1997.

Schouten, H., H.J.B. Dick, and K.D. Klitgord, Migration of mid-ocean-ridge volcanic segments, Nature, 326, 835-839, 1987.

Schouten, H., and K.D. Klitgord, The memory of the accreting plate boundary and the continuity of fracture zones, Earth Planet. Sci. Lett., 59, 255-266, 1982.

Schouten, H., and R.S. White, Zero-offset fracture zones, Geology, 8, 175-179, 1980.

Schulz, N.J., R.S. Detrick, and S.P. Miller, Two- and three-dimensional inversions of magnetic anomalies in the MARK area (Mid-Atlantic Ridge $23^{\circ} \mathrm{N}$ ), Mar. Geophys. Res., 10, 41-57, 1988.

Sempéré, J.-C., The origin of high-amplitude magnetization zones near spreading center discontinuities, Earth Planet. Sci. Lett., 107, 389-405, 1991.

Sempéré, J.-C., et al., The Mid-Atlantic Ridge between $29^{\circ} \mathrm{N}$ and $31^{\circ} 30^{\prime} \mathrm{N}$ in the last 10 Ma, Earth Planet. Sci. Lett., 130, 45-55, 1995.

Severinghaus, J.P., and K.C. Macdonald, High inside corners at ridge-transform intersections, Mar. Geophys. Res., 9, 353-367, 1988.

Shaw, W.J., and J. Lin, Models of ocean ridge lithospheric deformation: Dependence on crustal thickness, spreading rate, and segmentation, J. Geophys. Res., 101, 17977$17993,1996$.

Sinton, J.M., and R.S. Detrick, Mid-ocean ridge magma chambers, J. Geophys. Res., 97, 197-216, 1992.

Small, C., Observations of ridge-hotspot interactions in the Southern Ocean, J. Geophys. Res., 100, 17931-17946, 1995.

Stakes, D., C. Mevel, M. Cannat, and T. Chaput, Metamorphic stratigraphy of Hole 735B, in Proc. Ocean Drill. Program Scientific Results, edited by R.P. Von Herzen, and P.T. Robinson, pp. 153-180, Ocean Drilling Program, College Station, 1991.

Stein, S., H.J. Melosh, and J.B. Minster, Ridge migration and asymmetric seafloor spreading, Earth Planet. Sci. Lett., 36, 51-62, 1977.

Talwani, M., C.C. Windisch, and J. Langseth, M. G., Reykjanes ridge crest: A detailed geophysical study, J. Geophys. Res., 76, 473-517, 1971. 
Thibaud, R., P. Gente, and M. Maia, A systematic analysis of the Mid-Atlantic Ridge morphology and gravity between $15^{\circ} \mathrm{N}$ and $40^{\circ} \mathrm{N}$ : Constraints of the thermal structure, J. Geophys. Res., 103, 24223-24243, 1998.

Tivey, M.A., Vertical magnetic structure of ocean crust determined from near-bottom magnetic field measurements, J. Geophys. Res., 101, 20275-20296, 1996.

Tivey, M.A., H.P. Johnson, C. Fleutelot, S. Hussenoeder, R. Lawrence, C. Waters, and B. Wooding, Direct measurement of magnetic reversal polarity boundaries in a crosssection of oceanic crust, Geophys. Res. Lett., 25, 3631-3634, 1998.

Tivey, M.A., P.A. Rona, and H. Schouten, Reduced crustal magnetization beneath the active sulfide mound, TAG hydrothermal field, Mid-Atlantic Ridge at $26^{\circ} \mathrm{N}$, Earth Planet. Sci. Lett., 115, 101-115, 1993.

Tivey, M.A., and B.E. Tucholke, Magnetization of 0-29 Ma ocean crust on the MidAtlantic Ridge, $25^{\circ} 30^{\prime}$ to $27^{\circ} 10^{\prime} \mathrm{N}$, J. Geophys. Res., 103, 17807-17826, 1998.

Tolstoy, M., A.J. Harding, and J.A. Orcutt, Crustal thickness on the Mid-Atlantic Ridge: Bull's eye gravity anomalies and focused accretion, Science, 262, 726-729, 1993.

Tucholke, B.E., Massive submarine rockslide in the rift-valley wall of the Mid-Atlantic Ridge, Geology, 20, 129-132, 1992.

Tucholke, B.E., and J. Lin, A geological model for the structure of ridge segments in slow spreading ocean crust, J. Geophys. Res., 99, 11937-11958, 1994.

Tucholke, B.E., J. Lin, M.C. Kleinrock, M.A. Tivey, T.B. Reed, J. Goff, and G.E. Jaroslow, Segmentation and crustal structure of the western Mid-Atlantic Ridge flank, $25^{\circ} 25^{\prime}-27^{\circ} 10^{\prime} \mathrm{N}$ and 0-29 m.y., J. Geophys. Res., 102, 10203-10223, 1997a.

Tucholke, B.E., and H. Schouten, Kane Fracture Zone, Mar. Geophys. Res., 10, 1-39, 1988.

Tucholke, B.E., W.K. Stewart, and M.C. Kleinrock, Long-term denudation of ocean crust in the central North Atlantic Ocean, Geology, 25, 171-174, $1997 \mathrm{~b}$.

Weiland, C., D.S. Wilson, and K. Macdonald, High-resolution plate reconstruction of the Southern Mid-Atlantic Ridge, Mar. Geophys. Res., 17, 143-166, 1995.

Weiland, C.M., K.C. Macdonald, and N.R. Grindlay, Ridge segmentation and the magnetic structure of the Southern Mid-Atlantic Ridge $26^{\circ} \mathrm{S}$ and $31^{\circ}-35^{\circ} \mathrm{S}$ : Implications for magmatic processes at slow spreading centers, J. Geophys. Res., 101, 8055-8073, 1996.

Wessel, P., and W.H.F. Smith, Free software helps map and display data, Eos Trans. $A G U, 72,441,1991$.

White, R.S., D. McKenzie, and R.K. O'Nions, Oceanic crustal thickness from seismic measurements and rare earth element inversions, J. Geophys. Res., 97, 19683-19715, 1992. 
Wilson, D.S., and R.N. Hey, History of rift propagation and magnetization intensity for the Cocos-Nazca spreading center, J. Geophys. Res., 100, 10041-10056, 1995. 
Table 1. Average half-spreading rates for each ridge segment

\begin{tabular}{|c|c|c|c|c|c|}
\hline Anomaly & Time & Half rate & Half rate & Half rate & Half rate \\
\hline Interval & $\begin{array}{l}\text { Interval } \\
\text { (Myr) }\end{array}$ & $\begin{array}{l}\text { AN-1, } \\
\text { North } \\
(\mathrm{km} / \mathrm{Myr})\end{array}$ & $\begin{array}{l}\text { AN-1, } \\
\text { South } \\
(\mathrm{km} / \mathrm{Myr})\end{array}$ & $\begin{array}{l}\text { AN-2, } \\
\text { North } \\
(\mathrm{km} / \mathrm{Myr})\end{array}$ & $\begin{array}{l}\text { AN-2, } \\
\text { South } \\
(\mathrm{km} / \mathrm{Myr})\end{array}$ \\
\hline $1 n-2 A n$ & $0-2.8$ & $5.8 \pm 2.0$ & $9.1 \pm 3.0$ & $6.3 \pm 2.3$ & $8.2 \pm 2.0$ \\
\hline $2 A n-3 A n$ & $2.8-6.2$ & $5.6 \pm 1.9$ & $8.6 \pm 3.5$ & $6.3 \pm 3.2$ & $9.6 \pm 4.4$ \\
\hline $3 A n-4 A r^{1}$ & $6.2-9.3^{1}$ & $5.7 \pm 1.7$ & $8.2 \pm 2.1$ & $5.6 \pm 3.2$ & $8.3^{2}$ \\
\hline $4 \mathrm{Ar}^{1}-5 \mathrm{An}$ & $9.3^{1}-12.1$ & $5.8 \pm 0.8$ & $8.8 \pm 1.6$ & $5.6 \pm 3.1$ & $8.6^{2}$ \\
\hline $5 \mathrm{An}-5 \mathrm{ACADr}$ & $12.1-15.5$ & $5.6 \pm 2.2$ & $8.8 \pm 3.2$ & $5.7 \pm 1.9$ & $8.6 \pm 2.4$ \\
\hline $5 \mathrm{ACADr}-5 \mathrm{Dr}$ & $15.5-17.9$ & $5.3 \pm 0.7$ & $8.7 \pm 3.1$ & $5.3 \pm 1.8$ & $8.5 \pm 0.5$ \\
\hline $5 \mathrm{Dr}-6 \mathrm{An}$ & $17.9-21.0$ & - & $8.6 \pm 1.4$ & - & $8.5 \pm 0.3$ \\
\hline $6 \mathrm{An}-6 \mathrm{Cr}$ & $21.0-24.4$ & - & $8.2 \pm 1.1$ & - & $8.4 \pm 1.6$ \\
\hline
\end{tabular}

${ }^{1}$ Anomaly $4 \mathrm{r}(8.3 \mathrm{Ma})$ is used for north flank calculations.

${ }^{2}$ Calculation is based on one data point.

Table 2. Average total spreading rates for each ridge segment.

\begin{tabular}{llll}
\hline $\begin{array}{l}\text { Anomaly } \\
\text { Interval }\end{array}$ & $\begin{array}{l}\text { Time Interval } \\
(\mathrm{Myr})\end{array}$ & $\begin{array}{l}\text { Total spreading } \\
\text { rate, } \mathrm{AN}-1 \\
(\mathrm{~km} / \mathrm{Myr})\end{array}$ & $\begin{array}{l}\text { Total spreading } \\
\text { rate, } \mathrm{AN}-2 \\
(\mathrm{~km} / \mathrm{Myr})\end{array}$ \\
1n-2An & $0-2.8$ & $14.9 \pm 2.5$ & $14.6 \pm 2.1$ \\
2An-3An & $2.8-6.2$ & $14.1 \pm 2.7$ & $15.9 \pm 3.8$ \\
3An-5An & $6.2-12.1$ & $14.6 \pm 1.2$ & $14.2 \pm 1.6$ \\
5An-5ACADr & $12.1-15.5$ & $14.4 \pm 2.7$ & $14.2 \pm 2.2$ \\
5ACADr-5Dr & $15.5-17.9^{1}$ & $14.1 \pm 1.9$ & $13.7 \pm 1.1$ \\
\hline
\end{tabular}

${ }^{1}$ The calculation extends only to $20 \mathrm{Ma}$ due to a lack of isochron identifications at older crustal ages on the north flank. 
Plate 1. Multibeam bathymetry data gridded at $500 \mathrm{~m}$ resolution and illuminated from the north. The Atlantis II fracture zone forms the western margin of the study area and the Novara fracture zone forms the eastern boundary of the study area. Star marks location of ODP Hole 735B on Atlantis Bank. (inset) Regional location map of survey area on the Southwest Indian Ridge. (inset) Plate boundary configuration in the study area (not to scale). AN-1 denotes the western segment and AN-2 denotes the eastern segment between the Atlantis II and Novara fracture zones, respectively. NM-1 denotes the westernmost segment between the Novara and Melville fracture zones. 


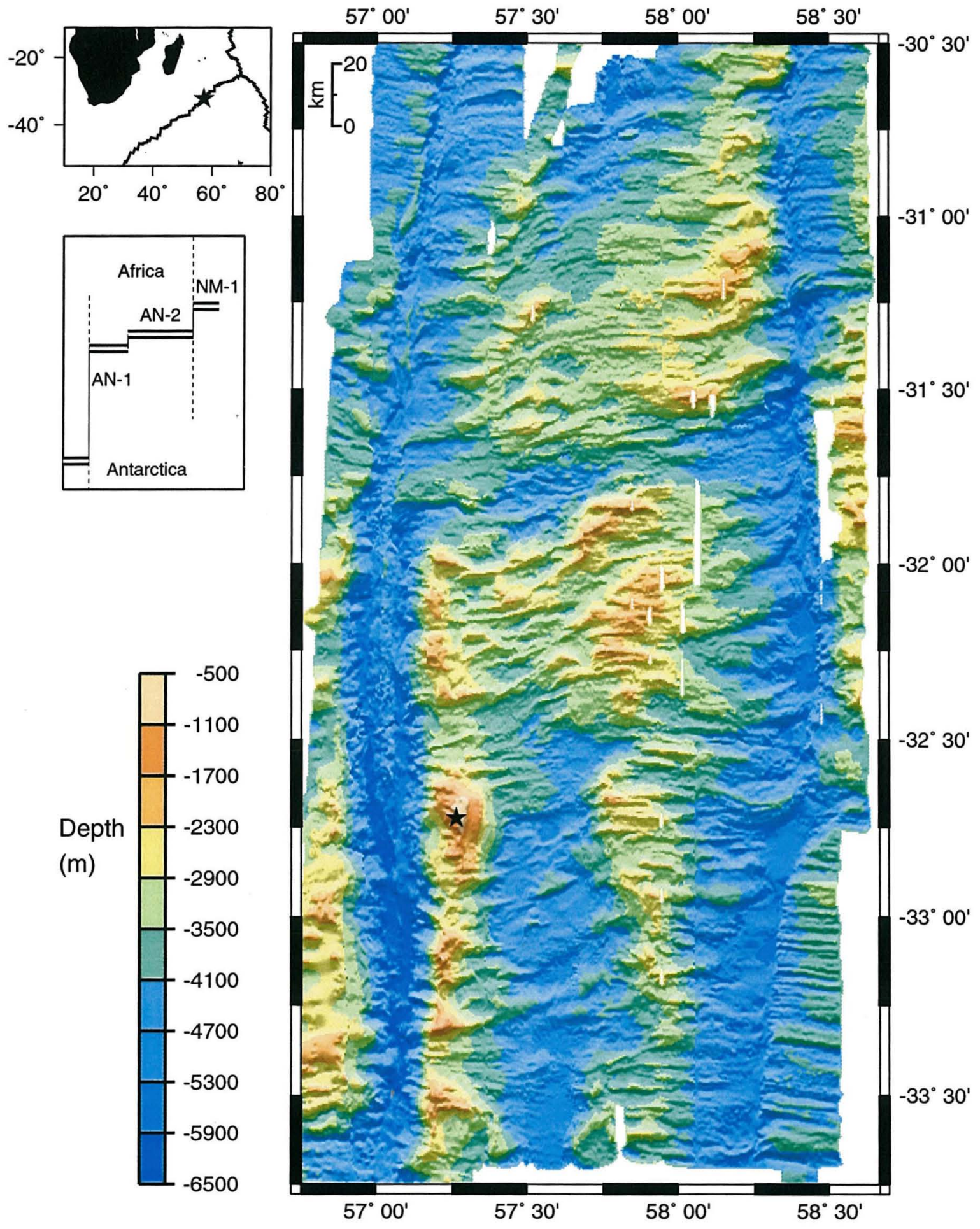


Figure 1. Ship tracks for data used in this study. Solid ship tracks are from a cruise on $\mathrm{R} / \mathrm{V}$ Yokosuka in 1998, dashed tracks are from a cruise on R/V Kairei in 2000, and shaded tracks are from cruise RC2709 on R/V Conrad in 1987. Star marks location of Ocean Drilling Program (ODP) Hole 735B on Atlantis Bank. 


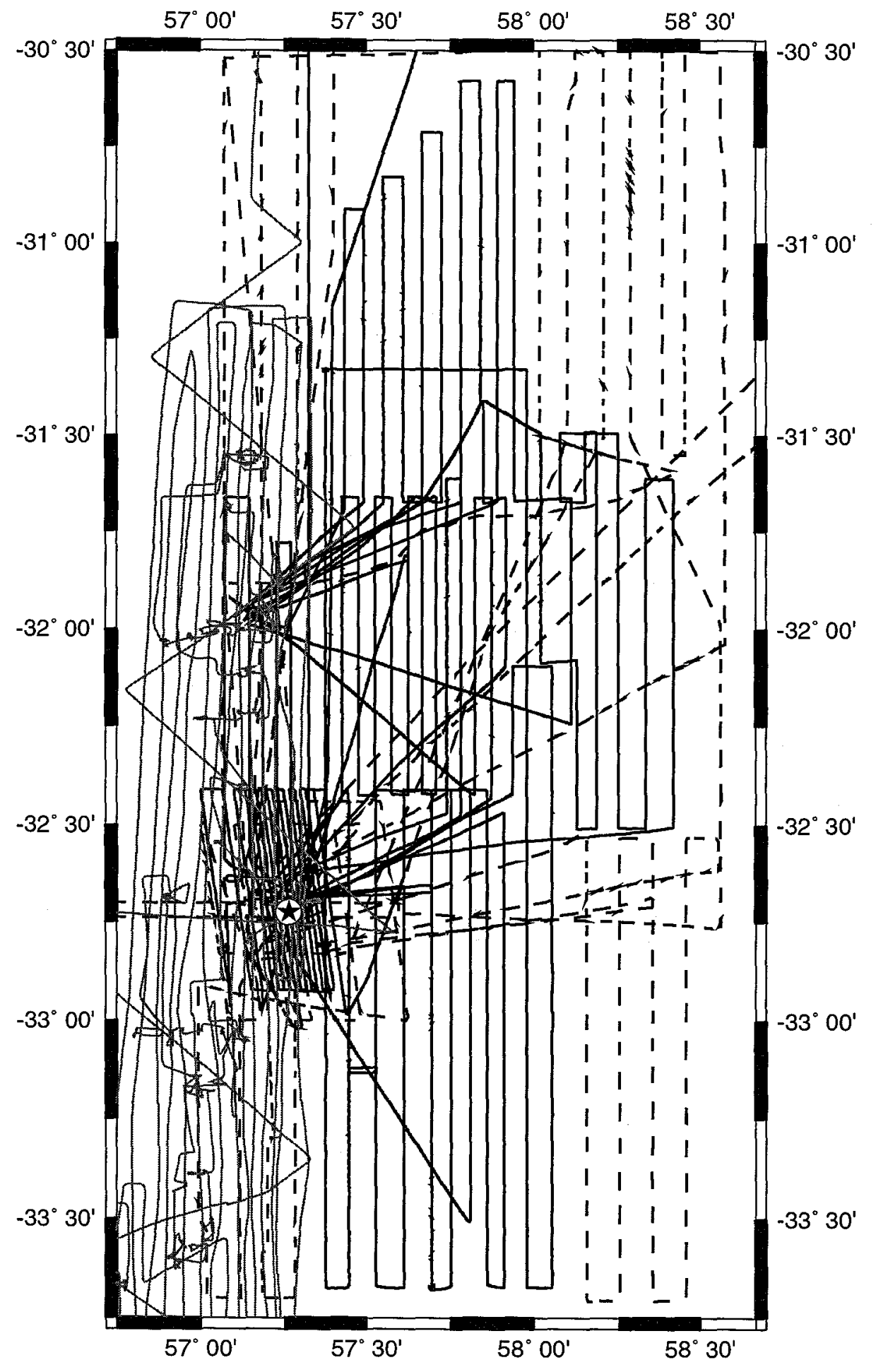


Figure 2. Track line magnetic anomalies, calculated by subtracting the International Geomagnetic Reference Field for the year 2000 [International Association of Geomagnetism and Aeronomy (IAGA), 2000] from the total magnetic field measurement at each point. Anomalies are not corrected for the effects of latitude or bathymetry. Star marks location of ODP Hole 735B on Atlantis Bank. 


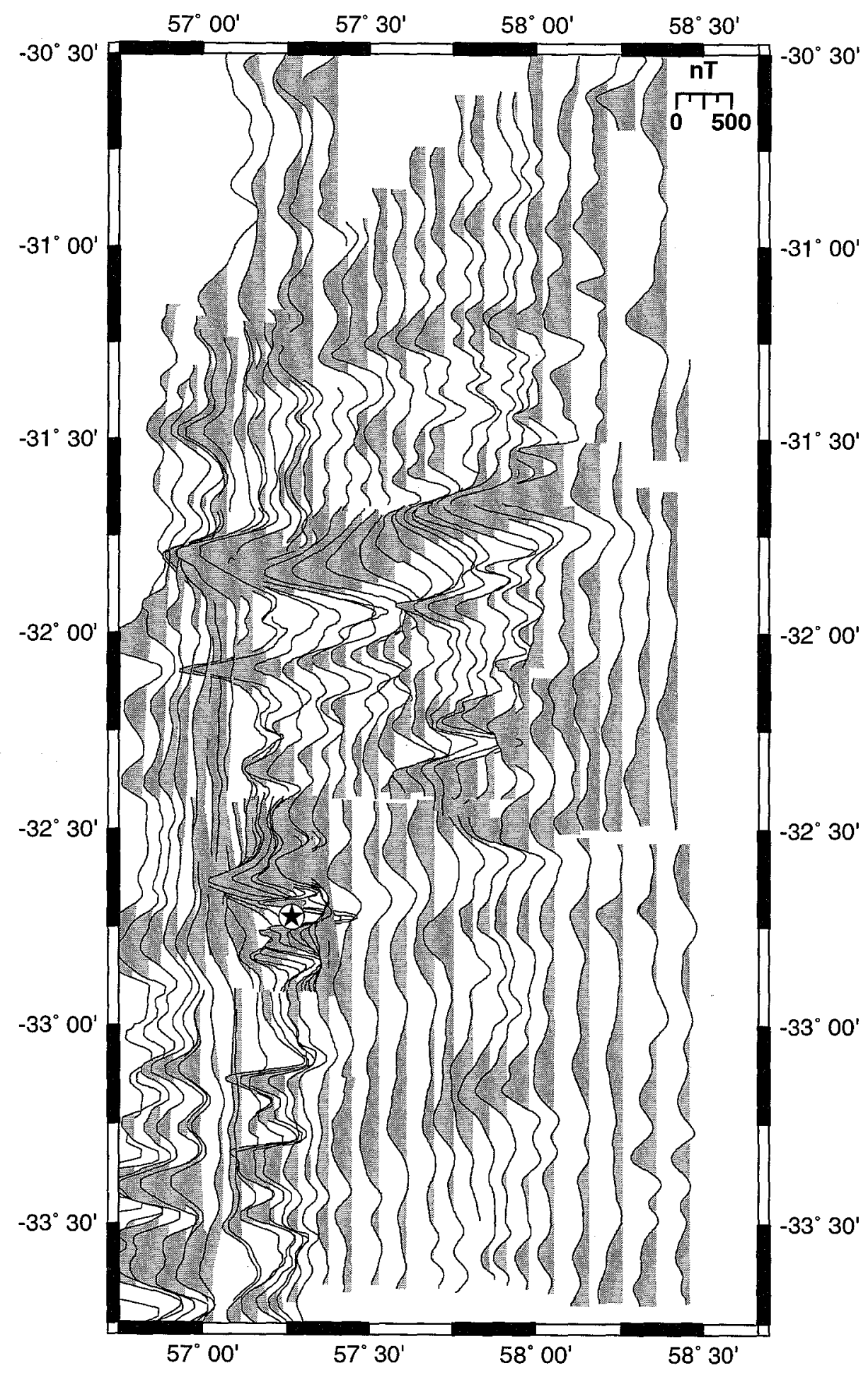


Figure 3. Crustal magnetization map derived by inverting a grid of the sea-surface magnetic anomalies shown in Figure 2, assuming a $500 \mathrm{~m}$ thick source layer and a geocentric dipole of $-51.1^{\circ}$. Color scale illustrates that $80 \%$ of the data lie between \pm 5 $\mathrm{A} / \mathrm{m}$. The grid is illuminated from the north to emphasize small-wavelength features. Selected chrons are labeled. Contour interval is $5 \mathrm{~A} / \mathrm{m}$. Thick solid lines mark the ridge axes, the middle of the fracture zone valleys, and the off-axis trace of the non-transform discontinuity (NTD). Thin solid line bordering the NTD trace denotes the NTD zone within which magnetic isochrons and bathymetric lineaments are oblique to the ridge. Thin white line marks an intra-segment, short-lived propagating rift (see text for details). Star marks location of ODP Hole 735B on Atlantis Bank. 


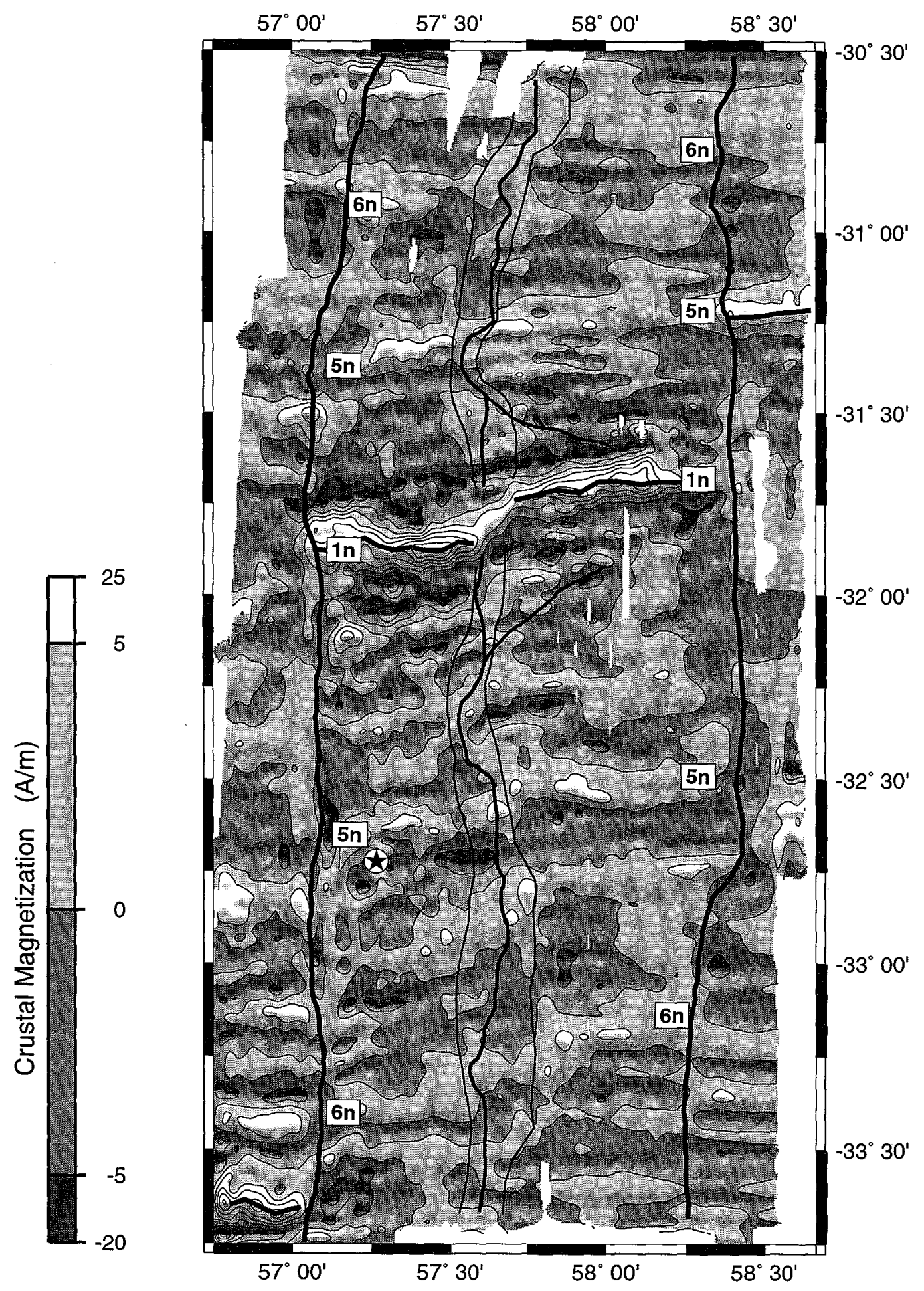


Figure 4. Track line magnetization profiles obtained by sampling the three-dimensional inversion solution (Figure 3 ) along the north-south oriented ship tracks. Filled circles denote peaks of normal polarity chrons and shaded squares denote peaks of reversed polarity chrons. Selected chrons are labeled; note that "5ACADn" denotes anomalies 5CAn and 5ADn, which merge together at these low spreading rates. The magnetic data pinpoint the termination of a change in plate motion (as indicated by bend in Novara fracture zone) at anomaly $6 \mathrm{n}(19.5 \mathrm{Ma})$. Segment boundaries are as in Figure 3. Star marks location of ODP Hole 735B on Atlantis Bank. 


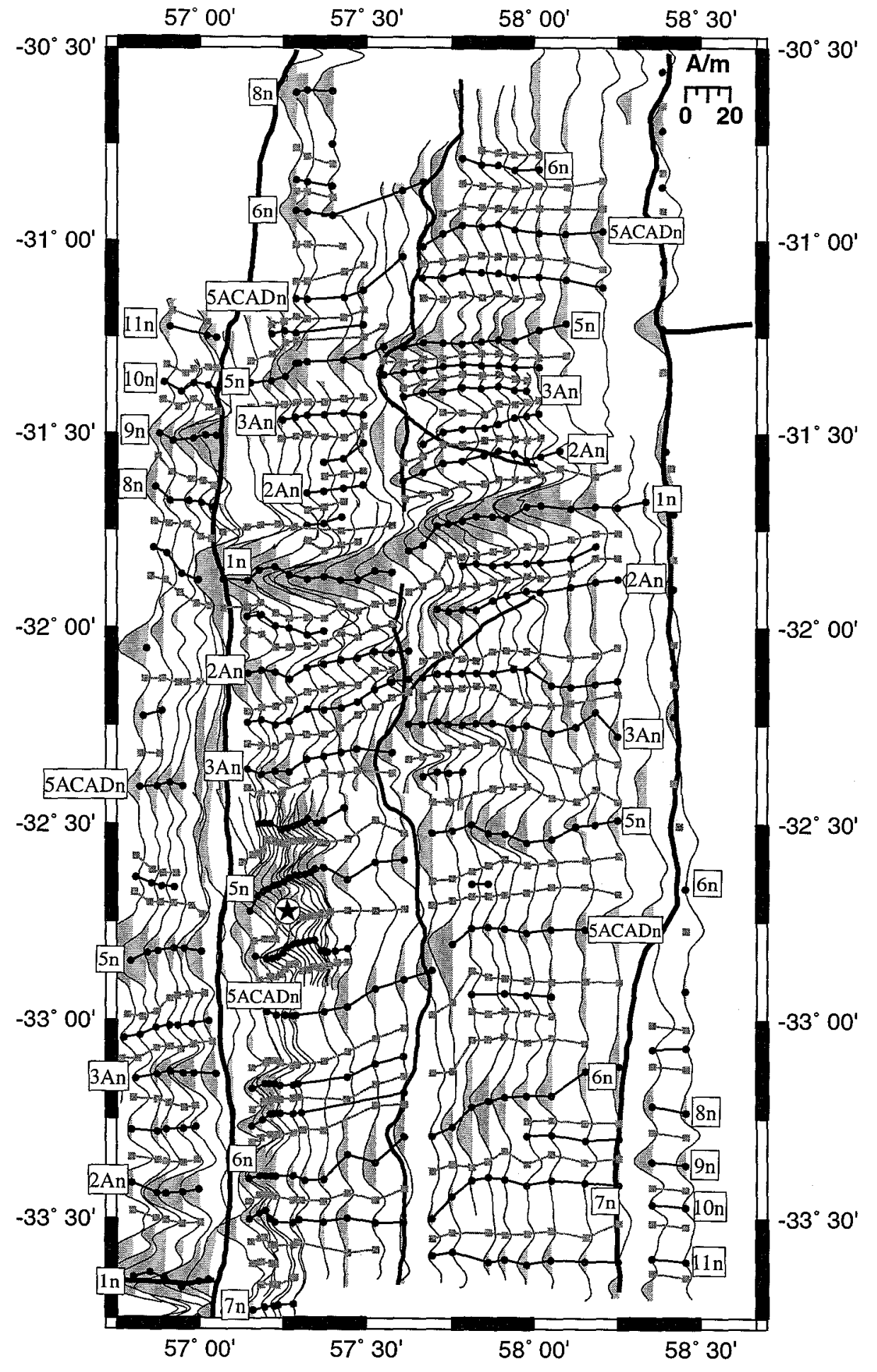


Figure 5. Representative magnetization profiles and corresponding synthetic models for the (a) southern and (b) northern flanks of the ridge. Dashed lines connect the identified isochrons on the data with the predicted isochrons on the model. Models are created by generating a magnetization square wave at a constant spreading rate, assuming a $500 \mathrm{~m}$ thick source with a constant magnetization of $\pm 6 \mathrm{~A} / \mathrm{m}$. The depth to the top of the source layer was chosen as the mean depth along each profile. To simulate a finite zone of emplacement, the square waves are smoothed with a Gaussian distribution of specified standard deviation. Standard deviations of $1 \mathrm{~km}$ and $2 \mathrm{~km}$ are shown. 

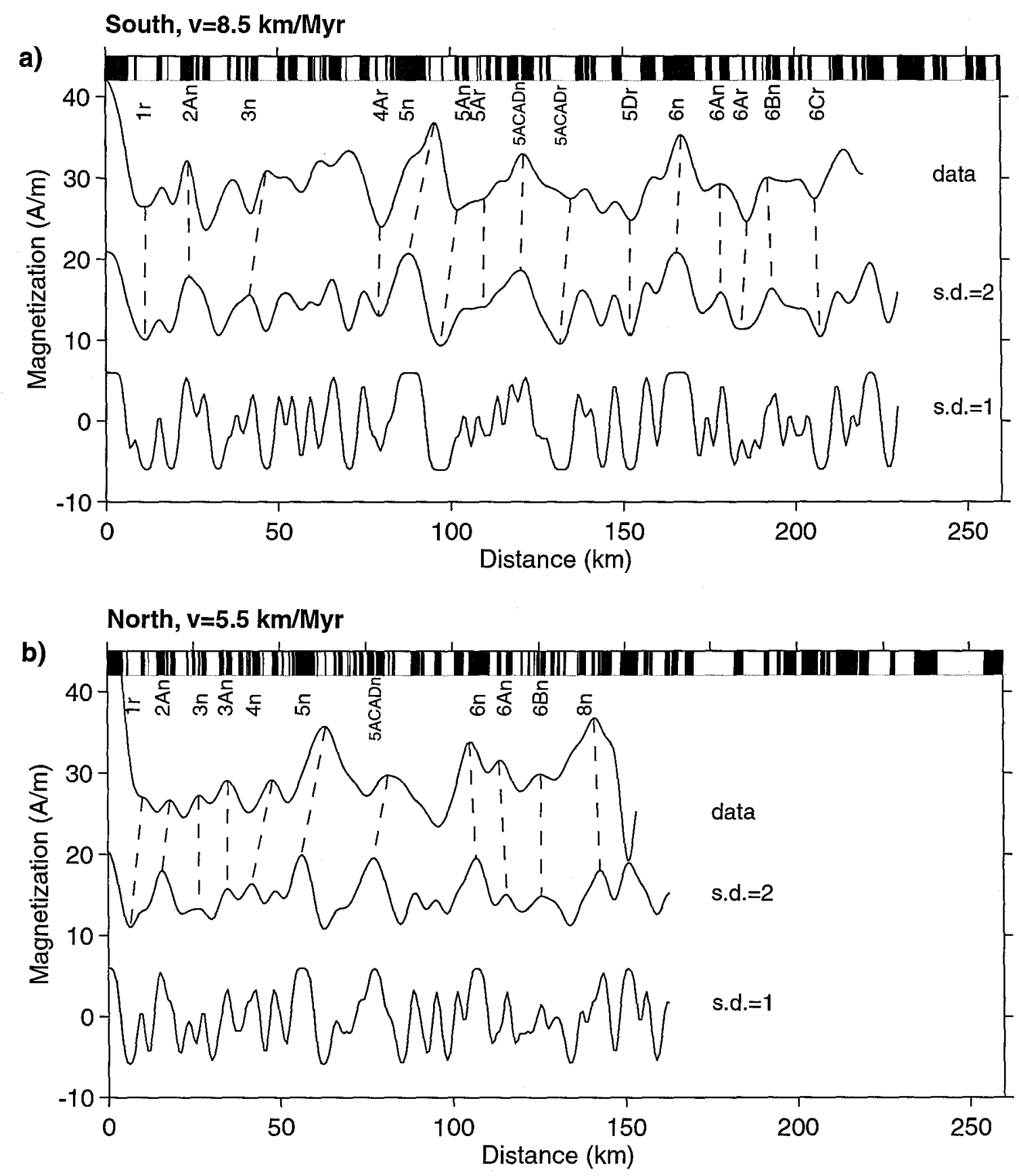
Figure 6. Magnetic anomaly age vs. distance from the central anomaly for the (a) north flank of AN-1, (b) north flank of AN-2, (c) south flank of AN-1, (d) south flank of AN-2, (e) both flanks of AN-1, and (f) both flanks of AN-2. The half-spreading rates in Figures 6a-d and the full spreading rate in Figures 6e-f are given by the slope of the least-squares fit line, denoted by the thick shaded line in each panel. The correlation coefficient, $r$, is greater than 0.997 for all least-square lines. The labeled chrons correspond to the $\sim 3 \mathrm{Myr}$ intervals used for the calculation. Spreading rate data extends to longer times in Figures c-d due to better resolution on the south flank than on the north flank. Error bars are shown by white lines within filled squares and correspond to one standard deviation of the distances between anomalies on all ship tracks included in the calculation. The full spreading rate for each segment is not exactly equal to the sum of the half-spreading rates for each flank due to elimination of the $4 \mathrm{r}$ and $4 \mathrm{Ar}$ chrons in the full-rate calculation. Tables 1 and 2 list the spreading rates and the associated errors for each panel. 

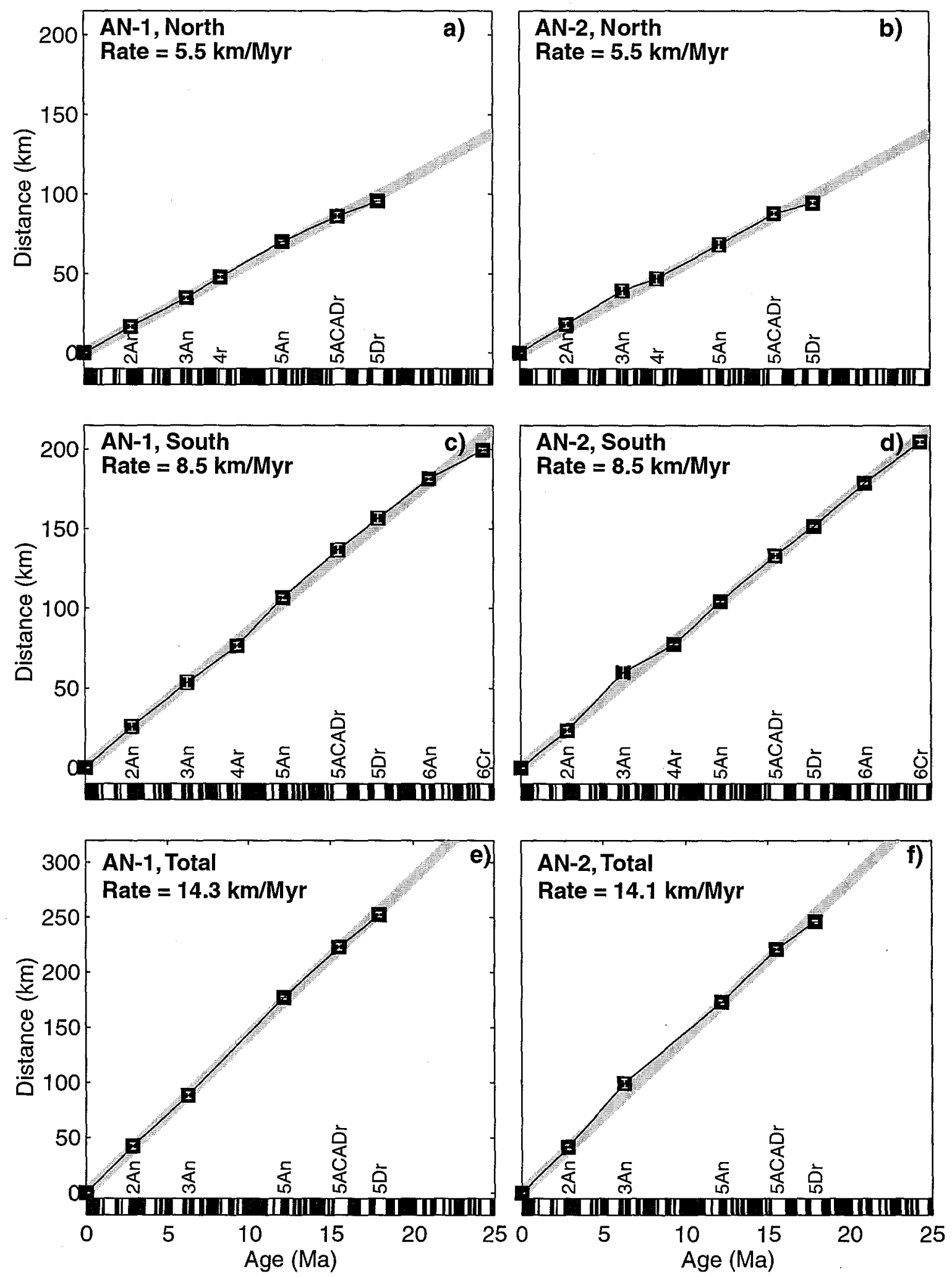
Plate 2. (a) Detailed bathymetry of axial valleys of segments AN-1 and AN-2. Contour interval is $150 \mathrm{~m}$ and illumination is from the north. Grid resolution is $150 \mathrm{~m}$. (b) Interpretive drawing depicting the major features of the inner valley floor. Bounding faults of each segment are denoted by lines with inward-facing ticks. IC denotes insidecorner tectonic setting and $\mathrm{OC}$ denotes outside-corner tectonic setting. 


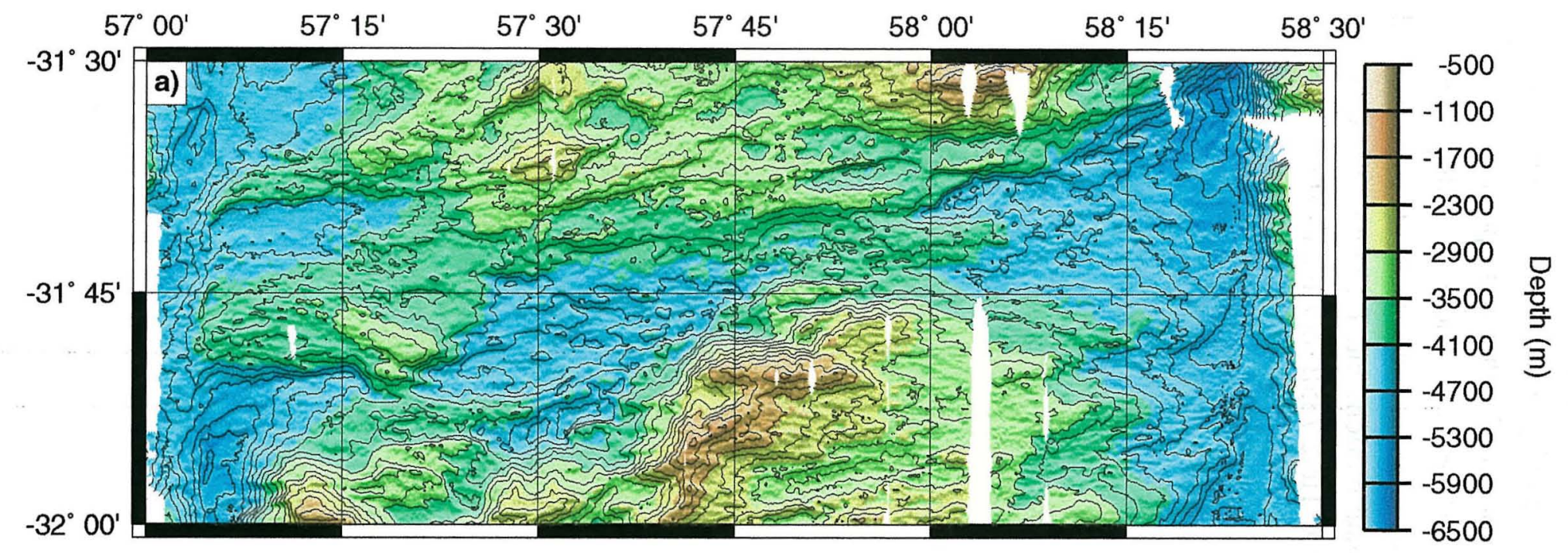

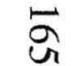

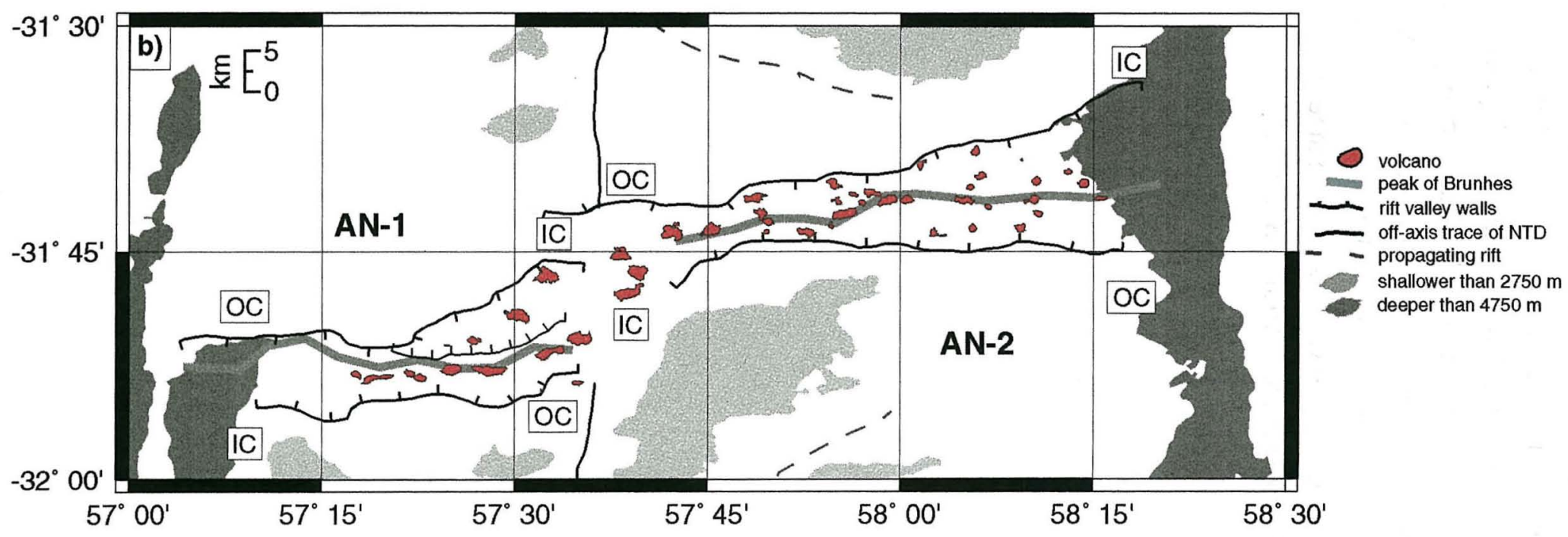


Figure 7. Linedrawing of major tectonic features in the study area. Segment boundaries are as in Figure 3. Thin shaded lines denote lineaments mapped from the seafloor morphology. Lightly shaded polygons denote topography that is elevated above $2.75 \mathrm{~km}$ water depth and darkly shaded polygons denote topography that is deeper than $4.75 \mathrm{~km}$ water depth. Axial valley volcanoes identified in Plate 2 are denoted by filled polygons between the bounding faults. L stands for L-shaped nodal deep, V stands for V-shaped nodal deep, PM marks the change in regional plate motion, and $\mathrm{T}$ denotes the region of highly lineated terrain. Star marks location of ODP Hole 735B on Atlantis Bank. 


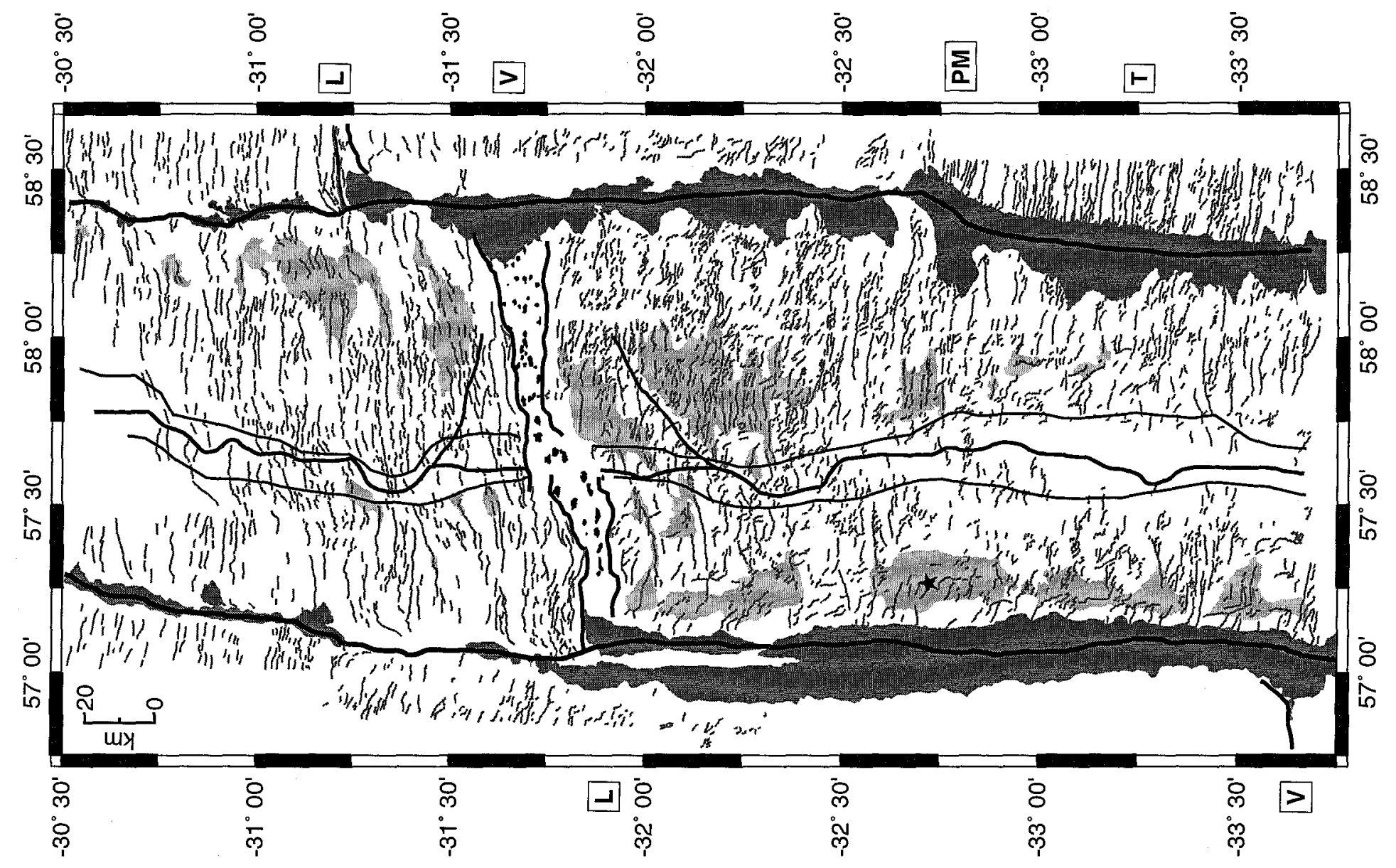


Figure 8. Length of segments AN-1 (solid line) and AN-2 (shaded line) on the (a) southern and (b) northern flanks of the spreading center. The length of each segment is calculated as the distance along axis between the axis of the NTD zone and the center of the bordering fracture zone valley. Dashed line is the sum of the two segment lengths and equals the distance between transforms. Panel widths are scaled by the ratio between the south and north flank half-spreading rates to emphasize the highly asymmetric spreading. Note that distance increases to the left in Figure 8a. Intervals denoted $A B$ and PR represent time periods over which Atlantis Bank was uplifted and the propagating rift was active, respectively. 


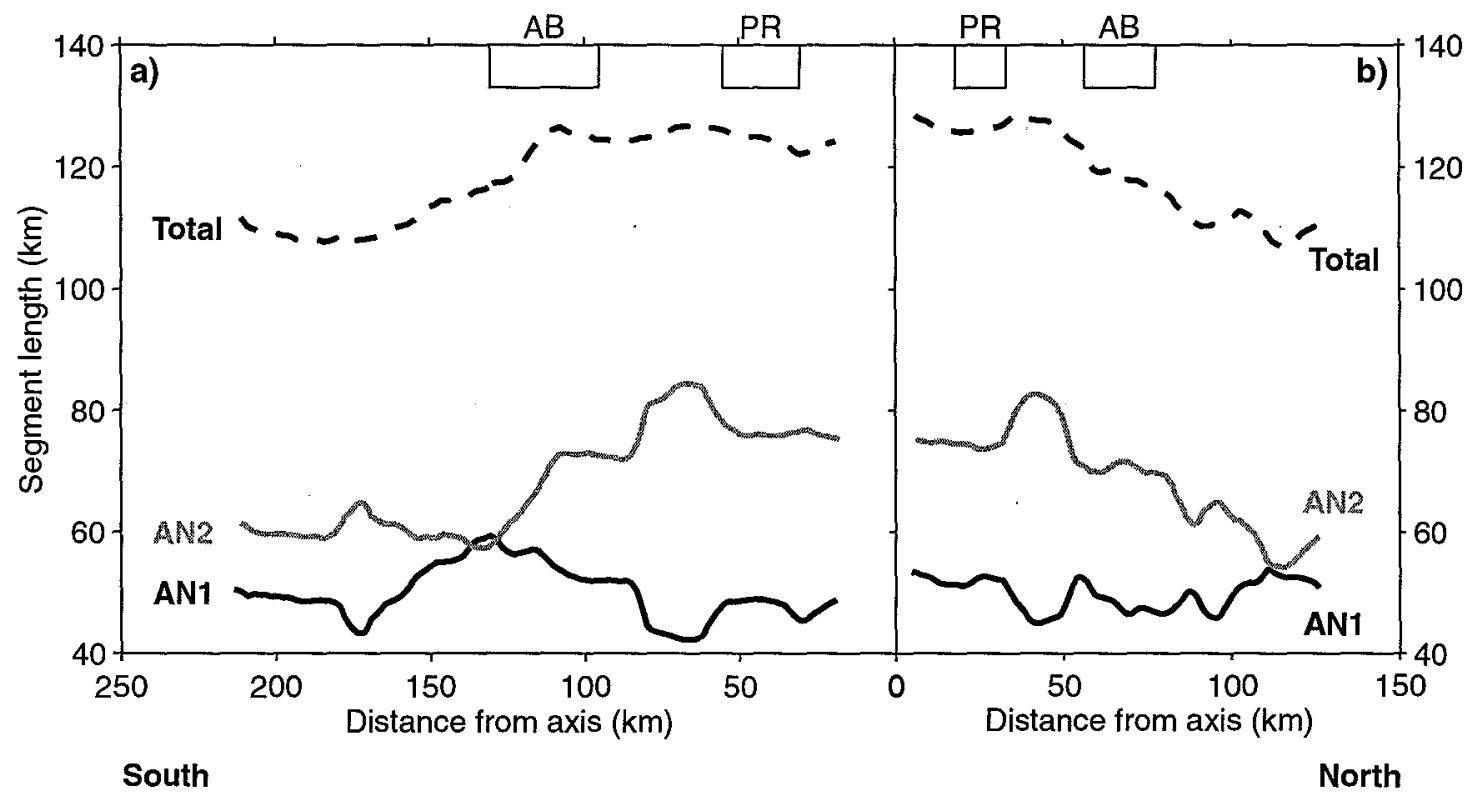


Figure 9. (a) Detail of crustal magnetization solution at ridge axis. Bars above the panel denote the axial extent of closed-contour highs, or magnetic sub-segments. Axial valley volcanoes identified in Plate 2 are denoted by filled polygons. Color intervals are the same as in Figure 3. Contour interval is $2 \mathrm{~A} / \mathrm{m}$. (b) Maximum magnetization of the Brunhes anomaly. The mean magnetization for AN-1 is $16.2 \mathrm{~A} / \mathrm{m}(4.6 \mathrm{std})$ and the mean value for AN-2 is $11.1 \mathrm{~A} / \mathrm{m}$ (4.9 std). (c) Seafloor depths at the locations of the Brunhes anomaly maxima in Figure 9b. Note the direct correlation between depth and magnetization amplitude. The arrows mark the locations of the transform offsets and the shaded box marks the width of the non-transform discontinuity zone. 

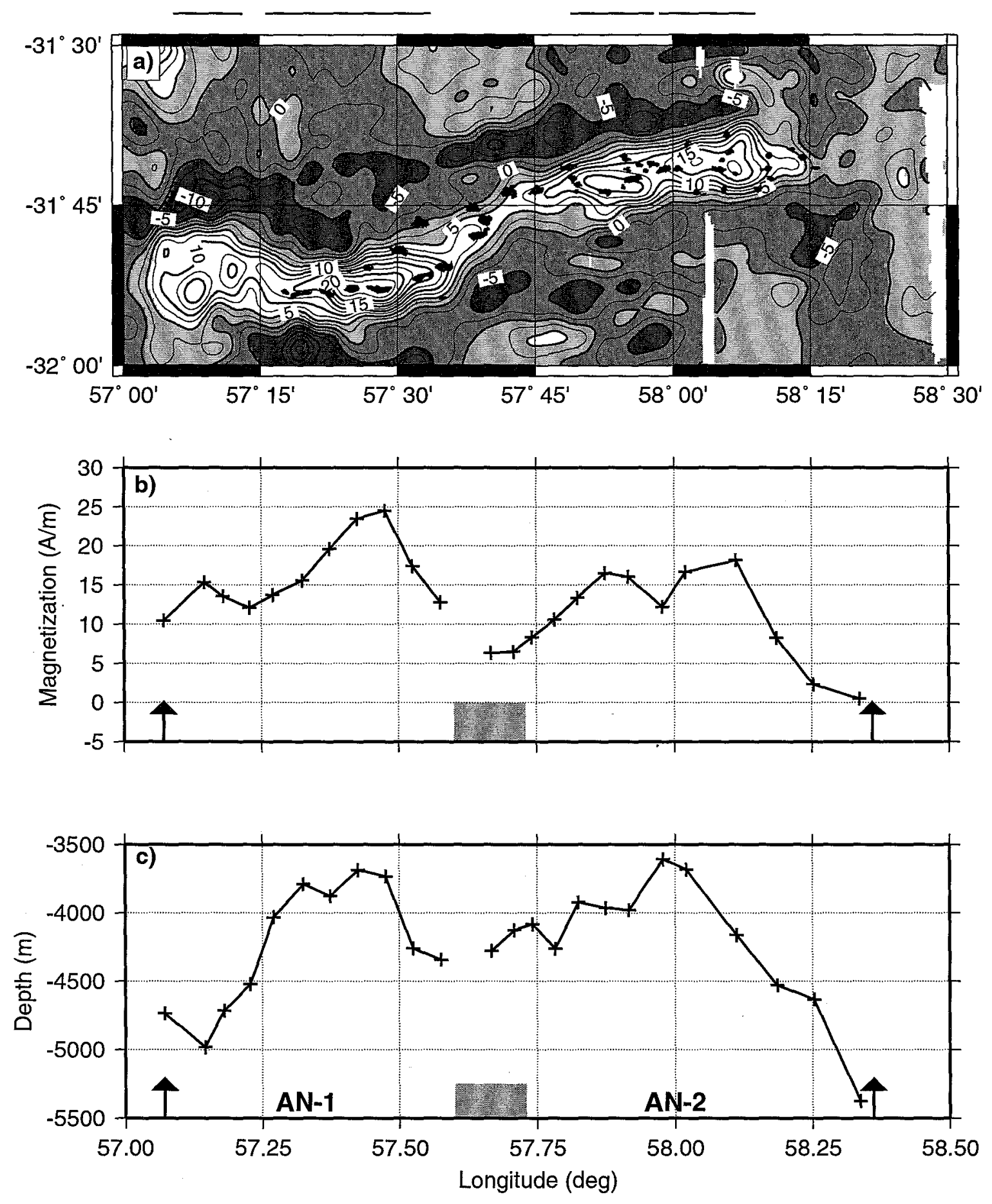
Figure 10. Peak magnetization amplitudes for the (a) southern and (b) northern flanks of the spreading center. Each data point represents the mean of magnetization maxima for tracks within the segment centers of $\mathrm{AN}-1$ and $\mathrm{AN}-2$. Error bars are one standard deviation on either side of the mean. Dotted lines connect anomalies $1 \mathrm{n}, 5 \mathrm{n}$, and $6 \mathrm{n}$ to illustrate long-term decay of crustal magnetization. Note that crustal magnetization decays more rapidly for crustal ages of 0 to $\sim 10 \mathrm{Ma}$ (anomalies $1 \mathrm{n}$ to $5 \mathrm{n}$ ) than for crustal ages of $\sim 10$ to $\sim 20 \mathrm{Ma}$ (anomalies $5 \mathrm{n}$ to $6 \mathrm{n}$ ). The total decay in magnetization intensity at both segments relative to the peak of the Brunhes anomaly is $72 \%$. Labeled chrons correspond to the anomalies used for the calculation. Panel widths are scaled by the ratio between the south and north flank half-spreading rates to emphasize the highly asymmetric spreading. Note that age increases to the left in Figure 10a. Intervals denoted $\mathrm{AB}$ and $\mathrm{PR}$ represent time periods over which Atlantis Bank was uplifted and the propagating rift was active, respectively. 


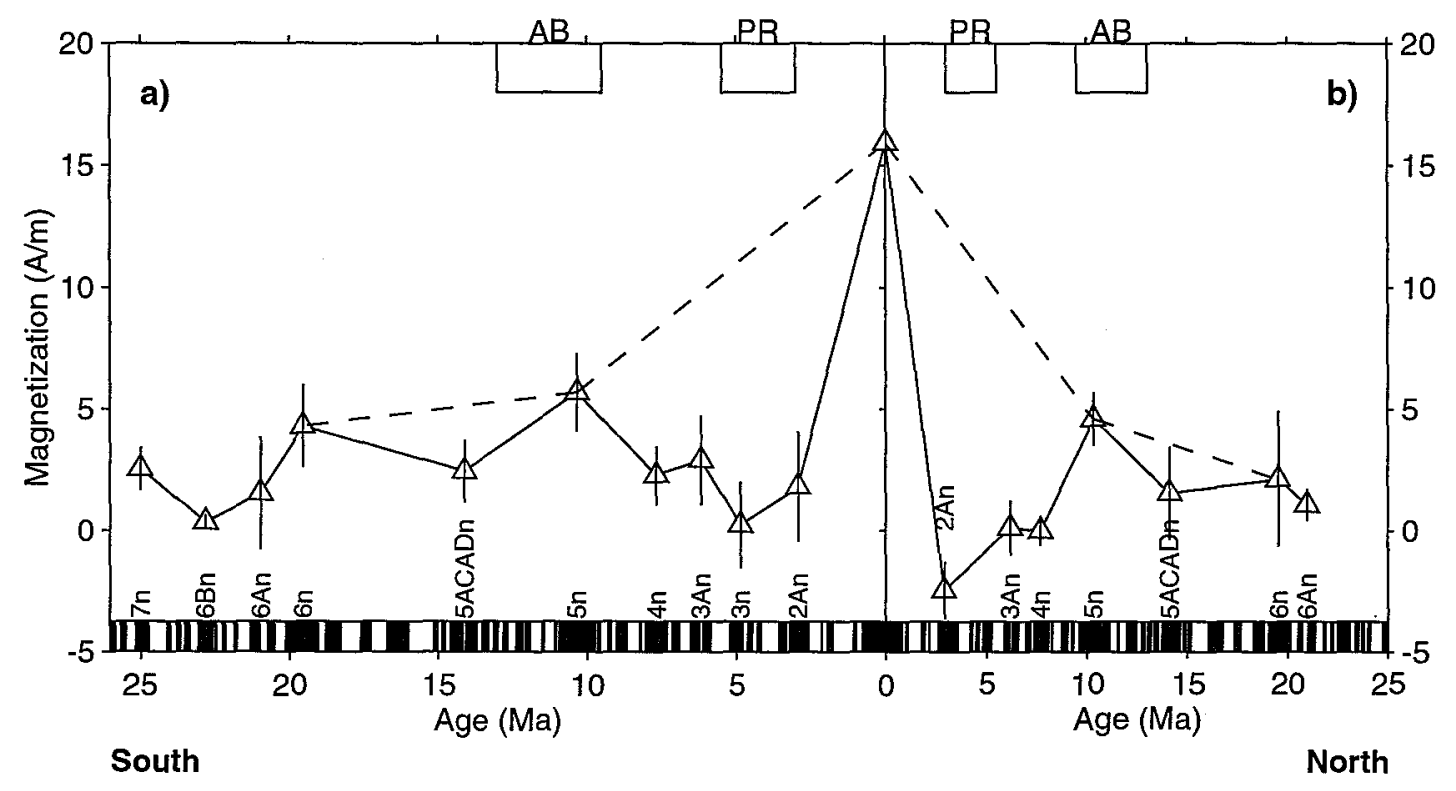


Figure 11. Along-isochron variation in crustal magnetization for (a) normal and (b) reversed polarity chrons. Each isochron is plotted relative to its mean value. Thick solid lines mark the middle of the fracture zone valleys and the off-axis trace of the NTD; thin solid lines mark a propagating rift. Ridge axes correspond to crustal age of $0 \mathrm{Myr}$. In both panels, shaded wiggle fill denotes weaker magnetization than isochron mean and black wiggle fill denotes stronger magnetization than isochron mean. Star marks location of ODP Hole 735B on Atlantis Bank. 


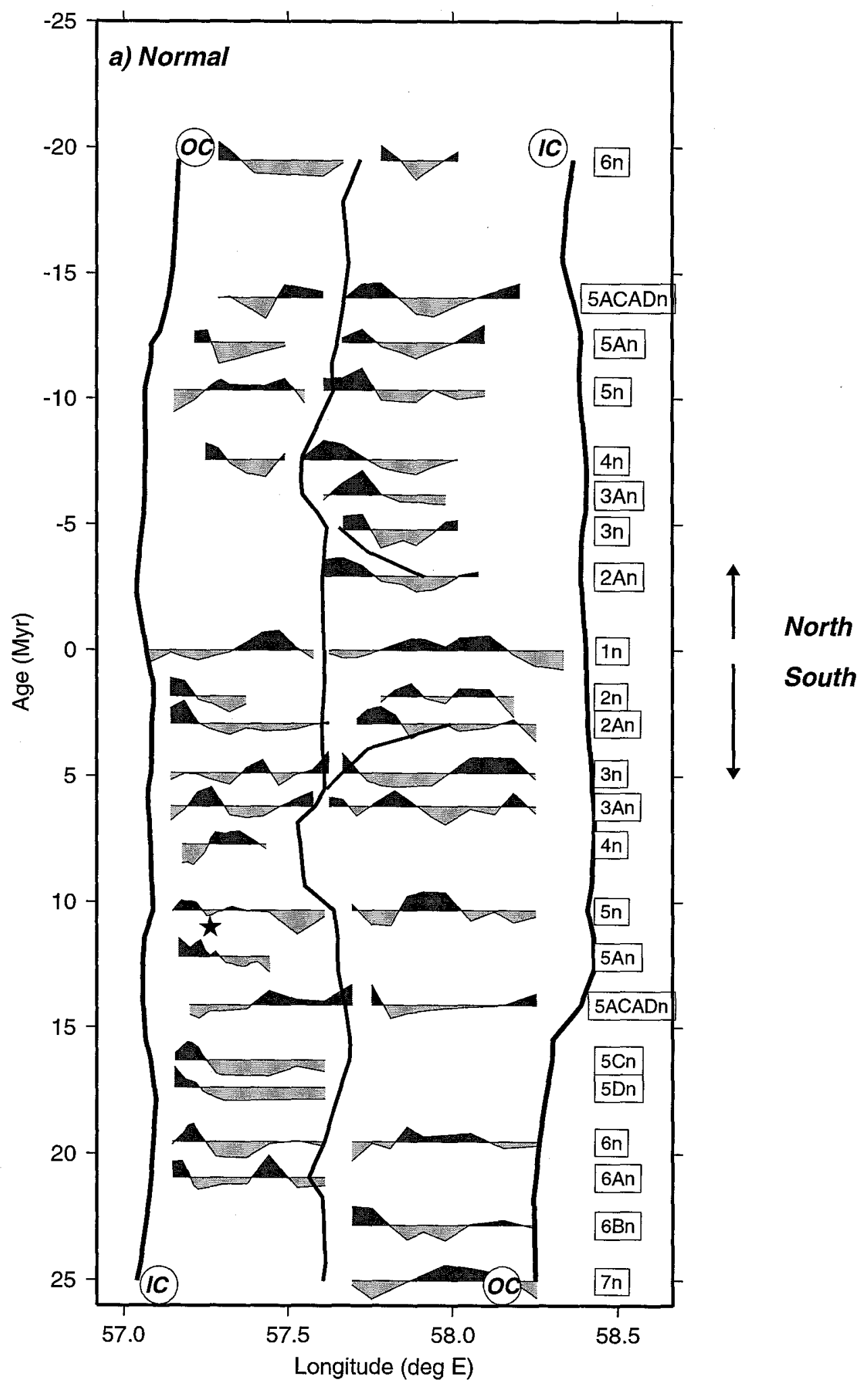


(Caption for Figure 11b is on page 82) 


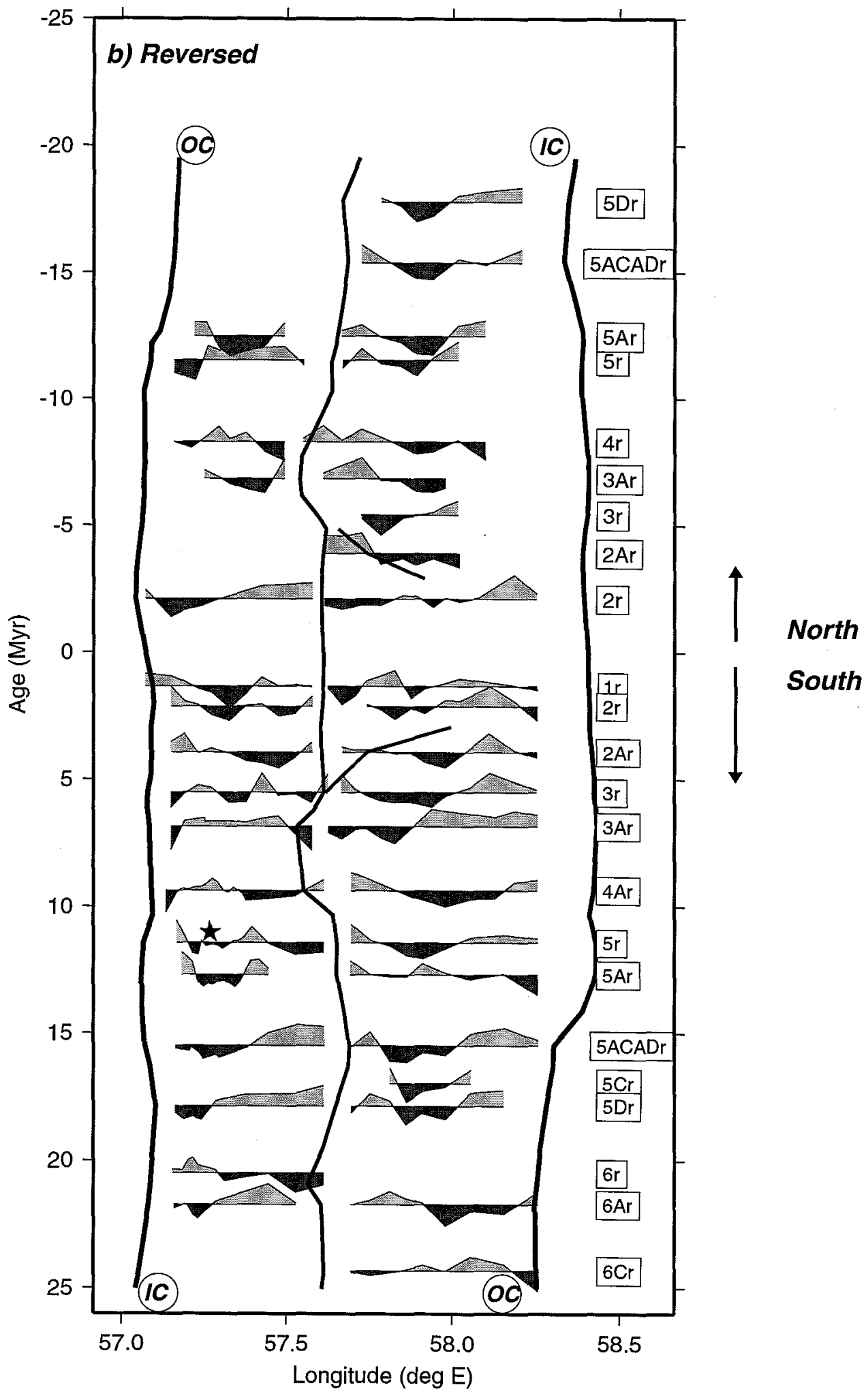


Figure 12. Along-axis profiles of the (a) upper crust and (b) lower crust used for modeling axial magnetization. The seafloor depth in Figure 12a corresponds to the true depth of segment AN-2. The magnetic field anomaly from each of these variable thickness layers was calculated and then inverted using the constant thickness source layer assumption of the inversion applied to the observed data. Source intensities of 10 $\mathrm{A} / \mathrm{m}$ and $5 \mathrm{~A} / \mathrm{m}$ were used for the upper and lower crust, respectively. (c) The observed axial magnetization of segment AN-2 (crosses) and the calculated magnetization profiles for the upper (light shading) and lower (dark shading) crustal sources. Both results fit the observed axial magnetization amplitude, but the $1 \mathrm{~km}$ thickness variation required of the upper crustal source is inconsistent with seismic observations, while the $2 \mathrm{~km}$ thickness variation of the lower crustal source agrees with seismic results. 

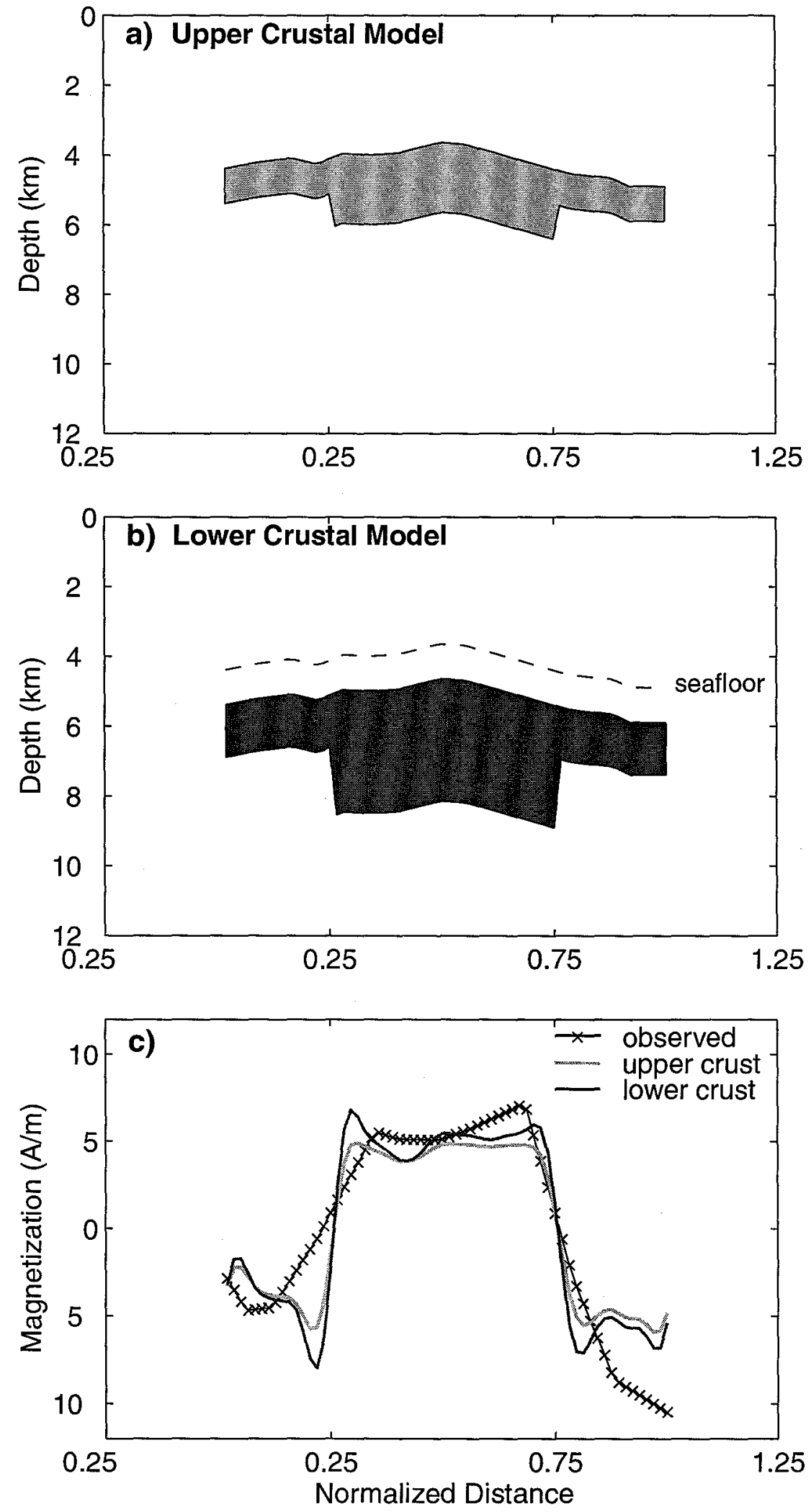
Figure 13. Inferred induced component of magnetization, defined as the sum of the normal and reversed polarity isochronal variations divided by two [Tivey and Tucholke, 1998]. The calculation was performed on gridded versions of the data presented in Figure 11. Note the tendency for the inferred induced component to align with the segment discontinuities, possibly indicating the presence of serpentinized lower crust and/or upper mantle. Segment boundaries are as in Figure 3. Star marks location of ODP Hole $735 \mathrm{~B}$ on Atlantis Bank. 


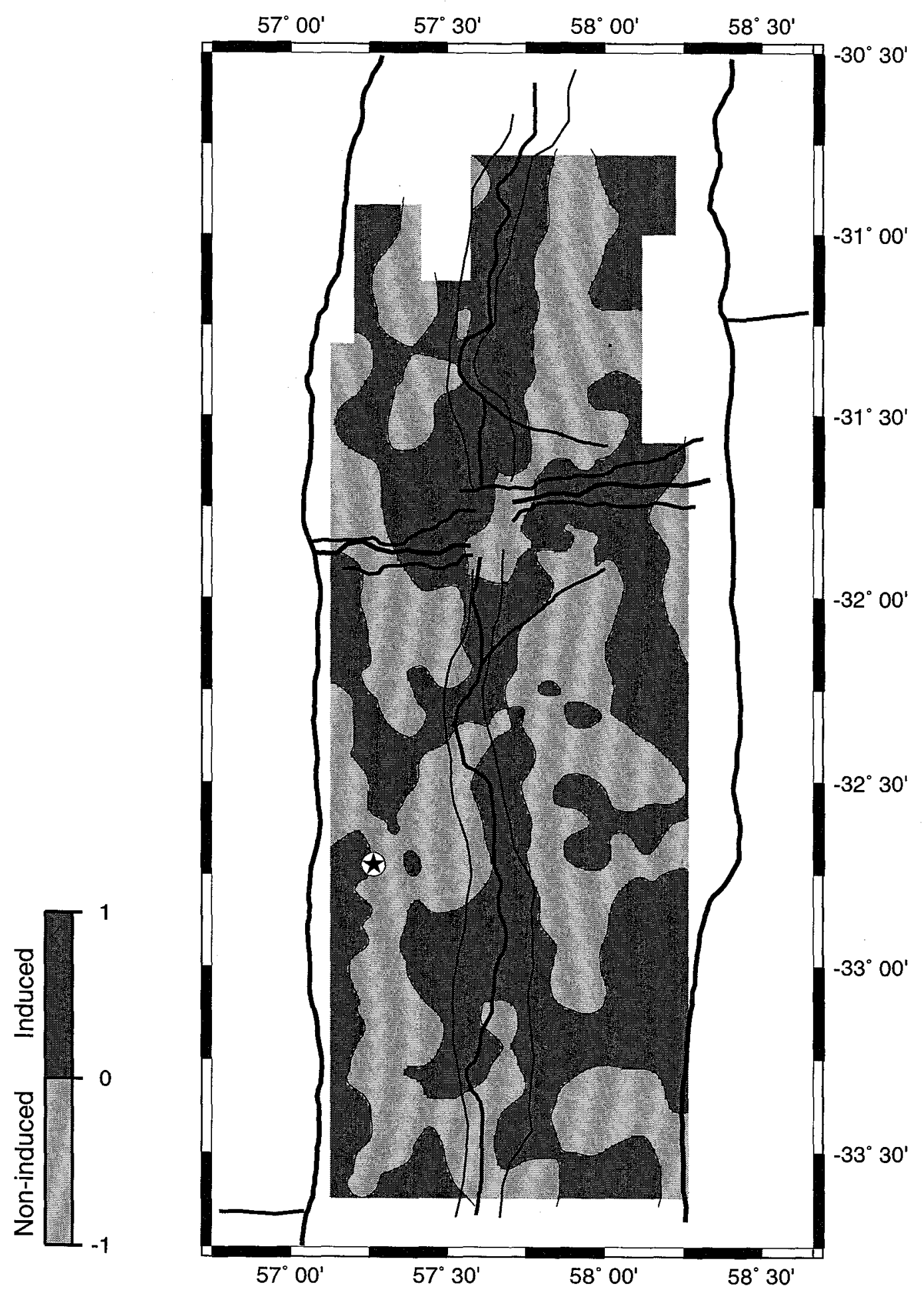


Figure 14. Schematic illustration summarizing the conclusions from this study regarding magnetization amplitudes for upper and lower crustal sources. (a) Apparent magnetization expected along axis, defined as the magnetization due to variations in source layer thickness alone, assuming the along-isochron magnetization intensity is uniform. Shaded line denotes the magnetization contribution from the upper crust, solid line denotes the contribution from the lower crust, and dotted line denotes their sum. (b) Same as in Figure 14a but for along-isochron profiles off axis. The magnetization of the lower crust has not changed while that of the upper crust has decayed dramatically relative to its on-axis value. (c) Crustal model assumed for Figures 14a-b. The crust is depicted with a true vertical scale, and incorporates a seafloor relief of $1 \mathrm{~km}$, an upper crustal thickness of $1.5 \mathrm{~km}$, and a lower crustal thickness of $1.5 \mathrm{~km}$ at the segment endpoints and $3 \mathrm{~km}$ at the segment center. White line within the upper crustal layer marks the base of the extrusive crust, assumed to be $0.5 \mathrm{~km}$ thick. 
a)

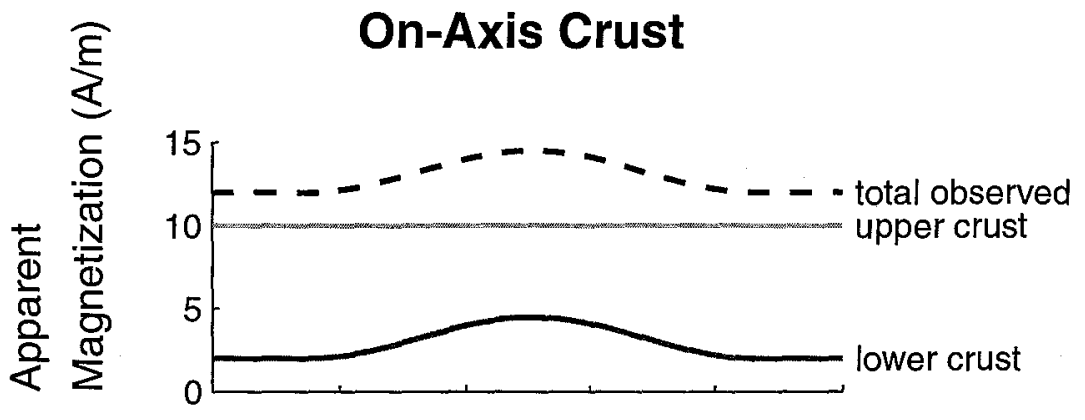

b)

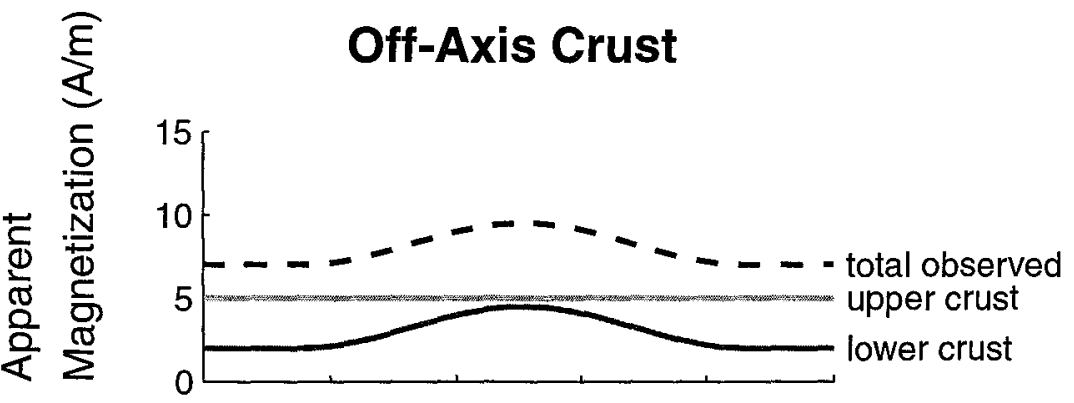

c)

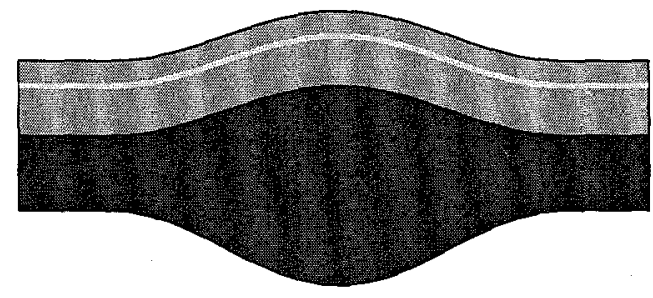

Upper crust

Lower crust 


\section{CHAPTER 4}

\section{Evidence from Morphology and Gravity Data for Asymmetric Crustal Structure across the Southwest Indian Ridge at $56^{\circ} 45^{\prime}-58^{\circ} 40^{\prime} \mathrm{E}$}

Abstract. We conducted a detailed geophysical study of the Southwest Indian Ridge at $56^{\circ} 45^{\prime}-58^{\circ} 40^{\prime} \mathrm{E}$ and from the ridge axis to $25 \mathrm{Myr}$ old crust on both flanks. The survey covered the Atlantis II and Novara fracture zones, a $15 \mathrm{~km}$ offset non-transform discontinuity, and two intervening ridge segments. Seafloor spreading has been highly asymmetric since at least $25 \mathrm{Ma}$, with half-rates of 8.5 and $5.5 \mathrm{~km} / \mathrm{Myr}$ on the Antarctic (south) and African plates (north), respectively. We obtained mantle Bouguer (MBA) and residual mantle Bouguer anomalies (RMBA) by removing from free-air gravity the attractions of seafloor topography, a reference crust, and theoretically predicted effects of lithospheric cooling. Models of relative crustal thickness variations were calculated by downward continuation of the RMBA to the crust-mantle interface. The results of the analysis reveal a single, large-amplitude $(\sim 40 \mathrm{mGal})$ mantle Bouguer gravity low centered approximately midway between the Atlantis II and Novara fracture zones flanking the ridge segments. This result, together with morphology, magnetic, and numerical models of mantle thermal structure suggest that a single region of mantle 
upwelling may exist beneath the two segments, and that the dominant wavelength of upwelling is controlled by the distance between the fracture zones ( 140 km apart), neglecting the smaller non-transform discontinuity. On the south flank of both segments, a relatively normal pattern of crustal production existed between $21-12 \mathrm{Ma}$, with thicker model crust beneath the midpoints of each segment than beneath the segment offsets. Crustal production was subsequently distupted by the uplift of an anomalously long and wide oceanic core complex (Atlantis Bank) between 12-9 Ma on the south flank of the western segment and by a propagating rift between 5.5-3 Ma on both flanks of the eastern segment. A region of $25 \%$ thicker model crust extends over the majority of the north flank of the eastern segment relative to the conjugate south flank. Seafloor morphology is also asymmetric across the segment, with rougher seafloor on the faster-spreading south flank (rms amplitude of $307.2 \mathrm{~m}$ ), and smoother seafloor on the slower-spreading north flank (rms amplitude of $133.7 \mathrm{~m}$ ). The observation of high amplitude abyssal hills on the faster south flank is opposite to the global inverse correlation between abyssal hill height and spreading rate. The asymmetric morphology and model crustal thickness may derive from excess crustal production on the north flank or excess crustal extension on the south flank. Alternatively, a north-south variation in mantle temperature and/or density may explain the observed asymmetries. 


\section{Introduction}

At the Mid-Atlantic Ridge (MAR), bathymetry and free-air gravity data show that transform and non-transform discontinuities divide the ridge axis into segments with lengths of 10-100 km [Sempéré et al., 1993], in response to a buoyant mantle upwelling and melt focusing [Whitehead et al., 1984; Crane, 1985; Lin et al., 1990; Magde and Sparks, 1997] or lithospheric faulting [Mutter and Karson, 1992] at each segment. The locus of a mantle diapir or melt focusing beneath an individual segment is inferred from systematic variations in bathymetry, mantle Bouguer gravity anomaly (MBA), and seismic crustal thickness. MBA is typically more negative at segment midpoints compared to segment offsets, and the along-axis location of a relative MBA low or "bull's-eye" is indicative of thickened crust [e.g., Tolstoy et al., 1993] or lower density mantle associated with the rising mantle or melt diapir [Lin et al., 1990]. Relative MBA lows are observed at nearly all surveyed segments of the MAR [e.g., Detrick et al., 1995; Thibaud et al., 1998]. At the Southwest Indian Ridge (SWIR), however, the correlation between individual ridge segments and individual MBA bull's-eyes appears to be less systematic. For example, along the SWIR between $15^{\circ}-25^{\circ} \mathrm{E}, \mathrm{MBA}$ bull's-eyes are weakly developed over only a few of the 14 surveyed segments and absent over the remaining segments [Grindlay et al., 1998]. The association between individual 
segments and discrete MBA lows is more clear between $49^{\circ}$ and $61^{\circ} \mathrm{E}$ on the SWIR [Rommevaux-Jestin et al., 1997; Cannat et al., 1999], where crustal accretion seems to resemble that at the MAR.

Non-transform discontinuities (NTD) at both the MAR and SWIR are much more abundant than transform offsets, suggesting that NTDs are fundamental structural boundaries of individual accretion cells. Non-transform offsets are characteristically unstable, tending to migrate along the ridge axis through time [Rona, 1976; Carbotte et al., 1991; Mendel et al., 1997; Tucholke et al., 1997]. Because NTDs are often shorter than transform faults, they have lesser influence on the mantle thermal regime. A critical issue in the effects of NTDs on mantle thermal structure is how deeply non-transform offset zones penetrate the lithosphere. If NTDs penetrate deeply enough to depress mantle isotherms and thus the top of the melting column, they may partition the mantle beneath the ridge into individual spreading cells in a similar manner as transform offsets. On the other hand, if NTDs extend only to the base of the crust and if mantle upwelling is strongly buoyancy driven, rising mantle diapirs or focused melt may be unperturbed by such surficial features.

In this study we investigate variations in morphology, gravity anomalies, and gravity-derived model crustal thickness at two ridge segments on the ultra-slow spreading 
SWIR to investigate the evolution of crustal structure and tectonic segmentation since 25

Ma. The data derive from two cruises that together obtained the most extensive off axis gravity survey that exists for the SWIR. Magnetic and topography data show that segments and discontinuities in the study area are similar to those on the central and northern MAR [e.g., Hosford, 2001] and thus that direct comparisons between the two ridge systems are reasonable.

\section{Geologic Setting}

The Southwest Indian Ridge between $56^{\circ} 45^{\prime} \mathrm{E}$ and $58^{\circ} 40^{\prime} \mathrm{E}$ consists of two spreading segments and three discontinuities (Figure 1a). The Atlantis II fracture zone at the western edge of the study area offsets the SWIR plate boundary by $200 \mathrm{~km}$, or $\sim 25$ Myr, in a left lateral sense. The Novara fracture zone near the eastern edge of the survey area offsets the SWIR by $50 \mathrm{~km}(7 \mathrm{Myr})$ also left-laterally. The two spreading segments, which are identified as AN-1 and AN-2 [Hosford, 2001], are separated by a $15 \mathrm{~km}$ (2 Myr) offset non-transform discontinuity. Unlike many non-transform offsets at the MAR and SWIR that change length and migrate along axis [e.g., Sempéré et al., 1995; Mendel et al., 1997; Tucholke et al., 1997], the NTD between AN-1 and AN-2 has been remarkably stable during the past $25 \mathrm{Myr}$. Both the offset and along-axis position of this 
NTD are nearly constant, indicating that the NTD may be just as stable as the adjacent Atlantis II and Novara fracture zones [Hosford, 2001]. Seafloor spreading has been perpendicular to the axis but asymmetric in the last $25 \mathrm{Myr}$, with a consistent halfspreading rate of $8.5 \mathrm{~km} / \mathrm{Myr}$ to the south and $5.5 \mathrm{~km} / \mathrm{Myr}$ to the north at both segments [Dick et al., 1991; Hosford, 2001]. Such prolonged asymmetry is not commonly observed along the mid-ocean ridge system; rather, asymmetric accretion tends to average out over time scales of more than a few million years [Stein et al., 1977; Carbotte et al., 1991].

A secondary discontinuity is observed in the bathymetric data within segment AN-2 as V-shaped fabric that is symmetric about the ridge axis (Figure 1a). This feature was interpreted by Hosford [2001] as the scar of an intra-segment, propagating rift that created a zone of tectonically disturbed seafloor and widened the distance between magnetic anomalies. This feature propagated westward from the western end of segment AN-2 at the trace of the NTD to the segment midpoint between 5.5 and $3 \mathrm{Ma}$.

The morphology of the axial rift valley and flanking seafloor of the two segments is described in detail by Hosford [2001] and briefly summarized here. The western ridge segment, $\mathrm{AN}-1$, is $48 \mathrm{~km}$ long and trends east-northeast from its intersection with the Atlantis II fracture zone to the NTD (Figure 1a). Axial depths vary by $\sim 1300 \mathrm{~m}$ along 
strike, from $5000 \mathrm{~m}$ at the western nodal deep, to $3700 \mathrm{~m}$ at the segment center, to 4300 $m$ at the NTD. A ridge composed of eight prominent volcanoes marks the primary locus of volcanic activity within the axial valley, which forms an hourglass shape in plan-view (Figure 1a and Plate 2 in Hosford [2001]). Seafloor on the south flank of AN-1 is consistently elevated and has strongly contrasting morphology compared to conjugate seafloor on the north flank. On the south flank, eight inside-corner massifs lie within a 10-20 km wide corridor adjacent to the active portion of the Atlantis II fracture zone (Figure 1a). A series of curvilinear ridges extend from these massifs to the trace of the NTD between the south wall of the axial valley and $32^{\circ} 25^{\prime}$ S. Seafloor on the north flank, in contrast, slopes gently downward from subdued rift mountain terrain near the NTD trace and segment midpoint to the inactive portion of the fracture zone (Figure 1a).

The eastern ridge segment, AN-2, spans $75 \mathrm{~km}$ from the NTD to the Novara fracture zone (Figure 1a). As at AN-1, the rift valley of $\mathrm{AN}-2$ also has an hourglass shape. Axial depths vary from $5300 \mathrm{~m}$ at the nodal deep of the Novara fracture zone to $3600 \mathrm{~m}$ at the segment center, and the neovolcanic zone consists of 31 volcanoes on the axial valley floor (Figure 1a and Plate 2 in Hosford [2001]). Off axis, rugged rift mountains flank $\mathrm{AN}-2$ to the south while relatively flat-lying seafloor is observed to the 
north (Figure 1a). Near the Novara fracture zone, elevated inside-corner terrain lies north of the ridge axis while deeper outside-corner terrain lies to the south.

The structure of the lower crust in the study area is inferred from three independent data sources - magnetics, seismic refraction, and Ocean Drilling Program (ODP) drill holes. The most indirect of these is the magnetic data collected coincidentally with the gravity data. Following pre-processing and inversion for crustal magnetization, Hosford [2001] find that axial magnetization varies from high values at segment centers to low values at segment ends, in contrast to the opposite trend often observed at the MAR [e.g., Grindlay et al., 1992]. If variations in iron and titanium content are small along strike, the axial magnetization pattern may be explained by a crustal model consisting of uniformly magnetized, constant thickness upper crust underlain by uniformly magnetized, lower crust that is $2-2.5 \mathrm{~km}$ thicker at the segment midpoint than at the distal ends [Hosford, 2001]. Seismic experiments also find evidence for a variable thickness lower crust along a seismic refraction line that trends parallel to the AN-1 rift valley on $\sim 12 \mathrm{Myr}$ old crust [Muller et al., 2000]. The sense of thinning, however, is opposite to that inferred from the axial magnetization. Beneath Atlantis Bank, which lies in a segment-end setting, seismic layer 3 is $3 \mathrm{~km}$ thicker than beneath the segment center to the east, although the ray coverage beneath Atlantis Bank is 
extremely poor and thus the results are not reliable. The most detailed information on the lower crust in the study area comes from ODP Hole 735B, a $1.5 \mathrm{~km}$ deep hole on Atlantis Bank drilled on legs 118 [Von Herzen and Robinson, 1991] and 176 [Dick et al., 1999]. Both drilling and subsequent submersible studies show that Atlantis Bank consists mainly of gabbro and serpentinized peridotite [Kinoshita et al., 2001].

\section{Data Sources}

The bathymetry and gravity data analyzed in this study derive principally from two JAMSTEC cruises, one in October-November 1998 on R/V Yokosuka [Kinoshita et al., 2001] and one in September 2000 on R/V Kairei [Arai et al., 2001]. Underway bathymetry, gravity, and magnetics data were collected on the two cruises along track lines oriented mostly perpendicular to the spreading center and spaced between 1.5 and 7 km apart (Figure 1b) (see Hosford [2001] for details on the multibeam systems and track coverage). Geophysical data from a cruise on R/V Conrad (RC2709 cruise) in 1987 [Dick et al., 1991] were added to fill in a narrow gap at the western edge of the study area. Together the three cruises provide nearly $100 \%$ multibeam bathymetry coverage (Figure 1a). 
The gravity field was recorded on $\mathrm{R} / \mathrm{V}$ Yokosuka with a La Coste/Romberg marine gravity meter and on R/V Kairei with a Bodenseewerke KSS-31 marine gravity meter. Data quality was excellent and gravity ties in port before and after both cruises indicated only minor instrument drift. To remove accelerations due to motions of the ship, the raw gravity data were filtered, merged with smoothed navigation, and corrected for Eötvös accelerations. Free-air gravity anomaly (FAA) was then calculated by removing the predicted gravity field from the 1967 international gravity formula. Gravity data from cruise $\mathrm{RC} 2709$ were included to complete the free-air gravity data set.

To check the consistency of free-air gravity data within and among cruises, differences in measured gravity at crossing track lines were examined. Prior to the application of any correction, the mean error for 1360 crossovers was $-1.1 \mathrm{mGal}$, with a standard deviation of $8.9 \mathrm{mGal}$. This crossover analysis showed that the RC2709 data were shifted by $-11 \mathrm{mGal}$ relative to the two recent cruises. After applying a constant shift of $11 \mathrm{mGal}$ to the RC2709 data, the standard deviation of all crossover values decreased to $7.4 \mathrm{mGal}$. Because we are interested in gravity variations on the order of 10 mGal, two additional correction techniques were used: (1) a track-by-track examination to remove duplicate tracks and those with obviously bad navigation; and (2) a leastsquares, crossover-error minimization calculation, following the method of Prince and 
Forsyth [1984]. The final, corrected data set had a standard deviation of $4.4 \mathrm{mGal}$ for 1048 crossovers. Some of this error likely derives from the large gravity gradients over Atlantis Bank, where $\sim 50 \%$ of the crossovers occur. To construct a free-air gravity map, the corrected data set was gridded with a minimum curvature algorithm [Wessel and Smith, 1991] at a node spacing of $1 \mathrm{~km}$.

\section{Gravity Analysis}

The free-air gravity anomaly, shown in Figure 2a, strongly reflects seafloor topography. FAA values are high over shallow features such as Atlantis Bank and other inside-corner massifs and low over deep features such as the transform valleys and the nodal deeps at the ridge-transform intersections. To reveal the more interesting subseafloor structure in the observed gravity signal, the predictable effects of a simple reference crustal model are removed from the FAA. This calculation, or mantle Bouguer correction, follows the method of Prince and Forsyth [1988] and Kuo and Forsyth [1988] in assuming a reference crust of constant thickness and constant density contrasts across the seafloor and Moho interfaces. We also use limited independent seismic constraints on the crustal thickness and ODP drill hole data on seafloor density contrast to calibrate the mantle Bouguer calculations. Both seismic [Muller et al., 1997; Muller et al., 2000] 
and rare earth element inversion [Muller et al., 1997] results yield a mean crustal thickness of $\sim 4 \mathrm{~km}$ in several locations on the flanks of segment AN-1. Data on seafloor density is derived from mini-core samples and in situ logging at the top of ODP Hole 735B. The uppermost layers average $2900 \mathrm{~kg} / \mathrm{m}^{3}$ [Dick et al., 1999], yielding a seafloor density contrast of $1870 \mathrm{~kg} / \mathrm{m}^{3}$ (assuming seawater density of $1030 \mathrm{~kg} / \mathrm{m}^{3}$ ). However, because gabbro crops out at the seafloor on Atlantis Bank, the density at the top of Hole 735B likely exceeds that elsewhere in study area where a volcanic upper crustal layer may exist. We thus assume a smaller seafloor density contrast of $1700 \mathrm{~kg} / \mathrm{m}^{3}$ and a Moho density contrast of $600 \mathrm{~kg} / \mathrm{m}^{3}$ in mantle Bouguer calculations, in accord with values used in other studies [e.g., Rommevaux-Jestin et al., 1997]. The gravitational attraction of the seafloor and Moho interfaces is calculated using the approach of Parker [1973]. To avoid edge effects related to the periodicity assumption of the fast Fourier transformation used in the Parker [1973] method, the topography grid is embedded within a grid of seafloor topography derived from satellite gravity data [Sandwell and Smith, 1997]. The resulting topographic and Moho interface corrections are subtracted from the FAA at each observation point to yield the MBA values, which are then gridded in the same manner as the FAA. 
Some earlier mantle Bouguer studies also account for the gravitational effect of a sediment layer [e.g., Prince and Forsyth, 1988]. In our study area, measurements of sediment thickness from seismic reflection profiles exist only for localized regions in the Atlantis II fracture zone valley and across Atlantis Bank [Dick et al., 1991; Muller et al., 2000]. The reflection profiles indicate that measurable sediment thicknesses are restricted to isolated ponds within the fracture zone valley and the trace of the NTD. Muller et al. [2000] estimated that a sediment pond in the fracture zone contained up to $900 \mathrm{~m}$ of sediment, assuming a constant sediment velocity of $1.5 \mathrm{~km} / \mathrm{s}$. Dick et al. [1991], however, estimated that the seismic velocity of pelagic sediment in the transform valley exceeded that of normal pelagic ooze, which would result in a thinner sediment section than estimated by Muller et al. [2000]. Because sediment sections of significant thickness appear to be restricted to isolated areas and because of the absence of information on sediment thickness in the rest of the study area, we decided not to include the sediment effects in mantle Bouguer calculations.

The MBA gravity field (Figure 2b) reflects lateral variations in crustal thickness, crustal density, and mantle density. To better understand the likely crustal contribution to the $\mathrm{MBA}$, it is desirable to remove predictive components of the mantle density variations. Numerical models show that the effect of lithospheric cooling is the dominant 
contributor to mantle density variations, while mantle compositional changes due to melt extraction might be significant locally [Lin and Phipps Morgan, 1992; Sparks et al., 1993]. In this study the gravitational effect of the cooling lithosphere was estimated using a plate-cooling relation for a lithosphere thickness of $100 \mathrm{~km}$ [Parsons and Sclater, 1977]. In the calculation, a seafloor age grid was constructed based on identifications of magnetic isochrons [Hosford, 2001], which are spaced densely enough to accurately represent the ridge-offset geometry in the study area. The mantle temperature field was then calculated on a 3-D grid consisting of 15 discrete layers from the seafloor to the base of the lithosphere, assuming seafloor and mantle temperatures of $0^{\circ} \mathrm{C}$ and $1300^{\circ} \mathrm{C}$, respectively. Temperature variations within each layer were converted to predicted density variations assuming a coefficient of thermal expansion of $3.4 \times 10^{-5}{ }^{\circ} \mathrm{C}^{-1}$ and a reference mantle density of $3300 \mathrm{~kg} / \mathrm{m}^{3}$. These density variations were then converted to predicted gravity effects on the sea surface (Figure 3a).

We did not use the commonly used passive mantle flow model of Phipps Morgan and Forsyth [1988] in calculating mantle thermal structure because this method is formulated only for symmetric seafloor spreading, which is not the case in our study area. The largest discrepancy between the thermal model of Parsons and Sclater [1977] used in this study and that of Phipps Morgan and Forsyth [1988] occurs at segment 
discontinuities because the plate-cooling formula of Parsons and Sclater [1977] neglects horizontal conduction of heat, which will be most important where young, hot lithosphere abuts old, cold lithosphere at ridge-transform intersections. Predicted lithospheric temperatures near fracture zones based on the Parsons and Sclater [1977] model thus have steeper gradients across the fracture zones than the predictions based on the Phipps Morgan and Forsyth [1988] passive flow technique.

The residual mantle Bouguer anomaly (RMBA) (Figure $3 b$ ) was calculated by subtracting from each MBA observation the thermal correction shown in Figure 3a. These along-track values were then gridded. Signals in the RMBA imply crustal thickness and density variations and/or mantle density variations unaccounted for by the Parsons and Sclater [1977] model. To investigate an end-member case of maximum crustal thickness variability, we calculated the relative crustal thickness variations that are required to explain the RMBA. The calculations were done using the method of Kuo and Forsyth [1988]. The RMBA was downward-continued to the assumed mean Moho depth of $4 \mathrm{~km}$ below the mean seafloor, assuming a Moho density contrast of $600 \mathrm{~kg} / \mathrm{m}^{3}$ and applying a filter with a lowpass cutoff wavelength of $20 \mathrm{~km}$ and a highpass cosine taper of $35 \mathrm{~km}$. The model crustal thickness (Figure $4 \mathrm{a}$ ) is the sum of the crustal 
thickness variations required to explain the RMBA and the $4 \mathrm{~km}$ reference crustal thickness.

Because we neglect sources other than Moho topography to explain the RMBA, the model crustal thickness values in Figure 4a may represent maximum estimates. Caution must be exercised so as not to over interpret the model crustal thickness results. To place bounds on the inferred crustal thickness in places where the crust-mantle density contrast of $600 \mathrm{~kg} / \mathrm{m}^{3}$ may not be appropriate, two additional sets of gravity and crustal thickness calculations were made for density contrasts of: (1) $800 \mathrm{~kg} / \mathrm{m}^{3}$, appropriate for reduced crustal densities caused by faulting and serpentinization within the fracture zones and non-transform offset; and (2) $400 \mathrm{~kg} / \mathrm{m}^{3}$, appropriate for the known density at Atlantis Bank. Most of the results presented below assume a Moho density contrast of $600 \mathrm{~kg} / \mathrm{m}^{3}$. However, where appropriate, a range of crustal thickness values is given from the results obtained utilizing the additional density models.

\section{Results}

\subsection{Regional Variations}

The dominant MBA pattern in the study area is a single, large-amplitude low with a minimum centered approximately midway between the Atlantis II and Novara fracture 
zones (Figure 2b). This quasi-circular bull's-eye is delineated by the $0 \mathrm{mGal}$ contour and is elongated in the spreading direction both south and north of the SWIR plate boundary. The peak-to-trough amplitude of the MBA bull's-eye, $40 \mathrm{mGal}$, is among the largest of the $\sim 20$ ridge segments between the Atlantis II fracture zone and the Rodriguez triple junction [Rommevaux-Jestin et al., 1997; Cannat et al., 1999] and approaches that of robust segments at the MAR [Detrick et al., 1995]. The MBA gravity field near the ridge axis appears not to reflect strongly the shorter-wavelength segmentation geometry of our survey area. On both the north and south flanks of the ridge axis, MBA contours cut across the paleotrace of the non-transform discontinuity (Figure 2b). On the north flank the closed MBA contours extend to the limit of the data coverage, while on the south ridge flank the gravity bull's-eye extends to the southern edge of a large highland $(\sim 10$ Myr old crust) (Figures 1a and 2b). Farther south, MBA contours extend parallel to the trace of the non-transform discontinuity zone. The regional MBA bull's-eye is bisected on both ridge flanks by the scar of a propagating rift (white dashed lines in Figure $2 \mathrm{~b}$ ). The inside-corner corridors of the two transforms have positive MBA signatures. The edge of another gravity bull's-eye is observed in the northeastern corner of the survey area centered on the segment ("NM-1") east of the Novara fracture zone (Figure 2b). 
Results of Rommevaux-Jestin et al. [1997] and Cannat et al. [1999] show that the amplitude of this MBA bull's-eye is similar to that at segment AN-2.

The predicted gravitational effect of mantle density variations, shown in Figure 3a, illustrates the long wavelength effect created by cooling and thickening the lithosphere off axis. The small offset NTD between segments AN-1 and AN-2 is not observed to have a strong gravitational signal associated with the predicted mantle thermal structure. Instead, the shape of the axial thermal correction reflects the overall east-northeast trend of the plate boundary between the fracture zones (Figure 3a). This age-based thermal correction also reflects the asymmetry in mantle thermal structure that results from the different half spreading rates across the ridge axis. The across-axis gradient of the thermal correction is predicted to be steeper on the slower spreading north flank than on the faster spreading south flank (Figure 3a).

The residual gravity anomaly calculated using this thermal correction ranges between -30 and $30 \mathrm{mGal}$ in amplitude (Figure $3 \mathrm{~b}$ ), nearly half the variation of the MBA. Since the long-wavelength trend in the MBA was removed by subtracting out the effects of lithospheric cooling, the resultant RMBA better reflects shorter-wavelength structure in the gravity field. The most distinctive feature of the RMBA map is an oval-shaped region of low residual gravity on the north flank of AN-2. The western boundary of this 
feature abuts the paleotrace of the NTD, and the eastern boundary is close to the insidecorner topography adjacent to the Novara fracture zone. The southern boundary of the RMBA low coincides with the wake of the propagating rift (Figure 3b). The conjugate trace of the propagator on the south flank of AN-2 also bounds the young side of a relative $\mathrm{RMBA}$ low.

The ridge axis discontinuities in the survey area are generally associated with positive residual gravity (Figure 3b). A circular RMBA high is centered over the presentday NTD and over its paleotrace south of $32^{\circ} 45^{\prime}$ S, where the MBA appeared to be correlated with the paleotrace of the NTD (Figure 2b). Bands of high residual gravity are observed at both transform offsets, but differ in geometry: a ribbon of high residual gravity is confined to the inside-corner corridor at the Atlantis II fracture zone, whereas a strip of positive RMBA at the Novara fracture zone extends over both the inside and outside corners.

Model crustal thickness values required to explain the RMBA gravity signal range between 0.5 and $5.5 \mathrm{~km}$ (Figure 4a). As expected, regions of relative RMBA highs correspond with relatively low model crustal thickness values, while regions of low residual gravity coincide with regions of relatively thick model crust. The thinnest model crust $(0.5-2.0 \mathrm{~km})$ is associated with the inside-corner corridors and the present day non- 
transform discontinuity (Figure 4a). Model crustal thickness values in these locations are $0.2-0.8 \mathrm{~km}$ larger when a Moho density contrast of $800 \mathrm{~kg} / \mathrm{m}^{3}$ is used. The thickest model crust (4.0-5.5 km) occurs on the north flank of segment AN-2, corresponding to the large region of low RMBA gravity (Figure 3b). To better illustrate regional patterns of inferred crustal thickness variations, the $3.5 \mathrm{~km}$ contour is used to delimit "normal" thickness crust (dark shading, Figure 4b); areas that fall outside the $3.5 \mathrm{~km}$ contour are assumed to be anomalously thin (light shading, Figure 4b).

5.1.1. Segment AN-1 south. Between 21 and $\sim 12.2 \mathrm{Ma}$, model crust emplaced at the segment midpoint was consistently thicker relative to that at either segment end (Figure 4b). Between $\sim 12.2$ and $6.2 \mathrm{Ma}$, this pattern reversed, with thicker model crust located beneath the Atlantis II transform and the NTD and thinner model crust located beneath the inside corner and segment midpoint. During this anomalous period of crustal production, three major tectonic events occurred on the south flank of segment AN-1: (1) the emplacement of Atlantis Bank within the inside-corner corridor (13 to 9.5 Ma), (2) the shortening of the segment by $10 \mathrm{~km}(9.4$ to $6.2 \mathrm{Ma})$, and (3) the widening of the Atlantis II fracture zone valley via the formation of a median tectonic ridge $(\sim 11.5 \mathrm{Ma})$. Since 6.2 Ma, regions of relatively thin model crust extend over the length of the 
segment, except for a brief time (4.9-2.1 Ma) when model crust of "normal" thickness formed at the NTD (Figure 4b).

5.1.2. Segment AN-1 north. Inferred crustal thickness patterns are not systematic on the north flank of AN-1. Irregularly shaped regions of "normal" model crust are observed near the outside corner between $\sim 19.5$ and 11.4 Ma and in isolated patches near the NTD (Figure 4b). The remainder of the segment has model crustal thicknesses of less than $3.5 \mathrm{~km}$.

5.1.3. Segment AN-2 south. Between 24 and $\sim 19.5 \mathrm{Ma}$, model crust of "normal" thickness extended from the segment midpoint to the Novara fracture zone and relatively thin model crust was emplaced near the NTD (Figure 4b). Crustal production then followed a consistent pattern of thicker model crust at segment midpoints relative to segment ends until 12.2 Ma, the same time when this systematic pattern ceased at $\mathrm{AN}-1$. Model crustal thickness then decreased below $3.5 \mathrm{~km}$ over the entire segment (except for an isolated patch between 10.3-9 Ma) until $\sim 6.5 \mathrm{Ma}$. The largest model crustal thickness at $\mathrm{AN}-2$ was produced between $\sim 6.5$ and $5 \mathrm{Ma}$ between the NTD and the segment midpoint, and this region of relatively thick crust is associated with the shallow topography of the rift mountains (Figures $1 \mathrm{a}$ and $4 \mathrm{~b}$ ). The spatial coincidence between the scar of the propagating rift and the northern boundary of normal thickness model 
crust (Figure 4) suggests that normal crustal production ceased during the westward migration of the propagator. Inferred crustal thickness values have remained low since the propagation event ended $3 \mathrm{Ma}$.

5.1.3. Segment AN-2 north. The north flank of segment AN-2 is underlain by normal to thick model crust between the NTD and the western edge of the inside-corner corridor at all crustal ages (Figure 4b). Unlike the conjugate south flank, where normal crustal production ceased during and after the propagation event, crustal production on the north flank of AN-2 appears to have been unaffected by the propagating rift. As expected for inside-corner settings, the inside corner adjacent to the Novara fracture zone is underlain by relatively thin model crust.

\subsection{Axial Variations}

Along both AN-1 and AN-2, MBA values are relatively high at segment offsets where seafloor is deep and relatively low at segment centers where seafloor is shallow (Figures $5 \mathrm{a}$ and $5 \mathrm{~b}$ ). The most negative axial gravity value at segment AN-1 occurs at the shallowest depth point, while the MBA minimum at segment AN-2 is displaced 10 $\mathrm{km}$ west of the shallowest seafloor. The along-axis discrepancy between the most negative $\mathrm{MBA}$ value and the shallowest seafloor at $\mathrm{AN}-2$ is better understood by 
examining the regional gravity field (Figure $2 b$ ), which shows that the most extreme axial MBA value at segment AN-2 actually corresponds to the center of the regional bull'seye. The MBA predicted by the mantle thermal model (dashed line, Figure 5a) along axis differs considerably from the observed axial MBA in that it does not mimic the shorter wavelength segmentation structure of the segments.

Inferred crustal thickness values along axis at both segments generally follow the expected trends, with relatively thinner crust at segment offsets than at segment midpoints (Figure 5c). However, model crustal thickness values are not symmetric about the segment center at either segment. The crust thins at AN-1 from a maximum of nearly $4 \mathrm{~km}$ at the Atlantis II transform to a minimum of $0.5 \mathrm{~km}$ approaching the NTD. When a Moho density contrast of $800 \mathrm{~kg} / \mathrm{m}^{3}$ is used, the model crust is $3.8 \mathrm{~km}$ thick at the Atlantis II nodal deep and $1.2 \mathrm{~km}$ at the NTD. At the midpoint of AN-1, a local crustal thickness maximum of $3 \mathrm{~km}$ correlates with the shallowest depth and most negative MBA along the segment. At AN-2, the model crustal thickness mimics the axial MBA nearly perfectly, with the maximum crustal thickness of $4 \mathrm{~km}$ coincident with the location of the most negative MBA. The minimum crustal thickness of $0.8 \mathrm{~km}$ occurs not at the intersection with the Novara transform but instead is displaced $18 \mathrm{~km}$ west of the nodal deep. Inferred crustal thickness at the Novara ridge-transform intersection is $2.2 \mathrm{~km}$. 
When a Moho density contrast of $800 \mathrm{~kg} / \mathrm{m}^{3}$ is used, the model crust is $2.4 \mathrm{~km}$ thick in this location.

Figure 6 presents a compilation of segment length and axial Bouguer gravity variation ( $\triangle \mathrm{MBA}$ in Figure 5a) for the MAR [Lin et al., 1990; Detrick et al., 1995] and

for the SWIR [Grindlay et al., 1998; Cannat et al., 1999], including segments AN-1 and AN-2 from this study. At the MAR, $\triangle \mathrm{MBA}$ correlates with segment length along a linear trend with a slope of $0.45 \mathrm{mGal} / \mathrm{km}$ [Detrick et al., 1995]. The correlation between segment length and $\triangle \mathrm{MBA}$ is poorer in general at the SWIR, but Figure 6 shows that segments AN-1 and AN-2 lie close to the linear trend defined for the MAR by Detrick et al. [1995]. This observation is consistent with the conclusion by Hosford [2001] from morphology and magnetic data that crustal accretion at AN-1 and AN-2 appears to occur in a similar manner as at the central and northern MAR.

\subsection{Spatial and Temporal Variations}

To investigate regional trends in MBA and inferred crustal thickness as a function of time, grids of MBA and crustal thickness were sampled on cross-axis profiles at the midpoints and endpoints of segments AN-1 and AN-2. To utilize the most reliable 
information in the calculated gravity and crustal thickness grids, cross-axis profiles are extracted along actual ship tracks (see Figure 4a for profile locations).

Figure 7 illustrates MBA, seafloor depth, and model crustal thickness as a function of crustal age along paleo-midpoints of segments AN-1 and AN-2. The MBA at both segments is generally well predicted by the mantle thermal model based on plate cooling (dashed lines in Figures 7a and d). The plate cooling model also predicts seafloor subsidence that agrees well with the long wavelength trend of the seafloor depth at crustal ages $>3 \mathrm{Ma}$, away from the influence of the dynamically supported axial valleys (dashed lines in Figures $7 \mathrm{~b}$ and e). As suggested in Figure 4, neither model crustal thickness amplitudes nor wavelengths are symmetric about the ridge axes at segment paleomidpoints. Larger inferred crustal thicknesses are observed south of AN-1 and north of AN-2 compared to their respective conjugate flanks (Figures $7 \mathrm{c}$ and $7 \mathrm{f}$ and Table 1). The influence of local tectonic events is highlighted in Figure 7. At AN-1, model crustal thickness at the segment midpoint increased by $1.4 \mathrm{~km}$ and $1.2 \mathrm{~km}$ on the south and north flanks, respectively, during much of the 13-9.5 Ma time period when Atlantis Bank was uplifted (Figure 7c). At AN-2, model crustal thickness at the segment midpoint decreased by $1.1 \mathrm{~km}$ and $0.6 \mathrm{~km}$ on the south and north flanks, respectively, during the 2.5 Myr life span of the propagating rift (Figure 7f). 
Significant variations in model crustal thickness are also observed along crossaxis profiles near the fracture zones. As observed at segment centers the long wavelength trend of the MBA is generally well explained by the assumed thermal structure of the mantle at both segments (Figures 8a and 8d). Seafloor depths, however, differ significantly from the subsidence relations appropriate for the segment midpoints, with seafloor at inside corners consistently elevated and seafloor at outside corners consistently depressed relative to the square-root-of-age relationship (Figures $8 \mathrm{~b}$ and $8 \mathrm{e}$ ). Asymmetric seafloor depth at the inside and outside corners is particularly pronounced at segment AN-1 where the deepest part of the inside corner is more elevated than the shallowest part of the outside corner at all crustal ages (Figure $8 \mathrm{~b}$ and Table 1). Within this inside-corner corridor, inferred crustal thickness generally varies inversely with seafloor depth and the model crust thins beneath the inside-corner highs (Figure 8c). When a density contrast of $400 \mathrm{~kg} / \mathrm{m}^{3}$ is used, the same pattern is observed but the model crust beneath the inside corner is $1.5 \mathrm{~km}$ thinner on average. The inside-corner corridor adjacent to the Novara fracture zone differs markedly from that at AN-1. Inferred crustal thickness remains fairly constant between 20-5 Ma (Figure 8f) and the mean insidecorner crustal thickness is not significantly different (within one standard deviation) from that of the conjugate outside corner (Table 1). When a density contrast of $400 \mathrm{~kg} / \mathrm{m}^{3}$ is 
used, the same pattern is observed but the model crust beneath the inside corner is $1.3 \mathrm{~km}$ thinner on average.

\section{Interpretation}

\subsection{Evidence for a Single "Super Segment" between Atlantis II and Novara}

\section{Fracture Zones}

The single mantle Bouguer gravity low between the Atlantis II and Novara fracture zones suggests that only one major mantle upwelling system exists beneath the two ridge segments. Morphology, magnetic, and modeling data also indicate that segments $\mathrm{AN}-1$ and $\mathrm{AN}-2$ vary in concert, implying that the segments may not be distinguishable within the upwelling mantle. The east-west trending linear topographic ridges south and north of the ridge axis commonly cross the trace of the NTD, exhibiting little or no disruption in structure (Figure 1a; see also Figure 7 in Hosford [2001]). This is most easily observed between the axis and $~ 10 \mathrm{Myr}$ old seafloor, where sediment does not obscure fine-scale basement topography. Intermingling of seafloor created at AN-1 and AN-2 is also observed on the north wall of the present day rift valley [Hosford, 2001]. Magnetic data show that half-spreading rates for the two segments are the same, within error, on both the north and south flanks since at least 20 Ma [Hosford, 2001]. 
The plate boundary geometry in the study area has also remained remarkably stable through time. Except for a $2.5 \mathrm{Myr}$ period when the propagating rift was active, the NTD between segments AN-1 and AN-2 maintained an offset length of $\sim 15 \mathrm{~km}$ and meandered along-axis by less than $20 \mathrm{~km}$ during the past $20 \mathrm{Myr}$ [Hosford, 2001]. Unlike many non-transform discontinuities that exhibit systematic migration patterns along the MAR [Rona, 1976; Schouten et al., 1987], the along-axis wandering of the NTD has not favored a particular direction, and neither segment has lengthened or shortened substantially in the last 20-25 Myr [Hosford, 2001].

Finally, numerical models of passive flow beneath a spreading center with similar geometry [Magde and Sparks, 1997; Hosford et al., 2000] and the mantle thermal model based on plate cooling (Figure 3a) suggest that lithospheric cooling associated with a small-offset discontinuity has little effect on mantle temperature and flow. All of the above evidence indicates that the small offset discontinuity between segments AN-1 and AN-2 may not be sufficient to disrupt a single mantle upwelling system between the Atlantis II and Novara fracture zones.

The inference of a single mantle upwelling system beneath the two ridge segments appears at odds with observed segment-scale variations in bathymetry (Figure $5 \mathrm{~b}$ ), model crustal thickness (Figure 5c), and crustal magnetization (Figure 10b in 
Hosford [2001]). However, crustal architecture is influenced by numerous factors other than the geometry of mantle upwelling, such as the crustal magma plumbing system, the geometry of faults along axis, the frequency of melt injections, and the thickness of the lithosphere. Thus, segment-scale variations in crustal architecture at segments AN-1 and AN-2 may derive from mechanisms within the shallow mantle $(<20 \mathrm{~km}$ deep $)$ and/or crust that partition melt into segment-scale packages. Such partitioning could occur by melt migration along the base of a sloping, impermeable boundary at the top of the melting region [Magde and Sparks, 1997] or via a crustal magma plumbing system that taps melt from the upper mantle. Segment-scale variations can also be created by local tectonic events. During the uplift of Atlantis Bank at the inside corner of AN-1, for example, crustal thickness at the segment midpoint on both flanks increased by $\sim 1.3 \mathrm{~km}$ (Figure 7c), while crust beneath both the inside corner and conjugate outside corner decreased by $\sim 1.5 \mathrm{~km}$ (Figure $8 \mathrm{c}$ ).

\subsection{Crustal Thickness Asymmetry at Segment AN-2}

To assess the magnitude and significance of crustal asymmetry in the study area, MBA and the associated model crustal thickness data from the north flank are plotted against the corresponding south flank values for segment paleo-midpoints at $\sim 2 \mathrm{Myr}$ 
intervals. Figure 9 shows that segments $\mathrm{AN}-1$ and $\mathrm{AN}-2$ differ markedly in mean MBA and model crustal thickness. At segment AN-1, the mean MBA on the north flank is slightly larger than the mean MBA on the south flank through time (Figure 9a), and inferred crustal thickness values are correspondingly lower to the north. However, the mean crustal thickness difference between the two flanks is less than $0.75 \mathrm{~km}$ at all crustal ages (Figure 9c), indicating that magmatic and tectonic processes occur in a symmetric fashion across the ridge axis of segment AN-1. In contrast, the mean MBA north of AN-2 is significantly and systematically more negative than south of AN-2 (Figure 9b), and north flank model crust at the paleo-midpoint of AN-2 is 0.6-1.9 km thicker than south flank model crust through time (Figure 9d).

Segment AN-2 also exhibits contrasting seafloor morphology on the African and Antarctic plates, with significantly rougher seafloor south of the ridge axis than north of the ridge axis (Figures 1a and 7e). To quantify seafloor roughness on the two flanks of AN-2 and to compare the results with those for $\mathrm{AN}-1$ and faster-spreading ridges, we calculate the average standard deviation of bathymetry from a long wavelength trend. All calculations were performed on $60 \mathrm{~km}$ long, equally spaced flow-line profiles at segment midpoints. Figure 10 and Table 2 present root-mean-squared (rms) abyssal hill height as a function of half spreading rate for our calculations (squares, Figure 10) and other 
published data (triangles, Figure 10). Figure 10 shows that the rms abyssal hill height on the faster-spreading south flank is $175 \mathrm{~m}$ larger than that on the slower-spreading north flank, confirming the qualitative observation that seafloor on the south flank of AN-2 appears rougher than seafloor on the north flank. In contrast, abyssal hill heights on the flanks of segment AN-1 are relatively similar (Figure 10). These results acquire further significance when placed within a global context, which shows that the AN-2 results do not follow the global inverse correlation between abyssal hill height and spreading rate [Figure 10 and Malinverno, 1991]. The rms height-spreading rate data for segment AN1 , on the other hand, obeys the general global trend.

The large discrepancy in crustal thickness on the flanks of segment AN-2 can be investigated with two end-member cases: either the crust on the north flank is anomalously thick or the crust on the south flank is anomalously thin. Alternatively, the asymmetric gravity signal across segment AN-2 may instead derive from a north-south variation in mantle temperature and/or density.

\subsubsection{Case 1: Anomalously thick crust on north flank of AN-2. Apparently thick}

crust (thin lithosphere) on the north flank of AN-2 suggests significant off-axis mantle melting or preferential accretion of crustal material to the north. This latter possibility appears unlikely because preferential emplacement of surficial flows to the north requires 
a significantly gentler relief on the northern axial valley wall than on the southern axial valley wall, which is not observed in the present-day morphology (Figure 1a). Off-axis mantle melting may arise from variations in mantle thermal or geochemical structure across the ridge axis. The presence of significantly elevated mantle temperatures beneath the north flank is an unlikely possibility, because the seafloor on the north flank is not shallower than that on the south flank as would be expected, and because there is little difference in the seamount population on the two flanks. Additionally, if the temperature is constant at the base of the mantle melting column, the presence of elevated mantle temperatures on the north flank is inconsistent with numerical models [Phipps Morgan and Forsyth, 1988; Lin and Parmentier, 1989] and the simple plate cooling solution (Figure 3a) that show decreasing mantle temperature with decreasing spreading rate. The presence of a compositional heterogeneity beneath the north flank is an untestable possibility with the currently available data, but isotopic data from the MELT area on the East Pacific Rise $\left(15^{\circ}-19^{\circ} \mathrm{S}\right)$ indicate that an embedded heterogeneity is a likely source of excess melting beneath the Pacific plate [Forsyth et al., 1998].

\subsubsection{Case 2: Anomalously thin crust on south flank of AN-2. Apparently thin crust}

(thick lithosphere) on the south flank of AN-2 suggests significant asymmetry in crustal extension across the ridge axis, with significantly higher degrees of extension on the 
south flank than on the north flank. A quantification of extensional strain on the flanks of AN-2 requires high-resolution side-scan data to accurately map fault scarps. Such a data set is not available for the study area. In general, though, observations at the MAR and East Pacific Rise show that extensional strain is inversely proportional to spreading rate [Carbotte and Macdonald, 1994], a relationship that is opposite to what we infer from the seafloor roughness data. A precedent for extremely asymmetric extension exists in the study area adjacent to the Atlantis II fracture zone, where the massifs within the insidecorner corridor have experienced extreme extension relative to the smooth seafloor within the outside-corner corridor.

\subsubsection{Case 3: Asymmetric mantle temperature/density structure. An alternate} scenario to these end-member cases is that the asymmetric gravity structure at segment AN-2 derives from an asymmetric mantle density structure across the ridge axis. The MELT area of the East Pacific Rise is a region of asymmetric crustal accretion, seafloor subsidence, seamount production, and MBA [Forsyth et al., 1998; Scheirer et al., 1998]. Two of the components in the MBA, crustal thickness and crustal density structure, are constrained by seismic experiments across the rise axis in the MELT area. Analysis of the seismic data shows that both the crustal thickness and the crustal seismic velocity structure (and thus density structure) are very similar beneath the Nazca and Pacific 
plates [Bazin et al., 1998; Canales et al., 1998]. The asymmetric MBA in the MELT area must therefore derive from an east-west variation in mantle temperature or density structure [Canales et al., 1998]. These results, combined with body and surface wave analyses, suggest a center of off-axis upwelling and melt production beneath the Pacific plate [Forsyth et al., 1998]. By analogy with the MELT results, the asymmetric MBA and RMBA across segment $\mathrm{AN}-2$ may derive from cross-axis variation in mantle temperatures and/or densities, with higher mantle temperatures/lower mantle densities on the African plate.

Because all three cases are consistent with each other, the observed asymmetries across segment $\mathrm{AN}-2$ may be explained by any combination of the possibilities discussed above. A seismic refraction line that runs perpendicular to AN-2 and extends a significant distance on each flank would provide crustal thickness and crustal density structure. Such information would help to determine the contribution of each case to the observed gravity.

\section{Conclusions}

We conducted a detailed geophysical survey on both flanks of the Southwest Indian Ridge between the Atlantis II and Novara fracture zones. The survey covered two 
spreading segments and an intervening $15 \mathrm{~km}$ offset non-transform discontinuity between the ridge axis and $25 \mathrm{Myr}$ old seafloor on both the Antarctic and African plates. A sustained period of asymmetric spreading at both ridge segments strongly influences crustal evolution. This long record of crustal accretion helps constrain hypotheses on what controls segmentation at slow-spreading ridges and on the interplay between magmatism and tectonism through time. The principal results from this study include:

1. A single, large amplitude mantle Bouguer gravity low is centered approximately midway between the fracture zones flanking the ridge segments. This observation, together with magnetic data, theoretical predictions of mantle thermal structure, and seafloor morphology, suggests that the two ridge segments are not distinguishable at depth in the mantle. Instead, a single mantle upwelling system supplies melt to the segments and segment-scale variations in inferred crustal structure derive from melt migration and local tectonic events.

2. A significant degree of asymmetry is observed in seafloor structure, residual mantle Bouguer gravity, and inferred crustal structure across the axis of the eastern segment in the study area. On the slower-spreading north flank, seafloor is smoother, residual gravity is lower, and inferred crustal thickness is greater than beneath the fasterspreading south flank. The relationship between the height of abyssal hills and spreading 
rate at this segment is opposite to the global trend of decreased abyssal hill height with increased spreading rate. The asymmetric model crustal thickness structure may derive from excess crustal production on the north flank or excess crustal extension on the south flank. Alternatively, a north-south variation in mantle temperature and/or density may explain the asymmetric gravity structure. Inferred crustal structure on conjugate flanks at the western segment in the study area is more uniform than that at the adjacent segment, and abyssal hill heights on the two flanks follow the expected inverse correlation between abyssal hill height and spreading rate.

3. A propagating rift that was active between 5.5-3 Ma appears to have significantly modified existing crustal structure and influenced subsequent crustal production at the eastern ridge segment. Episodes of relatively robust crustal production on each flank ended when the propagator initiated at the trace of the non-transform discontinuity between the segments. Anomalously low crustal production persists to the present day on the south flank of the segment despite the termination of the propagation event 3 Ma.

4. The uplift of an anomalously long and wide inside-corner massif (Atlantis Bank) between 13-9.5 Ma ended a long-lived period of crustal emplacement characterized by thicker crust at segment midpoints relative to segment ends. Model 
crustal thickness at the location of ODP Hole $735 \mathrm{~B}$ on Atlantis Bank is $1.75 \mathrm{~km}$, or 0.5 $\mathrm{km}$ greater than the $1.5 \mathrm{~km}$ long drill core. Crustal thickness at the drill hole location is reduced if a Moho density contrast appropriate for a gabbroic lower crust is used.

5. The correlation between along-axis mantle Bouguer gravity amplitude and segment length for the two segments is well explained by a linear trend defined for the MAR. This observation is consistent with those from morphology and gravity data that crustal accretion in this region of the SWIR occurs in a similar manner as at the MAR.

Acknowledgements. We thank the Japan Marine Science and Technology Center and the crews of R/V Yokosuka and R/V Kairei for helping to make the geophysics programs so successful. Constructive discussions with Jian Lin, Henry Dick, Maurice Tivey, Hans Schouten, Mark Behn, Jennifer Georgen, and Dan Scheirer are gratefully acknowledged during preparation of this chapter.

\section{References}

Arai, S., H.J.B. Dick, and M.S. Party, Cruise Report MODE 2000, pp. 319, Japan Marine Science Technology Center, 2001.

Bazin, S., H. van Avendonk, A.J. Harding, J.A. Orcutt, J.P. Canales, and R.S. Detrick, Crustal structure of the flanks of the East Pacific Rise: Implications for overlapping spreading centers, Geophys. Res. Lett., 25, 2213-2216, 1998. 
Canales, J.P., R.S. Detrick, S. Bazin, A.J. Harding, and J.A. Orcutt, Off-axis crustal thickness across and along the East Pacific Rise within the MELT area, Science, 280, 1218-1221, 1998.

Cannat, M., C. Rommevaux-Jestin, D. Sauter, C. Deplus, and V. Mendel, Formation of the axial relief at the very slow spreading Southwest Indian Ridge ( $49^{\circ}$ to $69^{\circ} \mathrm{E}$ ), $J$. Geophys. Res., 104, 22825-22843, 1999.

Carbotte, S., S.M. Welch, and K.C. Macdonald, Spreading rates, rift propagation, and fracture zone offset histories during the past 5 my on the Mid-Atlantic Ridge; $25^{\circ}$ $27^{\circ} 30^{\prime} \mathrm{S}$ and $31^{\circ}-34^{\circ} 30^{\prime} \mathrm{S}$, Mar. Geophys. Res., 13, 51-80, 1991.

Carbotte, S.M., and K.C. Macdonald, Comparison of seafloor tectonic fabric at intermediate, fast and super fast spreading ridges: Influence of spreading rate, plate motions, and ridge segmentation on fault patterns, J. Geophys. Res., 99, 13609$13631,1994$.

Crane, K., The spacing of rift axis highs: dependence upon diapiric processes in the underlying asthenosphere?, Earth Planet. Sci. Lett., 72, 405-414, 1985.

Detrick, R.S., H.D. Needham, and V. Renard, Gravity anomalies and crustal thickness variations along the Mid-Atlantic Ridge between $33^{\circ} \mathrm{N}$ and $40^{\circ} \mathrm{N}, J$. Geophys. Res., 100, 3767-3787, 1995.

Dick, H.J.B., J.H. Natland, and D.J. Miller, Proc. ODP, Init. Repts., 176 [CD-ROM], Ocean Drilling Program, Texas A\&M University, College Station, 1999.

Dick, H.J.B., et al., Tectonic evolution of the Atlantis II fracture zone, in Proc. Ocean Drill. Program Scientific Results, edited by R.P. Von Herzen, and P.T. Robinson, pp. 359-398, Ocean Drilling Program, College Station, 1991.

Forsyth, D.W., and M.S. Team, Imaging the deep seismic structure beneath a mid-ocean ridge: The MELT experiment, Science, 280, 1215-1218, 1998.

Grindlay, N.R., P.J. Fox, and P.R. Vogt, Morphology and tectonics of the Mid-Atlantic Ridge $\left(25^{\circ}-27^{\circ} S\right)$ from Sea Beam and magnetic data, J. Geophys. Res., 97, 6983$7010,1992$.

Grindlay, N.R., J.A. Madsen, C. Rommevaux-Jestin, and J. Sclater, A different pattern of ridge segmentation and mantle Bouguer gravity anomalies along the ultra-slow spreading Southwest Indian Ridge $\left(15^{\circ} 30^{\prime} \mathrm{E}\right.$ to $\left.25^{\circ} \mathrm{E}\right)$, Earth Planet. Sci. Lett., 161, 243-253, 1998.

Hosford, A., Crustal accretion and evolution at slow and ultra-slow spreading mid-ocean ridges, Woods Hole Oceanographic Institution/Massachusetts Institute of Technology Joint Program in Oceanography, Woods Hole, 2001. 
Hosford, A., J. Lin, and R.S. Detrick, Crustal evolution over the last 2 m.y. at the MidAtlantic Ridge $\mathrm{OH}-1$ segment, $35^{\circ} \mathrm{N}, J$. Geophys. Res., in press, 2001.

Hosford, A., M.A. Tivey, and D.K. Smith, Building the crust at the Southwest Indian Ridge, 57-5830' E, Eos Trans. AGU, 81 (48), Fall Meet. Suppl., F1129, 2000.

Kinoshita, H., H.J.B. Dick, and Y.S.S. Party, MODE'98 Leg 4 Cruise Report, pp. 221, Japan Marine Science Technology Center, 2001.

Kuo, B.-Y., and D.W. Forsyth, Gravity anomalies of the ridge-transform system in the South Atlantic between 31 and $34.5^{\circ} \mathrm{S}$ : Upwelling centers and variations in crustal thickness, Mar. Geophys. Res., 10, 205-232, 1988.

Lin, J., and E.M. Parmentier, Mechanisms of lithospheric extension at mid-ocean ridges, Geophys. J. Int., 96, 1-22, 1989.

Lin, J., and J. Phipps Morgan, The spreading rate dependence of three-dimensional midocean ridge gravity structure, Geophys. Res. Lett., 19, 13-16, 1992.

Lin, J., G.M. Purdy, H. Schouten, and J.-C. Sempéré, Evidence from gravity data for focused magmatic accretion along the Mid-Atlantic Ridge, Nature, 344, 627-632, 1990.

Magde, L.S., and D.W. Sparks, Three-dimensional mantle upwelling, melt generation and melt migration beneath segmented slow-spreading ridges, J. Geophys. Res., 102, 20571-20583, 1997.

Malinverno, A., Inverse square-root dependence of mid-ocean-ridge flank roughness on spreading rate, Nature, 352, 58-60, 1991.

Mendel, V., D. Sauter, L. Parson, and J.-R. Vanney, Segmentation and morphotectonic variations along a super slow-spreading center: The Southwest Indian Ridge $\left(57^{\circ} \mathrm{E}\right.$ $\left.70^{\circ} \mathrm{E}\right)$, Mar. Geophys. Res., 19, 505-533, 1997.

Muller, M.R., T.A. Minshull, and R.S. White, Crustal structure of the Southwest Indian Ridge at the Atlantis II Fracture Zone, J. Geophys. Res., 105, 25809-25828, 2000.

Muller, M.R., C.J. Robinson, T.A. Minshull, R.S. White, and M.J. Bickle, Thin crust beneath ocean drilling program borehole $735 \mathrm{~B}$ at the Southwest Indian Ridge?, Earth Planet. Sci. Lett., 148, 93-107, 1997.

Mutter, J.C., and J.A. Karson, Structural processes at slow-spreading ridges, Science, 257, 627-634, 1992.

Parker, R.L., The rapid calculation of potential anomalies, Geophys. J. R. Astron. Soc., 31, 447-455, 1973.

Parsons, B., and J.G. Sclater, An analysis of the variation of ocean floor bathymetry and heat flow with age, J. Geophys. Res., 82, 803-827, 1977. 
Phipps Morgan, J., and D.W. Forsyth, Three-dimensional flow and temperature perturbations due to a transform offset: Effects on oceanic crustal and upper mantle structure, J. Geophys. Res., 93, 2955-2966, 1988.

Prince, R.A., and D.W. Forsyth, A simple objective method for minimizing crossover errors in marine gravity data, Geophysics, 49, 1070-1083, 1984.

Prince, R.A., and D.W. Forsyth, Horizontal extent of anomalously thin crust near the Vema fracture zone from the three-dimensional analysis of gravity data, J. Geophys. Res., 93, 8051-8063, 1988.

Rommevaux-Jestin, C., C. DePlus, and P. Patriat, Mantle Bouguer anomaly along an ultra-slow spreading ridge: Implications for accretionary processes and comparison with results from central Mid-Atlantic Ridge, Mar. Geophys. Res., 19, 481-503, 1997.

Rona, P.A., Asymmetric fracture zones and seafloor spreading, Earth Planet. Sci. Lett., 30, 109-116, 1976.

Sandwell, D.T., and W.H.F. Smith, Marine gravity anomaly from Geosat and ERS 1 satellite altimetry, J. Geophys. Res., 102, 10039-10054, 1997.

Scheirer, D.S., D.W. Forsyth, J.A. Conder, M.A. Eberle, S.-H. Hung, K.T.M. Johnson, and D.W. Graham, Anomalous seafloor spreading of the Southeast Indian Ridge near the Amsterdam-St. Paul Plateau, J. Geophys. Res., 105, 8243-8262, 2000.

Scheirer, D.S., D.W. Forsyth, M.-H. Cormier, and K.C. Macdonald, Shipboard geophysical indications of asymmetry and melt production beneath the East Pacific Rise near the MELT experiment, Science, 280, 1221-1224, 1998.

Scheirer, D.S., K.C. Macdonald, D.W. Forsyth, S.P. Miller, D.J. Wright, M.-H. Cormier, and C.M. Weiland, A map series of the southern East Pacific Rise and its flanks, $15^{\circ} \mathrm{S}$ to $19^{\circ}$ S, Mar. Geophys. Res., 18, 1-12, 1996.

Schouten, H., H.J.B. Dick, and K.D. Klitgord, Migration of mid-ocean-ridge volcanic segments, Nature, 326, 835-839, 1987.

Sempéré, J.-C., et al., The Mid-Atlantic Ridge between $29^{\circ} \mathrm{N}$ and $31^{\circ} 30^{\prime} \mathrm{N}$ in the last 10 Ma, Earth Planet. Sci. Lett., 130, 45-55, 1995.

Sempéré, J.-C., J. Lin, H.S. Brown, H. Schouten, and G.M. Purdy, Segmentation and morphotectonic variations along a slow-spreading center: The Mid-Atlantic Ridge

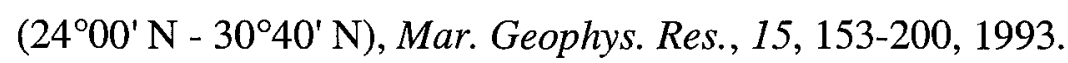

Sparks, D.W., E.M. Parmentier, and J. Phipps Morgan, Three-dimensional convection beneath a segmented spreading center: Implications for along-axis variations in crustal thickness and gravity, J. Geophys. Res., 98, 21977-21995, 1993.

Stein, S., H.J. Melosh, and J.B. Minster, Ridge migration and asymmetric seafloor spreading, Earth Planet. Sci. Lett., 36, 51-62, 1977. 
Thibaud, R., P. Gente, and M. Maia, A systematic analysis of the Mid-Atlantic Ridge morphology and gravity between $15^{\circ} \mathrm{N}$ and $40^{\circ} \mathrm{N}$ : Constraints of the thermal structure, J. Geophys. Res., 103, 24223-24243, 1998.

Tolstoy, M., A.J. Harding, and J.A. Orcutt, Crustal thickness on the Mid-Atlantic Ridge: Bull's eye gravity anomalies and focused accretion, Science, 262, 726-729, 1993.

Tucholke, B.E., J. Lin, M.C. Kleinrock, M.A. Tivey, T.B. Reed, J. Goff, and G.E. Jaroslow, Segmentation and crustal structure of the western Mid-Atlantic Ridge flank, 25 $25^{\prime}-27^{\circ} 10^{\prime} \mathrm{N}$ and 0-29 m.y., J. Geophys. Res., 102, 10203-10223, 1997.

Von Herzen, R.P., and P.T. Robinson, Proc. ODP, Sci. Res., 118, Ocean Drilling Program, Texas A\&M University, College Station, 1991.

Wessel, P., and W.H.F. Smith, Free software helps map and display data, Eos Trans. $A G U, 72,441,1991$.

Whitehead, J.A., Jr., H.J.B. Dick, and H. Schouten, A mechanism for magmatic accretion under spreading centers, Nature, 312, 146-147, 1984. 
Table 1. Bathymetry and Model Crustal Thickness Statistics for Study Area

\begin{tabular}{lcccccccc}
\hline & \multicolumn{2}{c}{ AN-1 North } & \multicolumn{2}{c}{ AN-1 South } & \multicolumn{2}{c}{ AN-2 North } & \multicolumn{2}{c}{ AN-2 South } \\
\cline { 2 - 10 } & SC & OC & SC & IC & SC & IC & SC & OC \\
\hline $\begin{array}{l}\text { Minimum depth } \\
\text { (m) }\end{array}$ & 2709 & 3322 & 2187 & 708 & 2545 & 2023 & 1638 & 3077 \\
Mean depth (m) & 3543 & 4114 & 3949 & 2317 & 3416 & 2983 & 3039 & 4113 \\
$\begin{array}{l}\text { Maximum depth } \\
\text { (m) }\end{array}$ & 4598 & 4718 & 4709 & 4570 & 4572 & 4765 & 4043 & 4815 \\
$\begin{array}{l}\text { Standard deviation } \\
\text { of depth (m) }\end{array}$ & 426 & 314 & 610 & 755 & 490 & 607 & 480 & 387 \\
$\begin{array}{l}\text { Minimum model } \\
\text { crustal thickness } \\
\text { (km) }\end{array}$ & 1.6 & 2.5 & 1.8 & 1.4 & 3.2 & 0.8 & 2.9 & 0.7 \\
$\begin{array}{l}\text { Mean model crustal } \\
\text { thickness (km) }\end{array}$ & 2.9 & 3.4 & 3.3 & 2.6 & 4.6 & 2.4 & 3.6 & 2.6 \\
$\begin{array}{l}\text { Maximum model } \\
\text { crustal thickness } \\
\text { (km) }\end{array}$ & 3.9 & 4.3 & 4.5 & 4.1 & 5.1 & 3.0 & 4.7 & 4.0 \\
$\begin{array}{l}\text { Standard deviation } \\
\text { of model crustal } \\
\text { thickness (km) }\end{array}$ & 0.7 & 0.5 & 0.5 & 0.8 & 0.5 & 0.4 & 0.5 & 0.8 \\
\hline
\end{tabular}


Table 2. Half-spreading Rate and Abyssal Hill Height Statistics

\begin{tabular}{|c|c|c|}
\hline & $\begin{array}{l}\text { Half-spreading } \\
\text { rate }(\mathrm{km} / \mathrm{Myr})\end{array}$ & $\begin{array}{l}\text { Abyssal hill } \\
\text { height (m) }\end{array}$ \\
\hline SWIR, AN-1 North flank ${ }^{1}$ & 5.5 & 275.1 \\
\hline SWIR, AN-2 North flank ${ }^{1}$ & 5.5 & 133.7 \\
\hline SWIR, AN-1 South flank ${ }^{1}$ & 8.5 & 233.2 \\
\hline SWIR, AN-2 South flank ${ }^{1}$ & 8.5 & 307.2 \\
\hline MAR, $25.5^{\circ} \mathrm{N}$, West flank ${ }^{2}$ & 13 & 144.4 \\
\hline SEIR, $41.5^{\circ} \mathrm{S}^{3}$ & 32.5 & 93.5 \\
\hline EPR, $16.5^{\circ} \mathrm{S}$, West flank ${ }^{4}$ & 69 & 55.8 \\
\hline EPR, $16.5^{\circ} \mathrm{S}$, East flank ${ }^{4}$ & 76 & 38.6 \\
\hline
\end{tabular}

${ }^{1}$ Spreading rate data from Hosford [2001]; ${ }^{2}$ Spreading rate and bathymetry data from Tucholke et al. [1997]; ${ }^{3}$ Southeast Indian Ridge spreading rate and bathymetry data from Scheirer et al. [2000]. Half-rate and abyssal hill height on each flank are equal; ${ }^{4}$ East Pacific Rise spreading rate and bathymetry data from Scheirer et al. [1996] 
Figure 1. (a) Bathymetry map of the study area gridded at $500 \mathrm{~m}$ resolution and illuminated from the north. The Atlantis II and Novara fracture zones form the western and eastern boundaries of the study area, respectively. Star marks location of Ocean Drilling Program (ODP) Hole 735B on Atlantis Bank. Solid white lines mark the middle of the fracture zone valleys, the off-axis trace of the non-transform discontinuity between the segments, and the rift valley walls. Shaded dotted line marks a propagating rift. All segment boundaries are from Hosford [2001]. (b) Ship tracks used for gravity data analysis. Thin shaded tracks correspond to cruise R/V Conrad cruise 2709 in 1987, solid lines correspond to a cruise on R/V Yokosuka in 1998, and dashed tracks correspond to a cruise on R/V Kairei in 2000. These tracks do not correspond to the full set of track lines acquired for multibeam bathymetry (see Figure 1 in Hosford [2001]) because they have been culled for crossover analysis and shortened to eliminate spurious gravity values introduced by ships' turns. Star marks location of ODP Hole 735B on Atlantis Bank. 


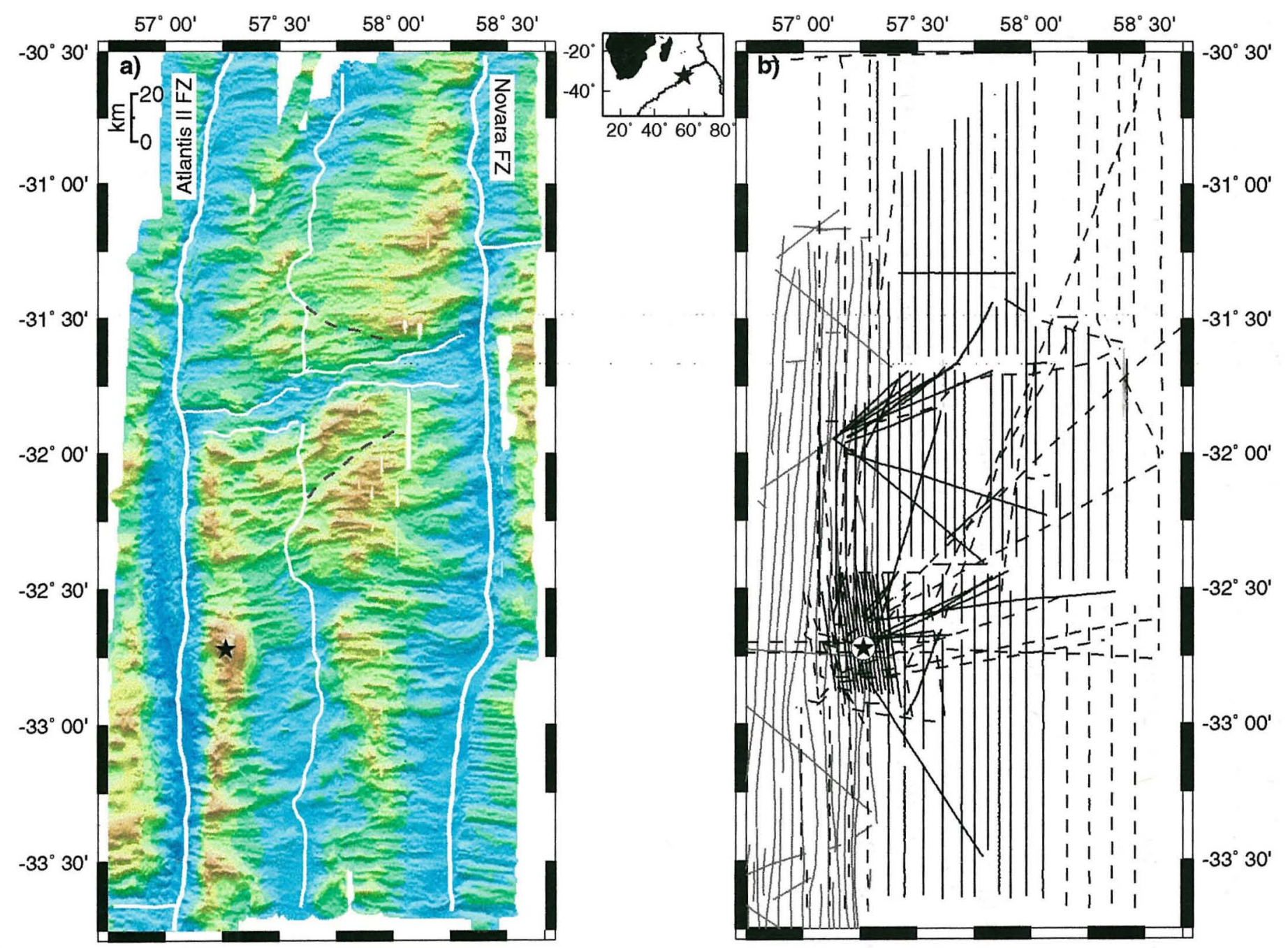


Figure 2. (a) Map of free-air gravity anomaly (FAA). FAA was calculated by subtracting the Eötvös effects and the international gravity formula from the total gravity field at each measurement point. Data were then corrected for crossover errors. All gravity grids are at $1 \mathrm{~km}$ spacing. Contour interval is $20 \mathrm{mGal}$. AN-1 denotes the western segment and AN-2 denotes the eastern segment between the Atlantis II and Novara fracture zones, respectively. White lines are as in Figure 1a. Star marks location of ODP Hole 735B on Atlantis Bank. (b) Map of mantle Bouguer gravity anomaly (MBA). MBA was calculated by removing from each FAA measurement the gravity effects of the seafloor and Moho interfaces, assuming a reference crust of constant thickness $(4 \mathrm{~km})$ and crust and mantle density contrasts of $1700 \mathrm{~kg} / \mathrm{m}^{3}$ and $600 \mathrm{~kg} / \mathrm{m}^{3}$, respectively. Contour interval is $10 \mathrm{mGal}$. The $0 \mathrm{mGal}$ contour defines the regional MBA "bull's-eye." White lines are as in Figure 1a. Star marks location of ODP Hole 735B on Atlantis Bank. 

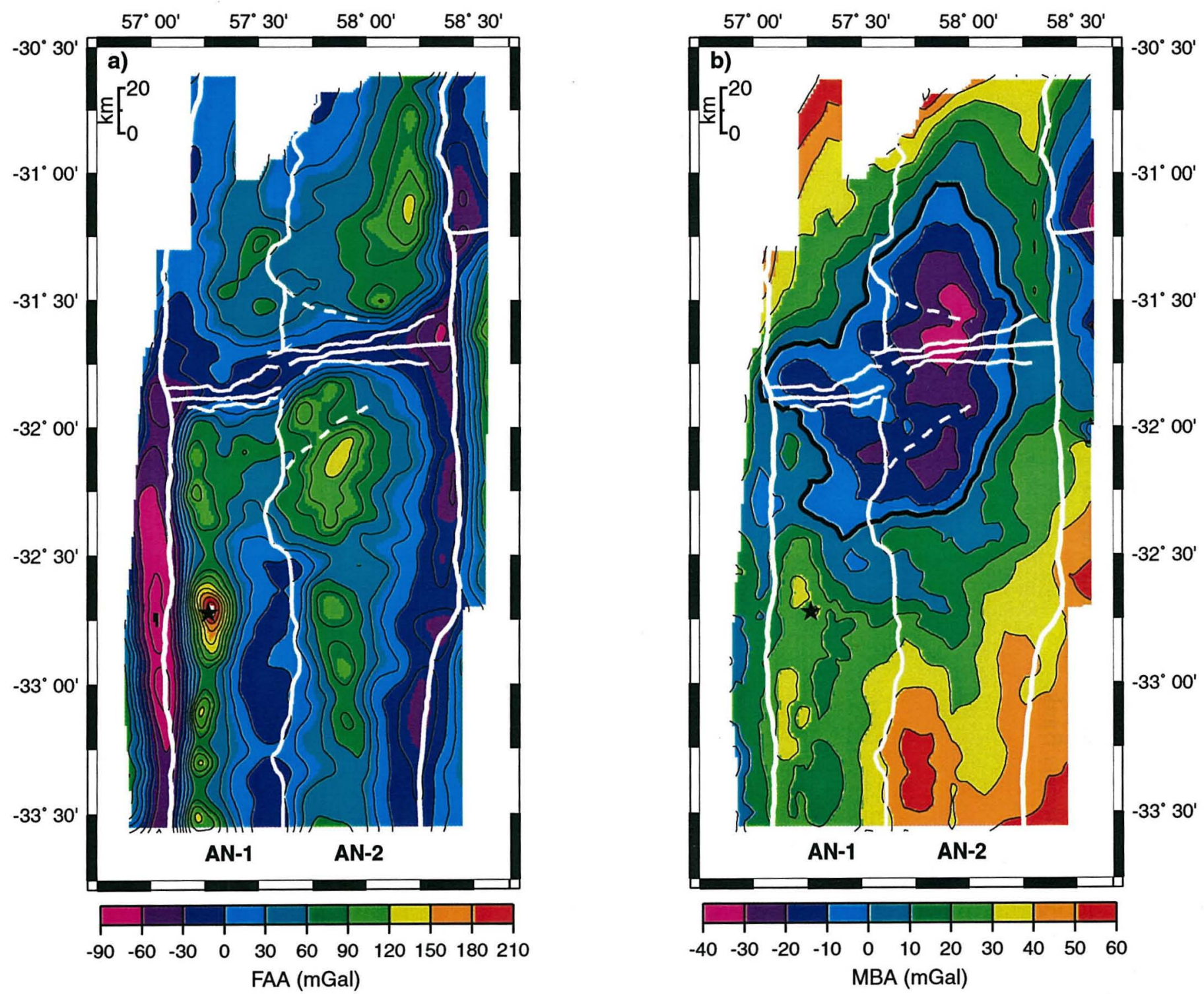
Figure 3. (a) Map of predicted gravity values arising from thermal effects of lithospheric cooling based on the Parsons and Sclater model [1977] (see text for details of calculations). (b) Map of residual mantle Bouguer gravity anomaly (RMBA). RMBA was calculated by removing from each MBA measurement the gravity effects of lithospheric cooling as shown in Figure 3a. The color scale is the same as in Figure $2 \mathrm{~b}$. Contour interval is $5 \mathrm{mGal}$. White lines are as in Figure 1a. Star marks location of ODP Hole 735B on Atlantis Bank. 

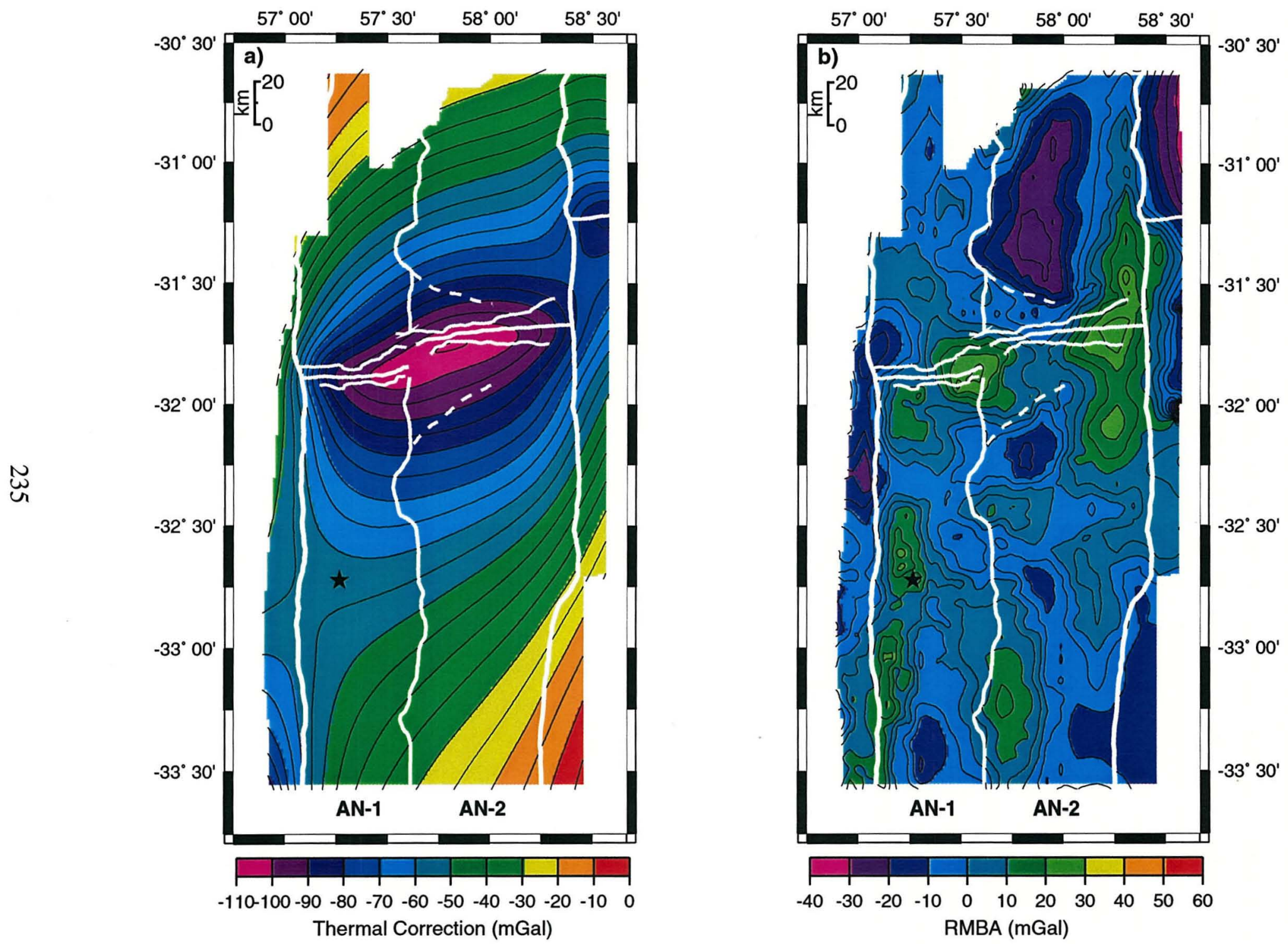
Figure 4. (a) Map of inferred crustal thickness, assuming that all of the RMBA arises from crustal thickness variations. Crustal thickness variations were calculated by downward continuing the RMBA to the base of a $4 \mathrm{~km}$ thick model crust and filtering the signal with a lowpass cutoff wavelength of $20 \mathrm{~km}$ and a highpass cosine taper of $35 \mathrm{~km}$. The model crustal thickness was obtained by adding the $4 \mathrm{~km}$ thick model crust to each relative crustal thickness value. Contour interval is $0.5 \mathrm{~km}$. Solid lines mark track lines used for flow-line analysis in Figures 7-8. White lines are as in Figure 1a. Star marks location of ODP Hole 735B on Atlantis Bank. (b) Inferred crustal thickness map in Figure $4 \mathrm{a}$ with contours to emphasize regions with $>=3.5 \mathrm{~km}$ thick crust (dark shading) and regions with $<3.5 \mathrm{~km}$ thick crust (light shading). Solid lines connect the peaks of magnetic anomalies identified by Hosford [2001], and are labeled with the corresponding crustal age in Myr. White lines are as in Figure 1a. Additional thin white lines bordering the trace of the NTD define the finite width of the NTD zone through time. Star marks location of ODP Hole 735B on Atlantis Bank. 

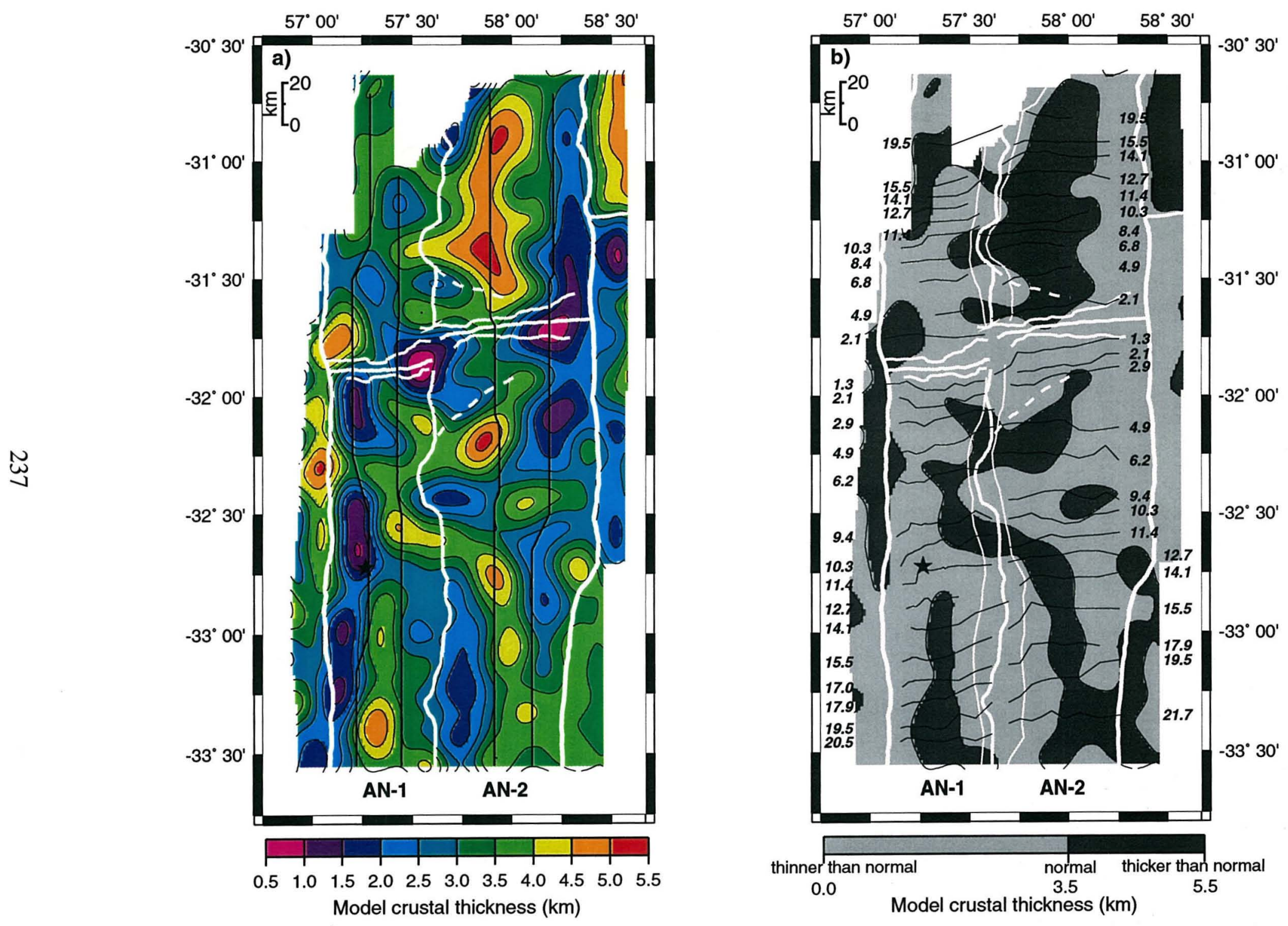
Figure 5. (a) Axial MBA profile, illustrating segment-scale variation. Dashed line is the predicted gravity effect of the mantle thermal structure due to lithospheric cooling. The mean is removed from each profile for comparison. The shaded line illustrates how the variation in axial MBA amplitude ( $\triangle M B A)$ is calculated for Figure 6. (b) Axial depth profile, illustrating the inverse correlation between MBA amplitude and seafloor depth. The shallowest seafloor correlates spatially with the most negative MBA at segment AN1 but is displaced $10 \mathrm{~km}$ east of the most negative MBA at segment AN-2. (c) Model crustal thickness along axis. The anomalously large inferred crustal thicknesses at the Atlantis II nodal deep likely is an artifact of the thermal correction used to calculate the RMBA. In all three panels, the arrows mark the locations of the transform offsets and the shaded box marks the width of the non-transform discontinuity zone. 

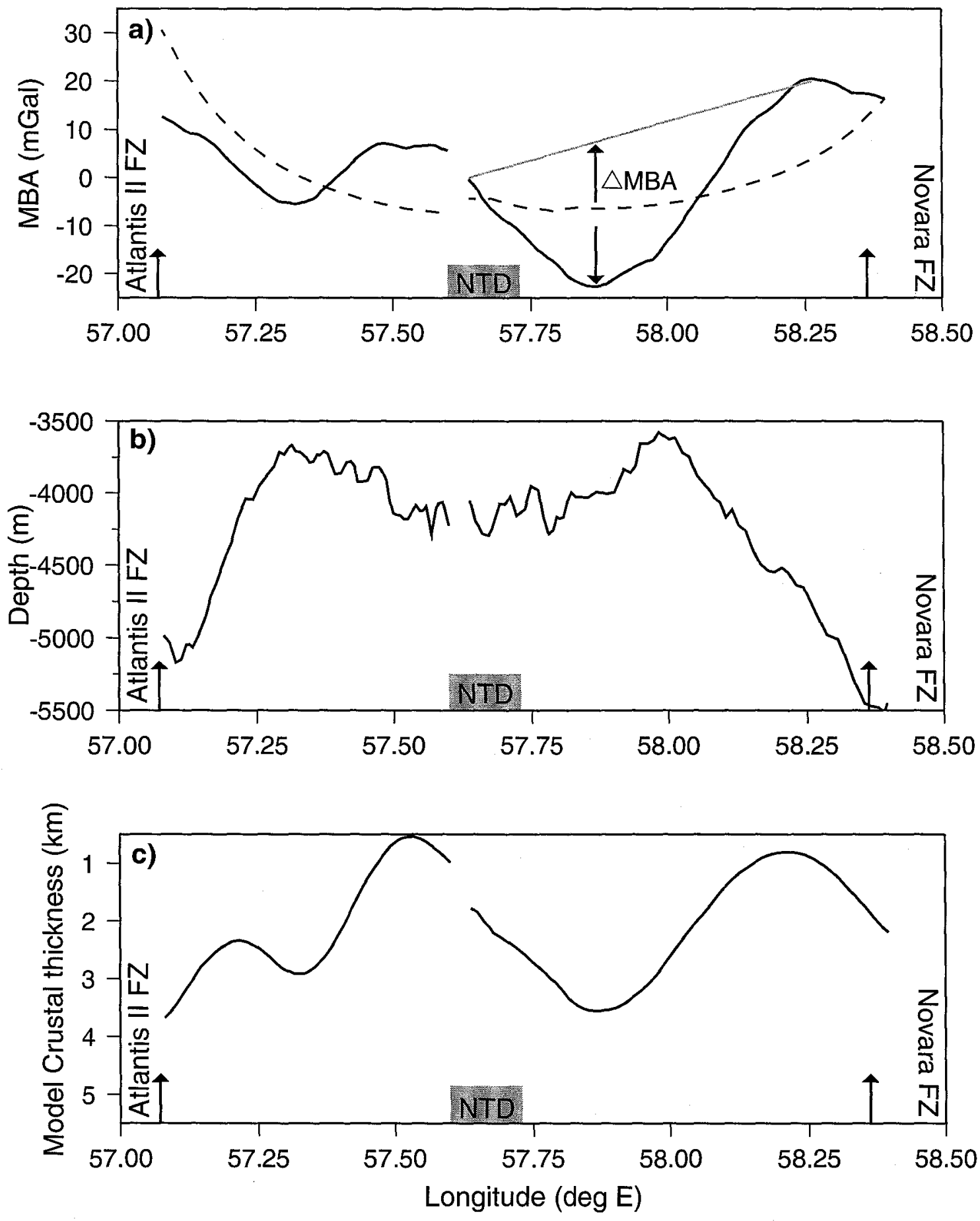
Figure 6. Relationship between the axial variation in MBA amplitude ( $\triangle M B A$, defined in Figure 5a) and segment length. Data for the MAR (open circles) are from Lin et al. [1990] and Detrick et al. [1995] and data for the SWIR (filled circles) are from Grindlay et al. [1998] and Cannat et al. [1999]. Segments AN-1 and AN-2 are labeled and represented by the filled squares. Shaded line corresponds to the best fit line for the MAR from Detrick et al. [1995]. In general, the correlation between segment length and $\triangle \mathrm{MBA}$ is more robust for the MAR than the SWIR. Segments AN-1 and AN-2 lie close to the MAR trend (shaded line). Note that each study used different reference crustal thicknesses in the MBA calculation. 


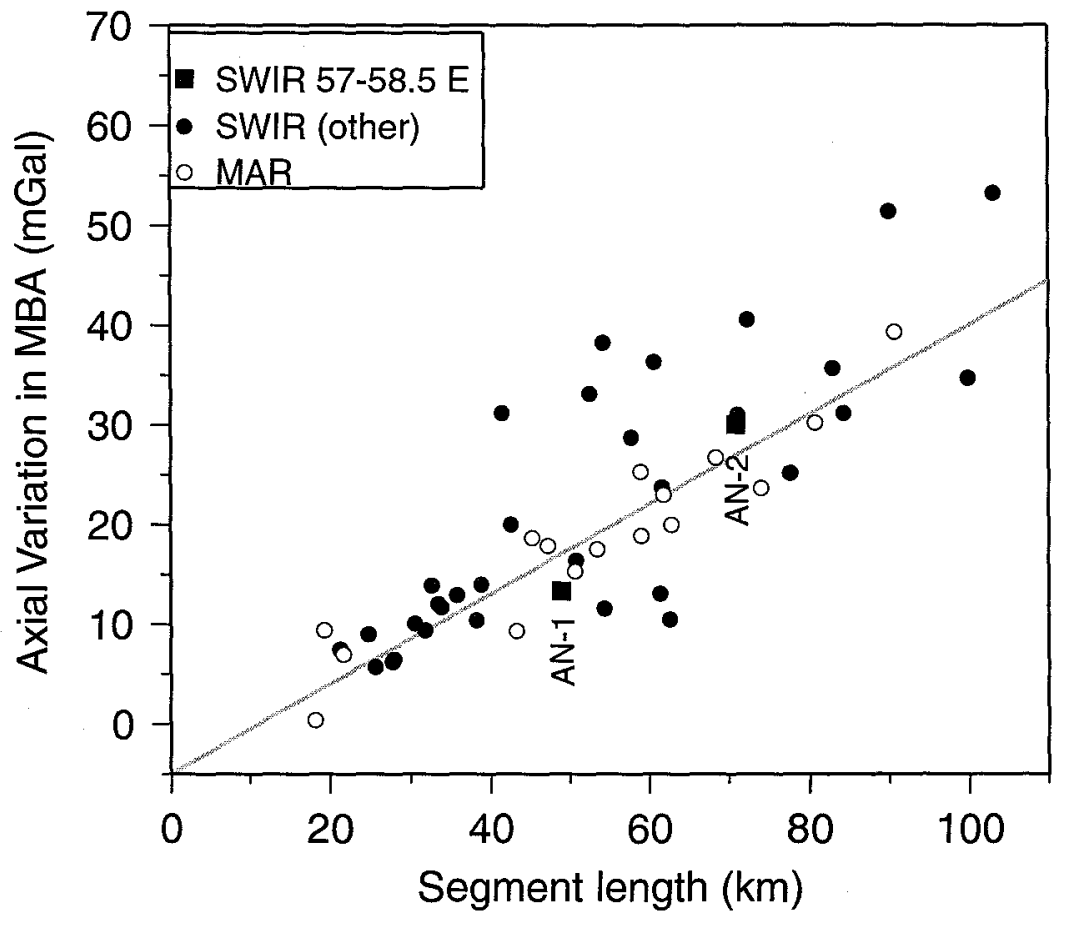


Figure 7. (a) Profile of MBA along paleo-midpoint of segment AN-1 (see location in Figure 4a). Dashed line is the predicted gravity effect of lithospheric cooling as extracted from the grid in Figure 3a. 0 Myr corresponds to the latitude and longitude of the peak of the central anomaly along the track. (b) Seafloor depth along the profile. Dashed line is the predicted seafloor subsidence derived using the same thermal parameters as used for modeling lithospheric cooling for gravity corrections. Predicted seafloor depths agree with the long wavelength trend of observed seafloor depths at crustal ages $>3 \mathrm{Myr}$, away from the dynamically supported axial valley. (c) Model crustal thickness along the profile. Interval denoted $A B$ represents time period during which Atlantis Bank was uplifted; the interval is dashed on the north flank to represent the crust that formed conjugate to Atlantis Bank. PM denotes the time of a near-instantaneous, $10^{\circ}$ counterclockwise change in plate motion 19.5 Ma. (d) Same as in Figure 7a, but for segment AN-2. (e) Same as in Figure 7b, but for segment AN-2. (f). Same as in Figure 7c, but for segment AN-2. Interval denoted PR represents time period during which the propagating rift was active on each flank. 

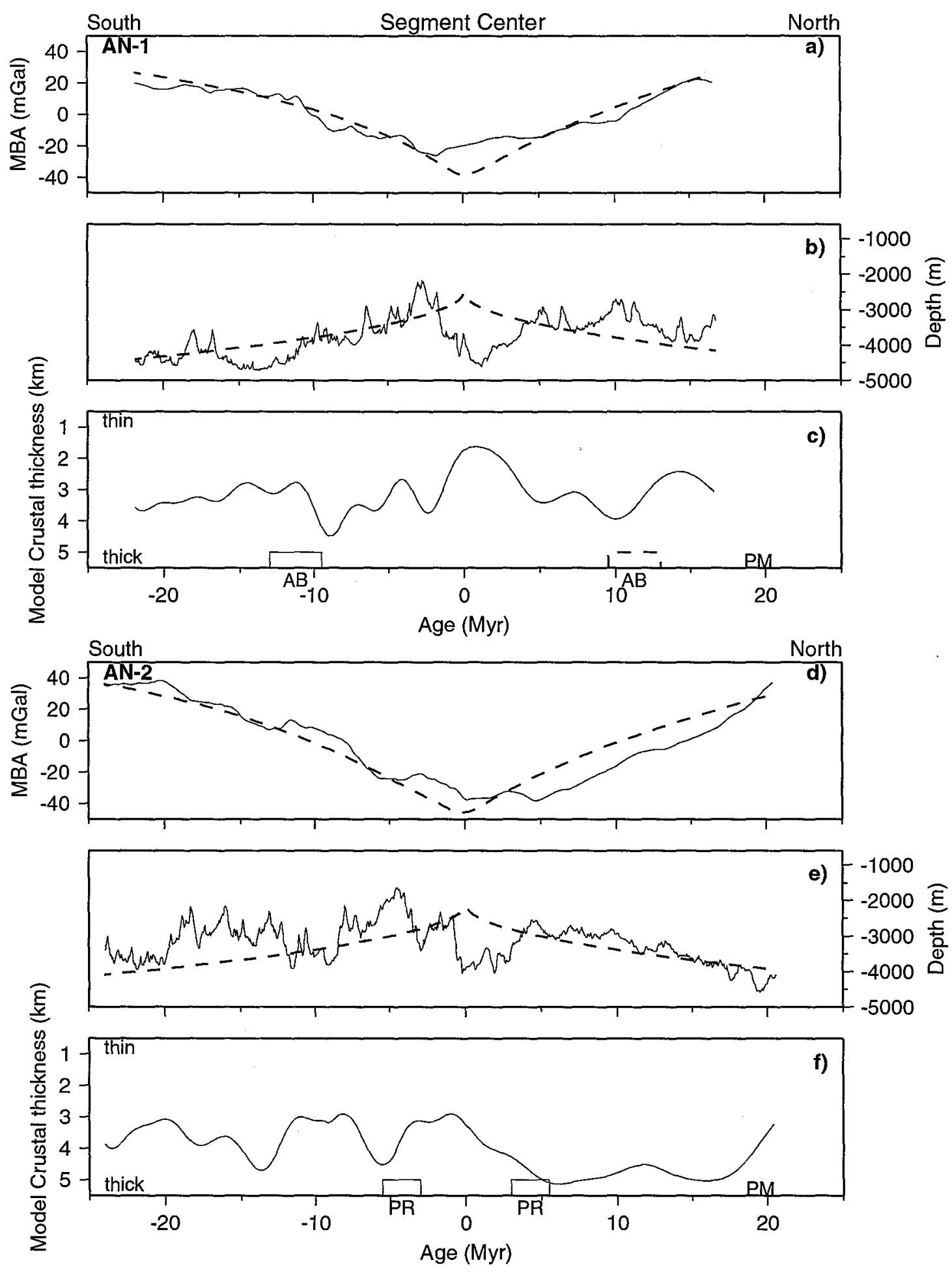
Figure 8. (a) Profile of MBA along inside- (south) and outside-corner (north) corridors of segment AN-1 (see location in Figure 4a). Dashed line is the predicted gravity effect of the lithospheric cooling as extracted from the grid in Figure 3a. (b) Seafloor depth along the profile. Dashed line is the predicted seafloor subsidence derived using the same thermal parameters as used for modeling the mantle thermal structure. (c) Model crustal thickness along the profile. Interval denoted $A B$ represents time period during which Atlantis Bank was uplifted; the interval is dashed on the north flank to represent the crust that formed conjugate to Atlantis Bank. PM denotes the time of a nearinstantaneous, $10^{\circ}$ counter-clockwise change in plate motion $19.5 \mathrm{Ma}$. (d) Profile of MBA along outside- (south) and inside-corner (north) corridors of segment AN-2. (e) Same as in Figure 8b, but for segment AN-2. (f) Same as in Figure 8c, but for segment AN-2. Interval denoted PR represents time period during which the propagating rift was active on each flank. 

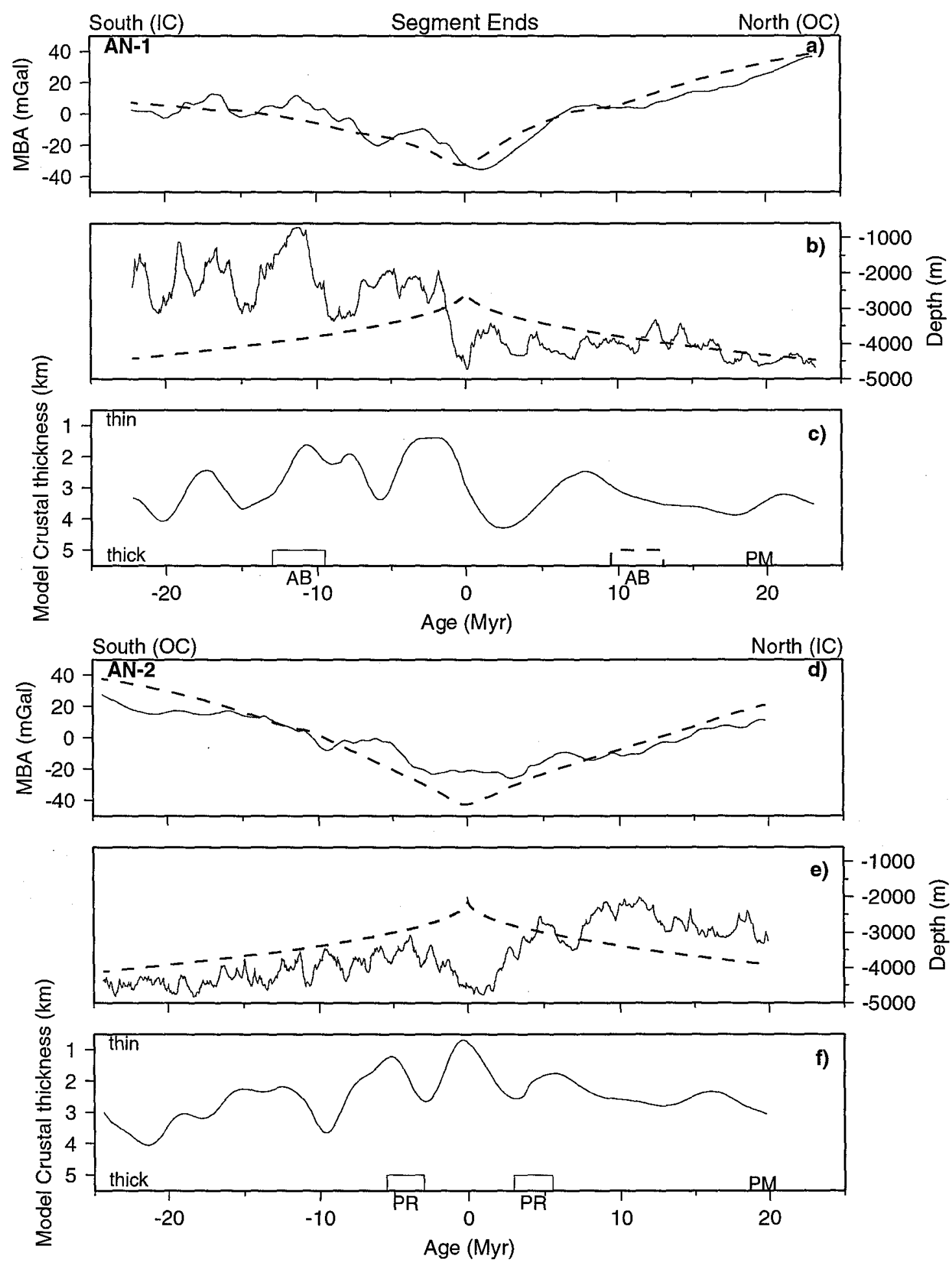
Figure 9. (a) Relationship between the mean MBA on the north and south flanks of segment AN-1. Mean MBA is calculated for ship tracks that cross the segment center at crustal ages defined by magnetic isochron identifications. Error bars correspond to one standard deviation on either side of the mean. Dashed line is the one-to-one relationship curve. Through time, MBA values on the north flank exceed those on the south flank by an average of $4.8 \pm 3.3 \mathrm{mGal}$. (b) Same as Figure 9a, but for segment AN-2. MBA values on the south flank exceed those on the north flank by an average of $14.0 \pm 8.0$ mGal. (c) Same as Figure 9a, but for mean model crustal thickness on the north and south flanks of segment AN-1. The mean difference between the two flanks through time is $0.3 \pm 0.3 \mathrm{~km}$, with the south flank slightly thicker. (d) Same as Figure $9 \mathrm{c}$, but for segment AN-2. Crust on the north flank averages $1.0 \pm 0.5 \mathrm{~km}$ thicker than on the south flank. 
MBA
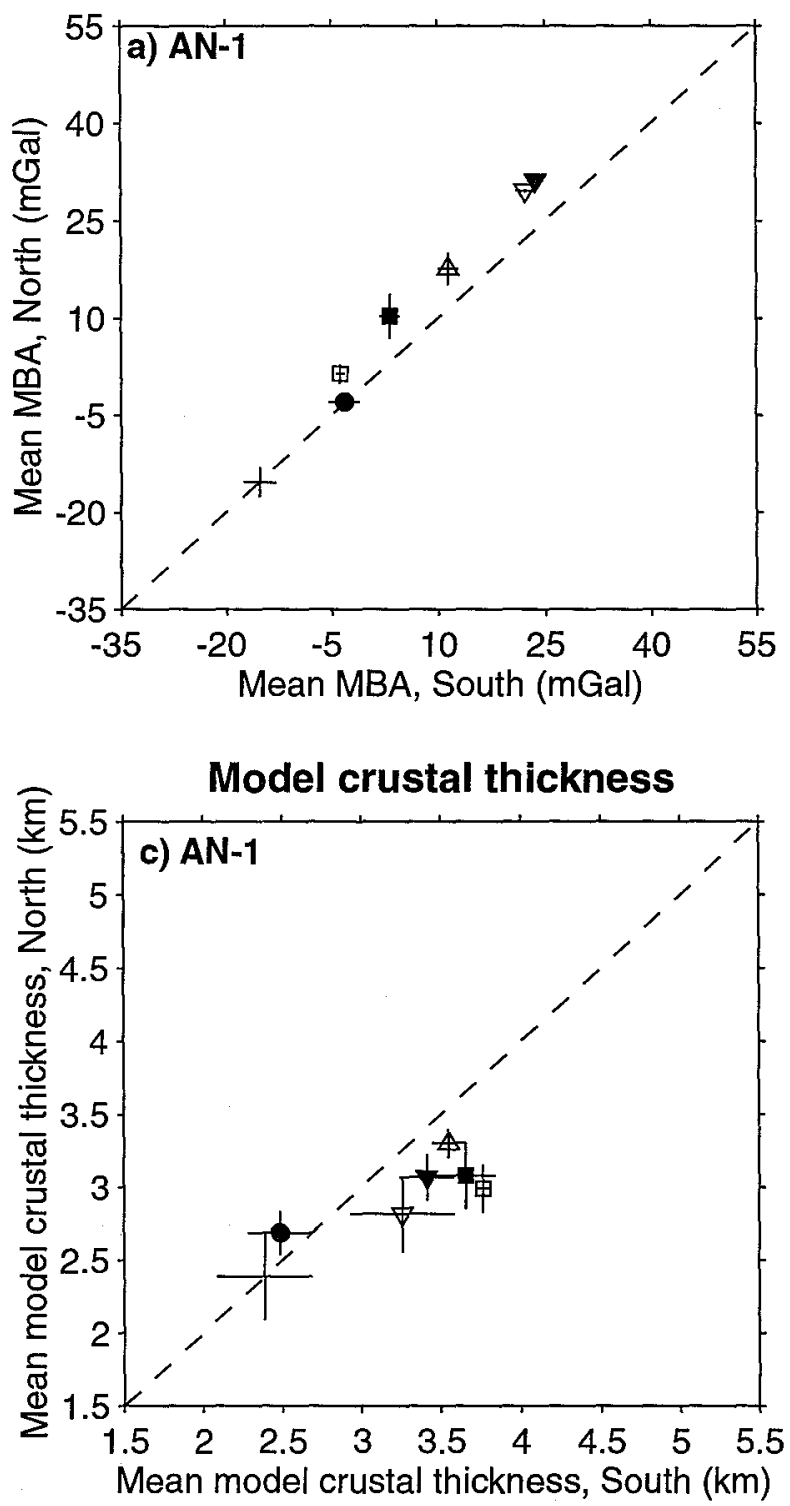

MBA

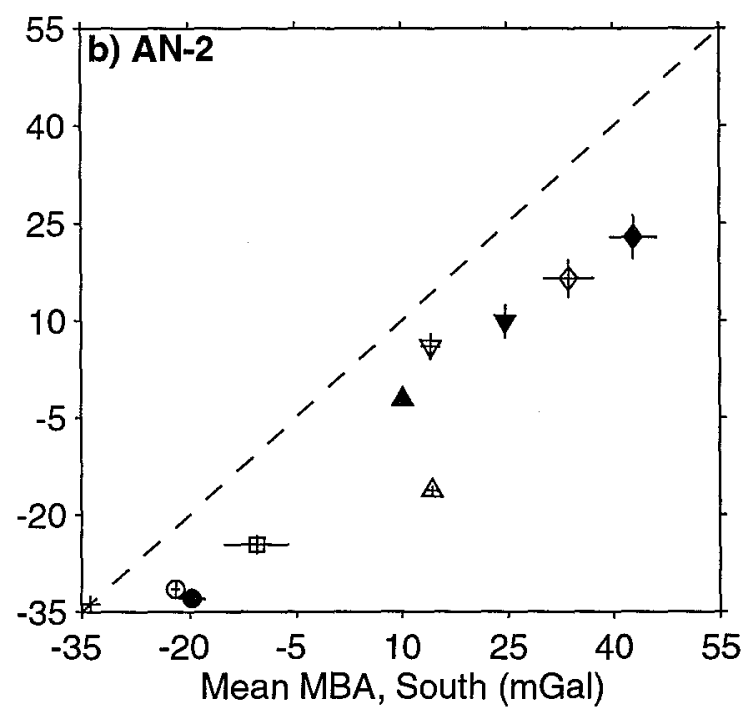

Model crustal thickness

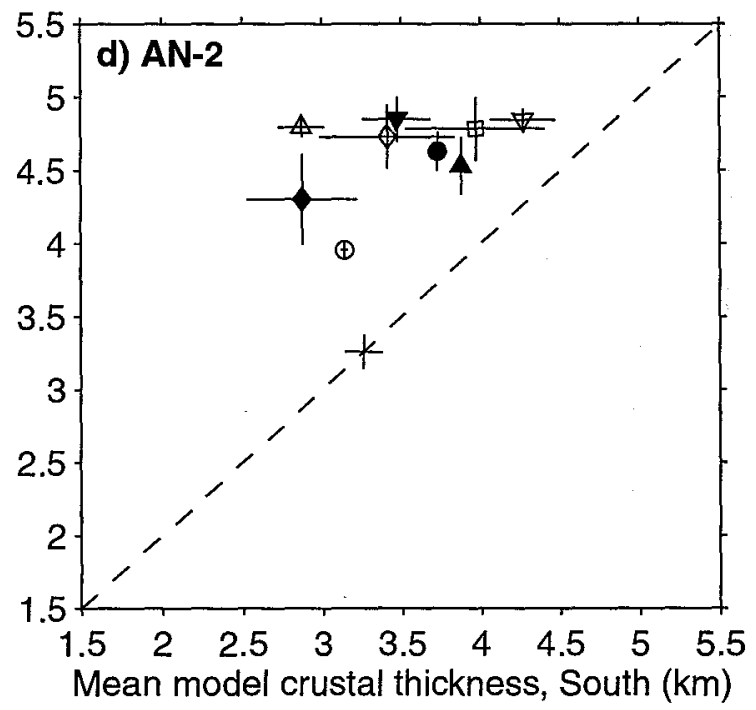

\begin{tabular}{cccccccccccc}
\hline 0.0 & 2.1 & 3.9 & 6.2 & 7.7 & 10.3 & 12.1 & 14.1 & 15.5 & 17.9 & 19.5 \\
$\times$ & 0 & $\bullet$ & $\square$ & $\square$ & $\triangle$ & $\Delta$ & $\nabla$ & $\nabla$ & $\diamond$ & $\diamond$
\end{tabular}

Crustal Age (Ma) 
Figure 10. Relationship between height of abyssal hills and half-spreading rate. Calculated abyssal hill heights (squares) were determined on equally spaced sample points along $60-\mathrm{km}$ long flow-line profiles on each flank of segments AN-1 and AN-2, segment J4 at $41.5^{\circ} \mathrm{S}$ on the Southeast Indian Ridge (SEIR) [Scheirer et al., 2000], and at $16.5^{\circ} \mathrm{S}$ on the East Pacific Rise (EPR) [Scheirer et al., 1996], and on the west flank of segment $\mathrm{E}$ at $25.5^{\circ} \mathrm{N}$ on the MAR [Tucholke et al., 1997]. Data within $30 \mathrm{~km}$ on either side of the SWIR and MAR axial valleys were excluded to minimize the signal of dynamic rift valley topography. Data within $10 \mathrm{~km}$ on either side of the SEIR and EPR axial highs were excluded. Abyssal hill height is determined by the root-mean-squared difference between the observed topography and its long wavelength trend. Segment AN-1 seems to follow the expected inverse correlation between abyssal hill height and spreading rate, while segment AN-2 does not. Published abyssal hill height data (triangles) are from Malinverno [1991]. 


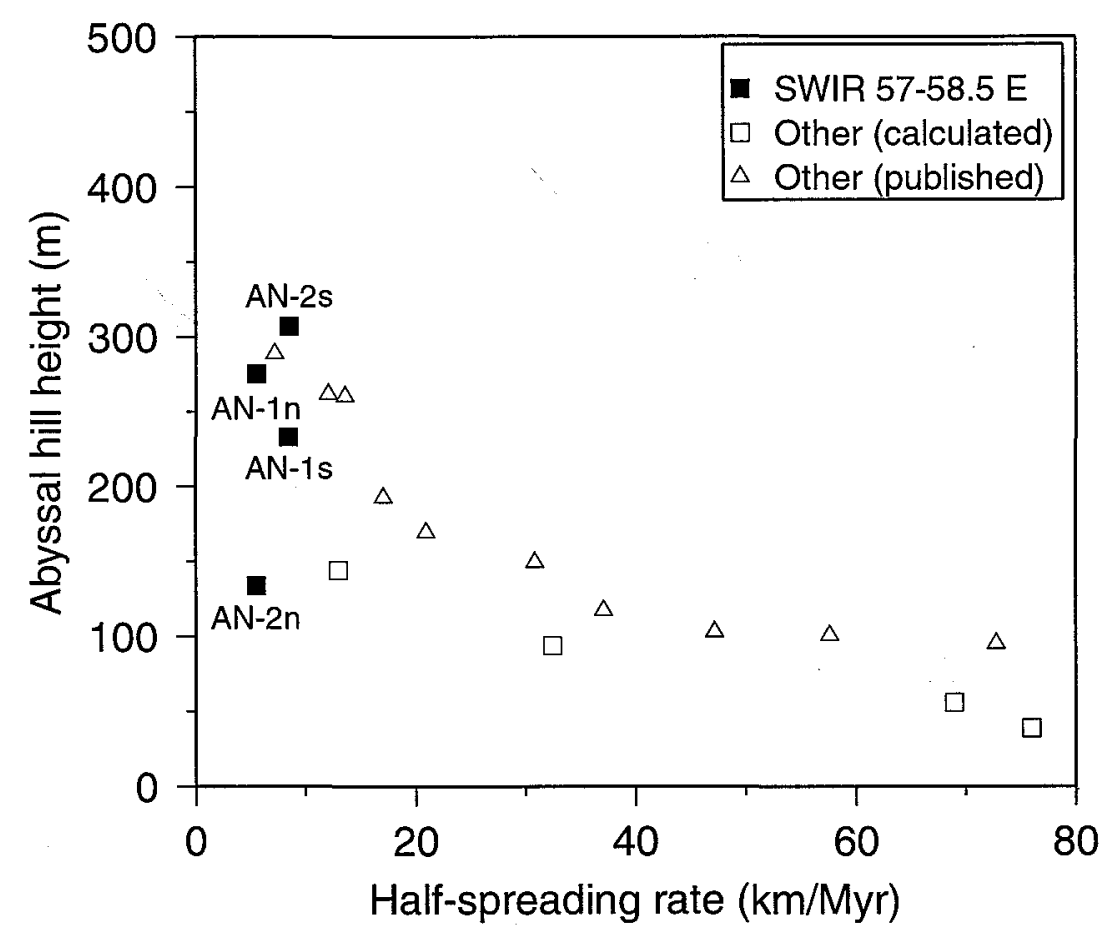


